\title{
Assessment of Modular Construction for Safety-Related Structures at Advanced Nuclear Power Plants
}

Manuscript Completed: February 1997

Date Published: March 1997

Prepared by

J. Braverman, R. Morante, C. Hofmayer

Brookhaven National Laboratory

Upton, NY 11973-5000

H. Graves, NRC Project Manager

Prepared for

Division of Engineering Technology Office of Nuclear Regulatory Research

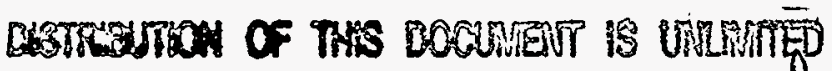
U.S. Nuclear Regulatory Commission Washington, DC 20555-0001 NRC Job Code L2261

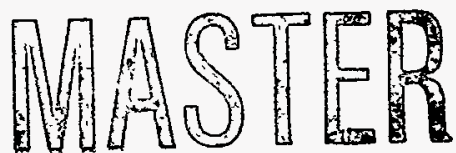


NUREG/CR-6486 has been reproduced from the best available copy 


\section{DISCLAMMER}

Portions of this document may be illegible in electronic image products. Images are produced from the best available original document. 


\section{DISCLAIMER}

This report was prepared as an account of work sponsored by an agency of the United States Government. Neither the United States Government nor any agency thereof, nor any of their employees, make any warranty, express or implied, or assumes any legal liability or responsibility for the accuracy, completeness, or usefulness of any information, apparatus, product, or process disclosed, or represents that its use would not infringe privately owned rights. Reference herein to any specific commercial product, process, or service by trade name, trademark, manufacturer, or otherwise does not necessarily constitute or imply its endorsement, recommendation, or favoring by the United States Government or any agency thereof. The views and opinions of authors expressed herein do not necessarily state or reflect those of the United States Government or any agency thereof. 


\begin{abstract}
Modular construction techniques have been successfully used in a number of industries, both domestically and internationally. Recently, the use of structural modules has been proposed for advanced nuclear power plants. The objective in utilizing modular construction is to reduce the construction schedule, reduce construction costs, and improve the quality of construction. This report documents the results of a program which evaluated the proposed use of modular construction for safety-related structures in advanced nuclear power plant designs. The program included review of current modular construction technology, development of licensing review criteria for modular construction, and initial validation of currently available analytical techniques applied to concrete-filled steel structural modules. The program was conducted in three phases. The objective of the first phase was to identify the technical issues and the need for further study in order to support NRC licensing review activities. The two key findings were the need for supplementary review criteria to augment the Standard Review Plan and the need for verified design/analysis methodology for unique types of modules, such as the concrete-filled steel module. In the second phase of this program, Modular Construction Review Criteria were developed to provide guidance for licensing reviews. In the third phase, an analysis effort was conducted to determine if currently available finite element analysis techniques can be used to predict the response of concrete-filled steel modules.
\end{abstract}




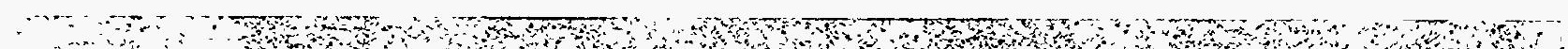




\section{CONTENTS}

Page

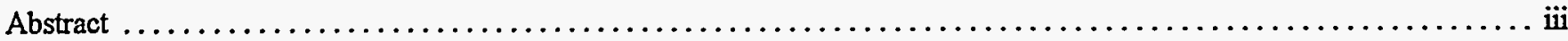

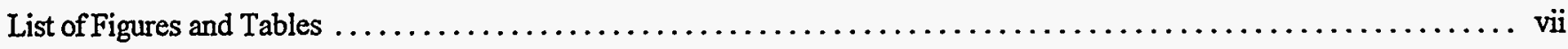

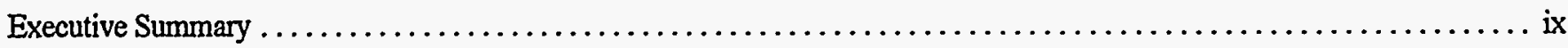

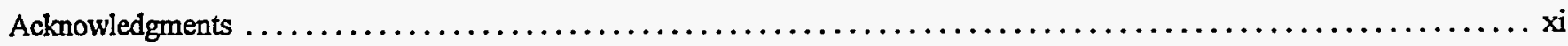

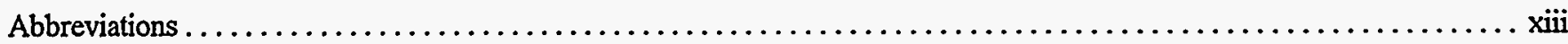

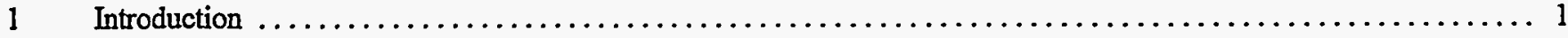

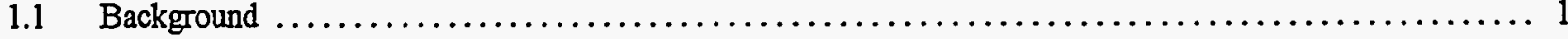

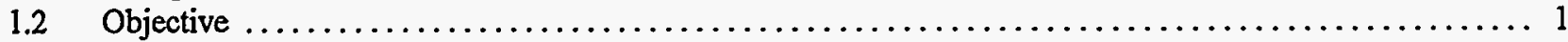

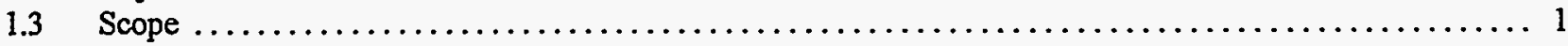

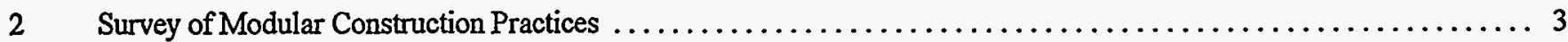

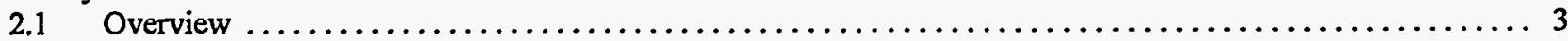

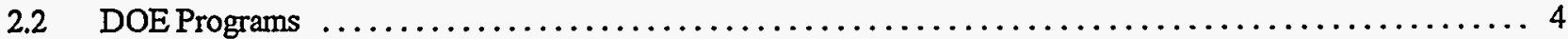

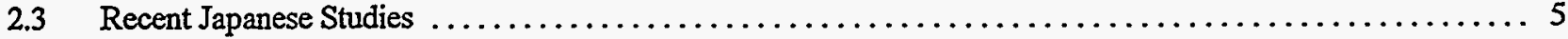

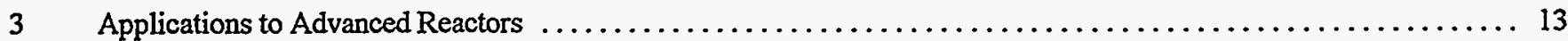

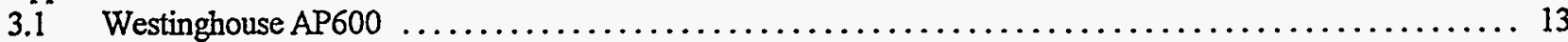

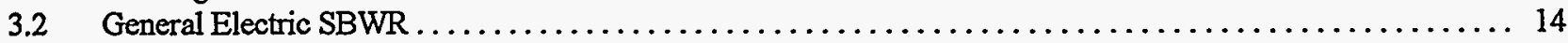

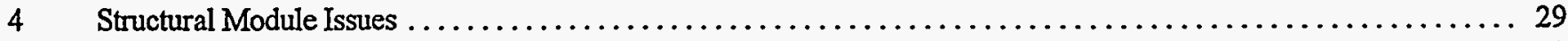

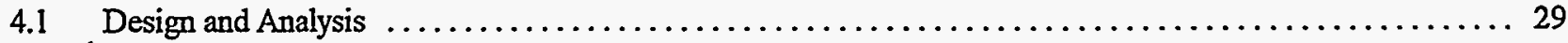

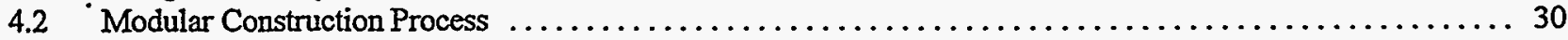

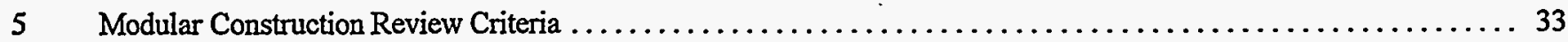

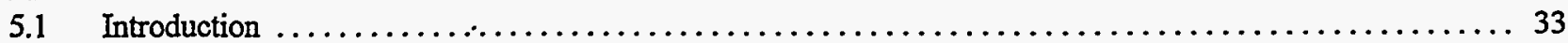

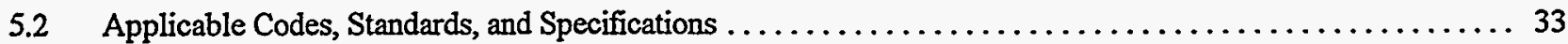

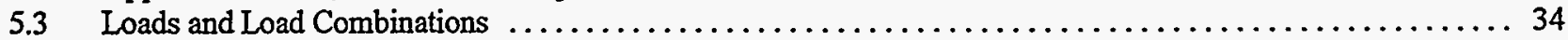

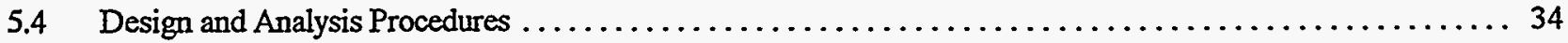

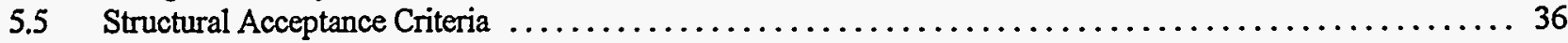

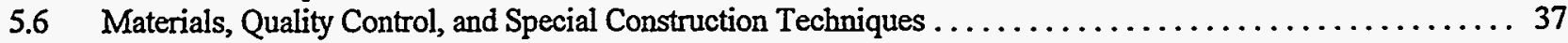

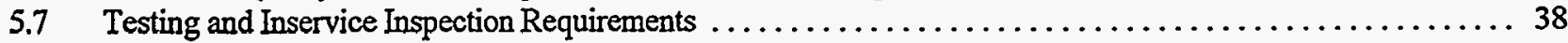

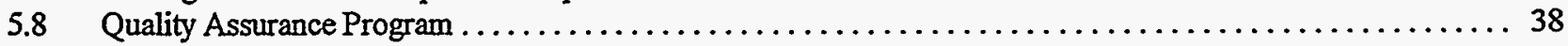

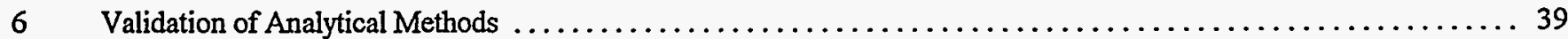

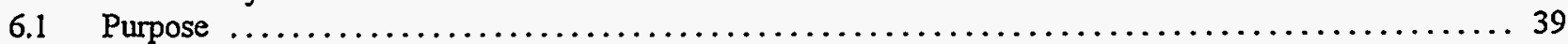

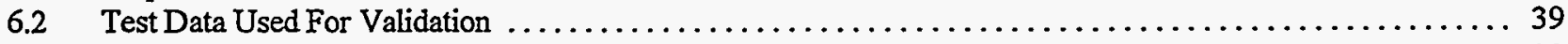

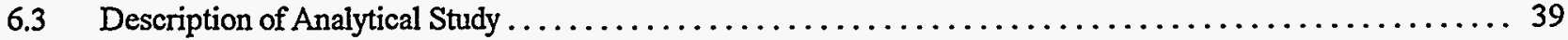

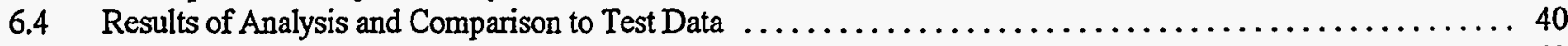

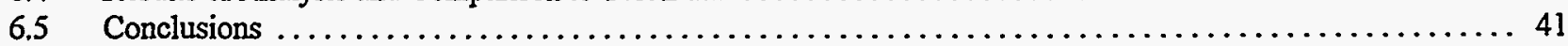

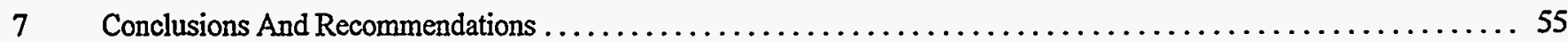




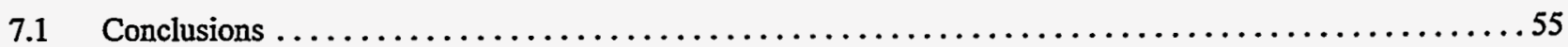

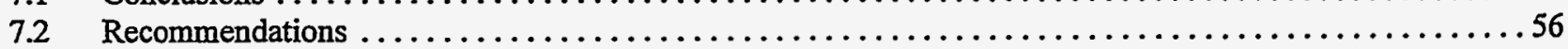

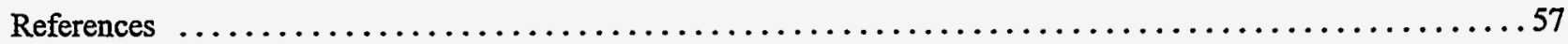

Page

Appendix A: Reliability of Modular Construction, Phase I Report - Identification of Issues $\ldots \ldots \ldots \ldots \ldots \ldots \ldots$

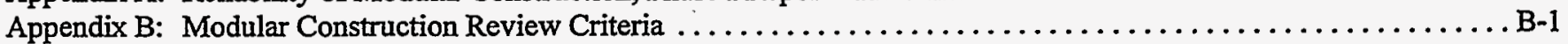




\section{LIST OF FIGURES}

Figure 2.3-1 Examples of "Prefabrication" and Large Block Prefabrication for a Nuclear Power Plant in Japan ..........9

Figure 2.3-2 Outline of Construction Method which Utilizes Concrete Filled Steel (SC) Structures $\ldots \ldots \ldots \ldots \ldots \ldots \ldots$

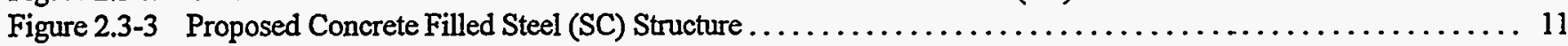

Figure 2.3-4 1/10th Scale Test Model of Inner Concrete Structure with Concrete Filled Steel (SC) Walls ........... 11

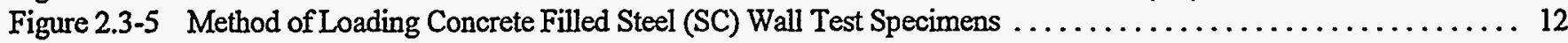

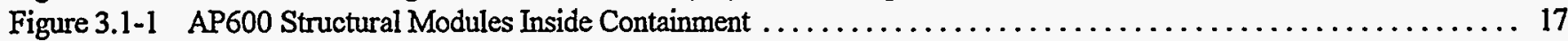

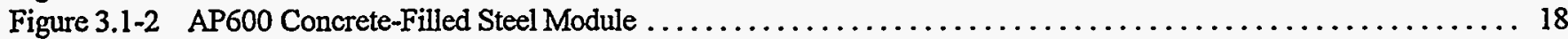

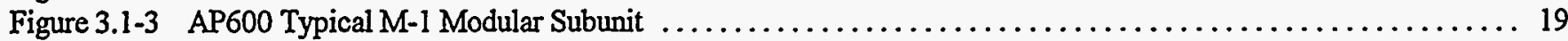

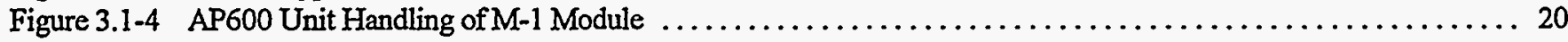

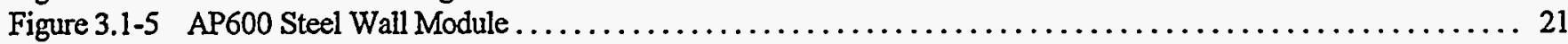

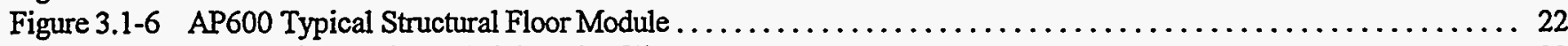

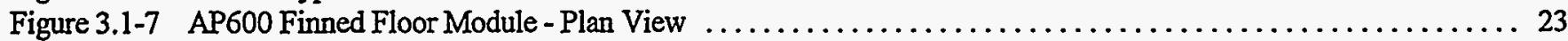

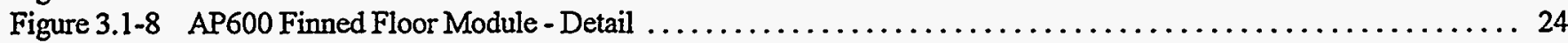

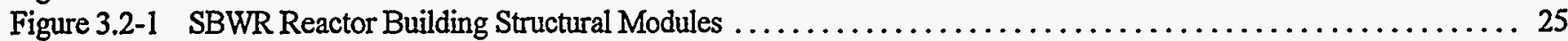

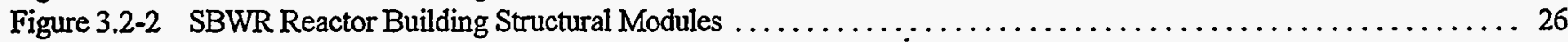

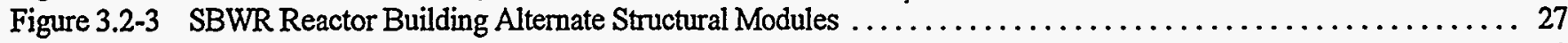

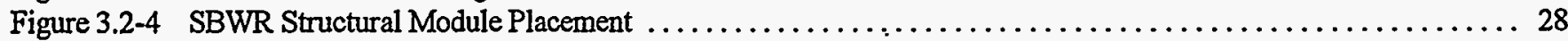

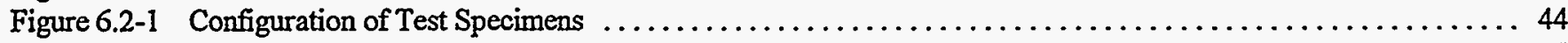

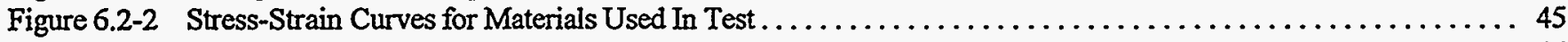

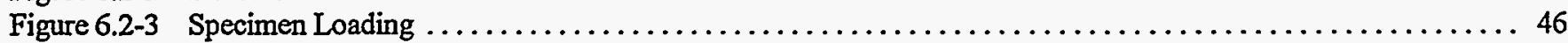

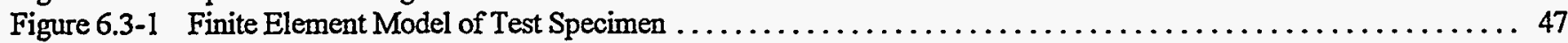

Figure 6.3-2 Finite Element Model of Test Specimen - Steel Elements $\ldots \ldots \ldots \ldots \ldots \ldots \ldots \ldots \ldots \ldots \ldots \ldots \ldots \ldots$

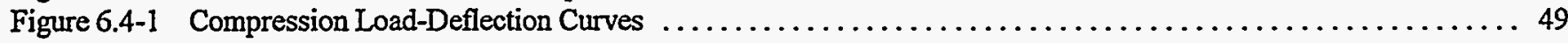

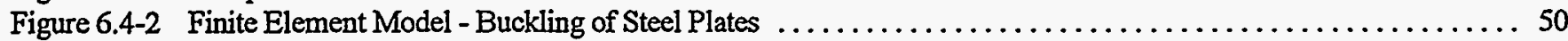

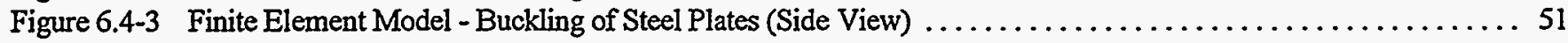

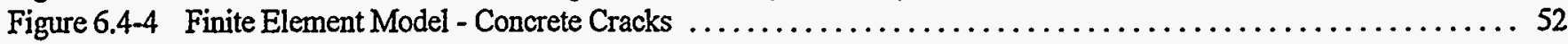

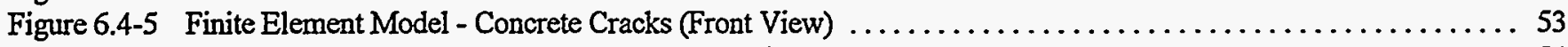

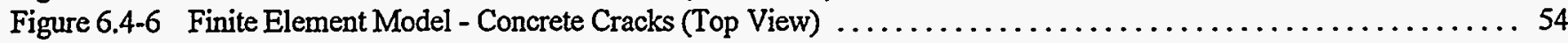

\section{LIST OF TABLES}

Table 2.1 Summary of Issues Discussed at the Third Designing for Constructability Workshop $\ldots \ldots \ldots \ldots \ldots \ldots .8$

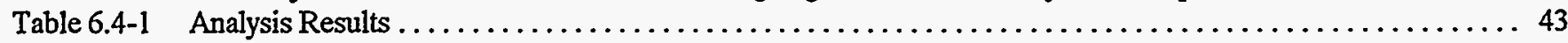




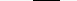




\section{EXECUTIVE SUMMARY}

Advanced reactor plants will be designed to maximize the benefits which can be obtained through the use of modular construction. Module designs attempt to maximize the use of standardized elements with consideration for space provisions, shipping, handling, storage, and interfaces. As a result of its proposed use in advanced reactor designs, the U.S. Nuclear Regulatory Commission sponsored a program to study the reliability of modular construction. The purpose of this study was to evaluate the application of modular construction to safety-related structures in advanced nuclear power plant designs. The types of modules include steel/concrete composite floors, beams, and columns; concrete-filled steel modules; structural steel modules; precast concrete modules; and prefabricated rebar mats, cages, and subassemblies.

The research effort consisted of three phases. In Phase I, modular construction practices used throughout the world were reviewed. This was performed by surveying existing standards, tests, and practices relating to the use of structural modules. The use of structural modules in the nuclear and non-nuclear industry was reviewed. As part of this effort the important issues affecting the use of structural modules in nuclear power plants were identified. Section 2 of this report presents the results of the survey of modular construction practices, Section 3 describes the specific structural modules proposed for the AP600 and SBWR plants, and Section 4 summarizes the key issues.

One of the findings of the Phase I effort was the need for specific licensing criteria for the use of structural modules in nuclear power plants. Therefore, the Modular Construction Review Criteria were prepared to provide guidance for use in licensing review activities. The purpose of this document is to supplement criteria that is already presented in the NRC Standard Review Plan. A summary of the Modular Construction Review Criteria is presented in Section 5.

A new type of structural element, the concrete-filled steel module, has been proposed for the AP600 simplified passive advanced light water reactor. In Japan, this type of module is being studied for use in their nuclear power plant construction programs. The techniques used for analysis and design of concrete-filled steel modules are not well defined. In addition, existing codes and standards do not specifically cover this type of module. To permit the practical and efficient application of the concrete-filled steel module and to satisfy licensing requirements, the structural behavior for this type of structure must be well understood. Therefore, an initial validation effort was performed to determine if currently available analytical methods could be used to predict the response of concrete-filled steel modules. A Japanese study, which contained detailed test data on a concrete-filled steel module was selected. A three dimensional finite element model of the test specimen was developed and analyzed for compressive loading up to the ultimate capacity. A description of the validation effort and the results are presented in Section 6.

Section 7 of the report presents the overall conclusions and recommendations of this program. Modular construction applied to safety-related structures in advanced reactor designs can be a major contributor toward improving the cost competitiveness of nuclear power. To be optimally effective, a high level of planning and coordination must be achieved, from the initial design concept through completion of construction. Unique fabrication, handling, transportation, and field assembly/fit-up activities must be performed in a manner which preserves the design integrity of the as-built, finished structure. The Modular Construction Review Criteria were developed to address these special requirements. For unique structural module designs, such as the concrete-filled steel module, verification of design/analysis methods is necessary, in the absence of accepted industry codes and standards. To this end, validation of analytical methods by comparison to test data is recommended. The limited validation effort conducted under this program demonstrated the capability of a currently available finite element method to predict the structural response of a specific configuration subjected to compressive loads.

Several recommendations are also suggested to verify the safe application of concrete-filled steel modules in nuclear power plants within the United States. They include expanding the validation effort to other configurations and other loadings (shear and bending) and pursuing a cooperative program with Japan which has recently begun a major multi-year modular construction research program to evaluate the behavior of concrete-filled steel modules. 


\section{ACKNOWLEDGMENTS}

The authors wish to thank Mr. Herman Graves of the U.S. Nuclear Regulatory Commission for his guidance and support in carrying out this extensive study. We appreciate his efforts in reviewing the NUREG and providing excellent advice to make this research effort successful. The authors also wish to thank Mr. Gunter Arndt formerly of the U.S. Nuclear Regulatory Commission for his contribution in the early stages of this research effort. The authors also acknowledge the cooperation of various organizations for allowing the reproduction of certain graphical information.

Special thanks to Ms. Barbara Roland (BNL) for preparing this manuscript. 


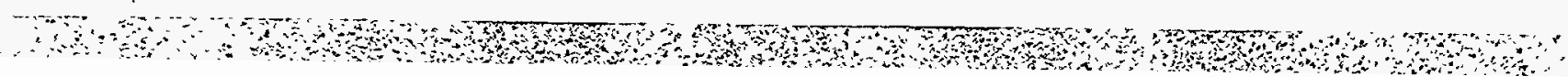




\section{ABBREVIATIONS}

ACI

AISC

ALWR

ANSYS

AP600

ASME

$\mathrm{BNL}$

DOE

DOF

EPRI

FEM

GDCS

GE

HVAC

IC

IRWST

LOCA

MHTGR

NRC

PRISM

PWR

$\mathrm{RC}$

RPV

S\&W

SAFR

SBWR

$\mathrm{SC}$

SRP

SSE

3D
American Concrete Institute

American Institute of Steel Construction

Advanced Light Water Reactors

Swanson Analysis System, Inc. - Computer Code

Simplified Passive Advanced Light Water Reactor Plant

American Society of Mechanical Engineers

Brookhaven National Laboratory

Department of Energy

Degrees-of-Freedom

Electric Power Research Institute

Finite Element Model

Gravity-driven cooling system

General Electric

Heating, Ventilation and Air Conditioning

Isolation Condenser

- In-containment Refueling Water Storage Tank

Loss of Coolant Accident

Modular High Temperature Gas-cooled Reactor

Nuclear Regulatory Commission

Prototype Reactor Inherently Safe Module

Pressurized Water Reactor

Reinforced Concrete

Reactor Pressure Vessel

Stone \& Webster Engineering Corporation

Sodium Advanced Fast Reactor

Simplified Boiling Water Reactor

Concrete-filled Steel

Standard Review Plan

Safe Shutdown Earthquake

Three Dimensional 


\section{INTRODUCTION}

\subsection{Background}

Modular construction techniques can be applied to many structures found in advanced reactor plants. The Electric Power Research Institute's (EPR) program on Advanced Light Water Reactors (ALWRs) recognized this and the associated benefits of a reduced construction schedule and lower costs. In the Utility Requirements Document (Ref. 1), EPRI has mandated that ALWR plants be designed to maximize the benefits of modular construction techniques. The Utility Requirements Document lists examples of modules which have been previously developed and represent the minimum level of effort expected for ALWRs. These include: basemat reinforcing steel assemblies; reactor vessel pedestal structural steel; reactor vessel nozzle support ring; containment vessel or liner plate; refueling pool and spent fuel pool liner plates; and precast concrete walls, beams, and slabs (where practical).

Several proposed advanced reactor designs utilize modular construction to shorten the construction schedule and reduce costs, thereby making these plants more competitive with alternative sources of power. These benefits are achieved by fabricating structural modules in off-site facilities in parallel with other fabrication and construction related activities. An additional benefit should be improved construction quality. To be successful, the use of modular construction techniques should be factored into the conceptual design phase. Engineering should be substantially complete prior to start of construction, in order to maximize the use of standardized elements.

As a result of the proposed use of modular construction in advanced reactor designs, the U.S. Nuclear Regulatory Commission sponsored a research program to study the reliability of modular construction applied to safety-related nuclear power plant structures.

\subsection{Objective}

The objective of this study was to evaluate the proposed application of modular construction to safety-related structures in advanced nuclear power plant designs. The study was separated into three phases, which were performed sequentially.

The first phase (Phase I) consisted of reviewing modular construction practices used throughout the world. This included both nuclear and non-nuclear applications of modular construction techniques. This review was performed by surveying existing standards, tests, and practices that have been used in modular construction with the goal of identifying what issues exist and what more is needed in order to support NRC licensing review activities. Phase I is summarized in Sections 2, 3, and 4. Appendix A provides the complete documentation of the Phase I effort.

The second phase (Phase II) was performed to develop Modular Construction Review Criteria which provide guidance for use by the NRC staff in licensing review activities. This effort was necessary because the Phase I work confirmed that no specific document provides guidance or criteria for the application of structural modules to nuclear power plants. Section 5 summarizes the criteria developed in Phase II. Appendix B provides the complete documentation of the Phase II effort.

The third phase (Phase III) was implemented to validate currently available analytical methods for a unique type of structural module: the concrete-filled steel module. No generally accepted design/analysis methodology currently exists for this type of module. Section 6 provides the results of Phase III.

\subsection{Scope}

The scope of this study covers safety-related structural modules that may be used in advanced nuclear power plants. The type of modules include steel/concrete composite floors, beams, and columns; concrete-filled steel modules; structural steel modules; precast concrete modules; and prefabricated rebar mats, cages, and subassemblies. A more detailed description of these modules and their application to advanced reactors is provided in Section 3. The advanced reactor designs reviewed during Phase I were the Westinghouse AP600 and the General Electric SBWR.

The key issues addressed in this study include: (1) strength, (2) ductility, (3) stiffness and stiffness degradation, (4) reliability of joints and connections, (5) damping values, and (6) QA/QC for design, construction, and transportation. Identification of other important issues and parameters was also part of the Phase I effort. 


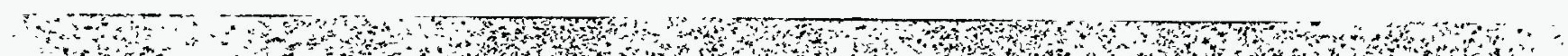




\section{SURVEY OF MODULAR CONSTRUCTION PRACTICES}

The initial effort in Phase I was to survey current practices and activities related to the use of modular construction. The review covered both nuclear and non-nuclear applications within the United States and around the world. The U.S. Department of Energy (DOE) has sponsored a number of studies on the use of modularization in nuclear power plants as part of DOE's technology programs. Japan has already utilized prefabrication and modular construction techniques in recent nuclear power plants. In addition, numerous tests and studies have been performed in Japan to understand the behavior of concrete-filled steel type structural modules. These sources were surveyed to learn what progress has been made, what are the significant issues and concerns; and what additional work is needed to support NRC licensing activities for ALWR's.

\subsection{Overview}

A Technology Transfer Task Team on Modularization was formed by DOE to survey the current use of modular construction in the nuclear and non-nuclear industries and to assess and evaluate the techniques available for potential application to nuclear power [Ref. 2]. The major objective of the team was to identify methods which utilities could apply to better control nuclear plant construction costs and schedules, as well as total power generation costs over the lifetime of a nuclear power plant facility. A major conclusion reached by the Task Team is that the use of modularization could result in a 12 percent reduction in total capital costs compared to nuclear plants built in a conventional manner. In addition, it was estimated that the overall construction schedule could be reduced from 8 years to 6 years.

DOE sponsored additional studies regarding the use of modularization in nuclear power plants. Duke Power Company performed the Design for Constructability Program with the overall goal of identifying and addressing changes in the nuclear industry to restore nuclear energy as an attractive option. The results of this program are contained in an extensive four volume report [Refs. 3 - 6]. Stone \& Webster Engineering Corporation (S\&W) also conducted studies to improve constructability and to simplify the design of future nuclear plants. References [7] and [8] report on two of the seven tasks performed by S\&W. The results of the Duke and S\&W studies as they relate to modular construction are discussed in Section 2.2.

A comprehensive system of modular construction employed by Avondale Industries is described in Reference [9]. The system was developed for marine programs, based on approaches used in Japan. They are now expanding their system for use in the industrial and utility markets. Major non-marine projects have included a sulphur recovery unit, hazardous and toxic waste treatment systems, and a hydroelectric power plant. The last example involved a large powerhouse module, approximately $456 \times 150 \times 120$ feet, which was floated from its shipyard construction location to its final location a distance of 208 miles up the Mississippi River [Ref. 10]. The shipbuilding and petrochemical industries have used modular construction techniques a great deal and appear to offer the best examples for technology transfer to the nuclear industry. The fossil power industry is also studying power plant modularization and formed a working group to identify the major issues [Ref. 11].

The Advanced Light Water Reactor Utility Requirements Document developed by the Electric Power Research Institute [Ref. 1] includes a requirement that ALWR plants "be designed to maximize the benefits which can be obtained through the use of modular construction techniques." Westinghouse is applying modularization concepts in the design of the AP600 [Refs. 12 and 13]. The major application of modular construction in this design is the use of concrete-filled steel plate structures. Other modules include steel (leave-in-place) form modules, and equipment modules. General Electric has also proposed a large scale modularization scheme for the SBWR [Ref. 14]. In this design $\mathrm{GE}$ is considering the use of rebar modules for pool walls, diaphragm floor modules, rebar modules for the RPV pedestal, containment wall liner modules, vent wall modules, and pool liner plate modules. Details of the structural modules proposed for use in the design of the AP600 and SBWR are discussed in Section 3.

Modularization has also been considered in the design of other advanced reactors such as the Sodium Advanced Fast Reactor (SAFR), the Modular High Temperature Gascooled Reactor (MHTGR), and the Prototype Reactor Inherently Safe Module (PRISM) [Ref. 15] and the CANDU3 Reactor. As part of the studies for these designs, new techniques for partial preassembly of concrete structures have been developed. Studies were also performed to aid in the development of guidelines for transporting modules, interface control and cost estimating. The authors of Reference 15 provided a very concise definition of a "module," which is also directly applicable to the manner in which it is used in this report. The term "module" is defined to be "a major system or structural subassembly, which can be assembled and tested in an offsite or out-of-position location, and installed by field forces as a single piece."

It is apparent from the cited reference material that there is a great deal of interest in modularization in both the nuclear and non-nuclear industries. There is much discussion on 
how modularization impacts current construction practices and the potential savings in costs and schedule, as well as improvement in quality. However, there is very little discussion of any potential safety issues that may be introduced by adapting modularization on a large scale to the nuclear industry. Bagchi and Tan [Ref. 16] have looked at modular construction from a regulatory perspective. Some of the issues they have cited include (1) assurance of composite action between steel elements and concrete in wall and floor elements, (2) assurance of the ductility of connections and joints between modules, (3) the judicious application of codes and standards, and (4) the establishment of an impeccable quality assurance and quality control program.

In the international arena, Japan has taken a leading role in the development and application of modular construction techniques for heavy construction projects, including nuclear power plants. Significant resources have been invested in testing of concrete-filled, steel wall structures (called "SC" structures in Japan). Recent Japanese studies [Refs. 17 thru 26] are discussed in detail in Section 2.3.

S\&W reviewed foreign nuclear power modularization and prefabrication experience. Some of the examples cited are:

1. France - Containment dome liners, reactor auxiliary piping, and mechanical modules for small equipment.

2. Japan - Large liner preassemblies of the containment vessel, pipe whip structures and pipe penetrations, modularized pipe and valve assemblies, and reinforcing steel.

3. Sweden - Staircases, wall elements, slab and roof elements, containment steel liner, process piping and pipe supports, and rackmounted units for the scram system.

4. Switzerland - Reinforcing steel; concrete elements for stairs, roof plates and shield blocks; portions of the drywell; composite steel and concrete reactor shield building penetrations; and the biological shield wall.

5. Taiwan - Reactor pedestal and containment liner.

The Duke study also reviewed international nuclear construction experiences, including that at the MuelheimKaerlich plant in Germany and Tsuruga $I I$ and Takahama $3 \& 4$ in Japan.

\subsection{DOE Programs}

Stone \& Webster Engineering Corporation (S\&W) and Duke Power Company studied the use of modularization in nuclear power plants as part of the Department of Energy's technology programs in support of advanced light water reactors.

\subsubsection{Stone and Webster Study}

As part of the S\&W study, a number of modularization approaches for a typical advanced light water reactor plant were developed and reviewed. It was emphasized that for modularization to be cost effective it must be considered from the plant's inception. In particular, it was noted that the general arrangement of a plant should consider the following features to support the modular concept: (1) align structural walls, columns and floors; (2) minimize bulk quantities and group functionally-related equipment; (3) minimize curved walls; (4) provide a clean interface between in-place and modular construction; and (5) accommodate modular access, interfaces, and equipment removal/maintenance.

Based on the above guidelines, the study developed typical module units for the radwaste and auxiliary buildings of a nuclear plant. The modules were repeated several times for use throughout the plant and ranged in weight from 20 to 300 tons. The largest module was $30 \mathrm{ft}$. wide, $50 \mathrm{ft}$. long and $30 \mathrm{ft}$. high. Some of the conclusions from this study are:

1. The use of templates is mandatory to assure the proper fit up of modules.

2. Interfacing components of modules must be designed with excess material, to be trimmed in the field to accommodate installation tolerances, stacking, and misalignment problems. Slotting connection holes, the use of shims and filler plates, etc. should be included in the module design.

3. Modular extremities must be located to assure proper clearance during installation.

4. The interface between structural wall modules will require closure plates.

5. Beam anchorage details were simplified by the use of hold down clips which eliminates the need for the tight tolerances associated with the use of anchor bolts. 
6. Specialty Q-decking is recommended to provide the ability to hang components from the underside of a concrete slab.

7. The concept of stay-in-place steel form modules can be expanded to suit specific building and component layouts.

8. The choice of the optimum method for splicing rebar for modular construction requires further study.

9. Modules may require the design of temporary structural steel supports to facilitate assembly/fabrication, transportation and lifting.

10. When concrete is not required for structural integrity, wall and floor modules could use alternative radiation shielding products such as lead/steel shot or sheets, boronpolyethylene pellets and sheets in combination with lead, or lithiumpolyethylene pellets.

\subsubsection{Duke Power Study}

Duke Power Company sponsored a number of workshops and meetings as part of their DOE program. In particular, the Third Designing for Constructability Workshop was devoted to the review of modular construction approaches and a discussion of the concerns that such approaches pose to the owner and/or constructor. A summary of the issues discussed at the workshop is provided in Table 2.1.

One of the major issues was the degree of standardization necessary to enhance modularization and the need for standardized equipment specifications. It was concluded that such specifications should address items such as accessibility, maintainability, procurement, electrical, avoidance/minimization of rework and module delivery for installation. Other issues included: (1) the need for up front planning and preparation as part of a detailed construction plan, (2) the development of a standardized QA program which includes the owner, as well as multiple vendors and module fabricators, and (3) the need to maximize owner QC inspections at the module fabricator's shop and to add inspections related to transportation induced loading.

The workshop also included a discussion of the need for a separate "Modularization" or "Module Fabricator" code. There was no consensus as to the need for a separate code.
However, there was consensus that the modular construction approach did necessitate an evaluation of code requirements, with at least some revisions and/or additions to current codes. Some of the issues to be addressed include (1) the need for and the role of the Authorized Nuclear Inspector, (2) the need for manufacturer vs constructor stamping programs for code piping; (3) the mixing of code work on the same module; and (4) standardization of the NF boundary.

\subsection{Recent Japanese Studies}

Japan has utilized a number of prefabrication and modularization techniques in the design and construction of recent nuclear power plants. Studies are being conducted to improve these techniques and tests are being performed to develop analysis methods and demonstrate the adequacy of selected designs. The results of some of these applications and studies are presented in References 17 to 26 which are summarized below.

\subsubsection{Large Block Prefabrication}

Tokyo Electric Power Co., Shimizu Corp., and Hitachi, Ltd. have jointly developed the large block prefabrication method (Ref. 17). In their method, they have distinguished between "prefabrication" wherein only a few types of construction materials are preassembled into standardized and simplified blocks and "large block prefabrication" in which a number of materials are integrated into larger and more complex units and installed using a large capacity crane. Examples of both are shown in Figure 2.3-1. They have been used during the construction of the Kashiwazaki Kariwa nuclear power plant. The method has been shown to save labor, shorten the construction period, improve construction safety, and improve working conditions/reduce laborious work. To be successful, the study concluded that the following engineering practices must be exercised (1) selection of large block prefabrication units; (2) construction planning utilizing advanced engineering tools such as 3D-CAD and a 3D survey system; (3) design improvement; (4) lifting and installing; (5) connecting parts together efficiently; and (6) implementing an intelligent network for data transmittal between head office, site office, general contractor, sub-contractors and mechanical manufacturer.

\subsubsection{Concrete-Filled Steel (SC) Structures for PWR Plant}

Mitsubishi Heavy Industries, Ltd., Kajima Corp. and Ohbayashi Corp. jointly studied the feasibility of using 
concrete-filled steel (SC) structures for a PWR type nuclear plant (Ref. 18). The study included the reactor building, control building and waste disposal building. The buildings consisted of SC bearing walls, columns of concrete-filled steel pipe, girders and beams of steel, and slabs and foundation mats of reinforced concrete. The buildings were designed for a high seismic load $(0.35 \mathrm{~g}$ to $0.5 \mathrm{~g})$ on a rock site. An outline of the construction method is shown in Figure 2.3-2. The conclusions of the study are (1) "Equivalent earthquake resistance to conventional reinforced concrete $(R C)$ structures can be maintained with significant reduction in shear wall thickness. This indicates that the $\mathrm{SC}$ structure becomes more desirable when the earthquake force becomes larger;" (2) "Regarding the construction, as it is possible to greatly increase the ratio of prefabricating work at the factory, a significant decrease in the job site man hours and field manpower is anticipated. Also, as a supplement to aforementioned, the possibility exists for reducing the job site man hours of the electro/mechanical systems work by fixing pipes and wires to the SC blocks at the factory;" and (3) "A significant saving of half to one year in construction period is possible due to the rationalization of the construction blocks."

\subsubsection{Static and Dynamic Testing of "SC" Walls for Horizontal Loading}

In order to obtain seismic design information, a model test of a concrete structure inside containment composed of concrete-filled steel (SC) bearing walls was conducted (Ref. 19). The tests provided information on elastic and inelastic behavior, stiffness, ultimate strength, and hysteretic and vibrational characteristics under horizontal seismic loads. The SC structure is a sandwich structure in which concrete is placed between two steel surface plates, as shown in Figure 2.3-3. Studs, shear bars, and web plates are attached to the steel plate in order to obtain a composite effect of concrete and steel plates. The model, which is a $1 / 10$ scale of the existing $1000 \mathrm{MWE}$ class plant, and test apparatus are depicted in Figure 2.3-4. It consists of the SC primary shield wall of the reactor vessel and a secondary shield wall for the steam generator, pressurizer, and fuel transfer canal. It also includes reinforced concrete (RC) structures consisting of the base mat and the upper and lower loading slabs.

The test consisted of two phases. Static horizontal loading tests were performed by applying horizontal forces on the upper and lower loading slab in proportion to the distribution of shear forces and bending moments predicted in the actual structural design. In addition, vibration tests were conducted with an inertia type hydraulic shaker. A sine sweep excitation was applied with a sweep frequency range between 20 and $200 \mathrm{~Hz}$ and a sweep velocity of 10 $\sec / \mathrm{Hz}$

The calculated concrete crack load and steel plate yield load were found to compare well with the test results. In terms of stiffness degradation, the tests demonstrated a reduction of $30 \%$ from the stiffness at elastic conditions for the SC structure at the $S_{1}$ load level. For the $R C$ structure the corresponding stiffness decrease was $65 \%$. The $\mathrm{S}_{1}$ load level was reported as corresponding to a U.S. SSE.

Equivalent viscous damping values were also determined from the test results. For the $\mathrm{SC}$ structure the damping is almost constant at $5 \%$ before the steel yields and it dramatically increases after that. For the RC structure the damping is almost constant at $5 \%$ before and after rebar yielding.

Based on the results of this test it was concluded that the SC structure is superior in ultimate strength and ductility capability compared to the RC structure. It also demonstrated well behaved hysteresis characteristics. The resuits of this test and those from further studies, which are apparently underway, will be used to establish a rational design method for SC structures in Japan.

\subsubsection{Compression and In-Plane Shear Tests of "SC" Walls}

In order to establish a rational design method for SC structures, additional compression and shear loading tests of SC wall specimens were performed (Ref. 20). These tests apparently are part of an overall program to establish SC design methods for determining:
1. compression ultimate strength
2. shear ultimate strength
3. combined compression and shear ultimate strength
4. adequacy of joints
5. reinforcing methods for details such as openings.

The tests described in Reference 20 are being used to address items (1) and (2) above. Stud bolts were welded to the surface plate at various spacings. For the compression tests, repeated compression loads are applied. For the shear tests, repeated positive and negative loads are applied using four hydraulic jacks. The method of loading the test specimens is shown in Figure 2.3-5. The conclusions from these tests were (1) "stud bolts are effective to prevent 
buckling of the surface plate;" (2) "occurrence of buckling can be predicted by applying Euler's equation for a column pin-supported at one end and fixed at the other end for compression loads and by the theoretical equation of a pinsupported plate of which the aspect ratio is infinitely large for shear loads;" (3) "occurrence of buckling has little effect upon the load-displacement behavior of the structure," and (4) "ultimate strength of the whole structure can be evaluated by the sum of the ultimate strength of concrete and steel plate."

\subsubsection{In-Plane Shear Tests of "SC" Walls of Various Design Configurations}

More recently, Obayashi Corporation performed an experimental study on the shear characteristics of a concrete-filled steel plate wall (Ref. 21). Seven wall-panel specimens were tested under repetitive in-plane pure shear loading. The specimens consisted of a pair of surface steel plates with connecting partitioning webs and shear bars, which are filled with concrete. The parameters investigated were the thickness of the surface steel plate, the number of partitioning webs, and the presence or absence of stud bolts. The study also presented an analytical model for predicting rigidity (before and after buckling), cracking strength, yield strength, and ultimate strength.

\subsection{6 "SC" Structures for ABWR Buildings; Compression, In-Plane Shear and Bending Tests}

In another program (Ref. 22), Tokyo Electric Power Co., University of Tokyo, and Kajima Corporation of Japan conducted a feasibility study and various tests on concretefilled steel structures termed "SC structures." The feasibility study evaluated the use of SC structures for constructing an $A B W R$ building. The study investigated the construction period, the material quantity and construction cost, and the manpower requirements using the $\mathrm{SC}$ structural system approach. An estimate of the quantity of construction material showed that a decrease of steel of about $20 \%$ is possible, and the use of forms become unnecessary. The total number of construction workers in the field will also decrease by around $30 \%$. Although the study indicates that the construction cost would be about the same as for RC buildings, the construction period would be 2 to 5 months shorter than that of a current RC building.

To study the structural properties and workability, three separate tests were performed. Reference 23 presents the results of the compression loading test of the $\mathrm{SC}$ wall specimens. Reference 24 presents the results of the shear and bending test of SC shear walls. The third test, which evaluates wall-floor joint connections, has not been reported as yet.

The results of the first test (Ref. 23) are discussed in detail in Section 6; data from this particular test were compared to analytical predictions. Some of the results/conclusions from the second test are (1) steel surface plates are more effective than steel reinforcing bars because, unlike rebars, they do not have directionality; (2) the ultimate strength of the concrete is improved by the restraining effects of the steel plates (confinement effects); and (3) sudden load drops caused by brittle failure of the concrete is suppressed by the steel plates.

\subsubsection{Miscellaneous Studies}

Other studies have also been conducted in Japan on the strength of concrete-filled steel box elements, which may be useful in establishing the design criteria for such structures in nuclear plants. Reference 25 reports the results of analysis and tests of such elements when subjected to combined bending, shear and axial forces. Reference 26 presents the results of an experimental study on the strength and deformation of concrete-filled box columns. 


\begin{tabular}{|c|c|c|}
\hline Subject & Comment & Issues/Examples \\
\hline $\begin{array}{l}\text { Quality } \\
\text { assurance }\end{array}$ & $\begin{array}{l}\text { New concerns on QA } \\
\text { and documentation } \\
\text { arise when a modular } \\
\text { approach is applied to } \\
\text { a major construction } \\
\text { project. }\end{array}$ & $\begin{array}{l}\text { - Code class work } \\
\text { - Mixed code classes on the same } \\
\text { module } \\
\text { - Configuration control } \\
\text { - inspection responsibilities } \\
\text { - Inspection of partially completed } \\
\text { modules } \\
\text { - Added inspection requirements } \\
\text { upon receipt of modules } \\
\text { - Damage protection } \\
\text { - Owner "umbrella" vs. } \\
\text { vendor-controlled QA programs } \\
\text { - QA interface accountabilities }\end{array}$ \\
\hline $\begin{array}{l}\text { Impacts on } \\
\text { vendor and } \\
\text { site } \\
\text { approaches }\end{array}$ & $\begin{array}{l}\text { Modularization will } \\
\text { require innovative } \\
\text { approaches to vendor } \\
\text { activities and side } \\
\text { efforts. }\end{array}$ & $\begin{array}{l}\text { - Modularization not requiring } \\
\text { miniaturization for maintainability } \\
\text { - Impact on productivity and rework } \\
\text { - Standardized vs. site-specific } \\
\text { modules } \\
\text { - Procurement of module } \\
\text { subcomponents } \\
\text { - Storage and damage protection } \\
\text { - Construction plan and sequencing } \\
\text { - Schemes for getting modules into } \\
\text { buildings } \\
\text { - Impact on "normally later" items } \\
\text { such as electrical, start-up, and } \\
\text { testing activities } \\
\text { - Field run items } \\
\text { - Influences of tolerances and field } \\
\text { fit-ups } \\
\text { - Configuration control } \\
\text { - Union jurisdictions vs. a team } \\
\text { concept }\end{array}$ \\
\hline $\begin{array}{l}\text { Owner } \\
\text { commitment, } \\
\text { cash flow, } \\
\text { and risks }\end{array}$ & $\begin{array}{l}\text { Modularization } \\
\text { definitely benefits site } \\
\text { schedule and cost. } \\
\text { The owner will be } \\
\text { concerned with: } \\
\text { - Changes created } \\
\text { in timing project } \\
\text { commitments } \\
\text { - Outlay of funds } \\
\text { - Changes in risk } \\
\text { factors }\end{array}$ & $\begin{array}{l}\text { - Cascading effect of late items and } \\
\text { - Bust in time deliveries } \\
\text { - absence of a critical module } \\
\text { - Owner cash flow for earlier } \\
\text { procurement } \\
\text { - Cash flow profile } \\
\text { - Warranty impacts } \\
\text { - Insurance against schedule } \\
\text { delays } \\
\text { - Broadening of the financial base }\end{array}$ \\
\hline
\end{tabular}

Table 2.1 Summary of Issues Discussed at the Third
Designing for Constructability Workshop [Ref. 4] 


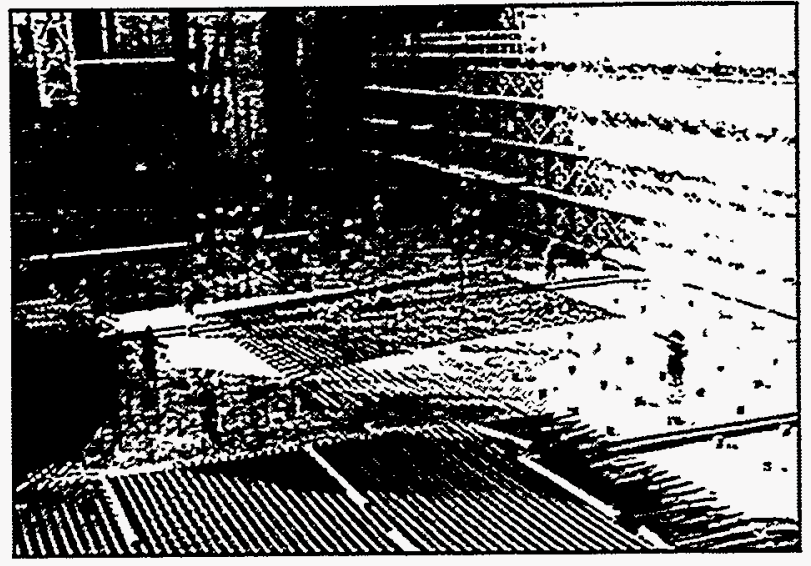

Photo 2-1. Rebar mesh prefabrication for Base Mat.

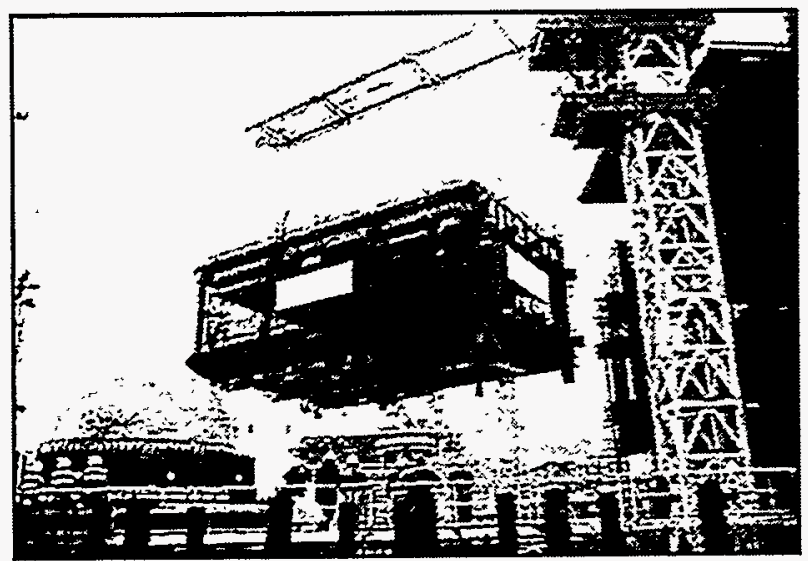

Photo 2-3. Room Module Method for Main Control Room (wt. 440 ton).

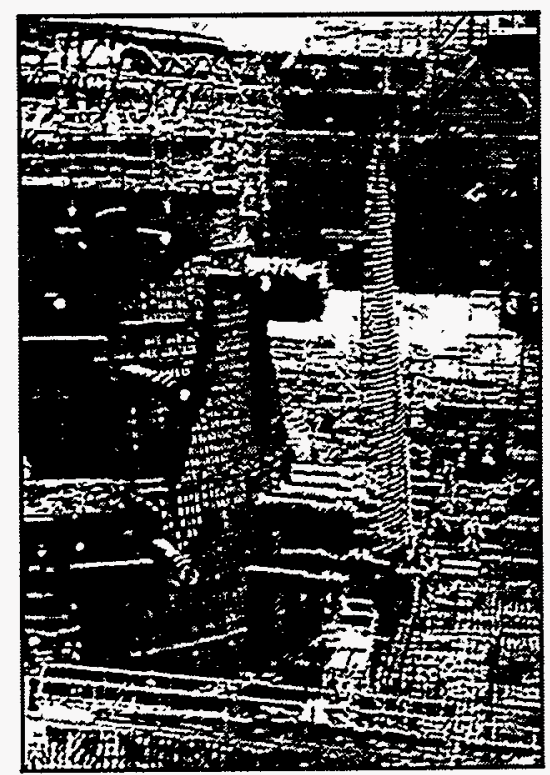

Photo 2-5. Rebar mesh prefabrication for Shield Wall (Conical).

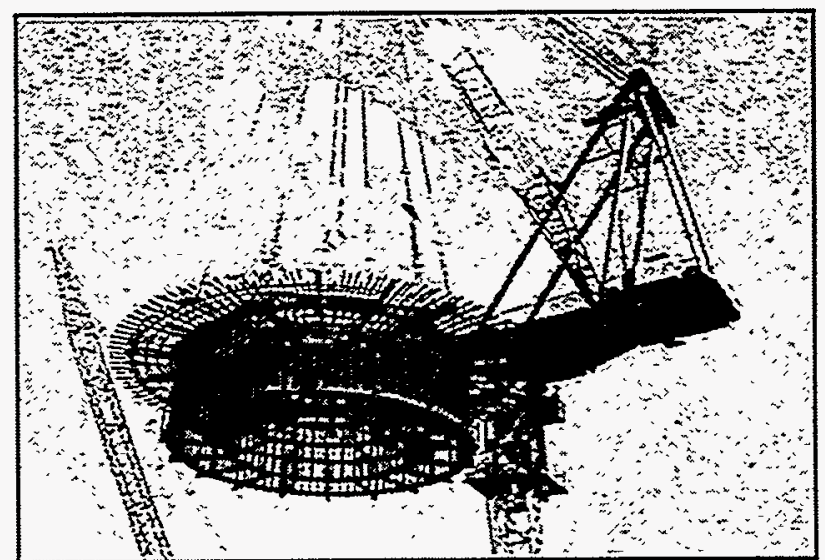

Photo 2-2. Large block prefabrication for Base Mat Central Part (wt. 100 ton).

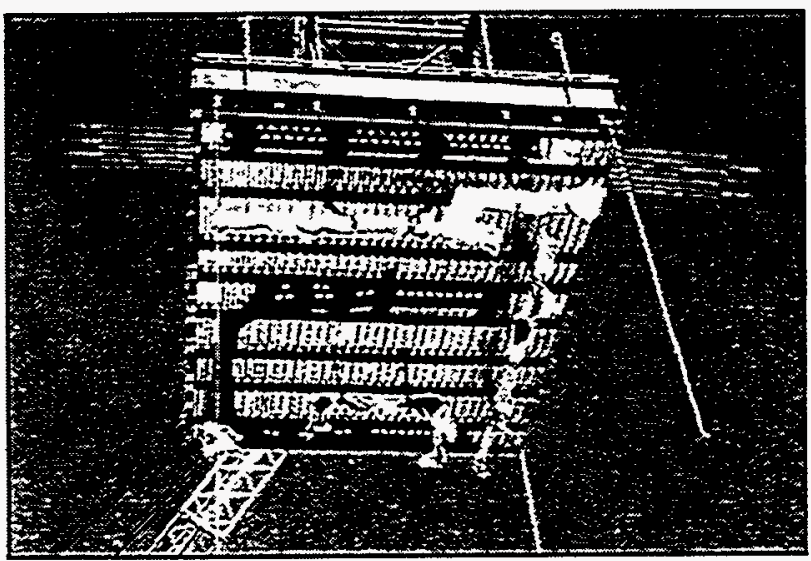

Photo 2-4. Composite Slab Method (wt. 50 ton).

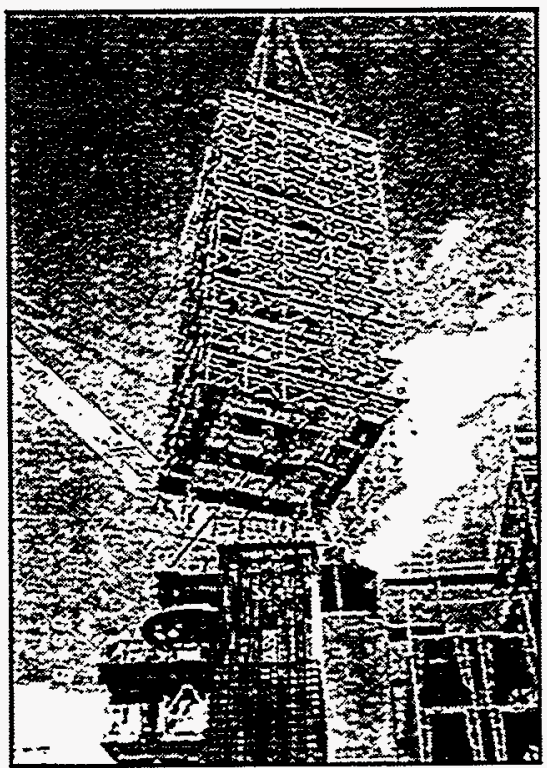

Photo 2-6. Scaffold prefabrication for T/G Pedestal.

Figure 2.3-1 Examples of "Prefabrication" and Large Block Prefabrication for a Nuclear Power Plant in Japan [Ref. 17] 


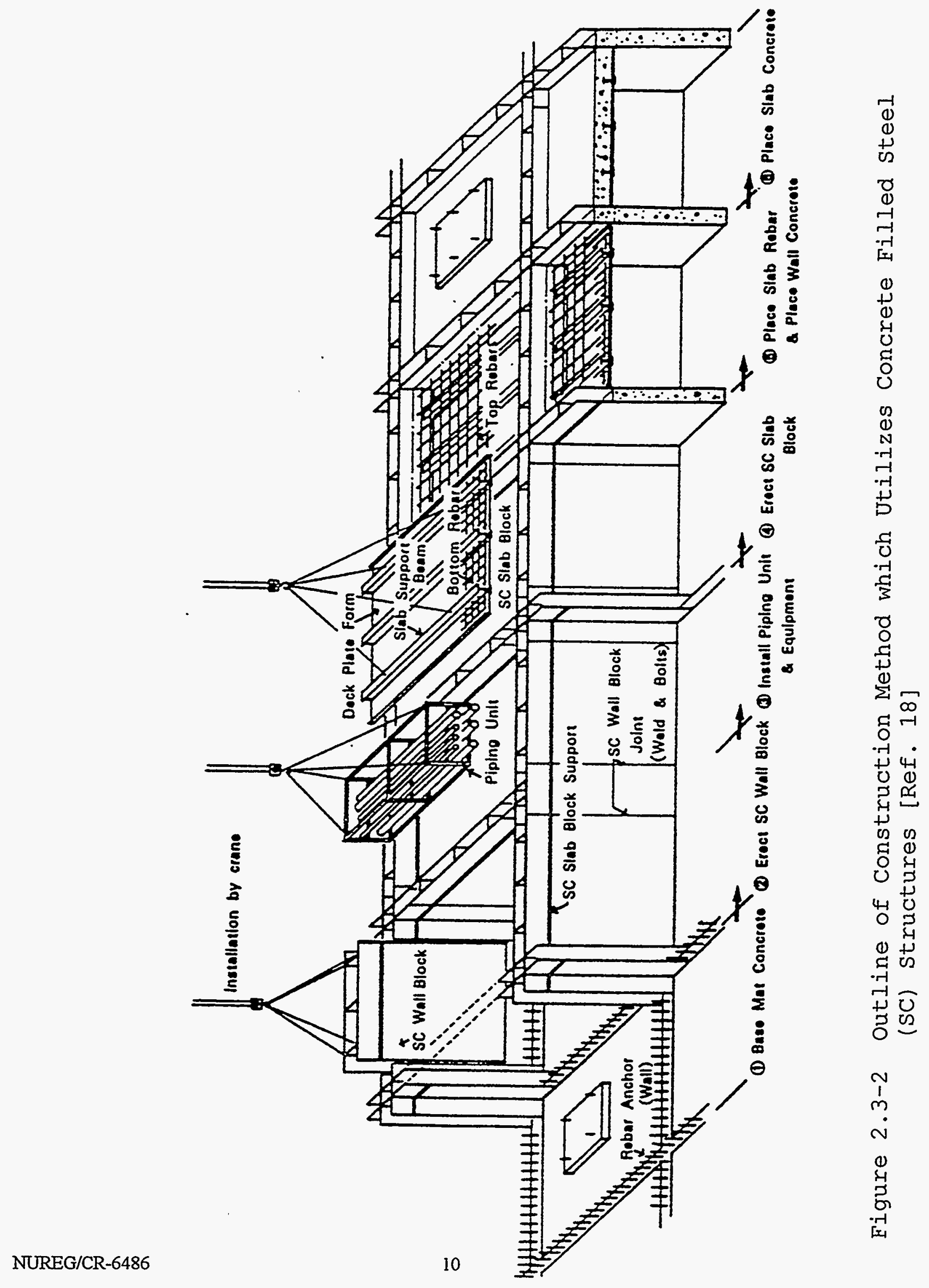




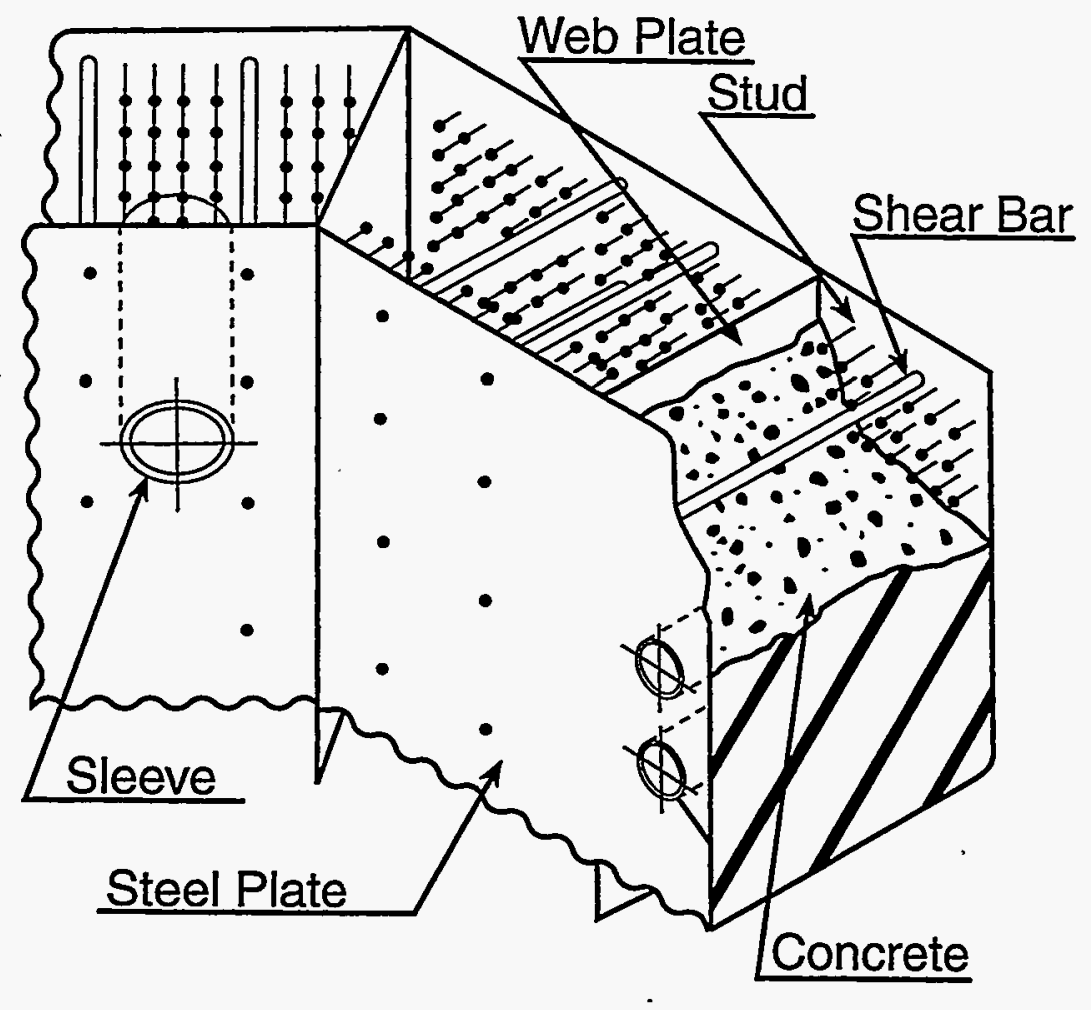

Figure 2.3-3 Proposed Concrete Filled Steel (SC) Structure [Ref. 19]

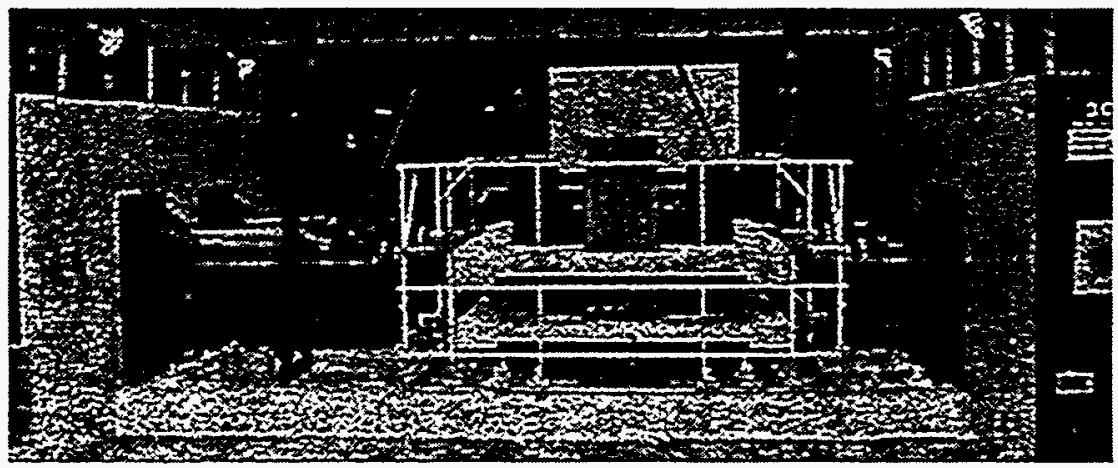

Figure 2.3-4 1/10th Scale Test Model of Inner Concrete Structure with Concrete Filled Steel (SC) Walls [Ref. 19] 

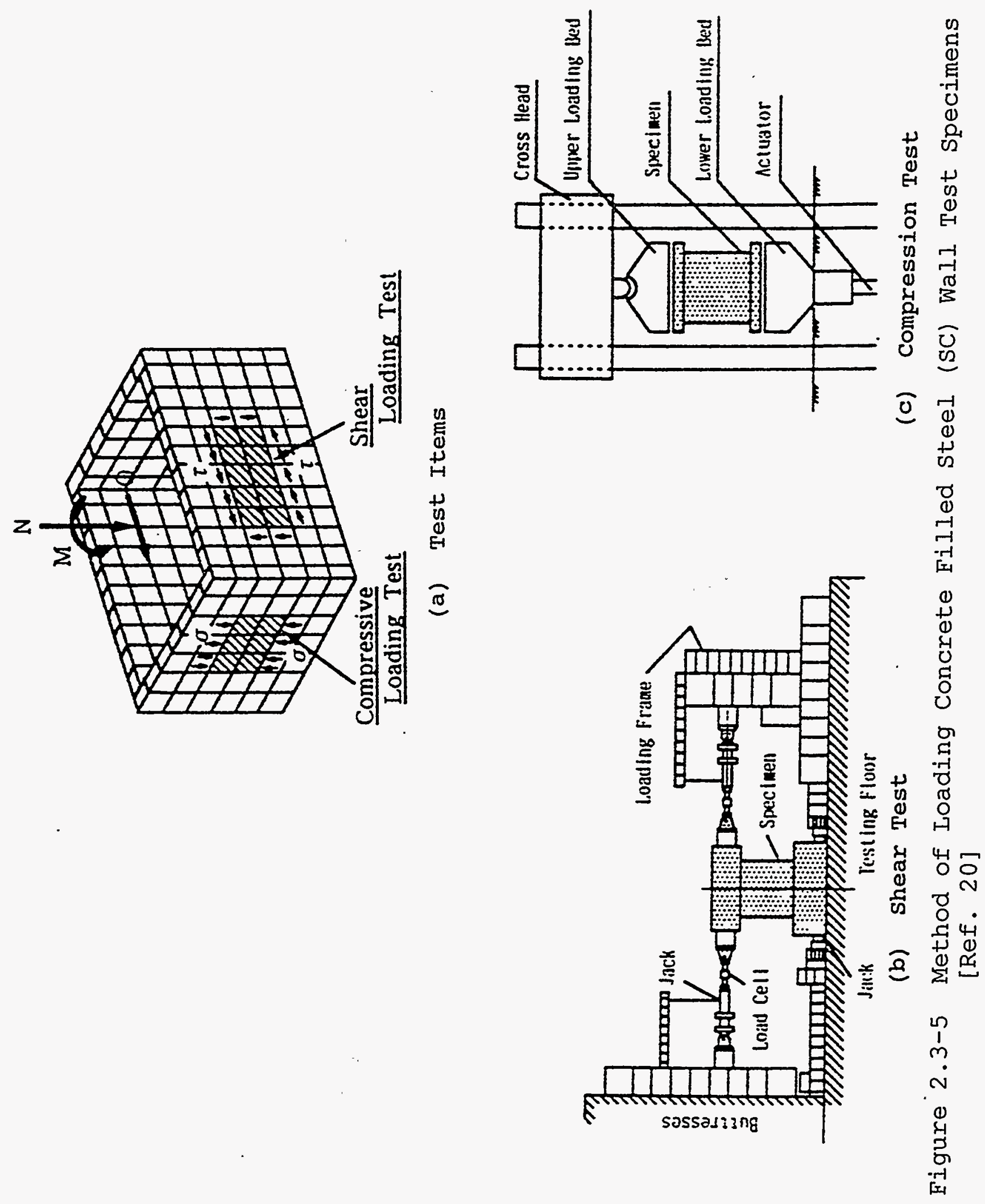


\section{APPLICATIONS TO ADVANCED REACTORS}

This Section provides a description of the types of structural modules being proposed for two advanced light water reactors: the AP600 plant and the SBWR plant. In addition to describing the configuration of the modules, available information on design/analysis approaches is provided. A more detailed description and discussion of the modules may be found in Appendix A.

\subsection{Westinghouse AP600}

The AP600 plant is a $600 \mathrm{MWe}$ simplified passive advanced light water reactor that is being designed by Westinghouse and its subcontractors. The plant houses a pressurized water reactor and has a number of innovations that make it economically more competitive with other sources of power. These innovations are intended to shorten the construction schedule, reduce costs, and make the plant operate more safely.

The plant design has been simplified and the plant arrangement has been optimized to reduce the number and size of systems and components. The benefits are reduced building volumes and a corresponding reduction in the quantity of building materials needed to construct the plant. A modular construction approach is also utilized to achieve the desired goals of lower costs and a reduced construction schedule. This can be achieved by prefabricating modules in off-site shops or subassembly areas, permitting modules to be constructed in parallel, rather than "stick-by-stick". Generally, shops and subassembly areas are more productive and should result in higher quality work than the conventional construction practice.

Several types of structural modules are utilized in the AP600 plant design. While most of the modules are located within the containment structure, modules are also used in the auxiliary building. The following describes the specific location and configuration of each type of structural module, based on the AP600 SSAR, Rev. 8 (Ref. 27).

\subsubsection{Structural Wall Modules}

The construction of containment internal wall structures utilizes a concrete-filled steel module, designated the " $M$ " module. The M modules consist of the walls surrounding the reactor, refueling canal area, two steam generators and the pressurizer. The location of the wall modules are shown in Figure 3.1-1. These modules consist of steel faceplates connected by steel trusses as shown in Figure 3.1-2. The trusses are primarily utilized to stiffen and hold the two faceplates during handling, erection, and placement of concrete. The steel faceplates are $1 / 2$ inch thick and are spaced apart either 30 inches or 48 inches, depending on the location. Shear studs are welded to the inside faces of the steel plates to form a connection to the concrete.

A typical M-1 modular subunit is shown in Figure 3.1-3. These subunits are constructed off-site. Due to size limitation on commercial railways these subassembly units are transported to the site where they are assembled into the M-1 structural module. The entire M-1 assembly is lifted into position using a sling detail shown in Figure 3.1-4.

The wall modules are anchored to the concrete base by means of dowels or other embedded steel connections in the concrete below. After erection, the walls are filled with concrete. Concrete is used where radiation shielding is required.

Structural wall modules are also used in the auxiliary building. The areas include the spent fuel pool, fuel transfer canal, and cask loading and wash down pits. The modules are similar to the structural wall modules described above for the containment internal structures.

It is noted that the M module described in Appendix $A$ is somewhat different because Westinghouse has recently revised the module design. The major change is to use shear studs instead of angles welded to the faceplates and the use of the trusses instead of diaphragm plates to hold the two faceplates. In addition, the design approach has also been revised as discussed later in this Section.

Wall modules without concrete fill are also utilized inside containment. The west wall of the in-containment refueling water storage tank (IRWST) is this type of module which is constructed solely from structural steel. This steel wall module consists of a stainless steel plate stiffened with structural steel tee shaped sections in the vertical direction and angles in the horizontal direction (see Figure 3.1-5).

\subsubsection{Steel Form Modules}

At the lower elevations inside containment, conventional reinforced concrete is used, except that permanent steel forms are utilized in lieu of removable forms. The permanent steel form modules consist of steel plates reinforced with angle stiffeners and tee sections. The angle and tee sections are welded to the steel plates on the concrete side of the module. Where loads from attached equipment or components may be transferred to the steel form modules, studs or similar embedded steel elements are welded on the concrete side of the plates.

Generally, the advantage of using permanent steel forms is that these wall modules can be fabricated and preassembled 
off-site in parallel with other ongoing construction activities. This reduces construction efforts at the site which results in cost savings to the project. In addition, savings are achieved by eliminating curing time and the need to strip forms, clean-up, and patch exposed concrete surfaces.

\subsubsection{Structural Floor Modules}

Several floors inside containment utilize floor modules consisting of steel tee sections welded to horizontal steel plates. The steel plates are stiffened by angle stiffeners. Reinforcing bars are placed above the top flange. After erection, concrete is poured on top of the horizontal plates embedding the steel sections and reinforcing bars. See Figure 3.1-6 for details of a typical floor module.

\subsubsection{Finned Floor Module}

Floors located above the main control room and instrumentation and control rooms in the auxiliary building are designed as finned floor modules. The purpose of the finned floor modules is to provide a passive heat sink for each room. The heat sink limits the temperature rise during the 72 hour period following a loss of operation of the nonradioactive ventilation system. The concrete mass of the ceilings and walls are designed to provide the required heat sink.

A finned floor is comprised of a $61.0 \mathrm{~cm}$ ( 24 in) thick reinforced concrete slab poured over a stiffened steel plate ceiling. Composite action of the steel and concrete is developed using shear studs welded to the steel plate and embedded in the concrete. The horizontal steel plates are stiffened by welding steel plates perpendicular to the ceiling plates. The steel fins project into the room and act as thermal fins to enhance the transfer of heat from the air to the concrete. See Figures 3.1-7 and 3.1-8 for details of this module. Several modules cut to the room width are prefabricated in a shop. On site they are installed side by side perpendicular to the room length.

\subsubsection{Summary of Analysis and Design Methods}

The analysis and design methods described in this report are based on the most current information presented in the AP600 SSAR, Rev. 8 (Ref. 27) and meetings with Westinghouse. Some portions of the methodology are still under review by the NRC and thus may be revised.

The methods of analysis used by Westinghouse to analyze the concrete-filled wall modules are similar to the methods used for reinforced concrete. For the containment internal structure, a three-dimensional (3D) finite element model is developed. The walls are represented as 3D shell elements with equivalent shell element thickness and modulus of elasticity. The equivalent properties are computed based on the combined concrete section and steel section properties, assuming integral behavior.

For seismic analyses of the containment internal structures and the auxiliary building modules, the monolithic initial stiffiness is used, because the stresses due to mechanical loads including the safe shutdown earthquake (SSE) are expected to be less than the concrete cracking stress. Some reductions in stiffness in portions of the structural modules that are boundaries to the IRWST are expected due to abnormal thermal transients. The SSE loads are obtained from a response spectrum analysis of the $3 \mathrm{D}$ finite element model of the structural modules inside containment. A damping value of 5 percent is used, based on cyclic load tests of structural modules performed in Japan (Ref. 19).

The general design philosophy for the concrete-filled steel modules is to design them as reinforced concrete structures in accordance with the requirements of ACI-349 (Ref. 28) with some supplemental requirements. This philosophy is followed because the faceplates are considered as the reinforcing steel, which is bonded to the concrete by headed studs. Structural steel modules, without concrete fill are designed as steel structures in accordance to AISC-N690 (Ref. 29) with supplemental requirements.

\subsection{General Electric SBWR}

The Simplified Boiling Water Reactor (SBWR) concept proposed by General Electric (GE) relies on building arrangements which optimize the layout of systems and accommodate personnel and equipment access for operation and maintenance. By reducing and simplifying the total quantity of systems and equipment, the total building envelope required to house safety systems was greatly reduced. The improvements have resulted in the placement of all safety functions within the reactor building. A reduction of more than $22 \%$ was achieved in the volume of the SBWR reactor building compared to existing nuclear plants. In addition to reducing the total quantity of material, enhancement of constructability is another objective of the design of the SBWR. This is achieved in the SBWR design by applying modular construction techniques. The use of modules for concrete and steel components should shorten the construction schedule, improve the quality of fabrication, and reduce the overall costs of construction. 


\subsubsection{Initial Proposed Applications of Modular Construction}

The GE SBWR Standard Safety Analysis Report (Ref. 30) does not describe the use of modular construction. Therefore, specific information was extracted from other sources (Refs. 31, 32). Structural components initially proposed for modularization were

1. Reinforcing bar assemblies for the basemat, building and containment walls, drywell and suppression chamber slabs, containment top slab, columns, floor slabs and beams.

2. Structural steel assemblies for the reactor building and turbine building superstructures. These modules will include roof trusses and siding.

3. Structural steel assemblies including stairs and platforms.

4. Steel liners for the containment, gravitydriven cooling system (GDCS) pool, isolation condenser (IC) pool, isolation condenser makeup pool, reactor well, steam separator storage pool, fuel transfer pools, spent fuel storage pools and spent fuel shipping cask loading pool.

5. Steel structures that will also serve as forms for the turbine pedestal, drywell vent wall and RPV pedestal.

6. Equipment assemblies containing components such as piping, condensers, cranes, diesel generators, HVAC units and numerous other equipment. These modules are for the reactor, turbine and radwaste buildings.

7. Precast walls in the reactor, turbine, and radwaste buildings.

Some of the major structural modules initially proposed for the SBWR reactor building are shown in Figures 3.2-1 and $3.2-2$. Some alternate modules for the reactor building are shown in Figure 3.2-3. Reinforcing bar modules for the basemat, columns, walls, and beams will be prefabricated and lifted into position with cranes. Structural steel modules will be lifted above the operating floor to construct the steel superstructure. The containment wall and pool liners will be prefabricated and installed as modules. Numerous steel structures inside containment will be placed into position and later filled with concrete. This type of modularization will be used for the reactor pedestal, diaphragm floor, wall between drywell and suppression chamber and the GDCS pool walls.

An open-top construction method will be employed for installation of the modules. A heavy lift crane will be used to place the prefabricated modules into the structure as soon as areas become accessible and before the overhead floor is constructed. This work would progress in parallel with civil construction activities on site. Figure 3.2-4 shows the placement of a vent wall module in the reactor building by a heavy lift crane.

Large composite modules will be used for the superstructure in the region above the grade clean area of the reactor building which houses the electrical and HVAC rooms. The large composite modules will contain a structural steel frame, precast siding panels, equipment and connecting piping, ducts and cabling. These modules will be assembled in a site fabrication area from smaller modules and components fabricated locally. GE stated that the use of these composite modules will require more investigation and evaluation in the next modularization review phase to confirm their applicability and economic benefit.

\subsubsection{Revised Application of Modular Construction}

In subsequent correspondence between $\mathrm{GE}$ and the NRC (Ref. 33), GE summarized its planned use of modular construction for SBWR as follows:

1. Rebar cages with liner plates for containment and RPV pedestal walls.

2. Rebar cages with steel beam and metal deck for floor slabs.

3. Structural steel modules for vent wall structure and diaphragm floor slab.

4. Rebar cages for the isolation condenser pool girders and basemat.

GE stated that there will be no precast concrete modules for major structural elements. 
Applications

\subsubsection{Summary of Analysis and Design Methods}

It appears that GE is still in the process of developing its final plan for utilitzation of modular construction. To date, no specific information pertaining to design/analysis methodology has been submitted. Since Design Certification of the SBWR is currently inactive, submittal of design/analysis methodology is not expected. 


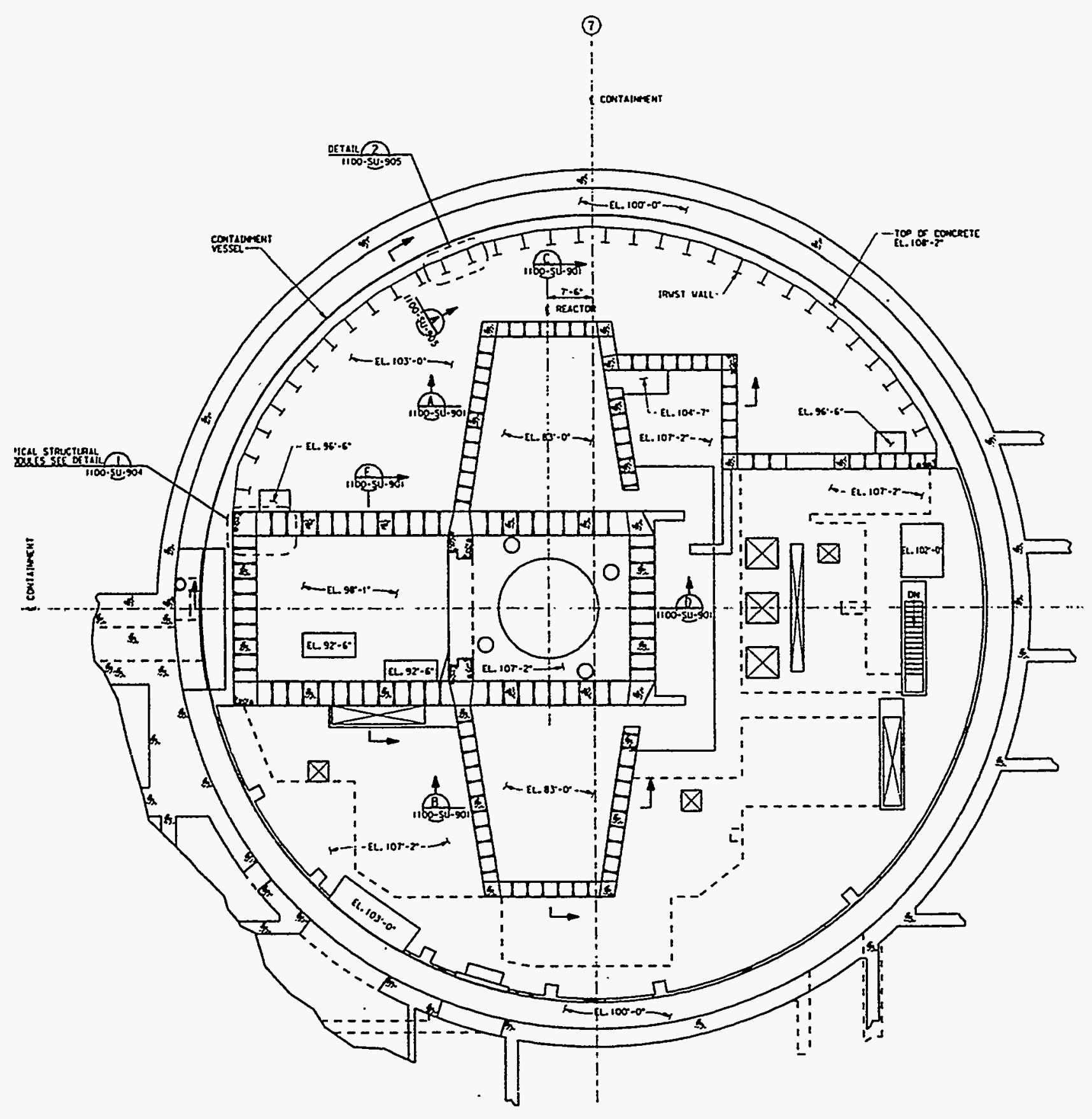

PLAN AT EL. $107^{\circ}-2^{*}$

Figure 3.1-1 AP600 Structural Modules Inside Containment [Ref. 27] 


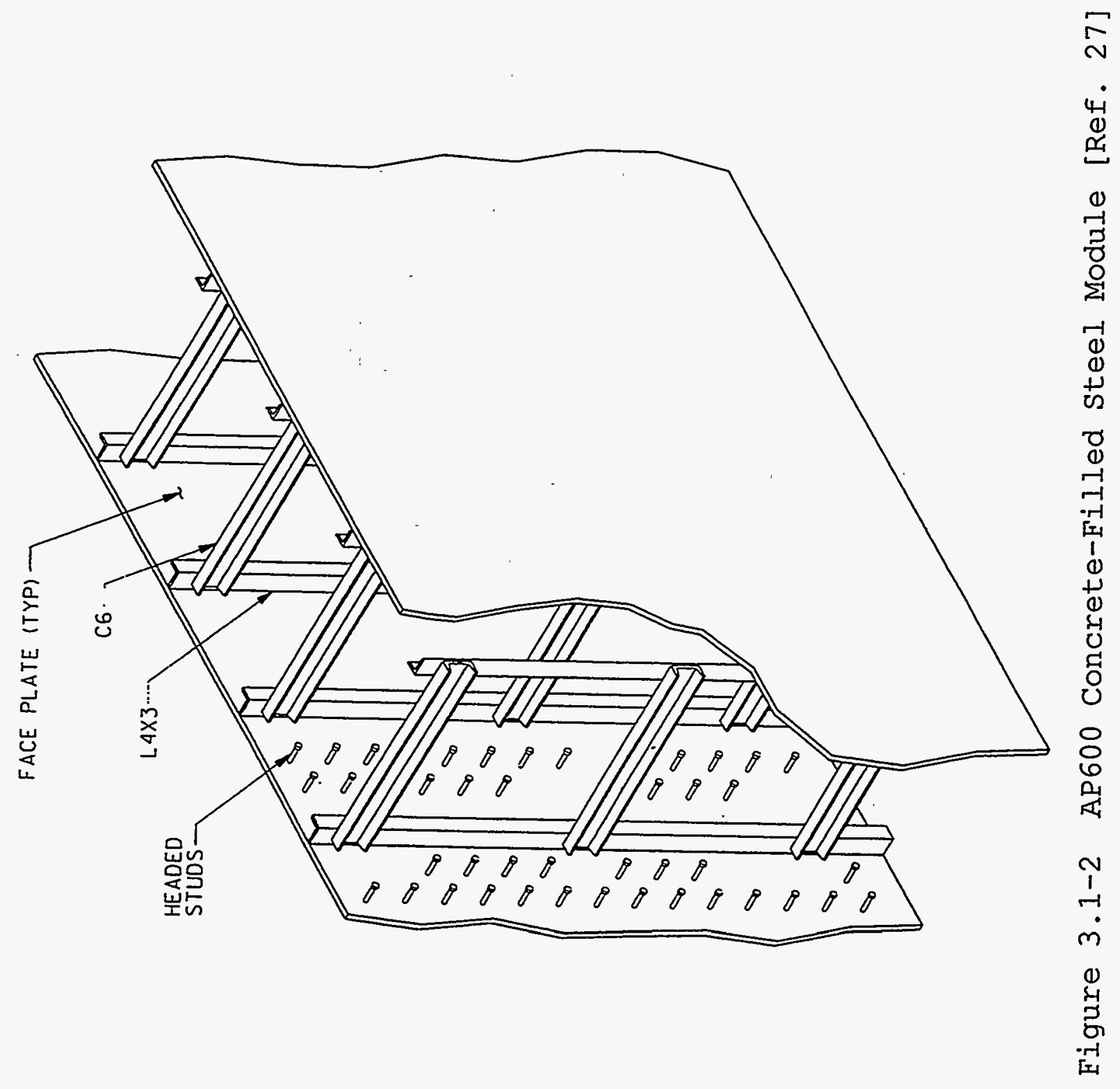




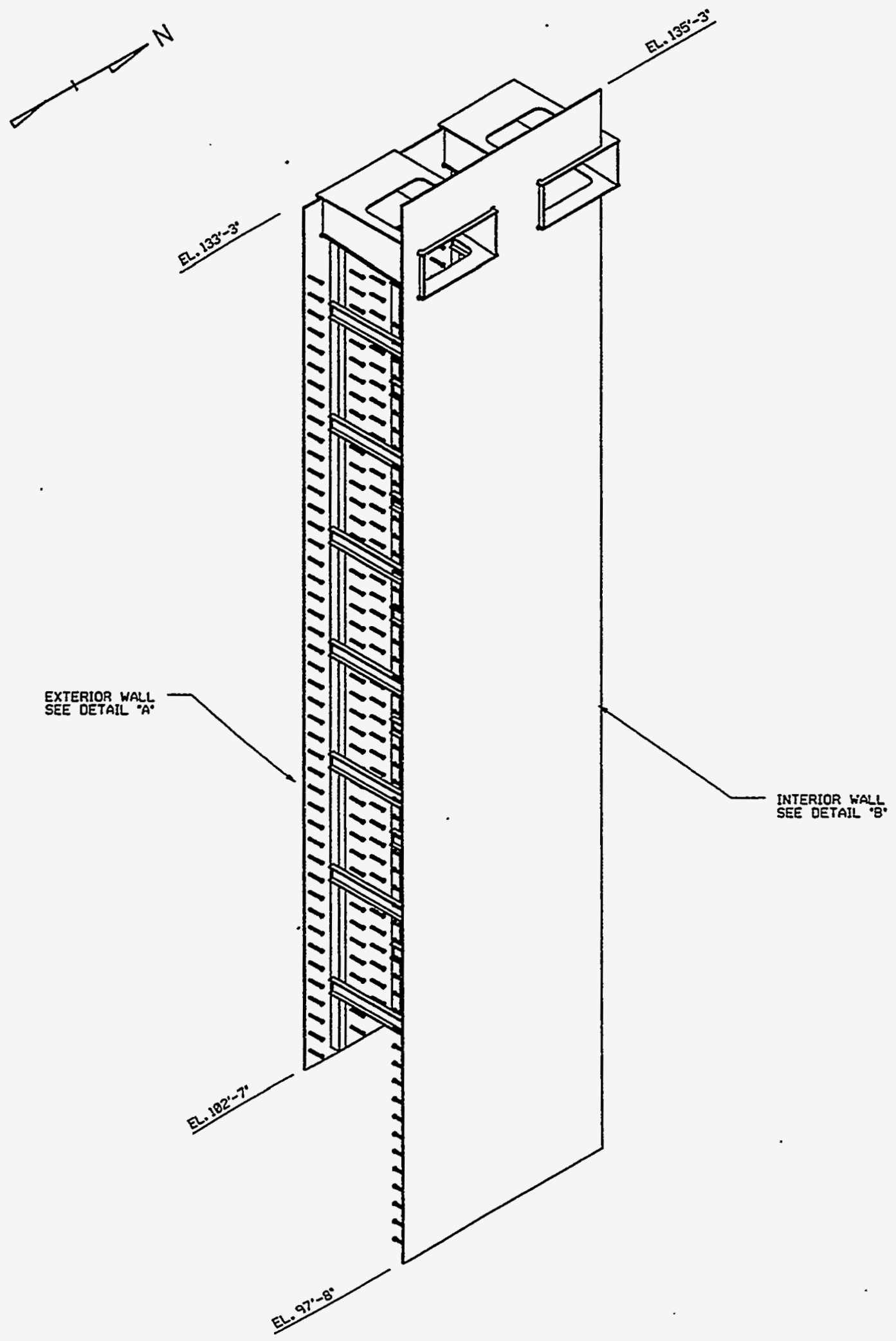

Figure 3.1-3 AP600 Typical M-1 Modular Subunit [Ref. 27] 


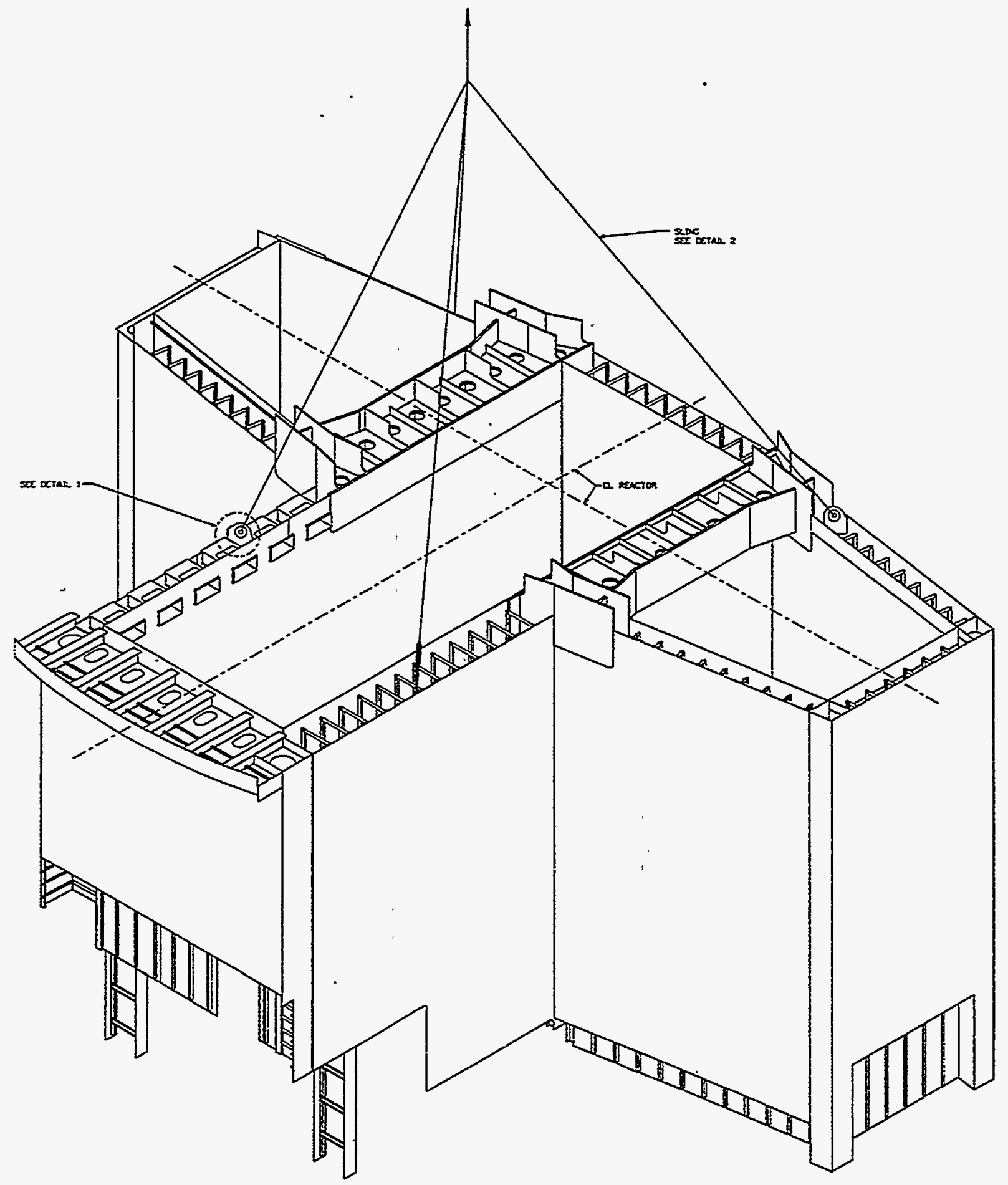

Figure 3.1-4 AP600 Unit Handling of M-1 Module [Ref. 27] NUREG/CR-6486 


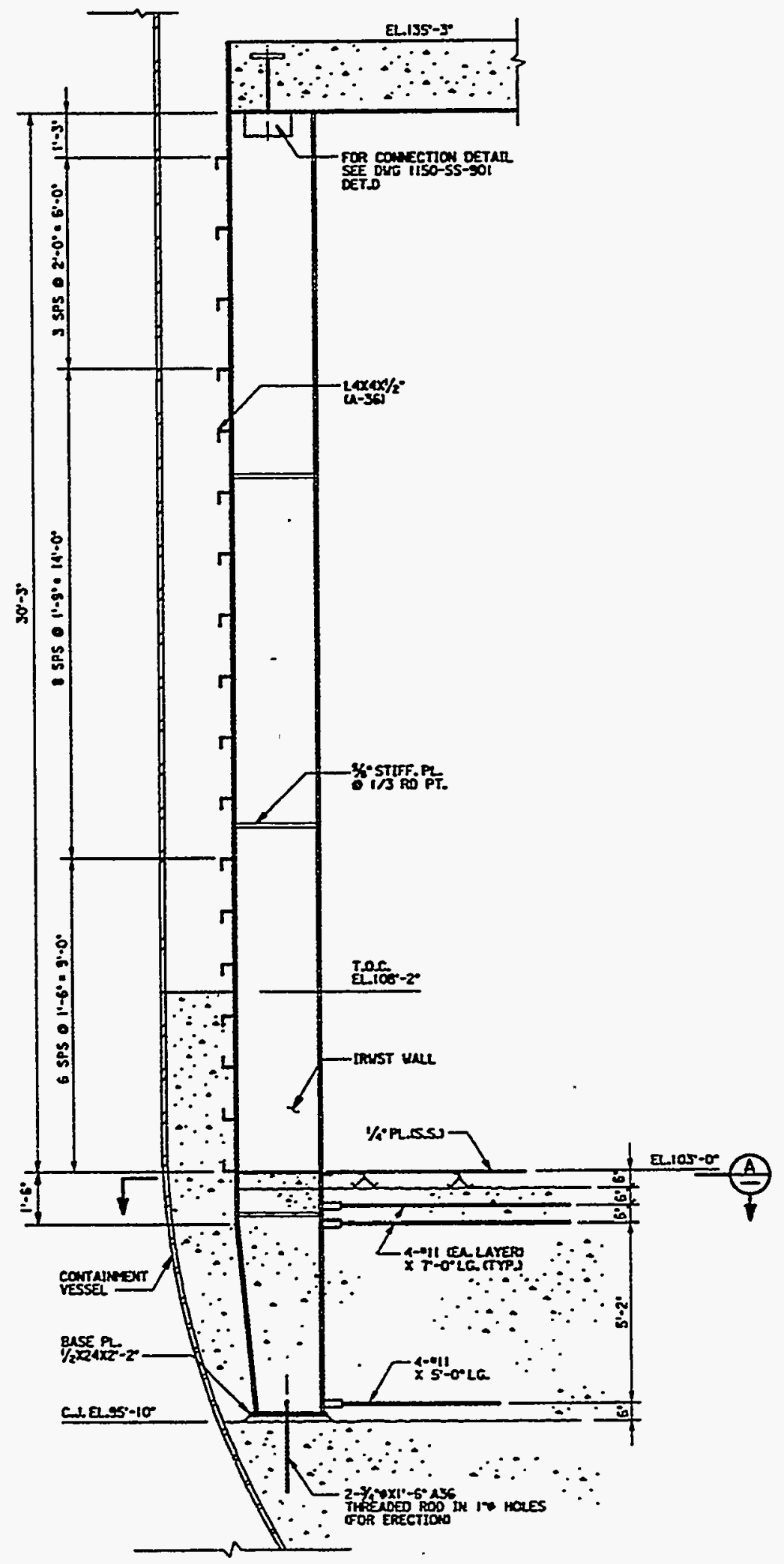

Figure 3.1-5 AP600 Steel Wall Module [Ref. 27] 


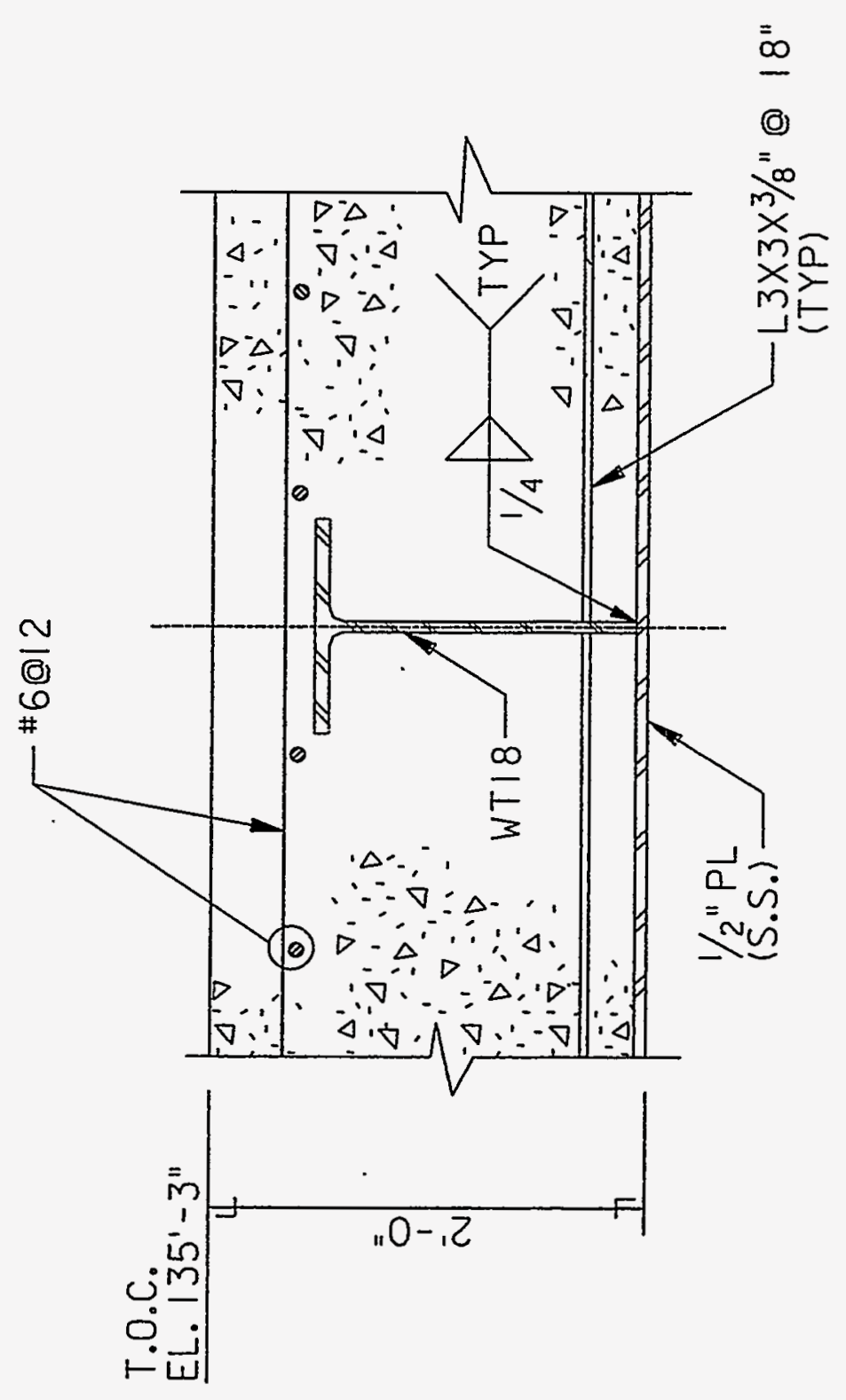

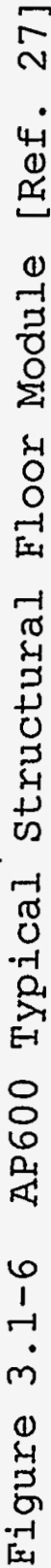




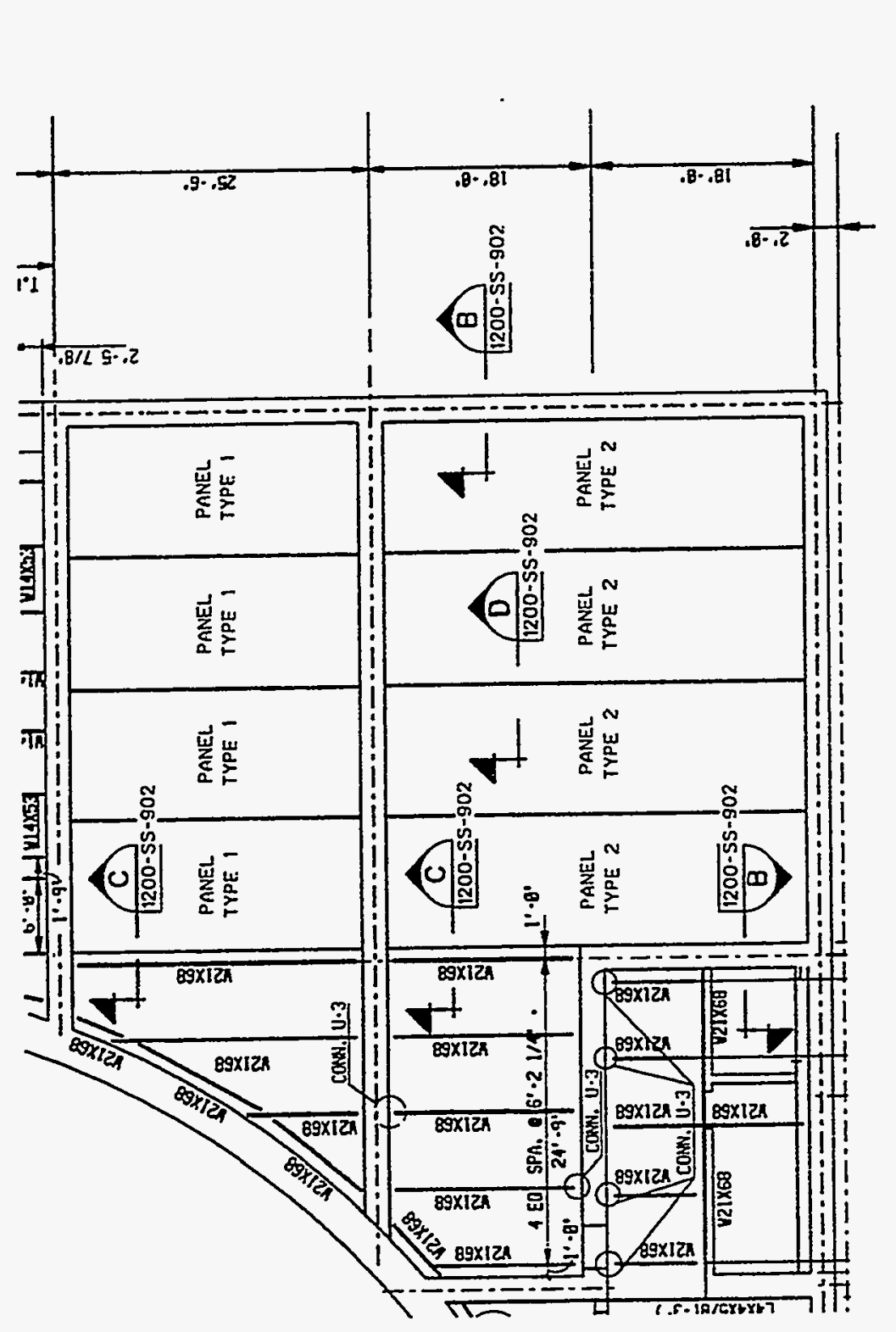

ล

4

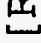

-

i-

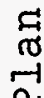

a

I

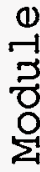

4

II

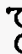

句

[x]

0
0
6
岶

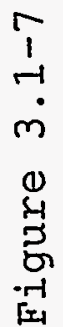




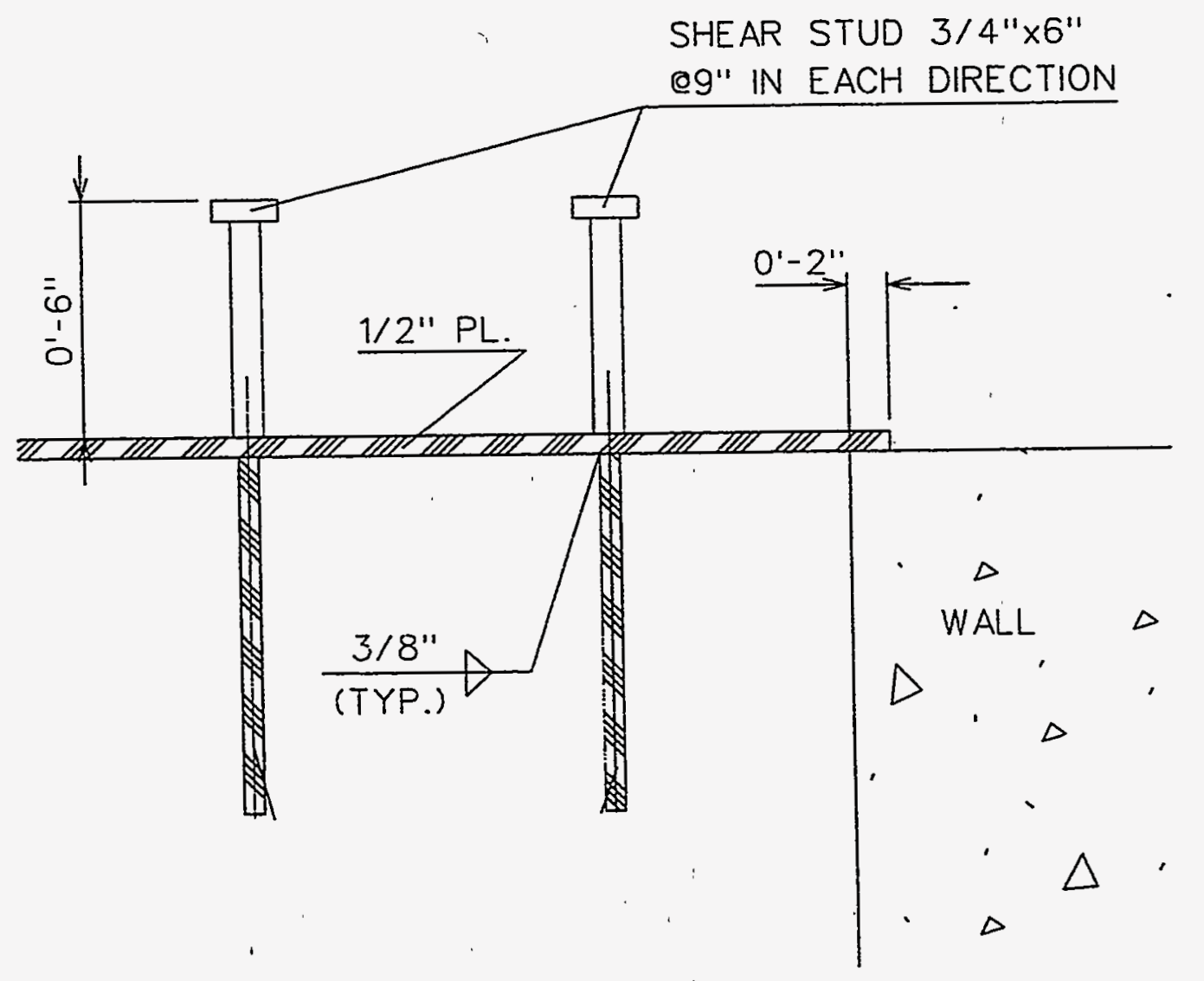

Figure.3.1-8 AP600 Finned Floor Module - Detail [Ref. 27] 


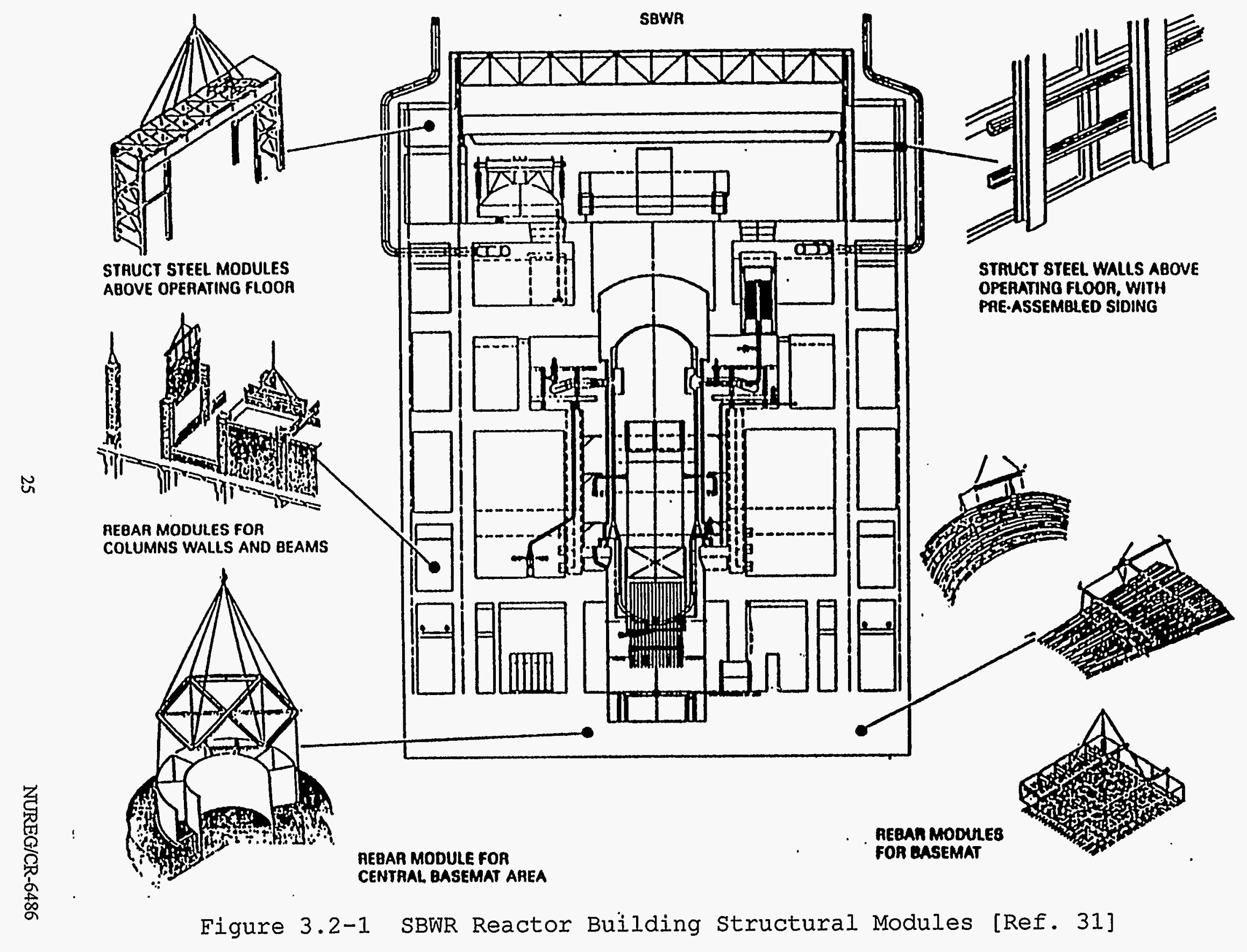




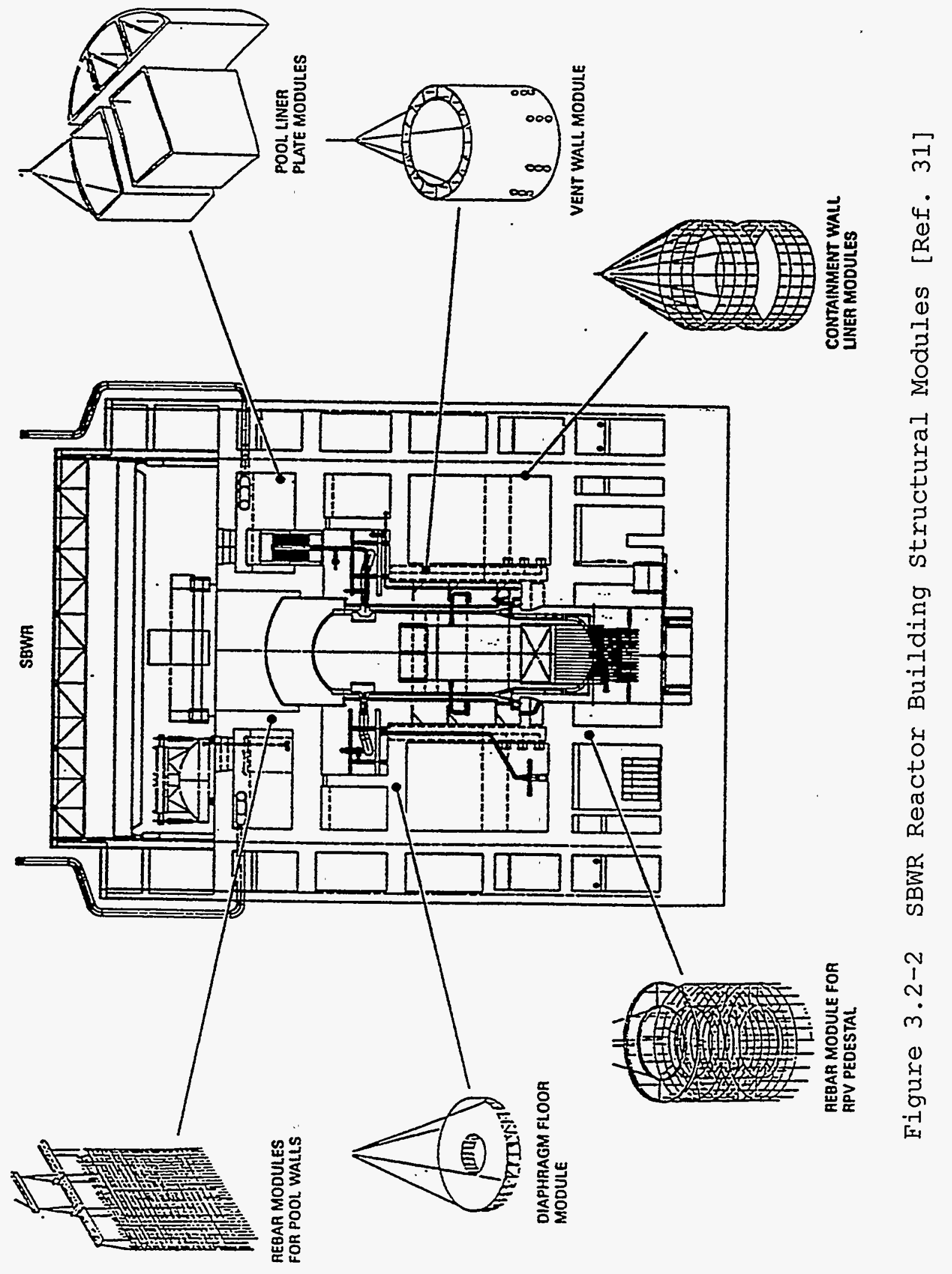

NUREG/CR-6486 


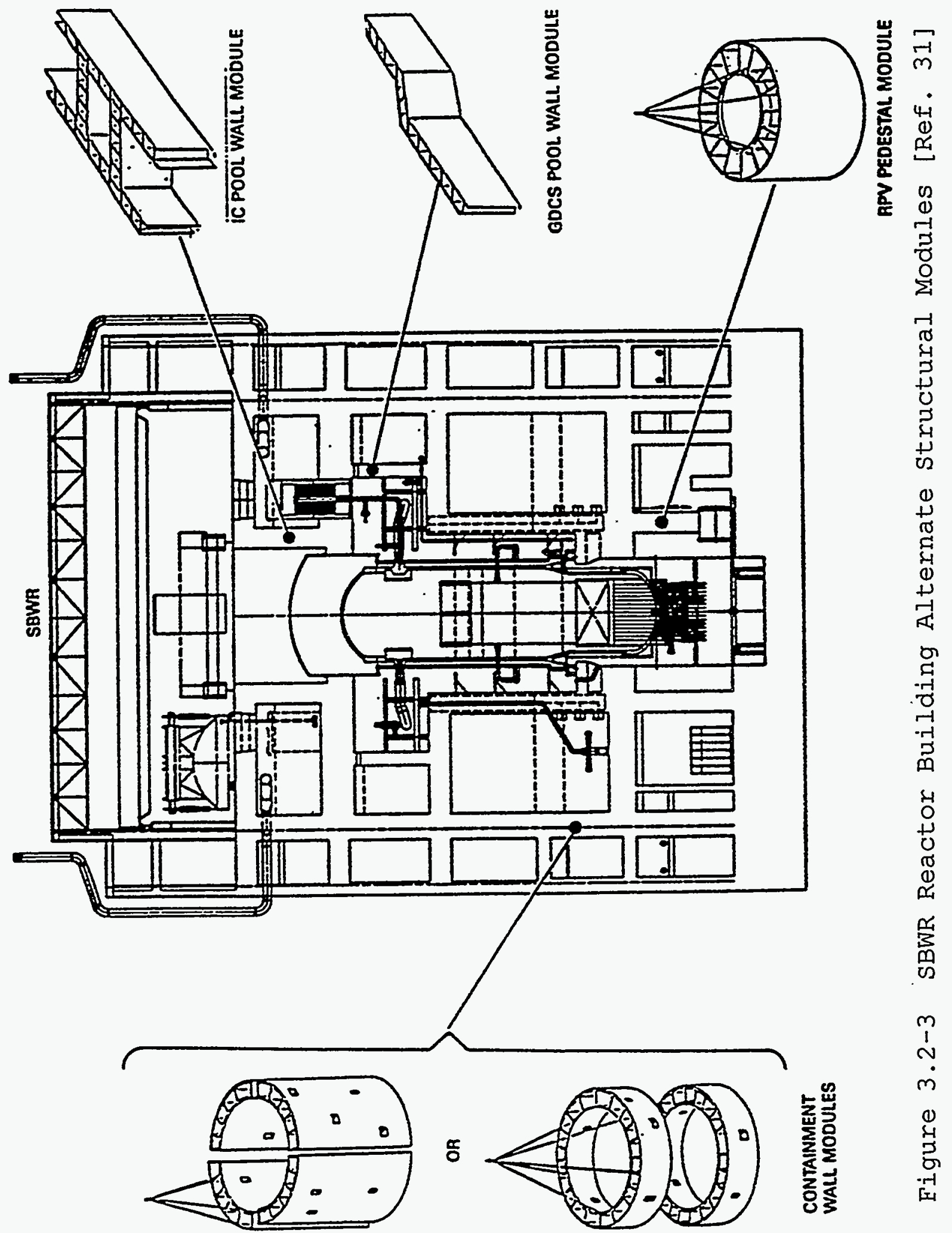




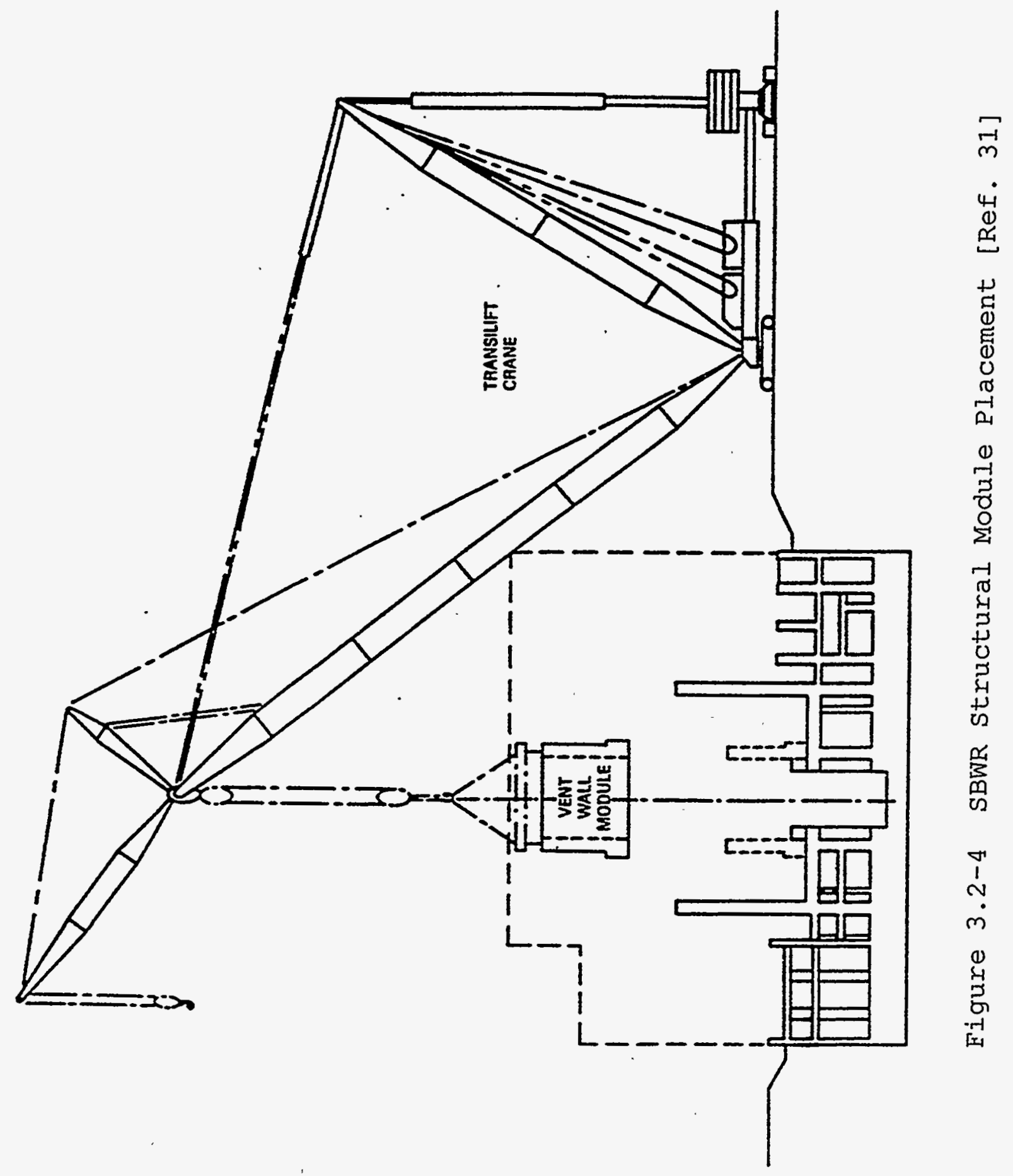




\section{STRUCTURAL MODULE ISSUES}

\subsection{Design and Analysis}

The use of structural modules in the nuclear power industry has been very limited. The survey of modular construction practices has identified a number of issues which need to be addressed. Other issues were identified based on the specific reviews of the licensing submittals for the AP600 and SBWR advanced light water reactor plants.

The major issues identified for design and analysis of safetyrelated structural modules are

\section{Lack of codes and standards for certain} types of modules,

2. Unique loads during the fabrication, handling, transportation, storage and erection,

3. Determination of initial stiffness and stiffness degradation,

4. Damping values for use in dynamic analyses,

5. Validation of analytical methods,

6. Reliability of joints and connections,

7. Determination of effective ductility,

8. Determination of ultimate load capacity.

Issue No. I: Currently no specific code, standard, or licensing criteria exist for the analysis and design of structural modules to be used in nuclear power plants. While there are industry recognized codes such as the American Institute of Steel Construction (AISC) Specifications (Refs. 29 and 34) for steel structures and the American Concrete Institute (ACI) Code 349 (Ref. 28) for reinforced concrete structures, they do not address certain types of structural modules.

As discussed in Section 2.1, Bagchi and Tan (Ref. 16) have looked at modular construction from a regulatory perspective. They concluded that the design of concrete and steel modules needs careful study because most likely the ACI 349 code and AISC code are limited in their applicability to these types of structural modules.

Additionally, Reference 35 specifically reviewed industry structural codes and standards for application to advanced nuclear power reactors. It concluded that the $\mathrm{ACI}$ and
AISC standards do not cover configurations such as the concrete-filled steel modules proposed for the AP600. A special concern with these modules is the design equations and criteria required to address buckling and shear transfer.

Issue No. 2: Unique types of loadings arise due to the modular construction approach. Significant loads may develop due to prefabrication, handling, transportation, storage and erection of structural modules. The loads are expected to be significant because the modules will tend to be very large, heavy, and difficult to handle. All of the loadings need to be clearly identified, accurately calculated, and carefully evaluated. Usually these types of loads are not evaluated in the design of structures because the structures are assembled from small individual elements. However, with modular construction techniques, a large assembled structure may be lifted into position by a crane with cables that may place very large concentrated forces at a few discrete points on the assembled structure.

This issue was also highlighted in Reference 35 which stated: "Applicable standards need to be modified to incorporate construction loads and transportation loads as normal design loads for modular construction."

Issue No. 3: The accurate determination of initial stiffness and stiffness degradation with increasing load is essential for dynamic analysis, because the natural vibration characteristics are a function of stiffness. The natural vibration characteristics, in turn, determine the magnitude of response to a given dynamic excitation. When stiffness degradation is significant in the load range of interest, it is necessary to ensure that the assumed stiffness is consistent with the calculated response level.

The stiffness behavior of structural modules which combine steel and concrete in a unique manner must be well understood in order to develop a safe design for dynamic loadings. It is well known that the load deflection curve for a reinforced concrete section is not linear due to stiffness degradation with increasing load. Similarly, for certain types of structural modules, such as concrete-filled steel modules, stiffness degradation will occur. This has been noted in tests on concrete-filled steel modules performed in Japan (see Section 2.3).

Reference 19 reported that the in-plane shear stiffness degradation for this type of module configured with studs, web plates, and shear bars, is substantially less than for reinforced concrete structures. However, for configuration details which differ from the tested configurations and for other loadings, such as compression and bending, the extent of stiffiness degradation, compared to reinforced concrete 
structures, needs to be evaluated.

Issue No. 4: Another important parameter necessary to evaluate structural modules is the appropriate value of damping. For welded steel type structures or reinforced concrete structures, criteria is presented in the NRC Regulatory Guide 1.61 (Ref. 36). However, for hybrid type structures such as concrete-filled steel modules or for modules with special joints and connections for which test data is not available, the selection of an appropriate damping value is an important issue. This is a concern only for dynamic loads such as seismic, safety relief valve actuation or LOCA loads.

Reference 19 is the only source identified that provides actual test data for determining the damping value of concrete-filled steel modules. From the hysteresis response characteristic of the specimen, equivalent viscous damping values were determined. The damping value at the design load level was equal to 5\%. It should be noted that Regulatory Guide 1.61 indicates that damping values of $4 \%$ for welded steel structures and $7 \%$ for reinforced concrete structures should be used for the SSE load level. Therefore, the use of $5 \%$ damping for concrete-filled steel structures under SSE loads seems reasonable but should be reviewed on a case-by-case basis.

Issue No. 5: Analytical methods used to predict the response of certain types of modules such as the concretefilled steel modules are not well established. Typically, a computerized mathematical model is developed to perform the necessary analyses. However, questions arise as to how to calculate the actual properties of the modules and how to develop a realistic mathematical model which is representative of the module. For a wall constructed from concrete-filled steel modules as an example, a finite element model of the wall may be developed using equivalent shell elements. However, how would one develop an equivalent shell element that has all of the same properties as a concrete-filled steel module section? How accurate is the model representation, what are the important properties to be simulated, how sensitive is the response to variation in material and analysis parameters, and how can one verify these?

Analytical methods for concrete-filled steel modules were studied in Phase III of this program, to determine if currently available analytical methods can be used to predict the response of a concrete-filled steel module. See Section 6.

Issue No. 6: A very crucial issue is the reliability of joints and connections. Just as a chain is only as strong as its weakest link, the assembly of multiple modular subunits requires adequately designed joints and connections. If the cross-sections of modules are designed to carry specified design loads then the joints and connections must also be carefully evaluated to ensure they can transmit these loads to the next module or attachment point to the building.

The concern with adequately designed joints and connections was also identified in Reference 16. It noted numerous catastrophic failures of structures built of precast and prefabricated concrete elements during earthquakes such as in Armenia. An examination of these structures revealed the root cause to be primarily pocrly designed and constructed joints.

Issue No. 7: Ductility is important for safety-related structural modules because they must withstand significant dynamic loads due to earthquakes. Ductility enhances its safety because energy can be absorbed through large inelastic deformation prior to collapse. Even under static loads, it is common practice to ensure ductile behavior in order to preclude a sudden catastrophic failure. It is necessary to ensure that structural modules have an energy absorption capacity comparable to conventional steel and reinforced concrete structures. The design of ductile joints and connections between modular sub-units is also of paramount importance.

Issue No. 8: Determination of the ultimate local capacity is necessary to establish the design safety margin of a structure. The typical design process relies on codes and standards to ensure an adequate safety margin between design allowable loads and ultimate load capacity. For unique structural modules not covered by existing codes and standards, knowledge of the ultimate load capacity is the first step in developing a design methodology which ensures a safety margin comparable to that inherent in currently accepted codes and standards.

All of these issues are described in greater detail in the Phase I report (Appendix A).

\subsection{Modular Construction Process}

Modular construction includes the entire process from offsite fabrication all the way through construction and operation of the plant. Therefore, the issues associated with the modular construction process encompass many areas. The major phases of the modular construction process can be categorized as follows:
1. Off-site fabrication
2. Handling 

3. Shipping
4. Storage
5. Erection
6. Inspection/testing

7. Quality assurance/quality control

8. Maintenance

The issues associated with the modular construction process can be described by identifying the special provisions and/or requirements needed to ensure that the original design basis of the modules is maintained. Thus, all phases of the modular construction process must prevent excessive distortion or overstress conditions, maintain the geometric layout assumed in design, and prevent material degradation of the modules. From the Phase I review effort, specific issues related to the modular construction process have been categorized as follows:

- Provisions in design and fabrication to assure field fit-ups (e.g., tolerances or excess material to permit field adjustments).

- Designated lifting points for handling and erection; designed in advance.

- Configuration control (e.g., centralized and computerized with access by all subcontractors).

- Mixed code classes on the same module.

- Storage and damage prevention.

- Construction plan and sequencing.

- $\quad$ Procedures for module lifting/placement.

- Owner "umbrella" vs fabricator controlled QA programs.

- Shop and site inspections.

- Specification for supporting, securing, and protecting modules during transportation.

- Material degradation due to 60 year operating life (e.g., may require inservice inspection or consideration of degradation in design).

Further discussion of issues relating to the modular construction process is presented in Appendix A.

The Modular Construction Review Criteria, which are summarized in Section 5 and detailed in Appendix B, address the Design/Analysis and Construction Process issues in a systematic manner, in order to provide guidance for licensing review of advanced light water reactor plants. 


\section{MODULAR CONSTRUCTION REVIEW CRITERIA}

\subsection{Introduction}

The modular construction approach has been adopted as one of the major features of the advanced reactor plant designs. The use of structural modules has been submitted for review under the NRC Design Certification process. The objective of the NRC Design Certification process is to evaluate and approve, from a safety perspective, a standard nuclear power plant design which can be constructed at most U.S. sites without a detailed, site-specific design. Proposed utilization of modular construction must be evaluated in depth, to ensure that structural performance and margins of safety are maintained at levels comparable to existing nuclear plant structures.

Currently, there are no specific licensing criteria that provide guidance for the use of structural modules in nuclear power plants. Consequently, the Modular Construction Review Criteria was prepared to provide guidance for use in licensing review activities. Its purpose is to supplement criteria already presented in the NRC Standard Review Plan (SRP) (Ref. 37).

The scope of this review criteria is limited to structural modules. The type of modules include steel/concrete composite floors, beams, and columns; concrete-filled steel modules; structural steel modules; precast concrete modules; and prefabricated rebar mats, cages, and subassemblies.

The sections that follow summarize the modular construction review criteria developed under Phase $I$ of this program. The complete Modular Construction Review Criteria, which was issued as a BNL Technical Report, is provided in Appendix B.

\subsection{Applicable Codes, Standards, and Specifications}

\subsubsection{Steel/Concrete Composite Floors, Beams, and Columns}

These types of modular structures have been previously accepted for use in commercial nuclear power plants. The American Institute of Steel Construction (AISC) Specification " Ref. 34) and the American Concrete Institute (ACI) Code 349 (Ref. 28) cover steel/concrete composite

\footnotetext{
When endorsed by the NRC, it is expected that ANSV/AISC N690 (Ref. 29) will replace the AISC Specification as the reference standard for steel structures in the SRP.
}

floors, beams, and columns. Therefore, they can be used, as applicable and as supplemented by current NRC technical positions and Regulatory Guides.

\subsubsection{Concrete-Filled Steel Modules}

The lack of U.S. codes and standards covering this type of modular construction lends uncertainty to the design/analysis/construction basis. Reliance on a program of analysis and test is the only viable alternative until applicable codes and standards are developed and accepted by the NRC for use in safety-related, nuclear power plant applications.

Guidance can be obtained from accepted codes standards and regulatory guides, to the extent of their applicability. It is reasonable to limit steel and concrete stresses and deformations to AISC and ACI design allowables as specified in SRP Section 3.8 provided the predicted stresses and deformations are obtained from verified analysis methods, benchmarked against test data. Both overall behavior and local interaction of the steel and concrete portions of the module need to be evaluated.

\subsubsection{Structural Steel Modules}

The provisions of the AISC Specification (Ref. 34) or American Society of Mechanical Engineers (ASME) Boiler and Pressure Vessel Code (Ref. 38) as appropriate to the specific application, and as supplemented by current NRC technical positions and Regulatory Guides, can be used as the design/analysis/construction basis. The only difference from current practice is in the modular construction process.

\subsubsection{Precast Concrete Modules}

The use of precast concrete modules for safety-related structures or substructures is expected to be limited. The ACI Code 349 can be used as the design/analysis construction basis, provided the precast module meets the requirements which would apply to the corresponding poured-in-place concrete structure. Any applicable NRC technical positions and Regulatory Guides should also be satisfied. Special provisions to limit transportation loads, especially vibration and impact loads, are necessary to preclude damage during transit to the site. Special connection detailing is required to join pre-cast modular units into a final modular assembly. Inspection of precast modular units is necessary to ensure that the as-received condition and the in-place condition meet the applicable design requirements. 


\subsubsection{Prefabricated Rebar Mats, Cages, and Subassemblies}

Either the ACI Code 349 (Ref. 28) or the ASME Code (Ref. 39) defines the steel reinforcing requirements, depending on the application. Adherence to these design requirements is necessary. The in-place placement, connectivity, and splicing of rebar must meet the appropriate code requirements, regardless of the sequence leading up to the concrete pour. Any applicable NRC technical positions and Regulatory Guides should also be satisfied.

The procedures to ensure that the in-place geometry of the reinforcing steel meets the design requirements should be specified. In addition, the procedure for joining of rebar subassemblies to create a complete rebar assembly should be specified, with emphasis on ensuring the continuity of load transfer.

\subsection{Loads and Load Combinations}

The SRP defines the loads and load combinations, expected during plant operation, to be used for structural design. These are directly applicable to design of structures erected utilizing modular construction techniques. For modular construction, however, the process of off-site fabrication, transportation, and site erection may impose significant additional loads which typically are not considered for inplace construction. While these additional loads are not likely to control the overall structural design, it is important that each modular unit has sufficient strength and stiffness to resist these loads without any degradation of operating load capacity and without unacceptable permanent deformation. To allow either condition could negate the initial design assumptions.

During off-site fabrication, the method of supporting the module during the various stages of fabrication and the method of lifting and moving the module from one work station to the next will control the induced stresses and deformations. The completed module must be hoisted onto the transportation vehicle, supported, and tied down. These operations will impose a second set of loads on the module. During transit, the module will likely be subjected to both vibration and impact. Upon arrival on-site, the module is hoisted off the vehicle and supported on the ground. Final site assembly will impose lifting and fit-up/joining loads on the module. All of these construction-related activities must be executed in a manner which limits stress, deformation, and fatigue usage to acceptable levels (i.e., maintain the initial design basis).

In general, the construction-related loads need not be combined with the operating loads defined by the SRP because they do not occur concurrently. The exception to this would be any residual effects resulting from construction-related loads. For example, in concrete-filled steel modules, some residual stress and deformation of the steel plates is possible as a result of the in-place concrete pour process.

\subsection{Design and Analysis Procedures}

\subsubsection{Steel/Concrete Composite Floors, Beams and Columns}

Current NRC requirements and industry codes and standards are sufficient to define acceptable design and analysis requirements for composite structures. The AISC Specification, supplemented by NRC technical positions, provide requirements for composite construction consisting of steel beams or girders supporting a reinforced concrete slab or steel deck in nuclear facilities. ACI 349 provides requirements for composite compression members for nuclear facilities. The ACI code covers two types of composite columns: a structural steel encased concrete core and reinforced concrete around a structural steel core.

While acceptable criteria exist, special consideration should be given to unique aspects pertaining to modularization of composite structures. The design of the modules must consider the loads generated as a result of the fabrication, handling, transportation, and erection of steel as well as the pouring of concrete. These loads will often require supplementary steel to provide sufficient stiffness to maintain the module configuration from off-site fabrication to final placement.

\subsubsection{Concrete-Filled Steel Modules}

The lack of design and construction experience for concrete-filled steel modules has led to a number of issues, as described in Section 4. Limited experience is available from work conducted in Japan for concrete-filled steel modules similar to those proposed for advanced reactors in the U.S. While the reported test results provide a general sense of "robustness", the scope of the reported results is insufficient by itself to support generalizations about proper design/analysis assumptions.

The extent of applicability of existing codes and standards to new design concepts can be subject to considerable disagreement. Given the NRC's responsibility to ensure with a high level of confidence that the public safety is maintained for all credible events, it is necessary to demonstrate that the application of existing codes and 
standards to new design concepts maintains safety margins which are at least equivalent to existing safety margins. Therefore, any structural design concept which falls outside the boundaries of currently accepted codes and standards should require verification of the design/analysis methodology by comparison to applicable test data.

If a sufficient body of applicable test data already exists in the open literature, then project-specific testing may not be required. However, it is the applicant's responsibility to submit a sufficiently detailed justification for the proposed design/analysis methodology, based on the existing test data.

A structural verification program should be performed to substantiate the design/analysis methods for concrete-filled steel modules. This program should demonstrate that these methods maintain sufficient margins of safety when compared to design/analysis standards for other structural components such as reinforced concrete or structural steel.

Some important points that should be considered in the design and analysis of concrete-filled steel modules are

1. Structural behavior of modular units must be well understood. It is not sufficient to rely on perceived "conservative" assumptions of stiffness, load path, and structural strength criteria. In the design of modular units and the connection details, it is very likely that subtle situations exist, for which a simplifying assumption may not be readily classified as "conservative."

2. The connections between modular units which make up a complete modular assembly are critical elements in the response of the assembly. The connection detail will determine the load transfer path between modular units and the joint "ductility". This must be well understood to accurately evaluate the local behavior of the modular unit and the overall behavior of the modular assembly.

3. Given the current state-of-the-art in computer-aided structural analysis, detailed modeling/analysis of the modular unit and modular assembly can be performed. This analysis coupled with confirmatory testing of the basic modular unit and connection details, should make it possible to accurately predict both local and overall structural behavior. The need for so-called "conservative" assumptions should be minimized, and where necessary, the sensitivity of the structural behavior of the modular unit to a parameter variation should be performed to verify the original perception of "conservatism".

4. The complex interaction between steel and concrete cannot be adequately evaluated if the design methodology selectively relies on only one of the two structural elements to carry specific types of loading (i.e., bending, shear, and compression). A potentially serious pitfall of this approach is that the designer/analyst must work with several "different structures" to carry the applied loads. The probability of making an error is increased and the use of engineering judgement to qualitatively check numerical results becomes difficult. Most important, interactions which are ignored by the design methodology may precipitate a loading path and progressive failure which is the limiting condition of structural strength.

\subsubsection{Structural Steel Modules}

In view of the successful use of structural steel modules in the past, current NRC guidance and industry codes and standards are sufficient to define acceptable design and analysis requirements. However, special consideration needs to be given to several items that are unique to modular construction. The additional loads resulting from the construction/preassembly of larger modules need to be addressed. Currently, larger capacity lift cranes are available which may impose significant concentrated loads. These loads must be considered early on in the design stage of the modules.

In addition, supplementary steel will need to be preengineered to provide sufficient stiffness to maintain the module configuration from preassembly through transporting, lifting into place, and placement of concrete. This additional steel would not be wasted in a good design if its load carrying capability is included in the analysis and design of the assembled structure. 


\subsubsection{Precast Concrete Modules}

Current NRC requirements and industry codes and standards define acceptable design and analysis requirements which would apply to precast concrete elements. ACI 349 provides requirements for design of precast concrete members, which it defines as concrete elements cast elsewhere than their final position in the structure. Provisions are presented in the Code to address special conditions important to the design of precast concrete members. These include consideration of all loading and restraint conditions from initial fabrication to completion of the structure, requirements for design of connections, detailing requirements, and provisions for precast wall panels. Additional requirements are also specified for identifying and marking the members and for transporting, storing, and erecting the precast members.

In view of the limited use of precast concrete modules for safety-related structures at nuclear power plants, the analysis and design procedures should be carefully reviewed, particularly in the critical area of connections. The effects of all interconnecting details must be considered in the analysis and design to assure proper performance of the structural system. The connection details must be designed to provide for manufacturing and erection tolerances and temporary erection stresses.

\subsubsection{Prefabricated Rebar Mats, Cages and Subassemblies}

Prefabricated rebar modules do not represent a final structural unit. Rebar is covered as part of the reinforced concrete design/analysis process, which is addressed in existing accepted codes and standards. However, the prefabrication of many rebars into mats, cages, or subassemblies does introduce concerns dealing with the handling and placement of the rebar elements. Some rebar modules may require the design of special steel support structures to hold them in place. The structural support system may also be required to maintain the rebar spacing, to stiffen the rebar modules to prevent "racking" during handling, and for alignment to adjacent rebar modules.

Special attention should be given to the splicing of adjoining rebar modules, since staggering of the splices may be impractical. Staggering of rebars is desirable, to avoid developing a weak section at the interface. Special procedures will be necessary to ensure that the final placement of the reinforcement matches the design requirements to within acceptable tolerances.

\subsection{Structural Acceptance Criteria}

If the design of a specific type of modular unit is governed by recognized ASME, ACI, and AISC codes, as supplemented by the SRP and Regulatory Guides, then the only additional considerations for modular construction are those related to off-site fabrication, handling, shipping, storage and site erection.

The design process assumes that the geometry of the asbuilt structure is the same as the nominal design geometry, to within the dimensional tolerances which are accounted for in the design analysis. For modular construction, there are three major operations which potentially contribute to deviations from the nominal design geometry: off-site fabrication, transfer to site, and final erection of the structure using modular units. The cumulative effects of all three operations must not exceed the allowable dimensional tolerances accounted for in the design analysis. Off-site fabrication in a controlled environment should permit adherence to fairly tight tolerances. Handling, shipping and storage operations should be controlled by procedures to ensure that no permanent distortion is introduced. The major source of dimensional deviation is expected to be fitup of the individual modular units to form the completed structure.

For steel modules and steel components of composite modules, applied static loads due to lifting, handling, tie down and other operations should not cause material yielding, except at very localized stress concentrations. Vibration loads during transit or other operations should not induce alternating peak stress cycles which exceed the material endurance limit, per the applicable code. If an operation, such as shipping, subjects a modular unit to impact loads, every effort should be made to minimize them. The worst case combination of ambient temperature and impact loading should be evaluated, to preclude the possibility of brittle failure during any construction-related operation.

For precast concrete modules and composite steel/concrete modules fabricated off-site, concrete stresses should be maintained below applicable code design allowables for all construction-related operations. Possible vibration and impact loads should be minimized by procedural control. Cracking of concrete as a result of construction-related activities is not acceptable, unless such cracking has been adequately considered in the design analysis. All potential causes of concrete material deterioration must be eliminated.

For unique structural module designs, not presently governed by recognized codes and Regulatory Guides, a 
specific set of structural acceptance criteria must be defined. To the extent feasible, these should be drawn from applicable sections of currently recognized codes, as supplemented by Regulatory Guides. Any unique acceptance criteria should reflect the design philosophy embodied by the currently recognized codes. A detailed analysis program, verified by supporting test data, will be necessary to define the two key behavioral states of the module under load. The onset of nonlinear behavior establishes the limit of applicability for linear analysis methods, which are traditionally used for design calculations. The behavior of the structure beyond the limit of linear response must be investigated, to determine the ultimate load capacity and effective "ductility". Design margins against failure can then be defined in a manner consistent with those in currently recognized codes. The objective is to ensure that a comparable factor of safety is maintained. The applicant must submit the technical basis for the structural acceptance criteria for unique module designs. The information must be both comprehensive and concise, to accommodate an independent review.

\subsection{Materials, Quality Control, and Special Construction Techniques}

\subsubsection{Materials}

The current guidance presented in the SRP is directly applicable to modular construction. Concrete and steel materials should meet the applicable specifications of $\mathrm{ACI}$, AISC, or ASME. Any material not covered by the appropriate code or not previously accepted for the proposed application must be reviewed on a case-by-case basis for acceptability. The applicant should provide sufficient test data and user experience documentation to establish acceptability for the proposed application. In the utilization of modular construction, a widely accepted material may be proposed for a unique application. It is important that the material/application combination be reviewed for acceptability.

Special consideration should be given to the potential for inservice material degradation. This is particularly important for a sixty-year operating life. Potential material degradation should be addressed in one of two ways: inservice inspection and remediation or initial design to preclude the degradation. Susceptible areas which will be inaccessible after completion of construction should be addressed as part of the design process; i.e., eliminate the potential for inservice degradation.

For susceptible areas which will be accessible for inspection after completion of construction, an appropriate allowance for degradation - based on inservice experience at currently operating plants and a defined schedule for periodic inspection - should be factored into the design calculations. A remediation criterion should also be defined.

\subsubsection{Quality Control}

The SRP invokes the Quality Control requirements of ASME Section III for containments, ACI 349 for concrete structures, and AISC Specification for steel structures. There is direct applicability of these requirements for all types of modular construction considered herein, except for concrete-filled steel modules. The applicant should specifically define the quality control measures to be implemented for any type of modular construction not directly covered by one of the aforementioned codes. As applicable, the quality control requirements of these codes should be incorporated. The goal is to ensure that a level of quality control comparable to that required by existing codes is implemented for any unique type of modular construction.

For concrete-filled steel modules where composite behavior of the concrete and steel is assumed in the design/analysis, control of construction processes which affect the soundness of the interface between steel and concrete is essential to ensure achievement of design assumptions. The applicant should specifically address the measures to be taken and the proposed methods of verification.

For all types of modular construction, proper control of handling, shipping and storage operations is essential to meet overall quality requirements. For unique types of modular construction, the applicant should describe the measures to be taken to control these operations, citing prior applicable industry experience, existing test results, and/or proposed verification methods as the validation basis. For other types of modular construction, the applicant should commit to the implementation of measures which have previously been successful, by reference to an applicable code or procedure.

As previously discussed in Section 5.5, it is essential that final erection tolerances assumed in the design/analysis are not exceeded. Each step of the modular construction process must be sufficiently controlled to ensure that the cumulative effect of all operations satisfies the tolerance criteria. For unique types of modular construction, the applicant should describe the control measures to be implemented to meet the specified design tolerances. 


\subsubsection{Special Construction Techniques}

Modular construction techniques which are new or unique should be fully described so that an evaluation can be made to ensure that the structural integrity of the completed structure is maintained. The description of the modular construction techniques should cover the entire process from fabrication of the modules through transportation, storage, handling, inspection/testing, and erection. The information provided should demonstrate that the methods used do not degrade the structural quality of the modules in any manner that might affect the structural integrity of the structure.

\subsection{Testing and Inservice Inspection Requirements}

Regulatory Guide 1.70 (Ref. 40) and the SRP define specific testing and inservice inspection for concrete and steel containments, per the ASME Code Section III and applicable Regulatory Guides. For steel containments, Regulatory Guide 1.70 also specifies that "programs for inservice inspection in areas subject to corrosion should be provided." Also applicable to containments, Regulatory Guide 1.70 states: "If new or previously untried design approaches are used, the extent of additional testing and inservice inspection should be discussed." The SRP specifies that this be reviewed on a case-by-case basis. These requirements are all directly applicable to containments assembled by modular construction techniques.

For structures other than containment, there is no specific testing and inservice inspection defined in Section 3.8.3, 3.8.4 and 3.8.5 of Regulatory Guide 1.70 and the SRP. The extent of compliance with applicable codes (e.g., ACI, AISC, ASME) and Regulatory Guides should be indicated by the applicant. The need for and scope of testing and inservice inspection of these structures is initially determined by the applicant, subject to review and acceptance on a case-by-case basis.

Advanced reactors have a design life of sixty (60) years $50 \%$ longer than current operating plants. Based on the recent NRC study (Ref. 41) on aging degradation of civil/structural features at several older operating plants, it was concluded that with proper maintenance, inservice inspection, and occasional repair and correction of an unforeseen degradation condition, civil/structural features should not be a controlling factor in the life extension of existing plants to 60 years. The conditions observed at operating plants were evaluated in the context of a 60 year design life for Advanced Reactors. The results of this study can be utilized in the development of design, construction, inspection, and maintenance specifications.

\subsection{Quality Assurance Program}

An effective QA program is essential to achieve the desired improvements in construction cost and schedule, which are expected from utilization of modular construction techniques. Special considerations pertinent to the use of modular construction are discussed in the criteria report (see Appendix B). 


\section{VALIDATION OF ANALYTICAL METHODS}

\subsection{Purpose}

The purpose of this phase of the research program was to validate the use of currently available analytical methods in predicting the response of concrete-filled steel modules. The concrete-filled steel module was selected because this is a new type of structure that is not specifically covered by existing codes and standards. Also, techniques used for analysis and design are not well defined. As a result, this type of structural module had the most issues which were identified in Phase I.

To permit the practical and efficient application of the concrete-filled steel module and to satisfy licensing requirements, the structural behavior for this new type of structure must be well understood. Some test data on concrete-filled steel structures are available in the literature. This data can be used to address some of the issues and to validate analytical methods that would be used to design concrete-filled steel modules.

\subsection{Test Data Used For Validation}

Concrete-filled steel modules have been proposed for use primarily as shear wall structures inside and outside containment. These structures would be subjected to dead load, live load, pressure loads, seismic loads, and thermal loads. An individual wall section would primarily experience in-plane axial compression, in-plane and out-ofplane shear loads, and bending about two perpendicular inplane axes. The analysis effort in Phase III evaluated concrete-filled steel modules subjected to in-plane axial compressive loads. Recommendations for the evaluation of the modules for other loads are discussed in Section 7.

From the survey of modular construction practices, a few studies were identified which tested concrete-filled steel structures in compression (see subsection 2.3). One test (Ref. 23) was performed on concrete-filled test specimens similar to the type being proposed by Westinghouse for the AP600. Compared to the other tests, this reference provided the most complete information (numerous figures, tables, and numerical information), which is essential in making an independent analysis of the test for validation purposes.

Figure 6.2-1 presents the configuration of the test specimens. The specimens were one-fifth scale models. A total of four specimens were tested with varying stud spacing to thickness $(B / t)$ ratios of $20,30,40$, and 50 . The thickness $(t)$ of the steel surface plate was $3.24 \mathrm{~mm}(.128$ inches). Studs, having a diameter $(\phi)$ of $5 \mathrm{~mm}(.197$ inches), were used to anchor the surface plates to the concrete. Concrete with a compressive strength of 31.2 $\mathrm{MPa}(4,525 \mathrm{psi})$ was placed inside the specimens. Figure 6.2-2 shows the nonlinear properties of the steel plates and the concrete. The test specimens were placed in a compressive test machine as shown in Figure 6.2-3(a). They were subjected to four loading cycles as shown in Figure 6.2-3(b).

Geometric similarities of the test specimens to the Westinghouse concrete-filled steel module, are summarized as follows:

$\begin{array}{ccc}\begin{array}{c}\text { Geometric } \\ \text { Parameter }\end{array} & \begin{array}{c}\text { Test } \\ \text { Specimens }\end{array} & \begin{array}{c}\text { Westinghouse } \\ \text { Wesign }\end{array} \\ \begin{array}{c}\text { Width/thickness } \\ (W / t)\end{array} & 63.7 & 60 \text { to } 96 \\ \begin{array}{c}\text { Stud spacing/plate } \\ \text { thickness } \\ (B / t)\end{array} & 20 \text { to } 50 & 15 \text { to } 20 \\ \begin{array}{c}\text { Stud dia./plate } \\ \text { thickness } \\ (\phi / t)\end{array} & 1.56 & 1.5\end{array}$

\subsection{Description of Analytical Study}

A three dimensional (3D) finite element model (FEM) of one of the test specimens was developed. The test specimen corresponding to $\mathrm{B} / \mathrm{t}$ equal to 20 was selected, thereby matching the B/t ratio of the Westinghouse configuration. The FEM of the test specimen is shown in Figure 6.3-1. The model utilizes plastic shell elements to represent the steel plates and 3D reinforced concrete solid elements, without reinforcing bars, to represent the concrete.

Due to symmetry conditions, it was possible to reduce the size of the model to one-eighth of the actual specimen tested. For modeling purposes the specimen was cut in half with respect to its height, then in half along a vertical plane in the front-to-back direction and in half again along a vertical plane in the side-to-side direction.

The discretization of the concrete elements for the oneeighth model is two elements by six elements by six elements as shown in Figure 6.3-1. The nodes for the concrete elements in the vertical plane were located to match the actual location of the studs. For the steel elements, a finer mesh representation was utilized as shown in Figure 6.3-2, where the concrete elements have been removed for clarity. The steel surface plate lies on the $\mathrm{X}-\mathrm{Y}$ plane and has a pattern of four by four steel shell elements for each full size concrete element to capture the expected 
buckling deformation. The studs were represented by springs which connect the concrete nodes to the coincident nodes of the steel shell elements. The use of springs enables forces in the studs to be obtained directly from the computer output and facilitates the evaluation of module response to varying stud stiffnesses.

To match the test specimen, the FEM also included the vertical side plate, connecting the two surface plates of the specimen, and the horizontal ribs. It is believed that the ribs were provided to prevent bulging of the side plate, simulating the continuity of the wall.

The nonlinear material property of the side plate was modeled using a bilinear stress-strain curve. The nonlinear material property of the surface plate was modeled using a multilinear stress-strain curve because the transition from the elastic region to the plastic region is gradual (see Figure 6.2-2). For the concrete elements, a multilinear curve was also used to match the stress-strain values shown in Figure 6.2-2 up to a strain of .002. Beyond this strain, the curve used in the analysis remained flat at the peak stress value of $30.8 \mathrm{MPa}$. This approach was implemented to simulate the expected behavior of confined concrete. The steel plate enclosing the concrete would prevent the crushing of the concrete and the corresponding loss of stiffness as shown in Figure $6.2-2$ beyond a strain of .002 .

The boundary conditions consisted of symmetric boundary conditions at all nodes in the three planes where the specimen was cut to obtain the one-eighth model. Two different boundary conditions were evaluated at the top. The two different boundary conditions, fixed and free, were considered because from the information contained in the paper, it was not evident which case is applicable.

The loading consisted of monotonically increasing vertical downward displacement at all nodes at the top. Summing the reaction forces at all the nodes at the bottom provides the load corresponding to the imposed displacement. The resulting load-deflection data from the computer analysis can then be compared to the data obtained from the test.

\subsection{Results of Analysis and Comparison to Test Data}

To validate the analytical methods used, the response of the concrete-filled steel structure in terms of load-deflection data was determined. This data can be used to obtain important design information such as the stiffiess of the structure, the extent of stiffness degradation, the ultimate capacity, and the level of ductility. Accurately predicting the stiffness of the structure is extremely important for loads such as seismic and hydrodynamic events, where the natural frequencies of the structure determine the magnitude of the applied loads. The ultimate capacity and ductility are also important to ensure that the available design margins and energy absorbing capability are comparable to other conventional structures made from reinforced concrete or structural steel.

The initial stiffness of the computer model was determined to be $5.94 \mathrm{MN} / \mathrm{mm}(33,940 \mathrm{kips} / \mathrm{in})$. The ultimate capacity was determined to be $5.81 \mathrm{MN}(1,307 \mathrm{kips})$. These results are compared to the test data and hand calculations in Table 6.4-1. Excellent agreement is observed between the computer analysis, test results, and even hand calculations.

To gain an understanding of stiffness degradation (when it occurs and how severe it is), the load-deflection curves for the computer model and test specimen are presented in Figure 6.4-1. From the load-deflection curve of the computer model, the initial stiffness is relatively constant up to approximately $4.45 \mathrm{MN}$ or 78 percent of the ultimate value. When this is compared to the test data, good agreement occurs up to $3.02 \mathrm{MN}$ and then the computer model somewhat overpredicts the stiffness at higher loads. Reference 23 also noted an overprediciton of stiffness at higher loads. It attributed this to the localized failure of the concrete in the region between the stud heads and steel faceplate during the test. This effect was not captured in the existing computer model because a very refined region near each stud would be required. Another factor that may have contributed to the differences is the cyclic loading of the test specimen, as shown in Figure 6.2-3(b). The cyclic loading may have introduced some cracking in the concrete prior to the final load cycle to failure.

The load-deflection curves shown in Figure 6.4-1 begin at a displacement of $.09 \mathrm{~mm}$ (.0035 in) rather than 0.0. This was done because the load-deflection of the test specimen between 0.0 and $.09 \mathrm{~mm}$ indicates that there was some unexplained initial condition. There might have been small initial slippage due to the test apparatus or redistribution of loads in the initial load application (e.g., from the steel to the combination of steel and concrete). Thus, the ANSYS load-deflection curve was shifted $.09 \mathrm{~mm}$, to match the starting point of the linear elastic curve of the test specimen.

Information regarding the top and bottom end conditions during the test were not provided in Reference 23.

Therefore, two separate analyses were performed, one based on fixed boundary condition at the top and a second analysis with a free boundary condition. The fixed condition corresponds to full restraint in all degrees-offreedom (DOF) except one. The remaining DOF, which corresponds to translation in the vertical direction, is used to 
impose the displacement input. The free end condition case has all of the DOF released except for translation in the vertical direction. The results of these two analyses on an earlier model for the two different end conditions were very close (within 3\%). Therefore, end conditions are not a significant factor for this configuration.

Analyses were also performed to evaluate the effect of the stud/anchorage stiffness. The first run was based on very high stiffnesses for all the springs in all three translational DOF. Another run was made using a realistic stiffness for the axial (pull out) direction of the studs. The realistic axial stiffness used was based on the actual stud diameter of 5 $\mathrm{mm}$ (.197 in) and a length of $57.1 \mathrm{~mm}$ (2.25 in) which was scaled from Figure 6.2-1. The results from these two analyses were almost identical indicating that, for this configuration and stiffness range, the response is not sensitive to changes in stiffness values. A review of the forces in the springs revealed that the maximum forces are $5.04 \mathrm{kN}(1,134 \mathrm{lbs})$ in the $\mathrm{X}$ direction, $5.32 \mathrm{kN}(1,195 \mathrm{lbs})$ in the $\mathrm{Y}$ direction, and $.351 \mathrm{kN}(79 \mathrm{lbs})$ tensile force in the $\mathrm{Z}$ direction. .

To evaluate the effect of buckling on the response of the concrete-filled structure, the large strain option in the ANSYS program was activated. This permitted the analysis to account for the stiffness changes that result from changes in the element geometry. Figure 6.4-1 shows the loaddeflection results for this analysis with buckling and also for the case without buckling.

These curves demonstrate that buckling occurs above 5.34 MN (1,200 kips) where the two curves diverge. The difference in capacities between the two curves is very small. After buckling occurs, the load-deflection curve slowly drops off and matches the test data at a displacement of $2.63 \mathrm{~mm}(.104 \mathrm{in})$. The buckling deformation at the last load step is shown in Figures 6.4-2 and 6.4-3.

The results of the analysis indicates that the surface plate begins to yield near the top comer at a vertical input displacement of $.76 \mathrm{~mm}(.03 \mathrm{in})$. General yielding of the surface plate occurs at approximately $1.0 \mathrm{~mm}$ (.04 in). A vertical input of $1.0 \mathrm{~mm}$ is equal to an average strain of $.001587 \mathrm{~mm} / \mathrm{mm}$. At this level of strain the concrete inelastic deformation begins to be more pronounced.

With increasing displacements, the concrete also begins to crack near the top corner, at a vertical input displacement of approximately $1.3 \mathrm{~mm}$ (.05 in). Then the cracks extend down to the bottom predominantly near the side plate. The locations and orientation of the cracks are shown in Figures 6.4-4 through 6.4-6 for the last load step corresponding to $2.6 \mathrm{~mm}$ (.10 in) displacement. A crack is displayed as a circle at locations of cracking. These symbols are shown at all integration points for each element where cracking occurs. Each integration point can crack in up to three different planes. The plane formed by the circle defines the orientation of the crack plane. Examination of these figures indicate that most cracks occur near the end plate, closer to the bottom of the model, and are oriented along a vertical plane. This suggests that the cracks occurred primarily due to the constraint conditions caused by the relatively stiff end plate and thick ribs. These cracks do not affect the compressive load capacity of the modeled structure.

The effective ductility for the concrete-filled steel module is evident by examining the load-deflection curves in Figure 6.4-1. The area bounded by the load-deflection curve provides a measure of the ductility or energy absorption capability. Considering the range of displacements analyzed, the level of ductility and energy absorption capability from the analysis is comparable to the test data. It should be noted that the analysis was performed up to a displacement of $2.63 \mathrm{~mm}$ which corresponds to the peak load capacity of the test specimen. Based on the actual test results, the specimen continued to support gradually diminishing loads at displacements well beyond $2.63 \mathrm{~mm}$. Thus, the concrete-filled steel module has much larger ductility than is shown by Figure 6.4-1.

\subsection{Conclusions}

The results of the analytical effort demonstrate that, for the configuration investigated, currently available analytical methods can be applied to predict the response of concretefilled steel modules subjected to compressive loads. The comparison of the load-deflection curve obtained from the analysis and the corresponding curve from the test has led to the following conclusions:

(1) Currently available analytical methods can be used to predict the response of the module up to yielding of the steel faceplates. This would typically be the level to which structural elements are normally designed.

The analysis predicted with reasonable accuracy the ultimate capacity of the module when faceplate buckling is included in the analysis. Without buckling, the comparison is still reasonably close, because the closely spaced stud pattern precludes buckling prior to yielding.

(3) Beyond the yielding of the faceplate, which corresponds to 78 percent of the ultimate capacity, the computerized analysis somewhat overpredicts 
Validation

the stiffness. Reference 23 also noted an overprediction of stiffness at higher loads. It attributed this to the localized failure of the concrete around the studs. Another contributing factor may be the cyclic loading applied to the test specimen. This may have introduced some cracking in the concrete prior to the final load cycle to failure.

(4) Considering the range of displacements analyzed, the level of ductility and energy absorption capability from the analysis is comparable to the test data. Based on the test data, the concretefilled steel module has energy absorbtion capability well beyond the deflection magnitude reached in this study.

(5) The response of the analytical model was not sensitive to the axial stiffness of the studs. Varying the axial stiffness of the studs resulted in almost identical results. The pullout forces in the studs are relatively small (a maximum of $.351 \mathrm{kN}$ (79 lbs)).

(6) The boundary conditions at the top and bottom do not affect the response of the analytical model. This is based on evaluating the model for both fixed and free boundary conditions at the loaded surfaces. 
Table 6.4-1 Analysis results

\begin{tabular}{cccc}
\hline Item & BNL Computer Model & Test Specimen & Hand Calculation \\
\hline $\begin{array}{c}\text { Initial stiffness } \\
\text { MN/mm (kips/in) }\end{array}$ & $5.94(33,940)$ & $5.63(32,150)$ & $5.84(33,360)^{*}$ \\
\hline $\begin{array}{c}\text { Ultimate Capacity } \\
\text { MN (kips) }\end{array}$ & $5.81(1,307)$ & $5.73(1,288)$ & $6.06(1,362)^{* *}$ \\
\hline
\end{tabular}

* $\quad \mathrm{K}=\left(\mathrm{E}_{\mathrm{C}} \times A_{\mathrm{C}}+\mathrm{E}_{\mathrm{FPL} .} \times A_{\mathrm{FPL} .}+\mathrm{E}_{\mathrm{EPL} .} \times \mathrm{A}_{\mathrm{EPL} L}\right) / \mathrm{h}$

** $\quad \mathrm{P}_{\mathrm{MAX}}=\mathrm{f}_{\mathrm{C}}^{\prime} \times \mathrm{A}_{\mathrm{C}}+\sigma \mathrm{y}_{\mathrm{FPL} .} \times \mathrm{A}_{\mathrm{FPL}}+\sigma \mathrm{y}_{\mathrm{EPL} .} \times \mathrm{A}_{\mathrm{EPL} \text {. }}$

c: $\quad$ concrete

FPL: faceplate

EPL.: $\quad$ end plate

$\mathrm{h}: \quad$ height of specimen 

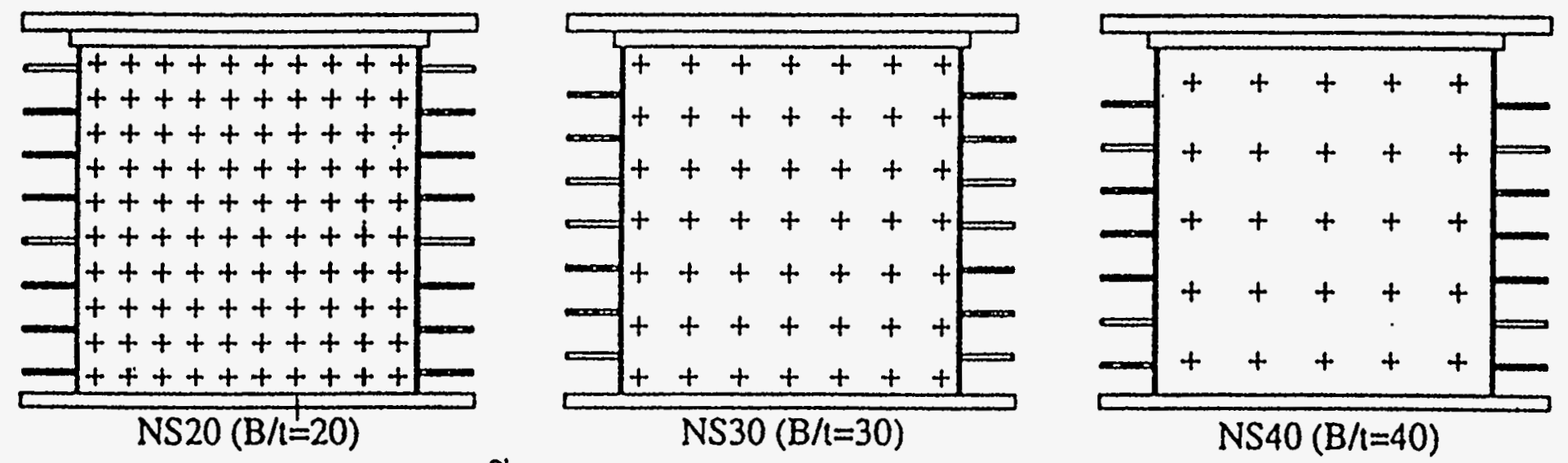

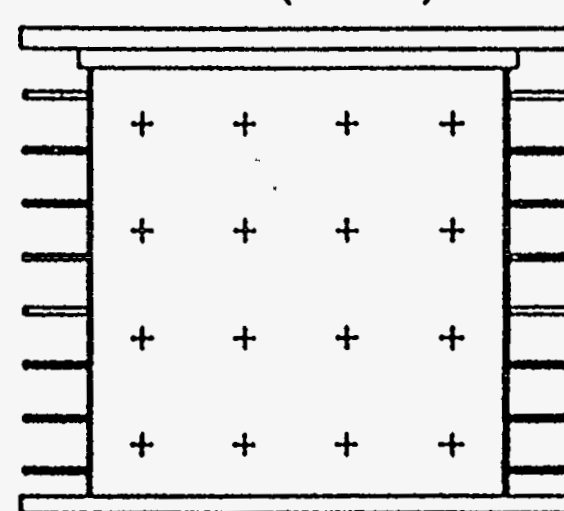

$\mathrm{NS} 50(\mathrm{~B} / \mathrm{l}=50)$

Dimensions of Test Specimens

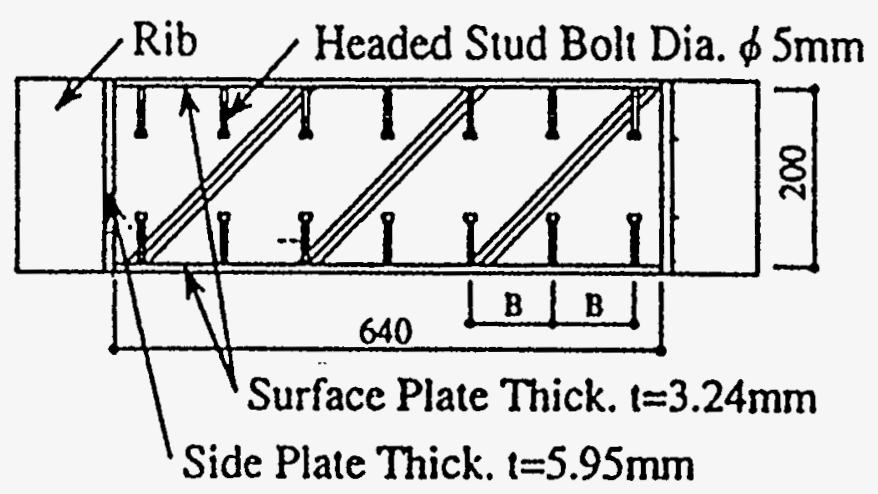

Figure 6.2-1 Configuration of Test Specimens [Ref. 23] 


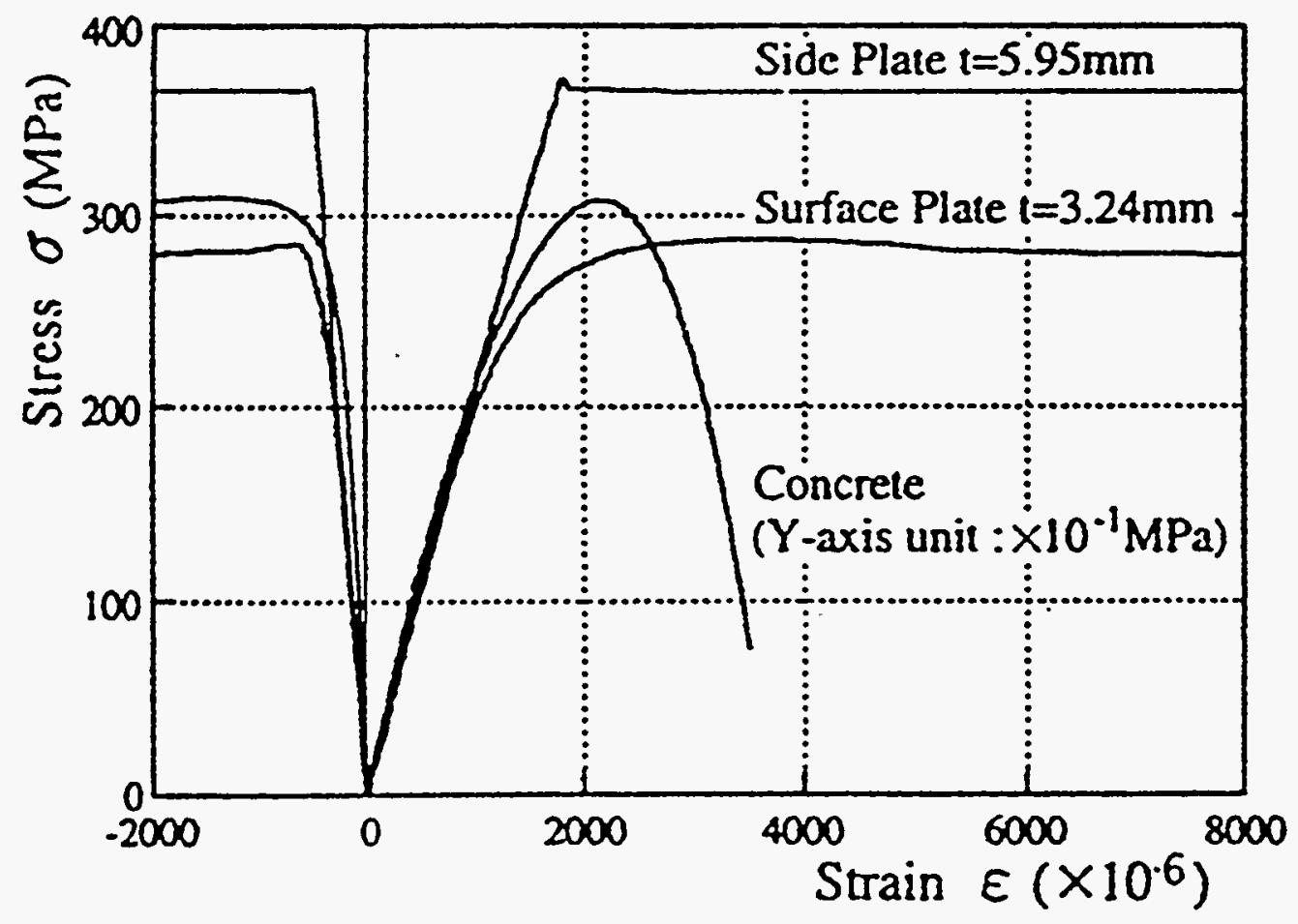

Figure 6.2-2 Stress-Strain Curves For Materials Used In Test [Ref. 23] 


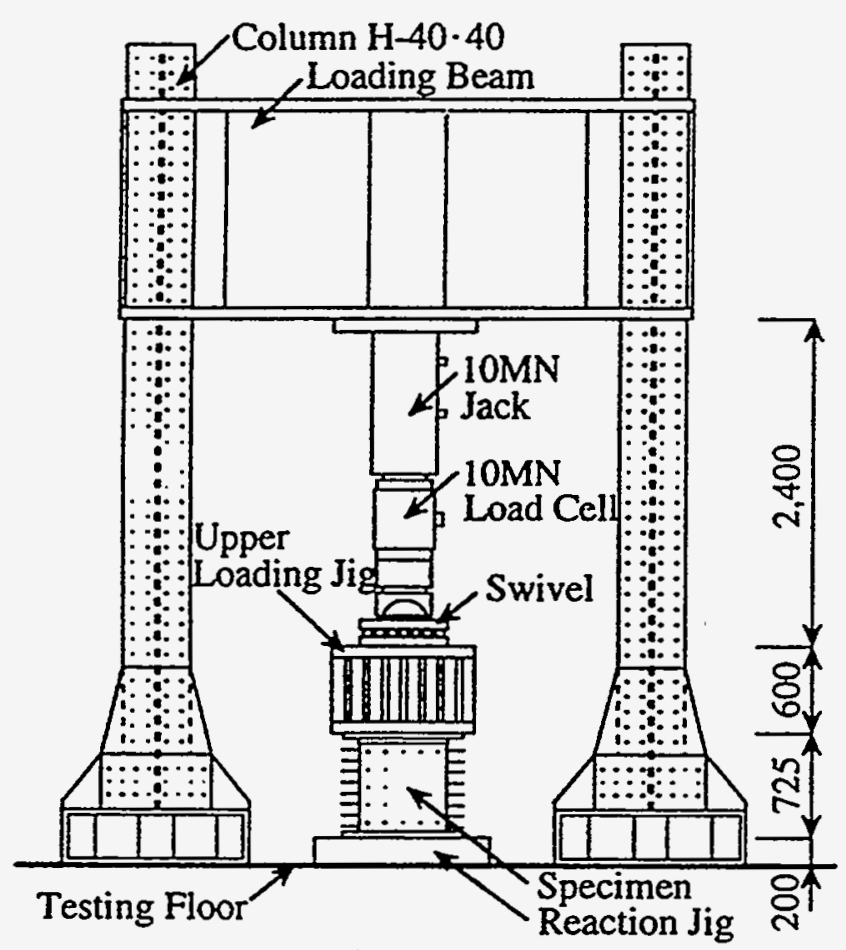

(a) Loading Apparatus

$$
\begin{aligned}
\text { Py : Yield Load } \\
\text { Py } \doteqdot 3.73 \mathrm{MN}
\end{aligned}
$$

Ps : Allowable Design Load for Seismic

Force etc. Ps=3.53 MN

PL: Serviceability Design Load

$$
\mathrm{Pl}_{\mathrm{L}}=2.35 \mathrm{MN}
$$

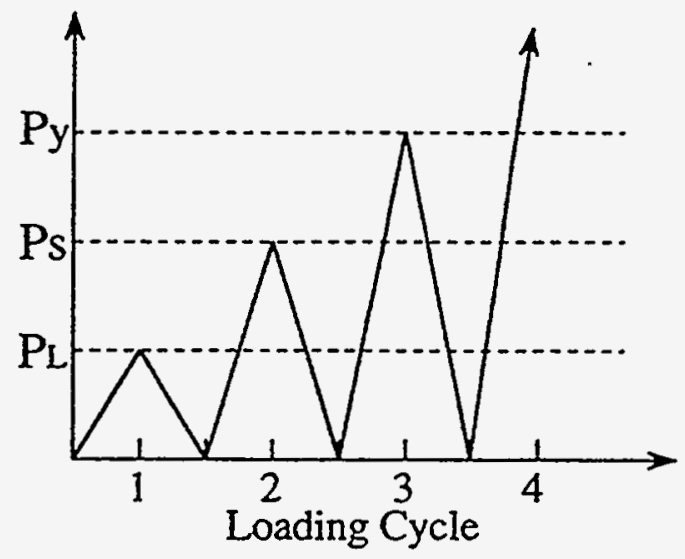

(b) Loading Cycle

Figure 6.2-3 Specimen Loading [Ref. 23] 


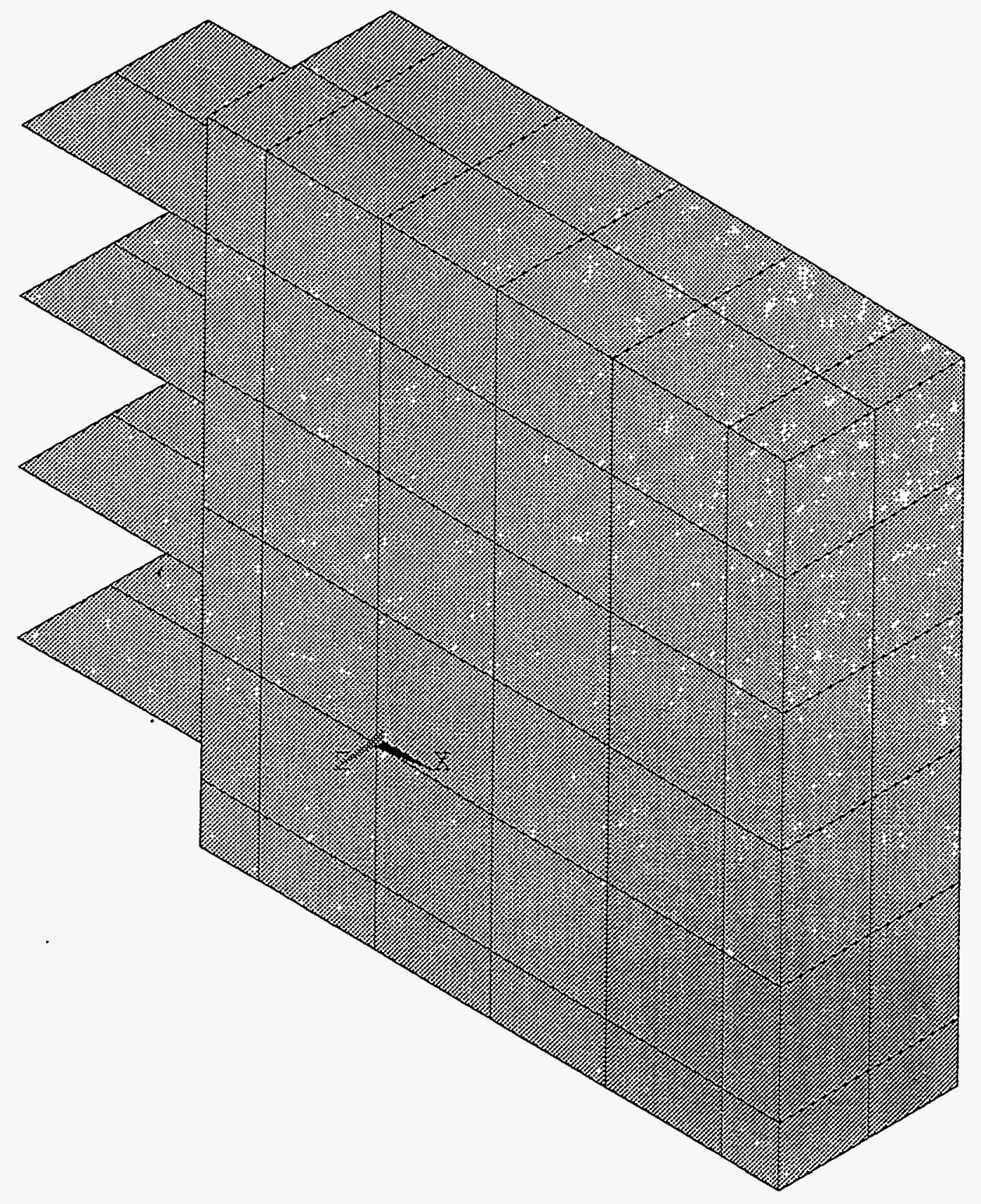

Figure 6.3-1 Finite Element Model of Test Specimen 


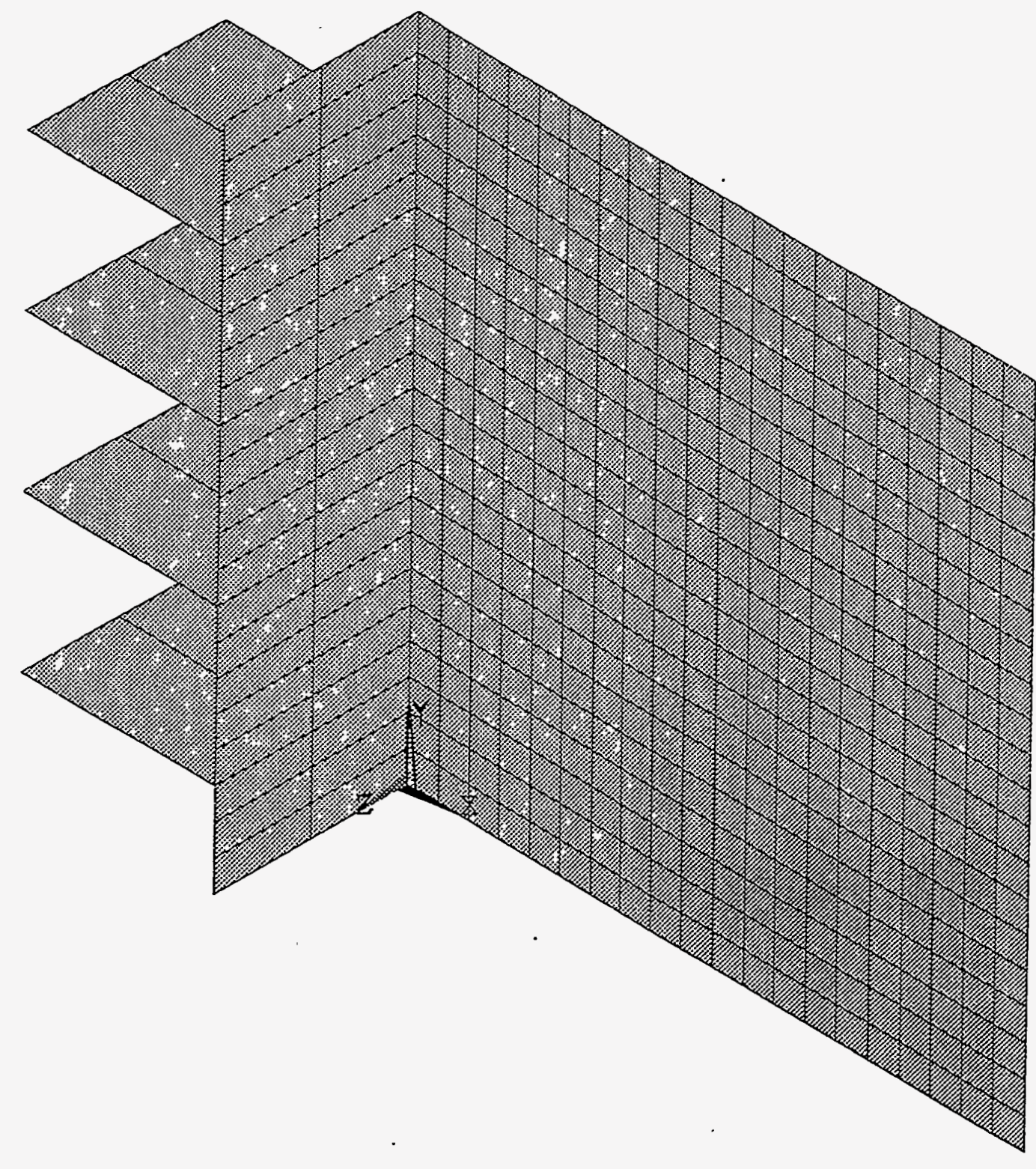

Figure 6.3-2 Finite Element Model of Test Specimen - Steel Elements 


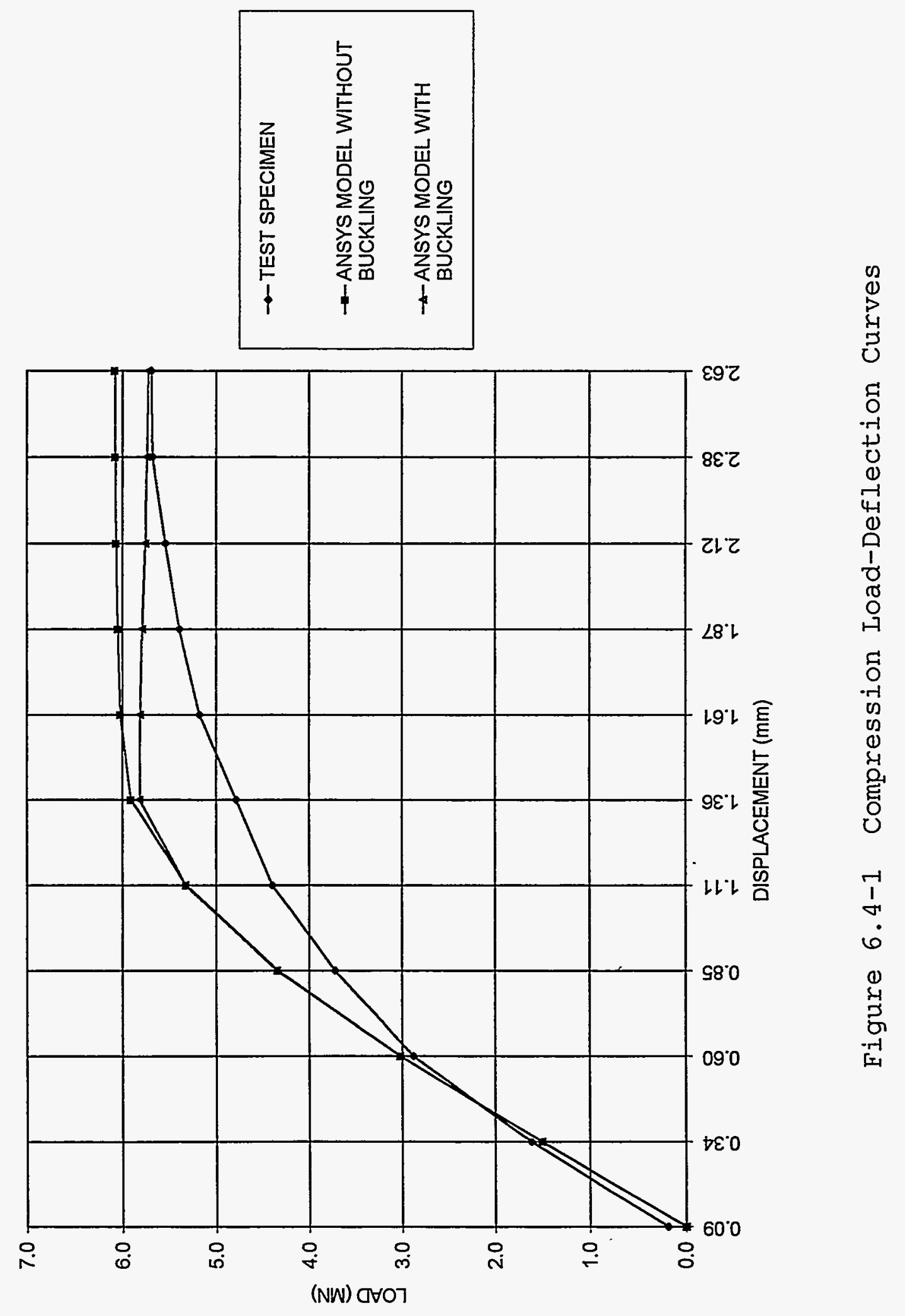




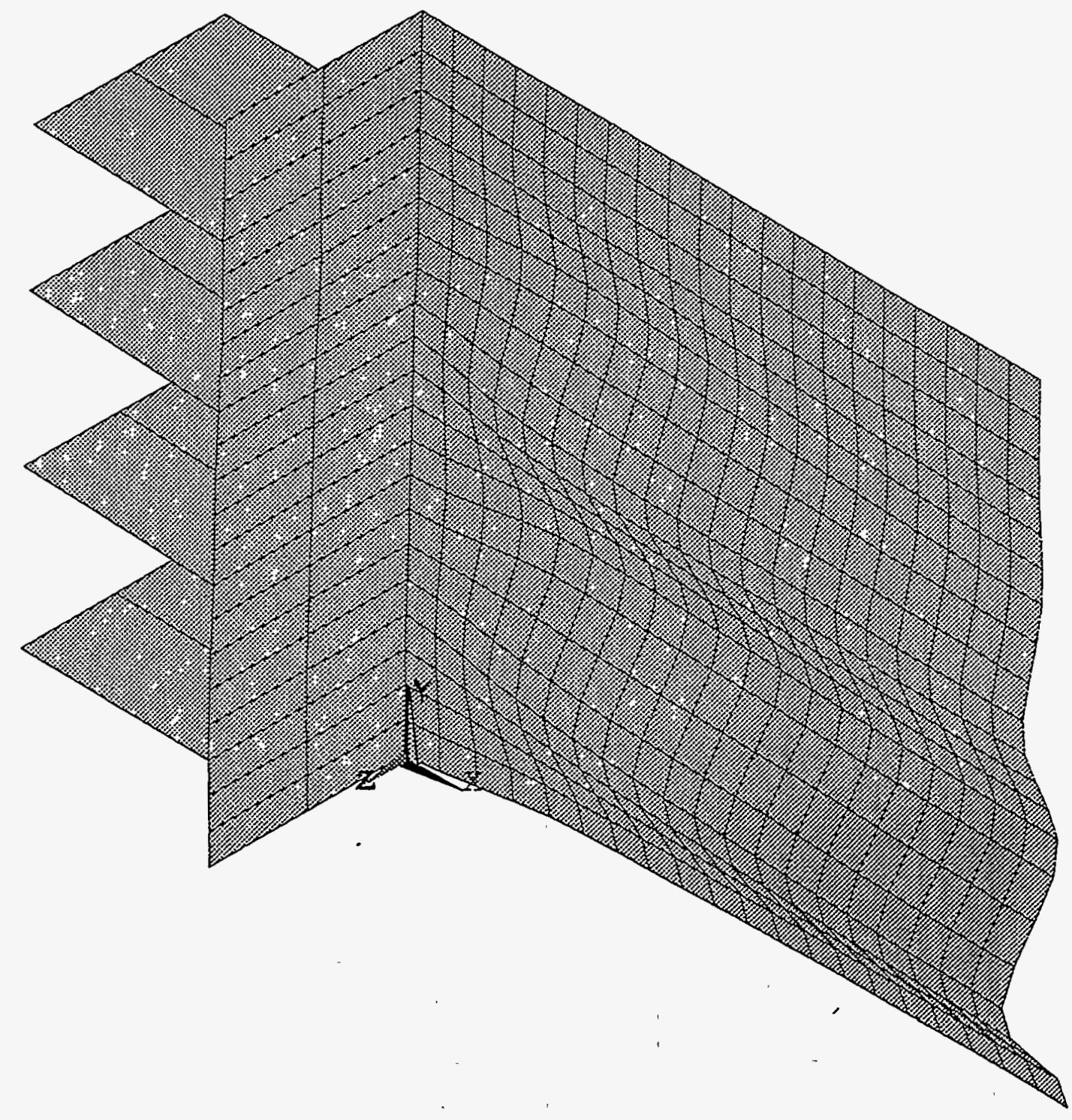

Figure 6.4-2 Finite Element Model - Buckling of Steel Plates 


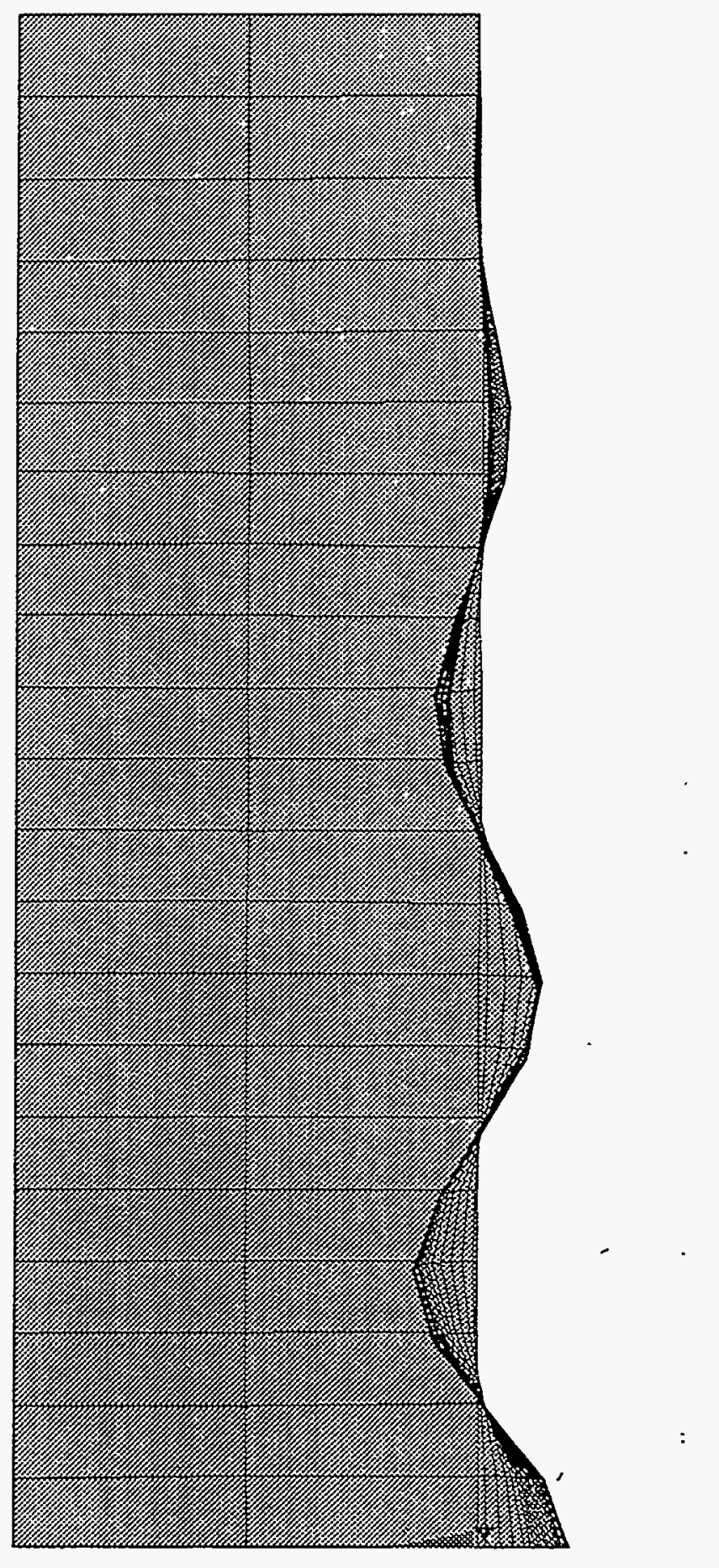

Figure 6.4-3 Finite Element Model - Buckling of Steel Plates (Side View) 


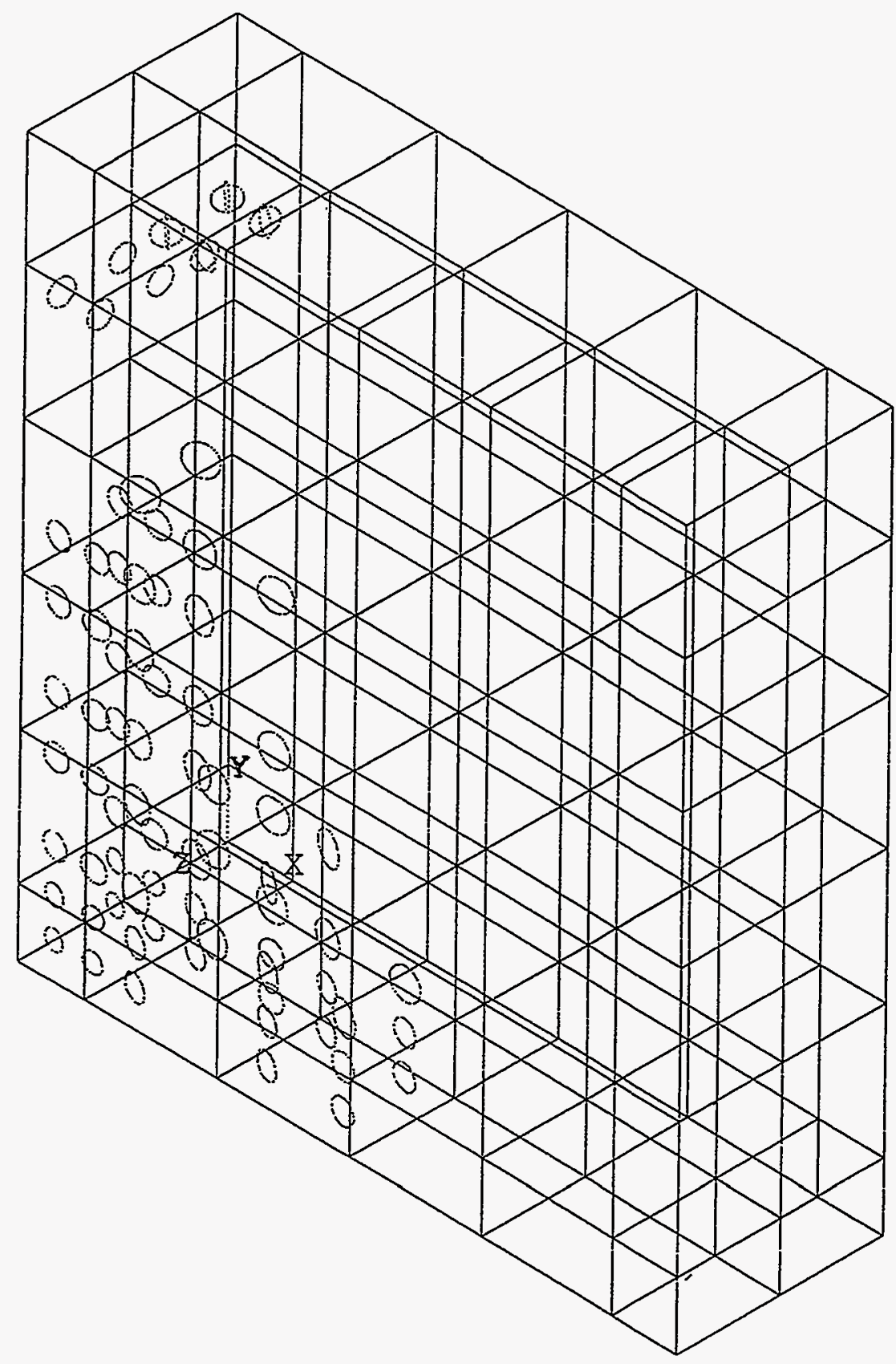

Figure 6.4-4 Finite Element Model - Concrete Cracks 


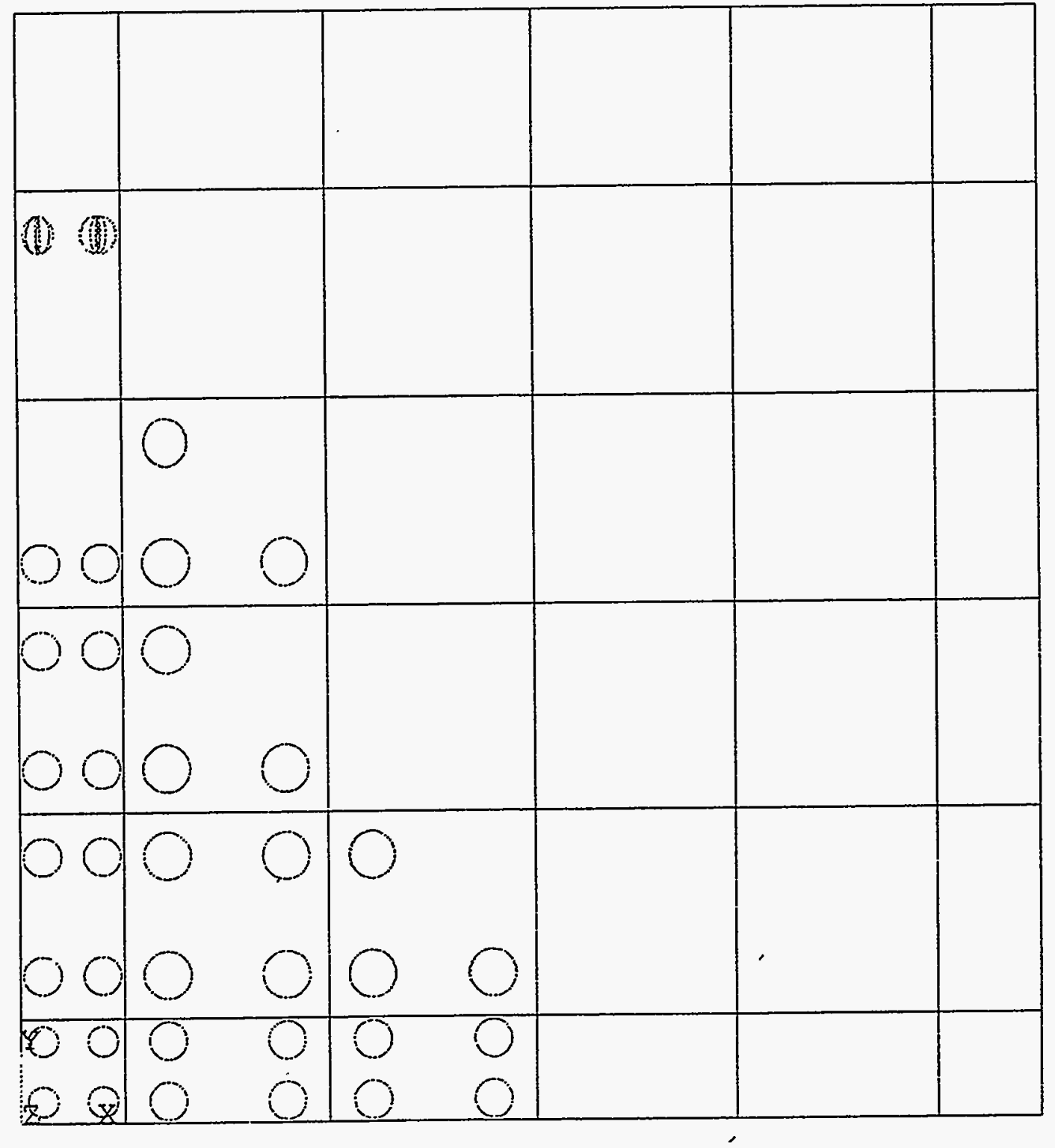

Figure 6.4-5 Finite Element Model - Concrete Cracks (Front View) 


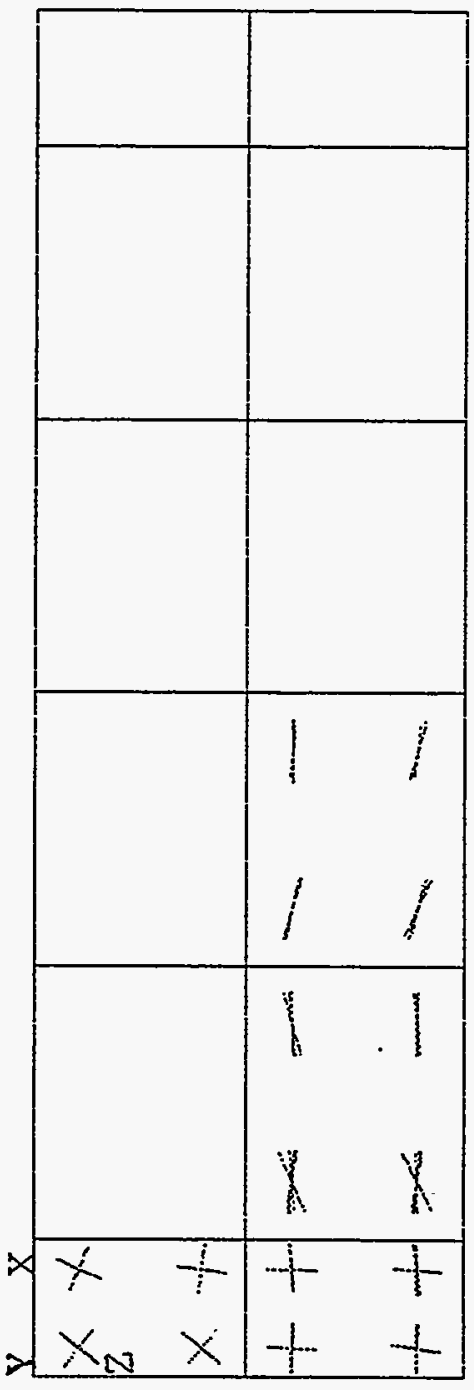

옹

0
ù
0
0
0
0

0
+1
0
4
0
I
0
0

1

겅

O

芩

$\underset{-1}{0}$

6
1
0

$\dot{0}$

崩 


\section{CONCLUSIONS AND RECOMMENDATIONS}

\subsection{Conclusions}

The use of modular construction in both the nuclear and non-nuclear industry was investigated. The U.S. Department of Energy sponsored a number of studies on the use of modularization in nuclear power plants. Japan has also performed many studies and has conducted scale model tests on concrete-filled steel type modules. These and other sources were surveyed to learn what progress has been made; what are the significant issues and concerns; and what additional work is needed to support NRC licensing activities for ALWR's. The conclusions reached from the research effort are as follows:

(1) Structural modules have been used successfully in the shipbuilding, petrochemical, and fossil power industry. In the nuclear industry, foreign countries which include Japan, France, Sweden, Switzerland, and Taiwan have used structural modules to varying levels. Within the United States the use of structural modules has been relatively limited.

(2) Modularization has been proposed for two ALWR plants consisting of the Westinghouse AP600 and the GE SBWR. Other advanced reactors which have also considered the use of structural modules include the Sodium Advanced Fast Reactor, the Modular High Temperature Gas-cooled Reactor, the Prototype Reactor Inherently Safe Module and the CANDU3 Reactor.

(3) Previous studies have concluded that modularization could result in approximately a 12 percent reduction in total capital costs compared to nuclear plants built in a conventional manner. In addition, it was estimated that the overall construction schedule could be reduced from 8 years to 6 years. A third benefit would be improvement in the quality of construction.

(4) From the survey of modular construction practices and the specific reviews of the licensing submittals for the AP600 and SBWR, a number of issues related to design and analysis of safety-related structural modules were identified as follows:

- Lack of codes and standards for certain types of modules

- Unique loads during the fabrication, handling, transportation, storage and erection
- Determination of initial stiffness and stiffness degradation

- Damping values for use in dynamic analyses

- Validation of analytical methods

- Reliability of joints and connections

- Determination of effective ductility

- Determination of ultimate load capacity

(5) Issues related to the modular construction process, which includes offsite fabrication, handling, shipping, storage, erection, inspection/testing, quality assurance/quality control, and maintenance, have also been identified. Specific issues related to the modular construction process are

- Provisions in design and fabrication to assure field fit-ups (e.g., tolerances or excess material to permit field adjustments)

- Designated lifting points for handling and erection; designed in advance

- Configuration control (e.g., centralized and computerized with access by all subcontractors)

- Mixed code classes on the same module

- Storage and damage prevention

- Construction plan and sequencing

- Procedures for module lifting/placement

- Owner "umbrella" vs fabricator controlled QA programs

- Shop and site inspections

- Specification for supporting, securing, and protecting modules during transportation

- Material degradation due to 60 year operating life (e.g.,, may require in service inspection or consideration of degradation in design)

Currently, there are no specific licensing review criteria that provide guidance for the use of structural modules in nuclear power plants. A Modular Construction Review Criteria document 
Conclusions

was prepared as part of this program to provide guidance for use in licensing review activities. Its purpose is to supplement criteria already presented in the NRC Standard Review Plan.

(7) An analytical research effort was conducted on concrete-filled steel modules with studs to determine if currently available analytical methods can be used to predict their response. The results of the analysis for compressive loads led to the following major conclusions:

- Currently available analytical methods can be used to predict the response of the module up to yielding of the steel faceplates. This would typically be the level to which structural elements are normally designed.

- The analysis predicted with reasonable accuracy the ultimate capacity of the module when faceplate buckling is included.

- Beyond the yielding of the faceplates, the computerized analysis somewhat overpredicts the stiffness. Based on the referenced test report, the overprediction of stiffness is judged to occur because of localized failure of the concrete near the stud during the test. Another contributing factor may be the cyclic loading of the test specimen.

- Ductile behavior was comparable to the test data.

These conclusions, obtained from the analytical research effort, provide strong evidence that currently available analytical methods can be used to predict the response of concrete-filled steel modules subjected to compressive loads.

\subsection{Recommendations}

The limited validation of analytical methods applied to concrete-filled steel modules, conducted during Phase III, should be expanded to encompass (1) additional loadings (in-plane and out-of-plane shear and out-of-plane bending) and (2) a broader range of geometric configurations. While the initial results appear to confirm that currently available analytical methods are indeed applicable to design analysis and quantification of design margin, it is emphasized that only a single configuration, subjected only to in-plane compressive loading was investigated. Generalization of these results cannot be supported at this time.
In-plane shear behavior of concrete-filled steel modules is extremely important for the evaluation of seismic response; consequently, any additional analytical verification should first concentrate on this behavior. Out-of-plane bending and shear loads are also generated by seismic loads, but are typically less significant. However, the use of concretefilled steel modules as pressure retaining boundaries, such as in the AP600 IRWST, requires that out-of-plane behavior be accurately evaluated. In this case, the combination of pressure and out-of-plane seismic loads will significantly influence the selection of design parameters for a concrete-filled steel module. The response to secondary loadings, such as thermal gradients, may also play a significant role in the design of concrete-filled steel modules.

Over twenty (20) variations of configuration details have already been tested in Japan, for one or more of the significant loadings discussed above. The applicability of current analytical methods should be verified for a selected group of tested configuration variations, in order to establish a reasonable confidence level for future analyses of untested configurations.

Japan has recently begun a multi-year modular construction research program to evaluate the behavior of concrete-filled steel modules. Therefore, it would be very beneficial if a cooperative program could be developed which would permit us to share information. This could provide valuable data useful in verifying the safe application of structural modules in nuclear power plants within the United States. 


\section{REFERENCES}

1. EPRI, "Advanced Light Water Reactor Utility Requirements Document," Vol. III, ALWR Passive Plant, Chapter 1, Overall Requirements, Rev. 0.

2. DOE/NE-0067, "Modularization and Nuclear Power," Report by the Technology Transfer Modularization Task Team for U.S. Dept. of Energy, June 1985.

3. DOE/SF/16566-1, "Design for Constructability Program - Volume I: Executive Summary," Duke Power Company Report for USDOE Technology Programs in Support of Advanced Light Water Reactors, March 1990.

4. DOE/SF/16566-2, "Design for Constructability Program - Volume II: Program Description," Duke Power Company Report for USDOE Technology Programs in Support of Advanced Light Water Reactors, March 1990.

5. DOE/SF-16566-3, "Design for Constructability Program - Volume III: Improving Construction Performance," Duke Power Company Report for USDOE Technology Programs in Support of Advanced Light Water Reactors, March 1990.

6. DOE/SF/16566-4, "Design for Constructability Program - Volume IV: Enhancing Constructability Through Design," Duke Power Company Report for USDOE Technology Programs in Support of Advanced Light Water Reactors, March 1990.

7. DOE/SF/16565-3, "Design

Requirements/Guidelines to Facilitate Constructability," Stone \& Webster Engineering Corporation Report for USDOE Technology Programs in Support of Advanced Light Water Reactors: Construction, January 1989.

8. DOE/SF/16565-4, "Prefabrication and Modularization Approach and Implementation," Stone \& Webster Engineering Corporation Report for USDOE Technology Programs in Support of Advanced Light Water Reactors: Construction, April 1989.

9. J.H. Cottrell and C.P. Boudreaux, "Repowering and Phased Expansion with Modular Construction," Proceedings of Second International Conference on Improved Coal-
Fired Power Plants, Palo Alto, CA, November 24, 1988, EPRI-GS-6422-Vol. 1, 1989.

10. J.L. Ehasz and J.M. Brooks, "Modular Construction Brings Hydropower Up the Mississippi," Proceedings of 1989 Fossil Power Plant Construction Conference, Cincinnati, $\mathrm{OH}$, August 29-31, 1989, EPRI-GS-7255, July 1991.

11. J. Gorgan, R. Claussen and M. Williams, "Modular Construction of Fossil Power Plants Report of Working Group Two: Issues and Action Items," Proceedings of 1989 Fossil Power Pant Construction Conference, Cincinnati, $\mathrm{OH}$, August 29-31, 1989, EPRI-GS-7255, July 1991.

12. H.D. Farin and W.E. Cummins, "AP600 Layout Features to Support 36 Month Construction Schedule," Proceedings of International Conference on Design and Safety of Advanced Nuclear Power Plants (ANP '92), Tokyo, Japan, October 25-29, 1992.

13. F.T. Johnson, R.S. Orr and C.P. Boudreaux, "Modular Construction Approach for Advanced Nuclear Plants," Transactions of Joint Meeting of the European Nuclear Society and the American Nuclear Society, Washington, D.C., October 30 - November 4, 1988.

14. M.P. Lagache, "Constructibility Enhancements for Advanced BWRs," Proceedings of International Conference on Design and Safety of Advanced Nuclear Power Plants (ANP '92), Tokyo, Japan, October 25-29, 1992.

15. D.A. Dilling, R.H. Hren and C.R. Snyder, "Modular Construction/Shop Fabrication in Advanced Reactor Designs," Proceedings of the American Power Conference, Chicago, II, April 24-26, 1989.

16. G. Bagchi and C.P. Tan, "Modular Construction from a Regulatory Perspective," Proceedings of the 2nd ASME/JSME International Conference on Nuclear Engineering, San Francisco, CA, March 21-24, 1993, Vol. 2, ASME 1993.

17. S. Suzuki, Y. Shimazaki, K. Sekiguchi and W. Kokubo, "Introduction of Large Block Prefabrication Method," Proceedings of International Conference on Design and Safety of Advanced Nuclear Power Plants (ANP '92), 
Tokyo, Japan October 25-29, 1992.

18. A. Kaneuji, Y. Okuda, K. Hara and H. Masumoto, Feasibility Study of Concrete Filled Steel (SC) Structure for Reactor Building," Transactions of the 10th SMiRT, Vol. H, pp. 67-72, August 1989.

19. H. Akiyama, H. Sekimoto, M. Tanaka, K. Inoue, M. Fukihara and Y. Okuda, "1/10th Scale Model Test of Inner Concrete Structure Composed of Concrete Filled Steel Bearing Wall," Transactions of the 10th SMiRT, Vol. H, pp. 7378, August 1989.

20. H. Akiyama, H. Sekimoto, M. Fukihara, K. Nakanishi and K. Hara, "A Compression and Shear Loading Test of Concrete Filled Steel Bearing Wall," Transactions of the 11th SMiRT, Vol. H, pp. 323-328, August 1991.

21. T. Takeda, T. Yamaguchi, T. Nakayama, $\mathrm{K}$. Akiyama and Y. Kato, "Experimental Study on Shear Characteristics of a Concrete Filled Steel Plate Wall," Transactions of the 13th SMiRT, Vol. 4, pp. 3-14, August 13-18, 1995.

22. M. Takeuchi, H. Akiyama, M. Narikawa, K. Hara, H. Tsubota and I. Matsuo, "Study on a Concrete Filled Steel Structure for Nuclear Power Plants (Part 1). Outline of the Structure and the Mock-up Test," Transactions of the 13th SMiRT, Vol. 4, pp. 15-20, August 13-18, 1995.

23. S. Usami, H. Akiyama, M. Narikawa, K. Hara, M. Takeuchi and N. Sasaki, "Study on a Concrete Filled Steel Structure for Nuclear Power Plants (Part 2). Compressive Loading Tests on Wall Members," Transactions of the 13th SMiRT, Vol. 4, pp. 21-26, August 13-18, 1995.

24. N. Sasaki, H. Akiyama, M. Narikawa, K. Hara, M. Takeuchi, S. Usami, "Study on a Concrete Filled Steel Structure for Nuclear Power Plants (Part 3). Shear and Bending Loading Tests on Wall Member," Transactions of the 13th SMiRT, Vol. 4, pp. 27-32, August 13-18, 1995.

25. H. Suzuki and B. Kato, "Shear Strengths of Concrete-Filled Steel Box Elements," Composite and Mixed Construction, Proceedings of the US/Japan Joint Seminar, Seattle, WA, July 1820, 1984, pp. 254-266, ASCE, 1985.
26. H. Ge and T. Usami, "Strength of ConcreteFilled Thin-Walled Steel Box Columns: Experiment," ASCE, Journal of Structural Engineering, Vol. 118, No. 11, November 1992.

27. Westinghouse Electric Corporation, "Simplified Passive Advanced Light Water Reactor Program, AP600 Standard Safety Analysis Report, Rev. 8," prepared for the U.S. Department of Energy, June 19, 1996.

28. American Concrete Institute (ACI), "Code Requirements for Nuclear Safety Related Structures," ACI 349 - 1990.

29. American Institute of Steel Construction (AISC), "Specification for the Design, Fabrication and Erection of Steel Safety-Related Structures for Nuclear Facilities," AISC N690-1984.

30. General Electric Company, "SBWR Standard Safety Analysis Report," 25A5113 Rev. A, August 1992.

31. General Electric Company, "Extract from SBWR Technical Description for NRC Staff," GE Nuclear Energy, December, 1989.

32. M.P. Lagache, "Constructibility Enhancements for Advanced BWRs," Proceedings of International Conference on Design and Safety of Advanced Nuclear Power Plants (ANP '92), Tokyo, Japan, October 25-29, 1992.

33. General Electric Letter, P.W. Maraud to NRC, "Use of Modular Construction in the SBWR," January 18, 1993.

34. American Institute of Steel Construction (AISC), "Specification for Design, Fabrication and Erection of Structural Steel for Buildings," November' $1,1978$.

35. NUREG/CR-6358, "Assessment of United States Industry Structural Codes and Standards for Application to Advanced Nuclear Power Reactors," Prepared by Stevenson and Associates for the U.S. Nuclear Regulatory Commission, October 1995.

36. U.S. Nuclear Regulatory Commission, Regulatory Guide 1.61, "Damping Values for Seismic Design of Nuclear Power Plants," October 1973. 
37. U.S. Nuclear Regulatory Commission, Standard Review Plan, NUREG-0800.

38. American Society of Mechanical Engineers, Boiler and Pressure Vessel Code, Section III, Division 1, Subsection NE, "Class MC Components."

39. American Society of Mechanical Engineers, Boiler and Pressure Vessel Code, Section III, Division 2, "Code for Concrete Reactor Vessels and Containment."

40. U.S. Nuclear Regulatory Commission, Regulatory Guide 1.70, Rev. 3, "Standard Format and Content of Safety Analysis Reports for Nuclear Power Plants," November 1978.

41. NUREG-1522, "Assessment of Inservice Conditions of Safety-Related Nuclear Plant" Structures," U.S. Nuclear Regulatory Commission, June 1995.

42. ANSYS, Revision 5.1, Computer Code, Swanson Analysis Systems, Inc., September 1994. 


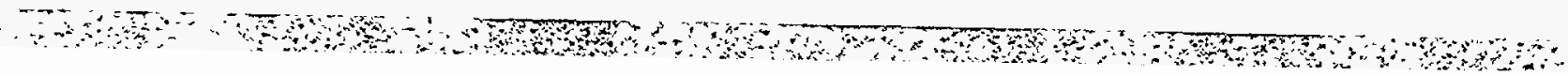




\title{
APPENDIX A
}

\author{
RELIABILITY OF MODULAR CONSTRUCTION \\ PHASE I REPORT - IDENTIFICATION OF ISSUES \\ BNL TECHNICAL REPORT NO. L-2261-1-8/93
}

NOTE: This report was issued in August 1993 and thus, is based on the module configurations proposed at that time. Since then, Westinghouse has made some revisions to their modules, particularly the concrete-filled steel modules.

Therefore, the following sections no longer apply to the current Westinghouse design of concrete-filled steel modules:

Section 3.1.1

Section 3.2.1

Section 3.3

Section 3.4

Section 5.0 


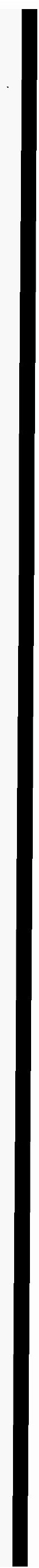




\section{RELIABILITY OF MODULAR CONSTRUCTION - PHASE I REPORT - IDENTIFICATION OF ISSUES}

J.I. Braverman, C.H. Hofmayer and P.C. Wang August 1993

Engineering Research \& Applications Division Department of Advanced Technology Brookhaven National Laboratory Upton, NY 11973 

TABLE OF CONTENTS

Page No.

1.0 Introduction . . . . . . . . . . . . . . 1-1

2.0 Survey of Modular Construction Practices . . . . . . . 2-1

2.1 Background . . . . . . . . . . . . . . . . 2-1

2.2 DOE Programs .................... . . $2-4$

2.3 Recent Japanese Studies . . . . . . . . . . 2-7

3.0 Evaluation of Westinghouse Applications . . . . . . . 3-1

3.1 Description of Modular Systems . . . . . . . . . 3-1

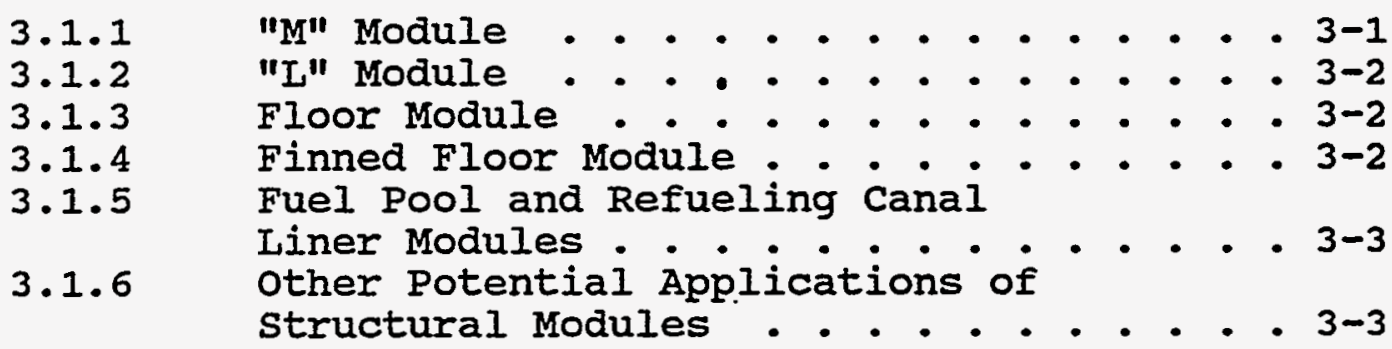

3.2 Summary of Analysis and Design Methods . . . . . . 3-4

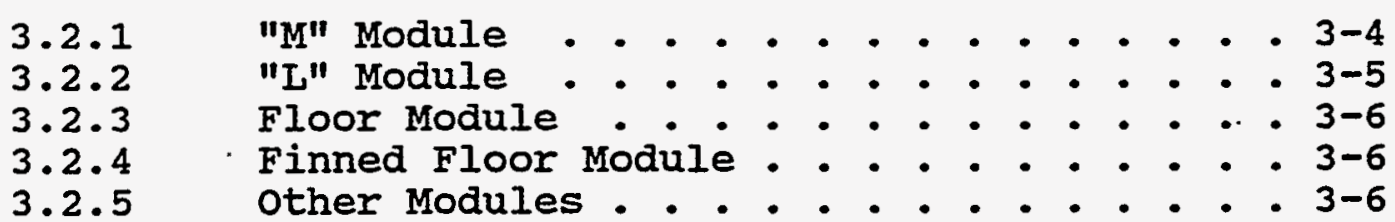

3.3 Evaluation of Critical Parameters . . . . . . . 3-7

3.3.1 Design Strength . . . . . . . . . . . 3-7

3.3.2 Ductility . . . . . . . . . . . . . . . . 3-9

3.3.3 Stiffness and Stiffness Degradation... . 3-10

3.3.4 Reliability of Joints and Connections . . 3-11

3.3.5 Damping Values ............. . 3-11

3.3.6 QA/QC for Design, Construction and

Transportation ........... 3-12

3.4 Overall Conclusions and Issues . . . . . . . . 3-12

4.0 Evaluation of General Electric Applications . . . . . 4-1

4.1 Description of Modular Systems . . . . . . . . . 4-1

4.2 General Conclusions and Issues . . . . . . . . . 4-3 
Table of contents - Continued

Page No.

5.0 Summary of Issues and Recommendations for Future Activities . . . . . . . . . . . 5-1

6.0 References ............... . 6-1 


\subsection{INTRODUCTION}

Advanced reactor plants will be designed to maximize the benefits which can be obtained through use of modular construction. This will be achieved by applying modular construction techniques in the early conceptual phases of the design and through the construction phase with engineering substantially complete prior to start of construction. Module types will be classified as to whether the module will be fabricated in major elements off-site with final assembly at an on-site shop, or will be fabricated entirely on-site in a module assembly area. Module designs attempt to maximize the use of standardized elements with consideration for: space provisions (for fit, maintenance, inspection); shipping; and interfaces. Finally, an erection plan based on delivery requirements and $a$ QC program for on-site storage are important because potential deterioration or damage from on-site storage can have a :iegative impact on the structural integrity of the modules if completed modules are stored on-site for an extended period.

As a result of its possible use in advanced reactor designs, the U.S. Nuclear Regulatory Commission is sponsoring a program to study the reliability of modular construction. This study involves modular safety-related structures usually found inside the containment and designed for postulated earthquake and pipe rupture. loads. standards to assure strength, ductility and reliability of joints and connections are needed to complete the licensing review of advanced passive and evolutionary reactors. Additionally, damping values for seismic analysis and information on stiffness degradation during earthquakes of modular elements are needed. Criteria for $Q A / Q C$ during transportation and installation of structural modules are also needed. For this program, the term "advanced reactors" is intended to include the following reactor designs which may use modular construction:

(1) AP600 (600MW reactor by Westinghouse)

(2) SBWR (600MW simplified Boiling Water Reactor, by GE)

The scope of this study is limited to structural modules. As a minimum, and to the extent that they are used in the above referenced advanced reactor designs, the following types of modules will be addressed:

(1) Prefabricated rebar mats, subassemblies, cages, etc., for:

\footnotetext{
a. Base mat;

b. Building and containment walls,

c. Drywell and suppression chamber slabs (SBWR)

d. Containment top slab (SBWR),

e. Columns, beams, walls, floor and roof slabs.
} 
(2) Precast concrete frame, wall, floor and roof elements, either prestressed (pre- or post-tensioned) or conventionally reinforced.

(3) Precast concrete modules, such as box or cylinder units for compartments.

(4) Composite or sandwich panels, consisting of concrete cores between two steel faces.

(5) Prefabricated structural steel assemblies for dual purpose - serving as forms for turbine pedestal, drywell vent wall, and reactor pressure vessel pedestal.

The parameters to be addressed include the following items:

(1) Strength

(2) Ductility

(3) Stiffness and stiffness degradation

(4) Reliability of joints and connections of modules

(5) Damping values

(6) QA/QC for design, construction and transportation

While advanced reactor vendors should be responsible for development of modular construction technology and its implementation to nuclear reactors, this study aims at providing adequate safety and quantifying margins (as defined by current ACI 349 and ACI 359 load combinations, and ASCE 4-86 requirements on seismic ductility of conventional structures) against design basis accidents and ultimate structural capacities.

Phase I of this program focusses on a review of existing standards, tests and practices that have been used in modular construction with the goal of identifying issues and what more is needed in order to support NRC licensing activities. Based on this review, Phase II will concentrate on providing acceptance and ITAAC (Inspection, Test, Analysis, \& Acceptance Criteria) criteria, and outline a program of tests and analyses that could be used to establish safety margins against design basis accidents and ultimate structural capacities. In phase III the tests and analyses identified in Phase II will be performed, as well as any additional research/testing that may need to be done. The results of this effort will also be used in the development of attributes for ITAACs for construction of modular units.

Section 2.0 discusses the results of a survey of modular construction practices with emphasis on studies conducted by the 
U.S. Department of Energy and ongoing activities in Japan. Sections 3.0 and 4.0 present the results of evaluations of Westinghouse and General Electric applications of modular construction techniques based on the information available to date. Finally, section 5.0 provides a summary of the technical issues and recommendations regarding the direction of future efforts. 


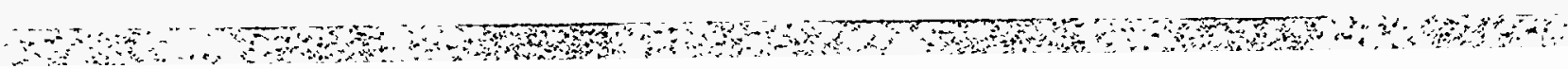




\subsection{SURVEY OF MODULAR CONSTRUCTION PRACTICES}

\subsection{Background}

In 1985 the Department of Energy (DOE) formed a Technology Transfer Task Team on Modularization to "briefly survey the current use of modular construction in the nuclear and non-nuclear industries and to assess and evaluate the techniques available for potential application to nuclear power" [1]. The emphasis of the team's efforts was on identifying the means for utilities to better control nuclear plant construction costs and schedules, as well as total power generation costs over the lifetime of a nuclear power plant facility.

The Task Team study concluded that modularization could result in a 12 percent reduction in total capital costs compared to nuclear plants built in a conventional manner. It was also estimated that the overall construction schedule would be reduced from 8 years to 6 years. These estimates are based on average construction experience for many plants. The Team also recommended that guidelines be established for future advanced reactors which identify how modularization can improve construction, maintenance, life extension and decommissioning.

As part of its technology programs in support of advanced light water reactors, DOE has sponsored additional studies regarding the use of modularization in nuclear power plants. Duke Power Company performed the Design for Constructability Program with the overall goal of identifying and addressing changes in the nuclear industry to restore nuclear energy as an attractive option. The results of this program are contained in an extensive four volume report [2-5]. Volume II of the report provides information on modular construction experiences and summarizes the results of a workshop on concerns that modularization would present to nuclear plant owners, designers and constructors. stone \& Webster Engineering Corporation (S\&W) also conducted studies to improve constructability and to simplify the design of future nuclear plants (References [6] and [7] are reports on two of the seven tasks performed by S\&W). One of the S\&W studies [7] identifies present and past practices of modularization in both the nuclear and non-nuclear industries and presents a number of prefabrication, preassembly and modularization approaches for a typical advanced reactor plant. The results of the Duke and $S \& W$ studies as they relate to modular construction are discussed in more detail in Section 2.2.

All of the above studies highlight the fact that modularization has been used in most U.S. industries, including shipbuilding, petrochemical, aircraft, aerospace and automobile. Furthermore, a number of examples are cited where modularization has been used in the U.S. nuclear industry. These include the use of reinforcing steel modules; precast concrete; containment and

$$
\text { 2-1 }
$$


fuel related liner modules; tank, piping and equipment preassemblies; etc.[7]. However, modularization has not been extensively and systematicaliy used in the nuclear industry. The shipbuilding and petrochemical industries have used modular construction techniques a great deal and appear to offer the best examples for technology transfer to the nuclear industry. The fossil power industry is also studying power plant modularization and formed a working group to identify the major issues [8]. The issues identified by the group include labor, quality, standardization and transportation.

Reference [9] describes a comprehensive system of modular construction employed by Avondale Industries. The system was developed for their marine programs based on approaches used in Japan. They are now expanding their system for use in the industrial and utility markets. Major non-marine projects have included a sulphur recovery unit, hazardous and toxic waste treatment systems, and a hydroelectric power plant. The last example involved a large powerhouse module, approximately $456 \times 150$ $x 120$ feet, which was floated from its shipyard construction location to its final location a distance of 208 miles up the Mississippi River [10]. The steel structure consisted of over 200 modular units which were assembled together with eight turbines and generators to form one large powerhouse module (see Figure 2.1). once in place the steel module is filled with 110,000 cubic yards of concrete. Avondale is also involved with the application of modular construction to Westinghouse's design of the AP600. One of the major applications of modular construction in this design is the use of concrete-filled steel plate structures.

The Advanced Iight Water Reactor (ALWR) Utility Requirements Document developed by the Electric Power Research Institute [11] includes a requirement that ALWR plants "be designed to maximize the benefits which can be obtained through the use of modular construction techniques." As noted above, Westinghouse is applying modularization concepts in the design of the AP600 $[12,13]$. In addition to the concrete-filled structural steel modules, the other techniques being considered include steel (leave-in-place) form modules, wall rebar curtains, equipment modules and containment vessel modules. General Electric has also proposed a large scale modularization scheme for the design of the SBWR [14]. In this design GE is considering the use of rebar modules for pool walls, diaphragm floor modules, rebar modules for the RPV pedestal, containment wall liner modules, vent wall modules, and pool liner plate modules. Further details of the structural modules currently being proposed for use in the design of the AP600 and SBWR are discussed in sections 3.0 and 4.0 , respectively.

Modularization has also been considered in the design of other advanced reactors such as the Sodium Advanced Fast Reactor (SAFR), the Modular High Temperature Gas-cooled Reactor (MHTGR) and the Prototype Reactor Inherently Safe Module (PRISM) [15]. As part of 
the studies for these designs, new techniques for partial preassembly of concrete structures have been developed. Studies were also performed to aid in the development of guidelines for transporting modules, interface control and cost estimating. since the term "module" appears in the names of two of these designs and is used in several ways, the authors of Reference [15] provided a very concise definition of this term which is also directly applicable to the manner in which it is used in this report. The term "module" is defined to be "a major system or structural subassembly, which can be assembled and tested in an offsite or out-of-position location, and installed by field forces as a single piece."

The S\&W study also reviewed foreign nuclear power modularization and prefabrication experience [7]. Some of the examples cited in their report are summarized as follows:

- France - Containment dome liners were fabricated and erected in one piece. Reactor auxiliary piping was prefabricated to the extent that $75 \%$ of the pipe welds were done in the shop. Mechanical modules for small equipment are used.

- Japan - Large liner preassemblies of the containment vessel are shop fabricated. Pipe whip structures and pipe penetrations are preinstalled in the containment preassemblies. Modularized pipe and valve assemblies are used to reduce field welding. Reinforcing steel is preassembled on the ground.

- Sweden - Prefabrication of concrete structures such as staircases, wall elements, and slab and roof elements was used. Contaínment steel liner, process piping and pipe supports were prefabricated. Modularized rack-mounted units for the scram system were installed.

- Switzerland - Reinforcing steel was preassembled. Concrete elements for stairs, roof plates and shield blocks were prefabricated. The lower part of the drywell was modularized by welding steel plates into inner and outer rings. Composite steel and concrete reactor shield building penetration modules and the biological shield wall were prefabricated.

- Taiwan - The reactor pedestal was preassembled as a steel structure. The containment liner was prefabricated into four quadrant sections per ring and lifted into place by crane.

The Duke study also reviewed international nuclear construction experiences, including that at the Muelheim-Kaerlich plant in Germany and Tsuruga II and Takahama $3 \& 4$ in Japan [3] . 
Since Japan appears to be extensively developing modularization techniques and they have traditionally invested a great deal of resources in testing to demonstrate the adequacy of the designs, a more detailed discussion of recent Japanese studies is provided in section 2.3 .

It is apparent from the above cited reference material that there is a great deal of interest in modularization in both the nuclear and non-nuclear industries. Their is much discussion on how modularization impacts current construction practices and the potential savings in costs and schedule, as well as the improvement in quality. However, the literature does not appear to include much discussion on any potential safety issues that may be introduced by adapting modularization on a large scale to the nuclear industry. A paper by Bagchi and Tan [16] has looked at modular construction from a regulatory perspective. Some of the issues they have cited which should be addressed include the following:

- assurance of composite action between steel elements and concrete in wall and floor elements

- assurance of the ductility of connections and joints between modules

- the judicious application of codes and standards

- the establishment of an impeccable quality assurance and quality control program

The following sections of this report will discuss in more detail some of the modular construction studies cited above and the application of modularization techniques by Westinghouse and General Electric to their advanced reactor designs. The intent of this discussion will be to fully identify the issues from a regulatory viewpoint and to recommend a course of action for their resolution.

\subsection{DOE Programs}

As discussed in section 2.1 stone \& Webster Engineering Corporation (S\&W) and Duke Power Company studied the use of modularization in nuclear power plants as part of the Department of Energy's technology programs in support of advanced light water reactors.

As part of the s\&W study [7], a number of modularization approaches for a typical advanced light water reactor plant were developed and reviewed. It was emphasized that for modularization to be cost effective it must be considered from the plant's inception. In particular, it was noted that the general arrangement of a plant should consider the following features to

$$
2-4
$$


support the modular concept:

- align structural walls, columns and floors.

- minimize bulk quantities and group functionallyrelated equipment.

- minimize curved walls.

- provide a clean interface between in-place and modular construction.

- accommodate modular access, interfaces, and equipment removal/maintenance.

Based on the above guidelines, the study developed typical module units for the radwaste and auxiliary buildings of a nuclear plant. The module units for the radwaste building included demineralizer, waste evaporator and charging pump cubicle composite modules, as well as a pipe rack module. The modules developed for the auxiliary building included an emergency feedwater pump cubicle composite module, an electrical switchgear room composite module and a structural wall module. The modules were repeated several times for use throughout the plant and ranged in size and weights from 20 to 300 tons. The largest module was $30 \mathrm{ft}$. wide, $50 \mathrm{ft}$. long and $30 \mathrm{ft}$. high.

Some of the conclusions from this study are as follows:

- The use of templates is mandatory to assure the proper fit up of modules.

- Interfacing components of modules must be designed with excess material to be trimmed in the field to accommodate installation tolerances, stacking, and misalignment problems. Slotting connection holes, the use of shims and filler plates, etc. should be included in the module design

- Modular extremities must be located to assure proper clearance during installation.

- The interface between structural wall modules will require closure plates.

- Beam anchorage details were simplified by the use of hold down clips which eliminates the need for the tight tolerances associated with the use of anchor bolts. 
- Specialty Q-decking is recommended to provide the ability to hang components from the underside of a concrete slab.

- The concept of stay-in-place steel form modules can be expanded to suit specific building and component layouts.

- The choice of the optimum method for splicing rebar for modular construction requires further study.

- Modules may require the design of temporary structural steel supports to facilitate assembly/fabrication, transportation and lifting.

- When concrete is not required for structural integrity, wall and floor modules could use alternative radiation shielding products such as lead/steel shot or sheets, boron-polyethylene pellets and sheets in combination with lead, or lithium-polyethylene pellets.

The study also provided recommendations and conclusions regarding mechanical, piping and electrical modules, as well as cost and schedule analyses, which are not discussed here since they are not relevant to the scope of this report.

The Duke Power Company sponsored a number of workshops and meetings as part of their DOE program [3]. In particular, the Third Designing for Constructability workshop was devoted to the review of modular construction approaches and a discussion of the concerns that such approaches pose to the owner and/or constructor.

The workshop was held on March 14-16,1989 in Orlando, Florida and was attended by more than thirty industry representatives, including designers, fabricators, constructors, vendors, and utility owners. The workshop included a discussion of issues associated with quality assurance, impacts on vendor and site approaches, and owner commitment, cash flow, and risks. A summary of the issues discussed at the workshop is included in Table 2.1 .

One of the major issues was the degree of standardization necessary to enhance modularization and the need for standardized equipment specifications. It was concluded that such specifications should address items such as accessibility, maintainability, procurement, electrical, avoidance/minimization of rework and module delivery for installation. This last item includes inspections, packaging and preparation for shipment, handling, receiving, storage, and module and component protection. other issues included: (a) the need for up front planning and preparation as part of a detailed construction plan, (b) the development of a standardized QA program which includes the owner,

$$
2-6
$$


as well as the potential for multiple vendors and module fabricators, and (c) the need for maximizing owner QC inspections at the module fabricator's shop and adding inspections related to transportation induced loading.

The workshop also included discussions as to the need for a separate "Modularization" or "Module Fabricator" code. There was no consensus as to the need for a separate code. However, there was consensus that the modular construction approach did necessitate an evaluation of code requirements with at least some revisions and/or additions to current codes. Some of the issues to be addressed include the following:

- the need for and role of the Authorized Nuclear Inspector.

- the need for manufacturer vs constructor stamping programs for code piping.

- the mixing of code work on the same module.

- standardization of the NF boundary.

The workshop brought together a number of key individuals involved with the development of modular construction techniques. The issues discussed focussed primarily on the needs and concerns of owners and constructors. However, further discussions with these individuals would assist in further defining the modular construction issues from a regulatory viewpoint and assist in developing an approach for their resolution.

\subsection{Recent Japanese Studies}

Japan has utilized a number of prefabrication and modularization techniques in the design and construction of recent nuclear power plants. Studies are being conducted to improve these techniques and tests are being performed to develop analysis methods and demonstrate the adequacy of selected designs. The results of some of these applications and studies are presented in References [17] to [22] which are summarized below.

Tokyo Electric Power Co., Shimizu Corp. and Hitachi, Itd. have jointly developed the large block prefabrication method [17]. In their method they have distinguished between "prefabrication" wherein only a few types of construction materials are preassembled into standardized and simplified blocks and "large block prefabrication" in which a number of materials are integrated into larger and more complex units and installed using a large capacity crane. Examples of both are shown in Figure 2.2 and have been used during the construction of the Kashiwazaki Kariwa nuclear power plant. The method has been shown to: 
(1) save labor

(2) shorten the construction period

(3) improve construction safety

(4) impröve working conditions/reduce laborious work

In carrying out the method, the following engineering practices must be exercised:

(1) selection of application parts

(2) construction planning utilizing advanced engineering

(3) design improvement

(4) lifting and installing

(5) connecting parts together efficiently

(6) carrying out an intelligent network for data transmittal between head office, site office, general contractor, sub-contractors and mechanical manufacturer

Connecting is cited as one of the most important aspects of the method. To meet the need to align all joints at once under complicated conditions, a new rebar splicing adjuster was developed and new rebar splicing methods were applied. Further studies are being performed to improve the technology, including the enlargement of blocks, promotion of automation and mechanization and improvement of structures. The last item includes consideration of steel (S), concrete filled steel (SC) and pre-cast concrete (PC) structures.

Mitsubishi Heavy Industries, Itd., Kajima Corp. and Ohbayashi corp. jointly studied the feasibility of using concrete filled steel (SC) structures for a PWR type nuclear plant [18]. The study included the reactor building, control building and waste disposal building. The buildings consisted of SC bearing walls, columns of concrete filled steel pipe, girders and beams of steel, and slabs and foundation mats of reinforced concrete. The buildings were designed for a high seismic load $(0.35 \mathrm{~g}$ to $0.5 \mathrm{~g})$ on a rock site. The assumptions used in the SC wall design are shown in Table 2.2. An outline of the construction method is shown in Figure 2.3. The conclusions of the study are as follows:

1. "Equivalent earthquake resistance to conventional RC structures can be maintained with significant reduction in shear wall thickness. This indicates that the SC structure becomes more desirable when the earthquake force becomes larger."

2. "Regarding the construction, as it is possible to greatly increase the ratio of prefabricating work at the factory, a significant decrease in the job site man hours and field manpower is anticipated. Also, as a supplement to aforementioned, the possibility exists for reducing the job site man hours of the electro/mechanical systems work

$$
2-8
$$


by fixing pipes and wires to the SC blocks at the factory."

3. "A slgnificant saving of half to one year in construction period is possible due to the rationalization of the construction blocks."

In order to obtain seismic design information, a model test of a concrete structure inside containment composed of concrete filled steel (SC) bearing walls was conducted [19]. The tests provided information on elastic and inelastic behavior, stiffness, ultimate strength, and hysteretic and vibrational characteristics under horizontal seismic loads. The SC structure is a sandwich structure in which concrete lies between two surface steel plates as shown in Figure 2.4. Studs, shear bars, and web plates are attached to the steel plate in order to obtain a composite effect of concrete and steel plates. The model, which is a $1 / 10$ scale of the existing 1000 MWE class plant, and test apparatus are depicted in Figure 2.5. It consists of the SC primary shield wall of the reactor vessel and a secondary shield wall for the steam generator, pressurizer, and fuel transfer canal. It also includes reinforced concrete (RC) structures consisting of the base mat and the upper and lower loading slabs.

The test procedure consists of two parts:

1. Static horizontal loading tests were performed by applying horizontal forces on the upper and lower loading slab in proportion to the distribution of shear forces and bending moments predicted in the actual structural design.

2. Vibration tests were conducted with an inertia type hydraulic shaker. A sine sweep excitation was applied with a sweep frequency range between 20 and $200 \mathrm{~Hz}$ and a sweep velocity of $10 \mathrm{sec} / \mathrm{Hz}$.

The calculated concrete crack load and steel plate yield load were found to compare well with the test results. The concrete crack occurrence load was determined by dividing the tensile strength of concrete by the principal tensile stress in the concrete as determined from an elastic FEM analysis. The steel plate yield load was also determined using the calculated forces from the elastic FEM analysis and the following assumptions:

1. All tensile forces are resisted by the steel plates.

2. The compressive forces are resisted by the steel plates and concrete in proportion to their stiffnesses.

Figure 2.6 shows the stiffness degradation. The vertical axis indicates the secant modulus of stiffness and the horizontal axis 
indicates the relative rotation angle (R). For the SC structure the stiffness at the $s_{1}$ load level with $R=0.48 \times 10^{-3}$ rad. decreased by $30 \%$ from the stiffness at elastic conditions. For the RC structure the corresponding stiffness decrease was $65 \%$. The $S_{1}$ load level.was reported as corresponding to a U.S. SSE.

Figure 2.7 shows equivalent viscous damping results. For the SC structure the damping is almost constant at $5 \%$ before the steel yields and it dramatically increases after that. For the RC structure the damping from the second cycle loop is almost constant at $5 \%$ before and after rebar yielding.

Based on the results of this test it was concluded that the SC structure is superior in ultimate strength and ductility capability compared to the RC structure. It also demonstrated well behaved hysteresis characteristics. The results of this test and those from further studies, which are apparently underway, will be used to estaolish a rational design method for SC structures in Japan.

In order to establish a rational design method for $\mathrm{SC}$ structures, additional compression and shear loading tests of SC wall specimens were performed [20]. These tests apparently are part of an overall program to establish SC design methods for determining:

(a) compression ultimate strength

(b) shear ultimate strength

(c) combined compression and shear ultimate strength

(d) adequacy of joints

(e) reinforcing methods for details such as openings

The tests described in Reference [20] are being used to address items (a) and (b) above. Table 2.3 shows the type of test specimens included in this program. stud bolts are welded to the surface plate at spacing $B$. For the compression tests repeated compression loads are applied. For the shear tests, the repeated positive and negative loads are applied using four hydraulic jacks. The method of loading the test specimens is shown in Figure 2.8 .

For the compression tests the initial stiffness, buckling of surface plates, and ultimate strength were evaluated. The initial stiffness was calculated by the following formula:

$$
K=(E A)_{e q} / H=\left(E_{c} A_{c}+E_{s} A_{s}\right) / H
$$

where

$$
\begin{array}{lll}
E_{c}, E_{8} & \text { Young's modulus of concrete and steel } \\
A_{c}, A_{s} & =\text { Section area of concrete and steel } \\
H & =\text { Height of specimen }
\end{array}
$$

The ratio of the test results to the calculated values based on the above formula were about 0.8 .

$$
2-10
$$


The buckling strength was calculated by Euler's equation with a buckling length equal to $0.7 \mathrm{x}$ stud spacing. Based on this assumption, the ratio of test results to calculated values ranged from 1.02 to $1: 44$.

The ultimate strength was calculated by the following formula:

$$
\mathrm{N}_{\max }=\mathrm{N}_{\mathrm{c}}+\mathrm{N}_{\mathrm{w}}+\mathrm{N}_{\mathrm{F}}=\mathrm{A}_{\mathrm{c}} \mathrm{f}_{\mathrm{c}}+\mathrm{A}_{\mathrm{w}} \sigma_{\mathrm{wy}}+\mathrm{A}_{\mathrm{F}} \sigma_{\mathrm{FCR}}
$$

where $\mathrm{N}_{c}, \mathrm{~N}_{\mathrm{w}}, \mathrm{N}_{\mathrm{F}}=$ strength of concrete, side plate and $A_{c}, A_{w}, A_{F}=\quad \begin{aligned} & \text { surface plate. } \\ & \text { Section area of concrete, side plate and }\end{aligned}$ $\mathrm{f}_{\mathrm{c}} \quad$ = $\quad$ compression strength of concrete

$\sigma_{\mathrm{wy}} \quad=\quad$ Yield strength of side plate

$\sigma_{\mathrm{FCR}} \quad=\quad$ Buckling strength of surface plate

Using this formula the ratio of test results to calculated values ranged from 0.99 to 1.06 .

For the shear tests the initial stiffness, buckling of surface plate, and ultimate strength were also evaluated. The initial shear stiffness was calculated by the following formula:

$$
\mathrm{K}_{\mathrm{s}}=(\mathrm{GA})_{\mathrm{eq}} / \mathrm{h}_{\mathrm{o}}=\left(\mathrm{G}_{\mathrm{c}} \mathrm{A}_{\mathrm{c}}+\mathrm{G}_{\mathrm{F}} \mathrm{A}_{\mathrm{F}}\right) / \mathrm{h}_{\mathrm{o}}
$$

where $G_{c}, G_{F}=$ shear modulus of concrete and surface $A_{c}, A_{F}=$ section area of concrete and surface $h_{0} \quad=\quad$ height of wall 1.25 .

The ratio of test results to calculated values was 0.94 to

The buckling stress values were found to be nearly equal to the theoretical values of a pin-supported plate of which the aspect ratio is infinitely large. No buckling occurs in test specimen S550 (see Table 2.3) for which $\mathrm{B} / \mathrm{t}$ is 50 .

The ultimate strength was calculated by the following equation:

$$
\operatorname{qmax}=\sigma_{\mathrm{FY}} / 2 \mathrm{~A}_{\mathrm{F}}+4.5 \sqrt{f_{c}} A_{c}
$$

where

$$
\begin{array}{ll}
\mathrm{A}_{\mathrm{F}}, \mathrm{A}_{\mathrm{c}} & =\begin{array}{l}
\text { Section area of surface plate and } \\
\text { concrete }
\end{array} \\
\sigma_{\mathrm{FY}} & =\text { Yield strength of surface plate } \\
\mathrm{f}_{\mathrm{c}} & =\text { Compressive strength of concrete }
\end{array}
$$


The ratio of the test results to the calculated values ranged from 1.00 to 1.02 .

The conclüsions from these tests were reported as follows:

1. "Stud bolts are effective to prevent buckling of the surface plate."

2. "Occurence of buckling can be predicted by applying Euler's equation for a column pin-supported at one end and fixed at the other end for compression loads and by the theoretical equation of a pin-supported plate of which the aspect ratio is infinitely large for shear loads."

3. "Occurence of buckling has little effect upon the loaddisplacement behavior of the structure."

4. "Ultimate strength of the whole structure can be evaluated by the sum of the ultimate strength of concrete and steel plate."

other studies have also been conducted in Japan on the strength of concrete-filled steel elements which may be useful in establishing the design criteria for such structures in nuclear plants. For example, Reference [21] reports the results of analysis and tests of such elements when subjected to combined bending, shear and axial forces. The paper presents closed form solutions for selected problems with verification by tests. Reference [22] presents the results of an experimental study on the strength and deformation of concrete-filled box columns. In this study, ten specimens (six concrete-filled steel box columns and four steel box columns) were tested to failure under concentric compression. From the test results it was concluded that high ductility as well as high strength can be expected from concretefilled columns. It was also found that longitudinal stiffeners can have a significant effect on the strength of both the steel columns and concrete-filled columns. 


\begin{tabular}{|c|c|c|}
\hline Subject & Comment & mples \\
\hline $\begin{array}{l}\text { Quality } \\
\text { assurance }\end{array}$ & $\begin{array}{l}\text { New concerns on QA } \\
\text { and documentation } \\
\text { arise when a modular } \\
\text { approach is applied to } \\
\text { a major construction } \\
\text { project. }\end{array}$ & $\begin{array}{l}\text { - Code class work } \\
\text { - Mixed code classes on the same } \\
\text { module } \\
\text { - Configuration control } \\
\text { - Inspection responsibilities } \\
\text { - Inspection of partially completed } \\
\text { modules } \\
\text { - Added inspection requirements } \\
\text { - upon receipt of modules } \\
\text { - Owner "umbrella" vs. } \\
\text { - QA } \\
\text { vendor-controlled QA programs }\end{array}$ \\
\hline $\begin{array}{l}\text { Impacts on } \\
\text { vendor and } \\
\text { site } \\
\text { approaches }\end{array}$ & $\begin{array}{l}\text { Modularization will } \\
\text { require innovative } \\
\text { approaches to vendor } \\
\text { activities and side } \\
\text { efforts. }\end{array}$ & $\begin{array}{l}\text { - Modularization not requiring } \\
\text { miniaturization for maintainability } \\
\text { - Impact on productivity and rework } \\
\text { - Standardized vs. site-specific } \\
\text { modules } \\
\text { - Procurement of module } \\
\text { subcomponents } \\
\text { - Storage and damage protection } \\
\text { - Construction plan and sequencing } \\
\text { - Schemes for getting modules into } \\
\text { buildings } \\
\text { - Impact on "normally later items } \\
\text { such as electrical, start-up, and } \\
\text { testing activities } \\
\text { - Field run items } \\
\text { - Influences of tolerances and field } \\
\text { fit-ups } \\
\text { - Configuration control } \\
\text { - Union jurisdictions vs. a team } \\
\text { concept }\end{array}$ \\
\hline $\begin{array}{l}\text { Owner } \\
\text { commitment, } \\
\text { cash flow, } \\
\text { and risks }\end{array}$ & $\begin{array}{l}\text { Modularization } \\
\text { definitely benefits site } \\
\text { schedule and cost. } \\
\text { The owner will be } \\
\text { concerned with: } \\
\text { - Changes created } \\
\text { in timing project } \\
\text { commitments } \\
\text { - Outlay of funds } \\
\text { - Changes in risk } \\
\text { factors }\end{array}$ & $\begin{array}{l}\text { - Cascading effect of late items and } \\
\text { - Bust in time" deliveries } \\
\text { - Balancing delivery schedule vs. } \\
\text { - Ownen of a critical module } \\
\text { procurement } \\
\text { - Cash flow profile } \\
\text { - Warranty impacts } \\
\text { - Insurance against schedule } \\
\text { - Belays } \\
\text { - Broadening of the financial base }\end{array}$ \\
\hline
\end{tabular}


Table 2.2 Seismic Design Method for SC Walls [18]

\begin{tabular}{|c|c|c|}
\hline $\begin{array}{l}\text { Type of } \\
\text { Load }\end{array}$ & Basic Design Principle & Design Method \\
\hline $\begin{array}{c}\text { Compressive } \\
\text { Load }\end{array}$ & $\begin{array}{l}\text { Shared by steel plates and } \\
\text { concrete according to } \\
\text { stiffness ratio. }\end{array}$ & $\mathrm{Na}=(\mathrm{Ac}+\mathrm{As}) \cdot \sigma \mathrm{c}$ \\
\hline $\begin{array}{l}\text { Tensile } \\
\text { Load }\end{array}$ & $\begin{array}{l}\text { Disregard tensile strength of } \\
\text { concrete. }\end{array}$ & $\mathrm{Ta}=\mathrm{As} \cdot \mathrm{fa}$ \\
\hline $\begin{array}{l}\text { Shear } \\
\text { Load }\end{array}$ & $\begin{array}{l}\text { Shared by cumulative strength } \\
\text { of steel plates and concrete. }\end{array}$ & $Q_{a}=A s \cdot f a+1.5 \tau_{A} \cdot A c$ \\
\hline $\begin{array}{l}\text { Lateral } \\
\text { Bending }\end{array}$ & $\begin{array}{l}\text { Same as RC design method } \\
\text { to disregard tensile strength } \\
\text { of concrete. }\end{array}$ & $\begin{array}{l}\text { Follow RC design } \\
\text { method }\end{array}$ \\
\hline $\begin{array}{l}\text { Lateral } \\
\text { Shear }\end{array}$ & \begin{tabular}{|l|} 
Both steel plate and concrete \\
part are cumulated. \\
Steel plate - Structural \\
Concrete, \\
Shear bar
\end{tabular} & $V a=a Q s+a Q c$ \\
\hline
\end{tabular}




\section{Table 2.3 Type of Test specimens [20]}

(a) Compression Test

\begin{tabular}{ccc}
\hline Soecimen & \multicolumn{3}{c}{$\begin{array}{c}\text { SLd spacing } \\
\text { (mm) }\end{array}$} & $B / t$ \\
\hline NS50 & 160 & 50 \\
\hline NS75 & 210 & 75 \\
\hline NS100 & 320 & 100 \\
\hline
\end{tabular}

(Compression Test) (NS50)

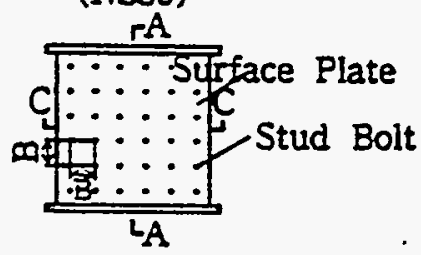

$$
\text { (NS75) }
$$
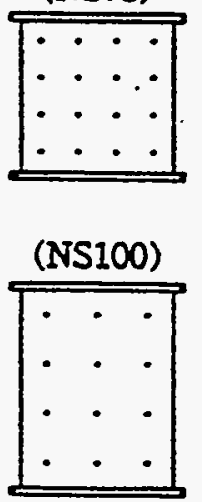

(b) Shear Test

\begin{tabular}{|c|c|c|}
\hline Specimen & $\begin{array}{l}\text { Stud spocins } \\
B(\mathrm{~mm})\end{array}$ & $8 / t$ \\
\hline$\$ 550$ & 160 & 50 \\
\hline $5 s 100$ & 320 & 100 \\
\hline ssi5o & 480 & 150 \\
\hline
\end{tabular}

(d) Arrangement of Stud Bolts (Shear Test) (SS50)

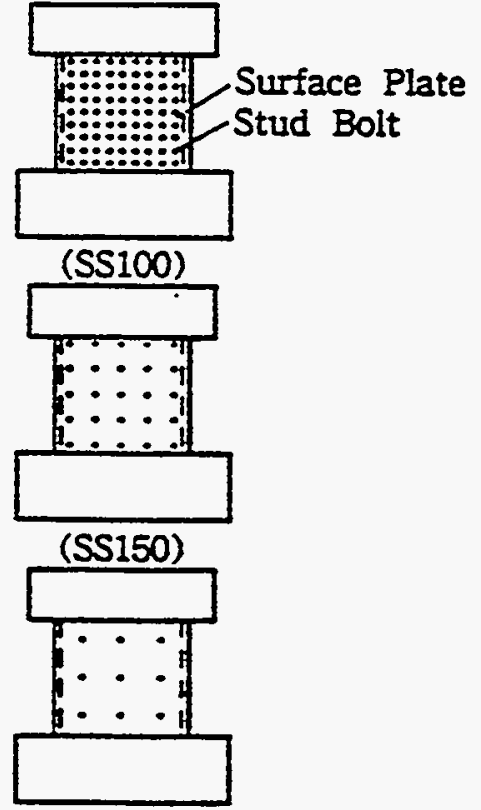

(c) Materials

\begin{tabular}{|c|}
\hline $\begin{array}{l}\text { Concrele } \\
F_{\mathrm{c}}=240 \mathrm{~kg} / \mathrm{\textrm {cm } ^ { 2 }}\end{array}$ \\
\hline $\begin{array}{l}\text { Surfece Plate } \\
\begin{aligned} \sigma_{\nabla} & =3050 \mathrm{k} / \mathrm{\textrm {em } ^ { 2 }} \\
l & =32 \mathrm{~mm}\end{aligned}\end{array}$ \\
\hline $\begin{array}{l}\text { Stad Boit } \\
\begin{aligned} \phi=50 \mathrm{~mm} \\
=35 \mathrm{~mm}\end{aligned}\end{array}$ \\
\hline
\end{tabular}

Sec. $A-A$

(Section)

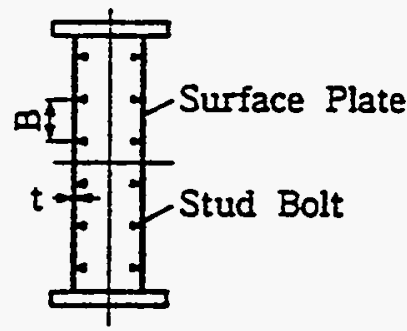

Sec. $C-C$

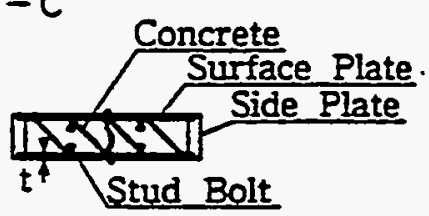




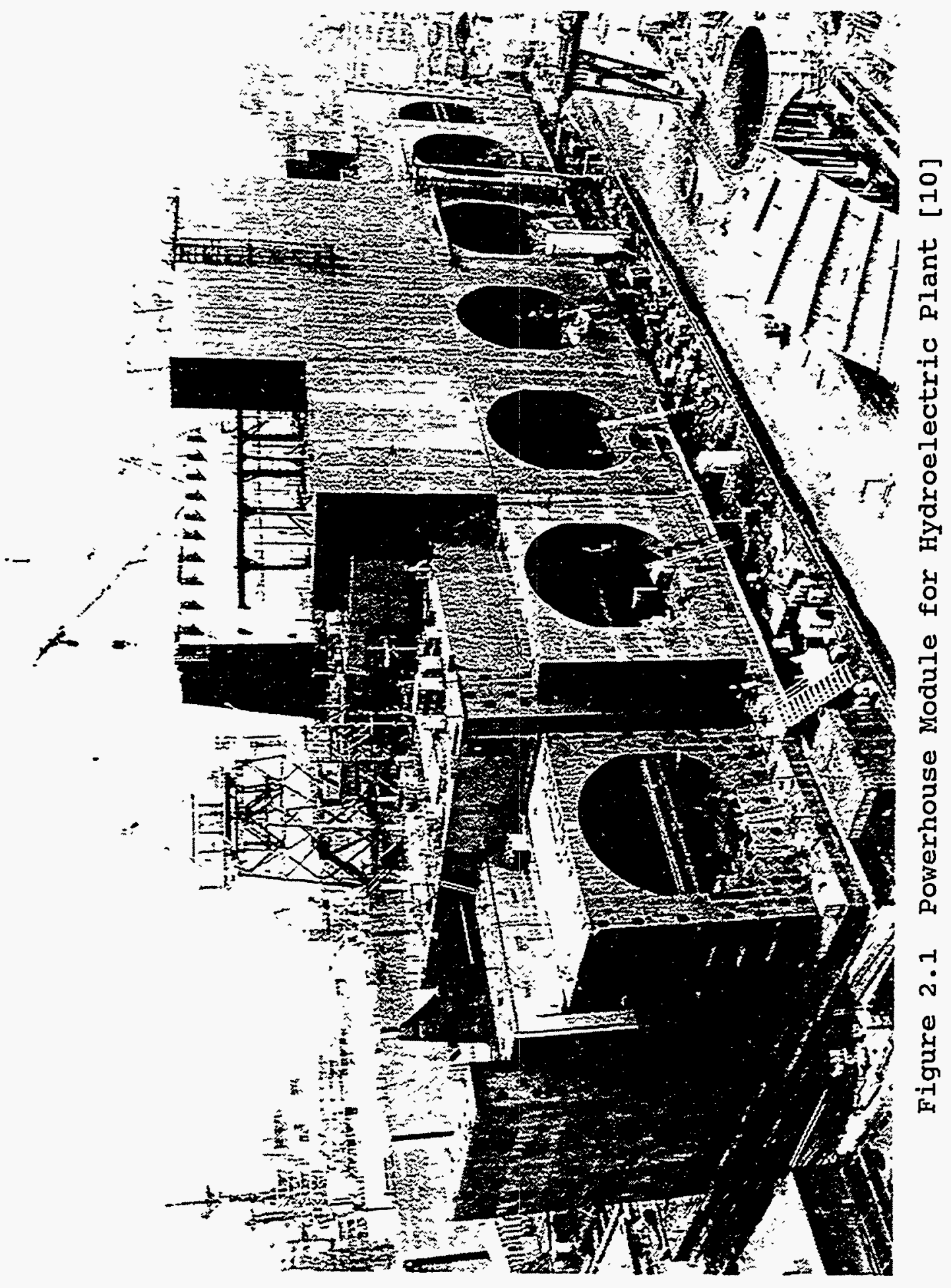




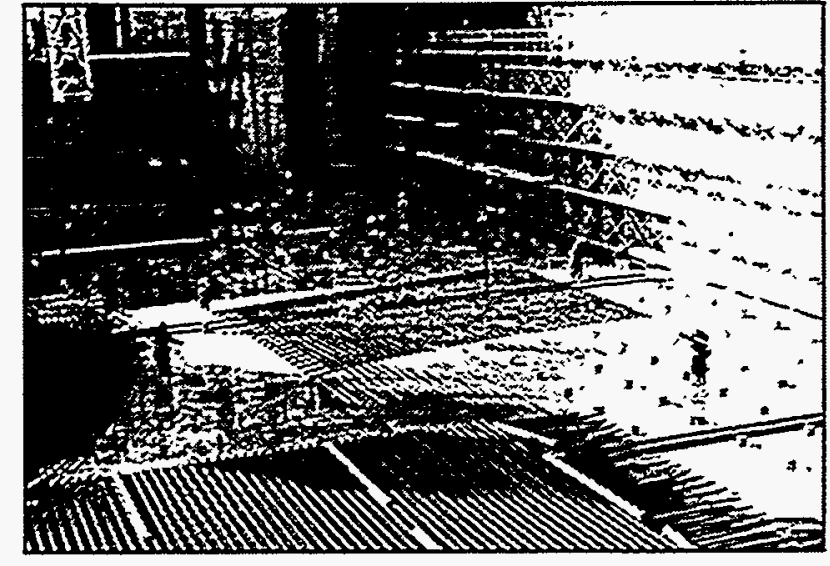

Photo 2-1. Rebar mesh prefabrication for Base Mat.

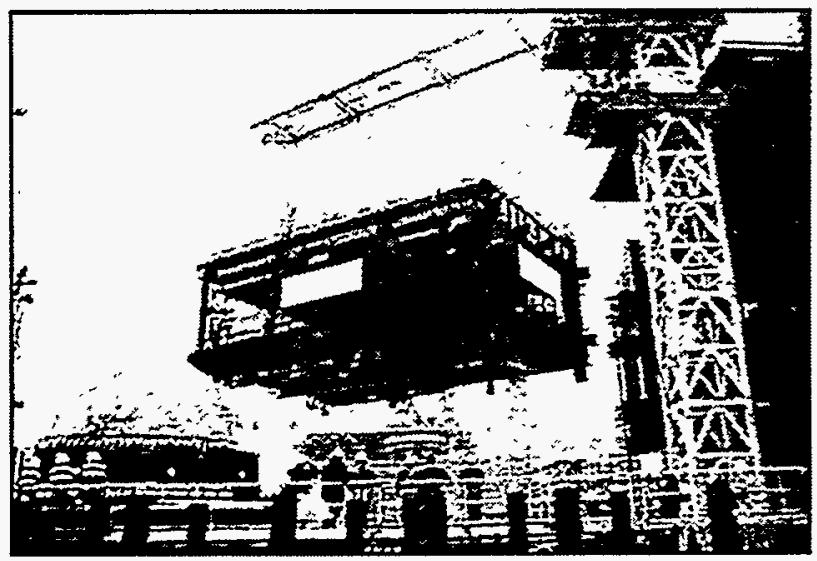

Photo 2-3. Room Module Method for Main Control Room (wt. 440 ton).

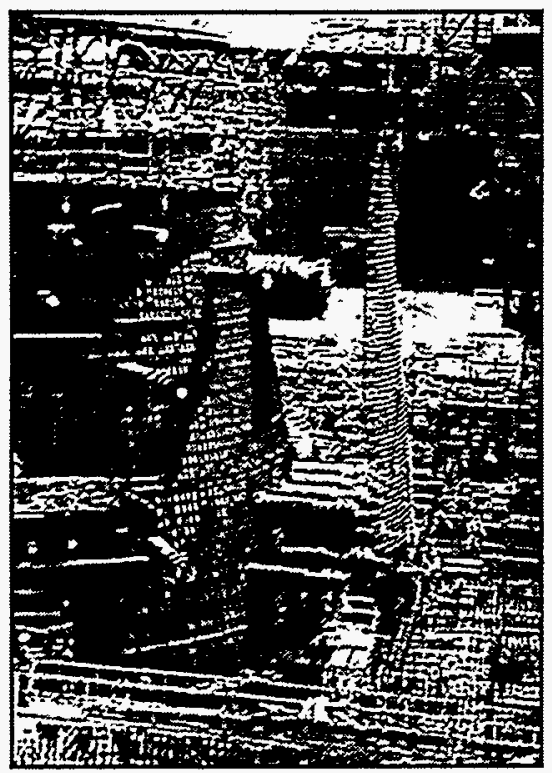

Photo 2-5. Rebar mesh prefabrication for Shield Wall (Conical).

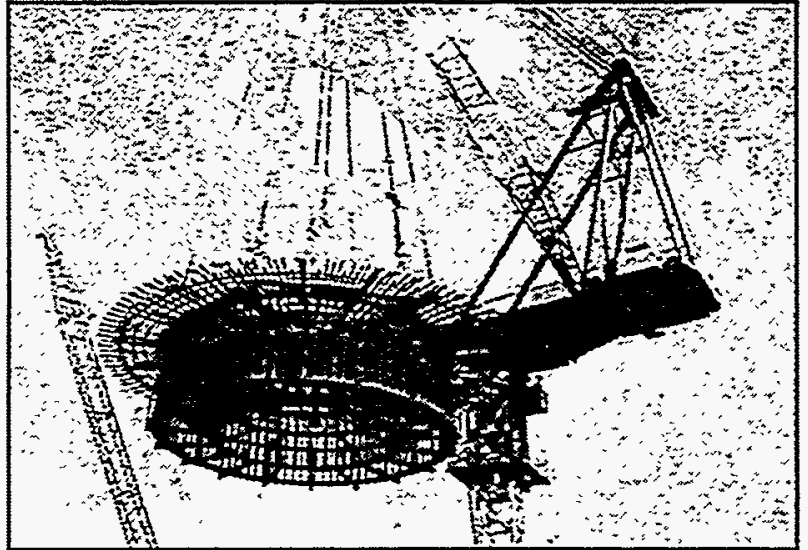

Photo 2-2. Large block prefabrication for Base Mat Central Part (wt. 100 ton).

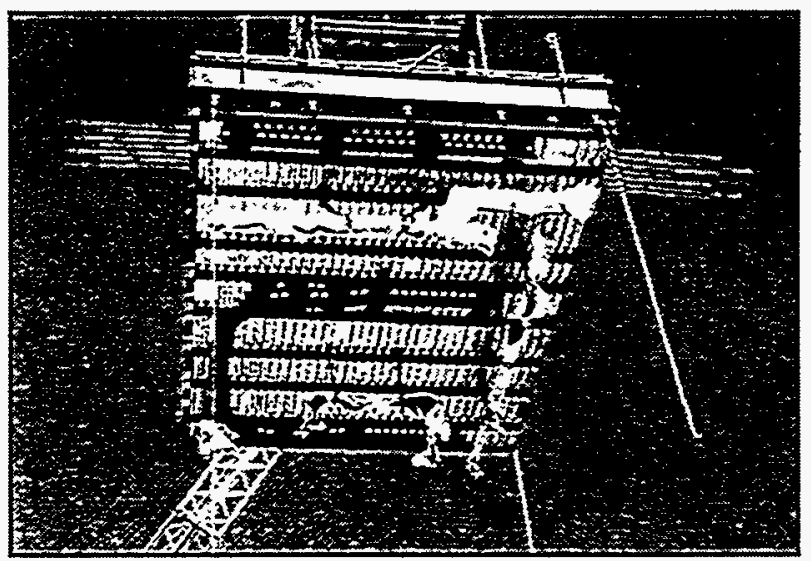

Photo 2-4. Composite Slab Method (wt. 50 ton).

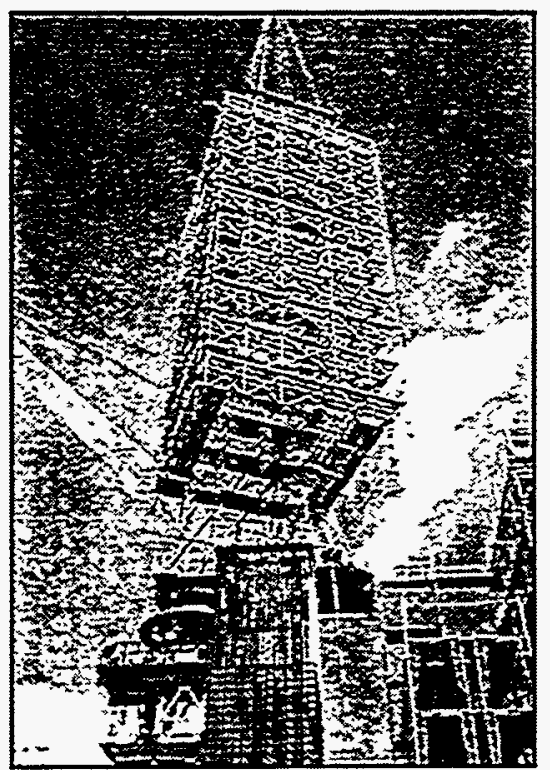

Photo 2-6. Scaffold prefabrication for T/G Pedestal.

$\begin{array}{ll}\text { Figure 2.2 } & \begin{array}{l}\text { Examples of "Prefabrication" and } \\ \text { "Large Block Prefabrication for a } \\ \text { Nuclear Power Plant in Japan [17] }\end{array}\end{array}$ 


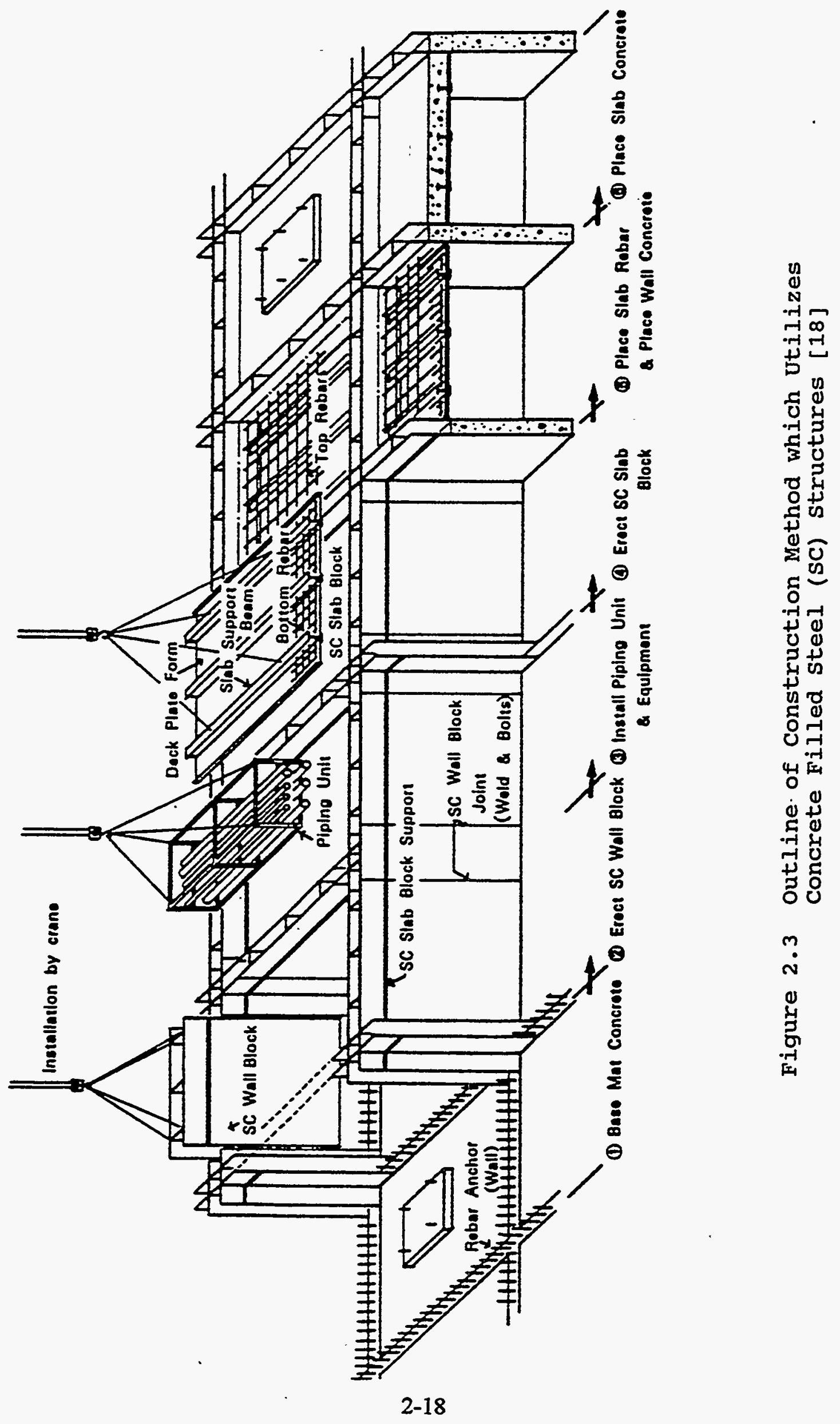




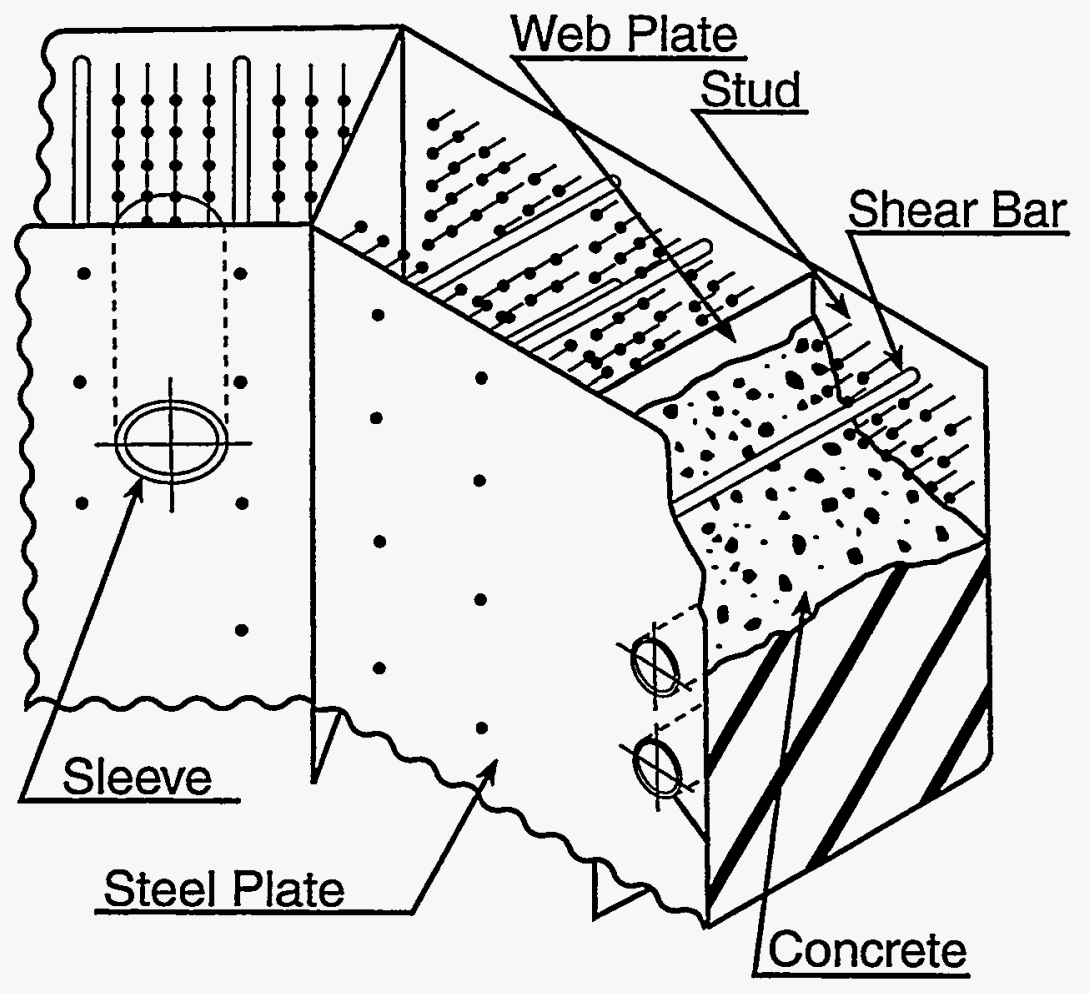

Figure 2.4 Proposed Concrete Filled Steel (SC) Structure [19]

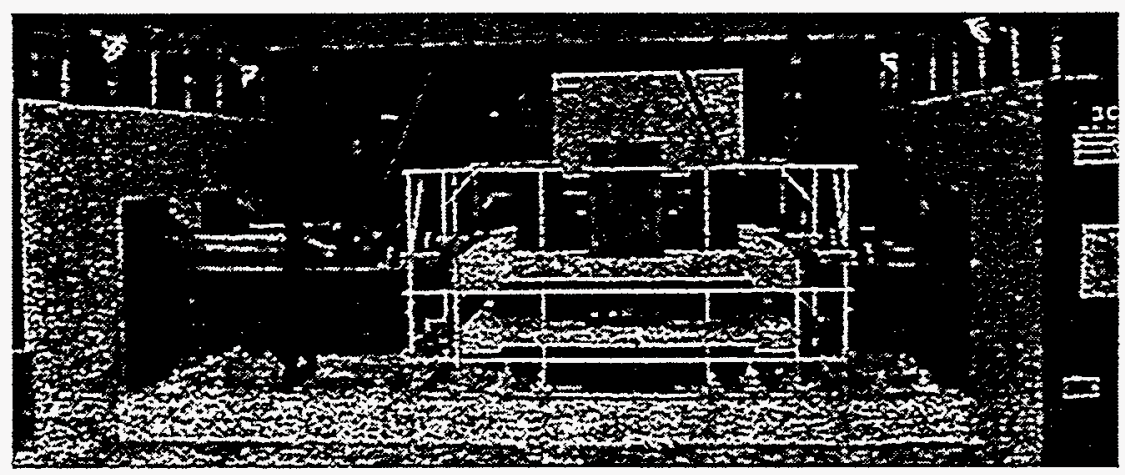

Figure 2.5 1/10th Scale Test Model of Inner Concrete Structure with concrete Filled Steel (SC) Walls [19] 


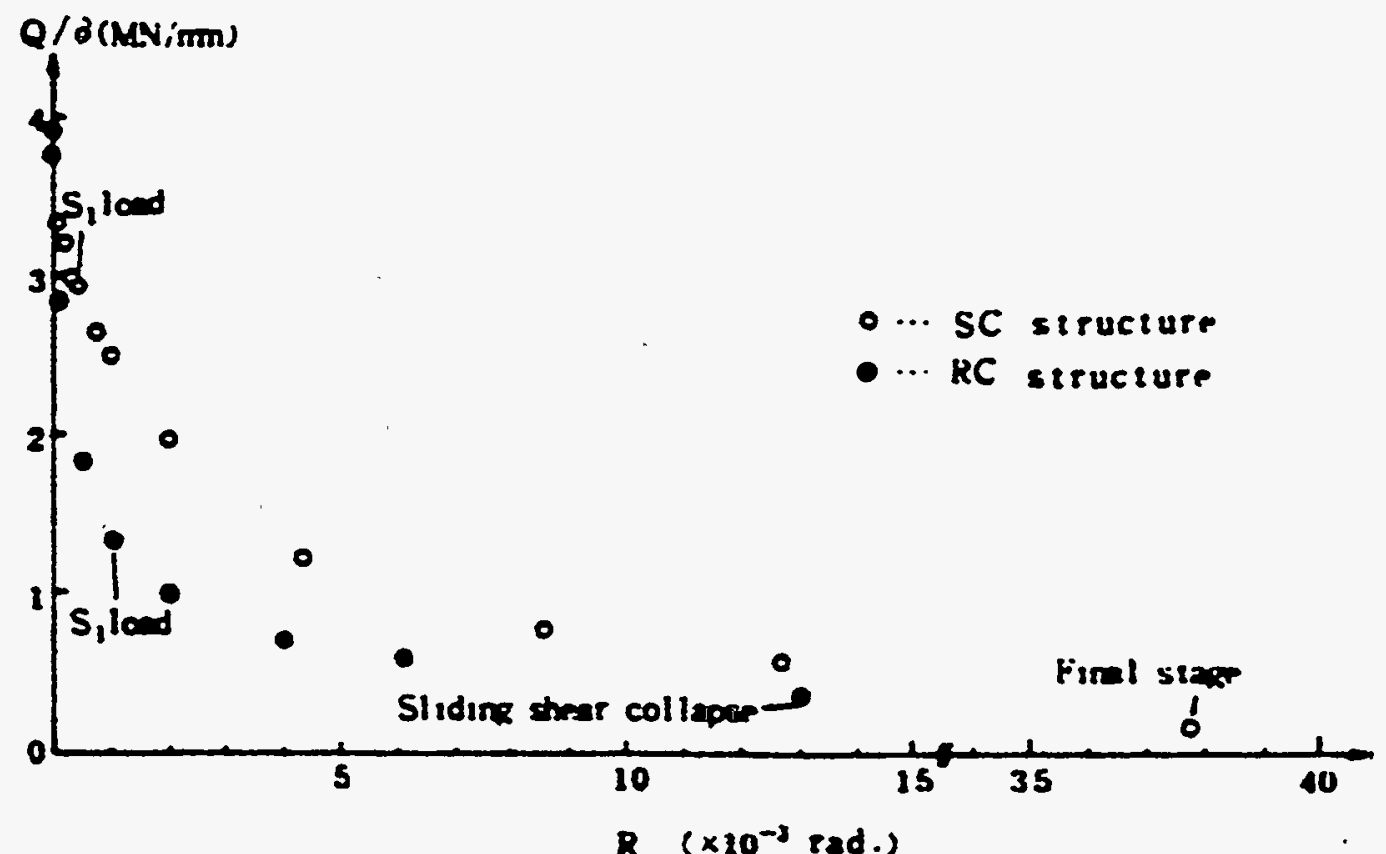

Figure 2.6 Stiffness Degradation of SC and RC Walls [19]

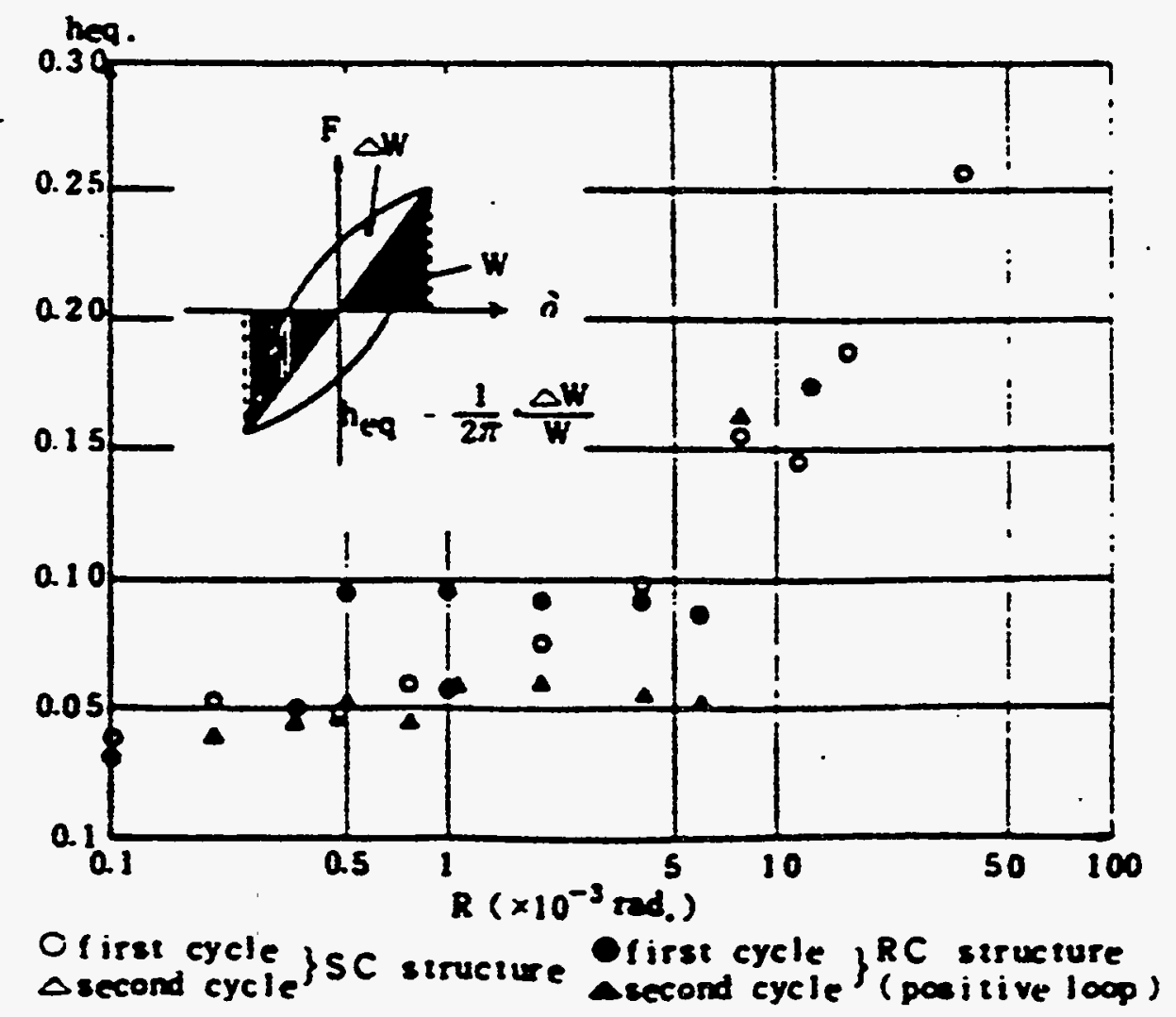

Figure 2.7 Equivalent Viscous Damping Factor for SC and RC Walls [19] 


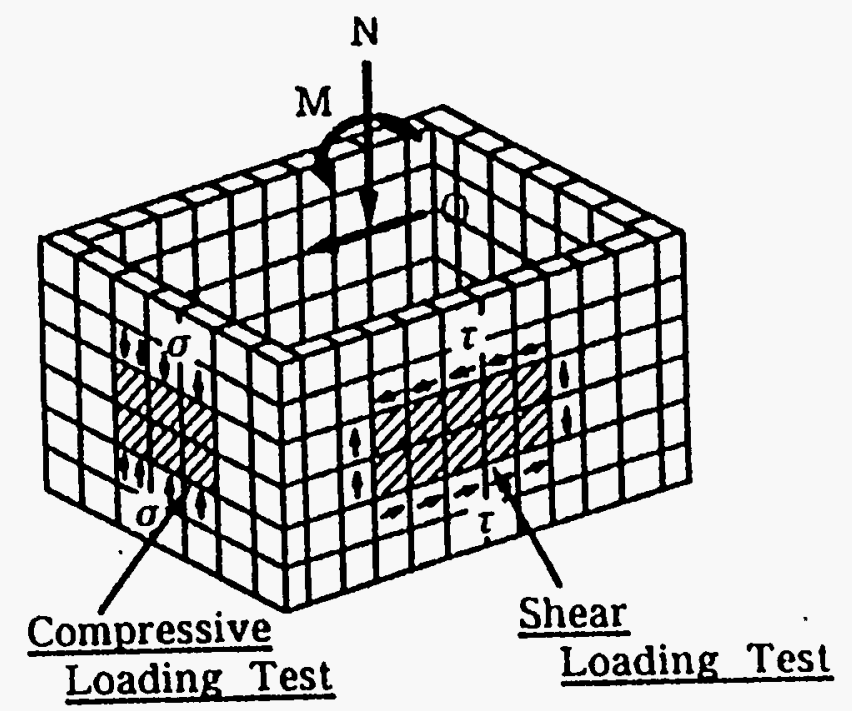

(a) Test Items

$\stackrel{N}{N}$

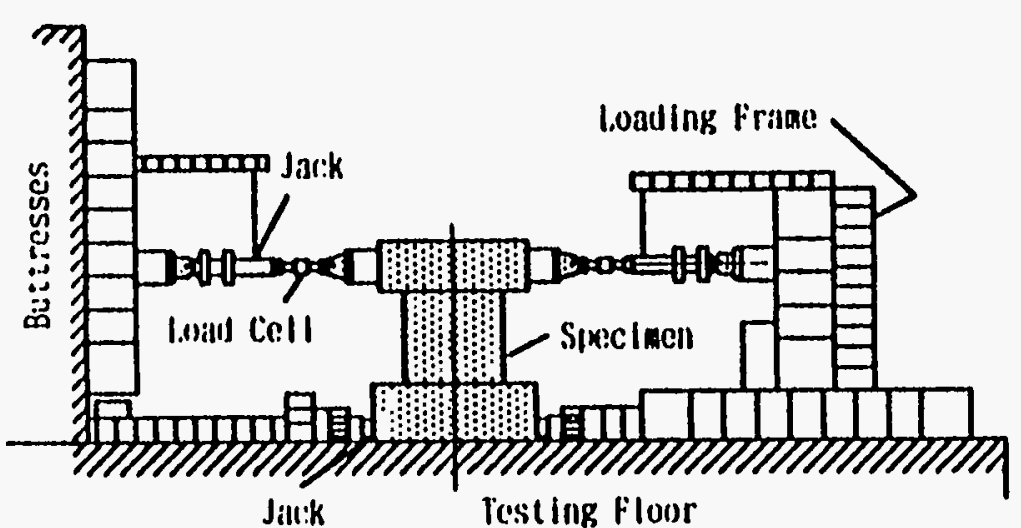

(b) Shear Test

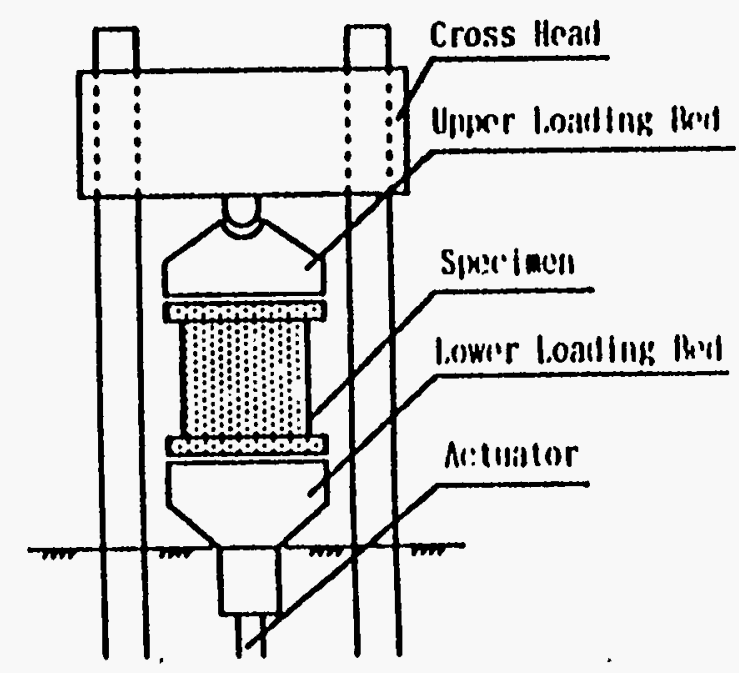

(c) Compression Test

Figure 2.8 Method of Loading Concrete Filled Steel (SC) Wall Test Specimens [20] 


\subsection{EVALUATION OF WESTINGHOUSE APPLICATIONS}

\subsection{Description of Modular Systems}

The AP600 Program is a simplified passive advanced light water reactor that is being developed by Westinghouse and its subcontractors. The AP600 plant which is rated at 600 Mwe utilizes a Westinghouse designed pressurized water reactor. To be competitive with alternative sources of power in terms of cost and construction schedule a number of innovations have been incorporated into the design of the AP600 plant.

A simplified plant design has been developed and the plant arrangement has been optimized to reduce the number and size of systems and components. This results in reduced building volumes and a corresponding reduction in material quantities. Coupled with these improvements, a modular construction approach is utilized to achieve the desired goals of lower costs and a reduced construction schedule. These can be achieved with modularization by prefabricating modules in a shop or site subassembly area. This permits modules to be constructed in parallel. In addition, the shop and subassembly area is generally more productive and would result in higher quality construction than work performed within the plant structures.

There are a number of different types of structural modules which are utilized in the AP600 plant design. Most of these modules are located within the containment structure. Figure 3.1 shows an elevation view of the containment. The following sections describe the specific location and configuration of each structural module.

\subsection{1. "M" Module}

"M" modules are used in the construction of containment internal wall structures above elevation $83^{\prime}$. The locations of the $M$ wall modules are shown on Figures 3.2 through 3.4 . These modules are prefabricated steel box sections with steel plates on each face stiffened by vertical diaphragms and horizontal angle stiffeners. A typical $M-1$ modular subunit is shown on Figure 3.5. These subunits are constructed offsite. Due to size limitation on commercial railways these subassembly units are transported to the site where they are assembled into the $M-1$ structural module shown on Figures 3.6 and 3.7 . The $M-1$ module consists of the walls surrounding the reactor, refueling canal area, and two steam generators. The entire $M-1$ assembly module is lifted into position using a sling detail shown on Figure 3.7 .

Wall modules are anchored to the concrete base by means of anchor bolts and dowels embedded in the concrete below El. 98'. After erection, the walls are filled with concrete. Concrete is used where radiation shielding is required. There is no 
reinforcing steel used since the concrete is not required to carry loads with some exceptions as noted in section 3.2 .

Wall modules without concrete fill are also utilized inside containment. The west wall of the refueling water storage tank is this type of module which is constructed solely from structural steel (see Figure 3.2).

Structural steel modules are constructed from $\mathrm{A} 36$ carbon steel plates and shapes. Stainless steel plates are used on the surface of modules that are in contact with water.

3.1 .2 "I" Module

" $L$ " modules are permanent steel forms used for the containment internal base concrete structures below Elevation 98'-6". The steel modules consist of $1 / 4 "$ " steel plates reinforced with 2 " $\times 2$ " angle stiffeners and 4" WT sections on the concrete side of the plate (Figure 3.8).

The $I$ wall modules are used in lieu of removable concrete forms. The advantage is that these wall modules can be fabricated and preassembled offsite in parallel with other ongoing construction activities. This reduces construction efforts at the site which results in cost savings to the project. In addition, savings are achieved by eliminating curing time and the need to strip forms, clean-up, and patch exposed concrete surfaces.

\subsubsection{Floor Module}

Floors in the containment interior above elevation $98^{\prime}$ consist of steel tee-sections welded to horizontal steel plates. The steel plates are stiffened by angle stiffeners. support is provided using deep girders whose webs pass through the horizontal plate. Reinforcing bars are placed above the top flange. After erection, concrete is poured on top of the horizontal plates embedding the upper section of the beams and reinforcing bars. See Figures 3.9 and 3.10 for the floor plan and details of the floor modules.

\section{1:4 Finned Floor Module}

Floors located above the main control room and instrumentation and control rooms in the auxiliary building are designed as finned floor modules [28]. The purpose of the finned floor modules is to provide a passive heat sink for each room. The heat sink limits the temperature rise during the 72 hour period following a loss of operation of the non-radioactive ventilation system. The concrete mass of the ceilings and walls are designed to provide the required heat sink.

A finned floor is comprised of a 24 inch thick reinforced concrete slab poured over a stiffened steel plate ceiling (see

$$
3-2
$$


Figures 3.11 and 3.12). Composite action of the steel and concrete is developed using shear studs welded to the steel plate and embedded in the concrete. The horizontal steel plates are stiffened by wëlding $1 / 2 " \times 9 "$ steel plates perpendicular to the ceiling plates. The steel fins project into the room and act as thermal fins to enhance the transfer of heat from the air to the concrete.

Several modules cut to the room width are prefabricated in a shop. On site they. are installed side by side perpendicular to the room length. Adjacent panels are made continuous by welding a flat bar along the interface of two panels.

\subsubsection{Fuel Pool and Refueling Canal Liner Modules}

As Westinghouse develops the construction plan, they will be considering the use of structural modules in the fuel pool area. Typically, fuel pools are constructed from reinforced concrete with stainless steel liners. The current plan is to use liner modules, but if there are sufficient construction benefits, structural modules would be used. These structural modules would be similar to those used for the refueling canal inside containment.

\subsubsection{Other Potential Applications of Structural Modules}

Westinghouse did not describe other potential uses of structural modules in the SSAR [23] or in their presentation to the NRC [25-27]. However, in the "Westinghouse AP600 Plant Description Document" [24], other types of structural modules were discussed. They include rebar support frames, rebar mats, and rebar curtain walls.

Prefabricated modular rebar support frames were proposed in the Nuclear Island Basemat [24]. After the bottom layer of rebar is installed, the upper rebar support frames would be set into position as one unit, aligned, braced, anchored and then the upper rebar would be installed. One type of frame would be used in the middle area of the slab, and another type, with pre-attached heavy expanded metal mesh, would be used at the construction joints as leave-in-place wire bulk heads (Figure 3.13).

Another application of modularization described in Reference 24 is for rebar mats. The upper and lower rebar mats would be preassembled and attached together as a module within an interior frame support system. This type of module would be used in thick mats such as the fuel handling building.

Wall rebar curtains could also be preassembled as set in components [24]. This would be most feasible in buildings where wall configurations and design details are standarized or common. These rebar wall curtains would be modularized with a prefabricated internal support frame with vertical and horizontal rebar attached 
as one component. After assembly, they would be lifted and set into place as a single unit (Figure 3.14).

\subsection{Summary of Analysis and Design Methods}

The codes and standards used to design the structural modules are AISC N690-1984 [29] and ACI 349-1990 [30]. AISC N690 is utilized primarily as the design code since the steel is designed to carry most loads. The ACI 349 code is used where credit is taken for concrete.

Loads acting on the structural modules are the same as for other Category I structures described in subsection 3.8 .4 .3 of the SSAR [23]. Tables 3.1 and 3.2 list the various loads and load combinations used for steel and concrete respectively. However, loads such as wind loads, tornado loads, and earth pressure do not apply because of the protection provided by the steel containment.

Using the $M$ modules as an example, dead load consists of the weight of the wall, equipment, floor above 135'-3" and hydrostatic load. Live load consists of live loads from the floors above and the automatic depressurization system. Safe shutdown earthquake (SSE) load consists of hydrodynamic load, out of plane wall inertia load and in-plane seismic loads.

\subsection{1 "M" Module}

The in-plane SSE loads are obtained from a response spectrum analysis of the finite element model of the containment internal structures (Figures 3.15 through 3.17). The finite element model consists of $3 \mathrm{D}$ shell elements representing the structural modules. Equivalent shell element thickness and modulus of elasticity of the structural modules are calculated neglecting the embedded angle stiffeners and vertical diaphragm plates. The shell element properties are calculated using the sum of the gross concrete section and the transformed steel plates of the structural module. other forces are obtained by manual calculations. For out of plane loads, the wall is analyzed as a member spanning vertically between the operating floor and the bottom of the refueling cavity.

The design method followed for the $M$ modules are dependent on the type and direction of load. For in-plane loads, axial compression is assumed to be resisted by both the steel box section and the concrete core, according to their relative stiffness (area times modulus of elasticity). Slenderness effect of the wall in the out-of-plane direction is considered according to ACI 349 [30].

For minimum steel thickness requirements, paragraph 10.14.6.1 of the ACI 349 Code [30] is satisfied. This paragraph applies to composite members with a concrete core encased by structural steel. The steel section that is considered in the composite section is determined using an effective width based on the postbuckling

$$
3-4
$$


strength of a plate. The plate is assumed simply supported with an unbraced length of the face plates equal to the span length between the embedded horizontal angles. The spacing of the horizontal stiffening angles is 18 inches. Figure 3.18 shows the effective width $b_{e}$ for the face plate and Figure 3.19 shows the postbuckling behavior of the plate.

Axial tension is assumed to be resisted only by the steel section. In-plane shear forces are assumed to be resisted only by the steel face plates parallel to the direction of shear force.

For out-of-plane loads, shear forces perpendicular to the plane of the wall are assumed to be resisted by the steel diaphragm plates. The steel diaphragm plates are parallel to this shear load.

Moments about the horizontal axis in the plane of the wall are assumed to be resisted only by the steel section. The face plates are treated as flanges and the diaphragm is treated as the web. The effective width of the compression flange is calculated in the same manner as described above for axial compression. In general, the walls are designed to span in the vertical direction. The moments about the vertical axis are assumed secondary.

The allowable stresses for each load combination are as set forth in Table 3.1 , and are based on the allowable stress limit coefficients per AISC N690 [29]. However, for critical locations in the face plates, an additional stress evaluation is performed to combine normal and shear stresses. This evaluation is based on the maximum distortion energy theory. By treating the face plates as a two-dimensional stress condition (out-of-plane shear stress is neglected), the stress condition at yield can be expressed as:

$$
\sigma^{2}+3 \tau^{2}=\left(\sigma_{y p}\right)^{2}
$$

For design of the structural modules the following allowable stresses are considered:

Normal condition

$$
\begin{aligned}
& \sigma^{2}+3 \tau^{2} \leq\left(0.6 \sigma_{y p}\right)^{2} \\
& \sigma^{2}+3 \tau^{2} \leq\left(0.6 \sigma_{y p}\right)^{2} \\
& \sigma^{2}+3 \tau^{2} \leq\left(0.96 \sigma_{y p}\right)^{2}
\end{aligned}
$$$$
\text { Severe condition }
$$

Extreme/abnormal condition

\subsection{2 "I" Module}

Since the I modules are used only as forms, they are designed only for construction loads. The modules are designed to resist wet concrete pressures of $1050 \mathrm{psf}$. Modules extend to the full height of the compartment but the concrete is placed in multiple pours. Forms at the top of each pour are braced back to the concrete of the previous pour. 
The floor modules are designed according to the requirements of section Q1.11 of AISC N690 [15]. For vertical downward loads, the floor modules are designed as a composite section. The composite action is assumed to meet the intent of the requirements of section 01.11 .1 for steel beams totally encased in concrete. The bottom of the steel sections are not encased in the concrete. However, a'steel plate is provided at the bottom of the slab welded to the steel section which provides concrete confinement (Figure 3.9) . The floor modules are designed as a one-way composite beam. The effective width of the concrete slab is based on section Q1.11.1 of AISC N690 [29]. The effective compression area of the concrete extends to the neutral axis of the composite member. The concrete area in the compression zone is transformed to an equivalent steel area by the modular ratio of concrete to steel.

For vertical upward loads, no credit is taken for composite action. only the steel members are relied upon to provide load carrying capability. The concrete and angle stiffeners are assumed to provide stability to the plates.

For in-plane shear loads, resistance is provided by the steel face plate alone.

\subsubsection{Finned Floor Module}

The finned floors are subjected to vertical and in-plane forces. Vertical downward and upward loads are applied to the floors. The floors behave as a one or two-way reinforced concrete slab depending on the length to width ratio of the room.

The finned floors are designed though, as simply-supported one-way reinforced concrete slabs. A one foot wide strip parallel to the vertical stiffeners is used to design the floor in accordance with ACI 349 [30]. Under positive bending moments, the concrete resists compression and the stiffened plate resists tension forces. Under negative bending moments, the stiffened plate resists compression and the reinforcing bars placed in the top level of the concrete resist tension. Horizontal in-plane forces are resisted by the stiffened plate and longitudinal reinforcing bars.

\subsubsection{Other Modules}

No analysis or design method is presented by Westinghouse for the fuel pool and refueling canal liner modules as well as the rebar modules. 


\subsection{Evaluation of Critical Parameters}

\subsubsection{Design strength}

For the Module, the general philosophy is that the steel is designed to carry most loads. This design approach is conservative since in reality the concrete would share in carrying some of these loads. The extent to which the concrete provides added strength though, has not been quantified and is difficult to estimate. The concrete does not have any embedded reinforcement and is not continuous from one wall section to the next due to the diaphragm steel plates. Ioad transfer in shear from the steel plates to the concrete is through horizontal angle stiffeners.

Although the strength of the concrete is not generally relied upon, there are a few instances where the concrete is required to resist certain loads or provide stability. For example, in addition to providing necessary shielding from radiation, the concrete stiffness is utilized in the seismic analysis of the reactor building to determine the loads imposed on the modules. The stiffness consideration of concrete is discussed below in Section 3.3 .3 of this report.

For in-plane loads under axial compression, both the steel. section and concrete are relied upon to resist the applied loads. The applied forces are distributed to the steel and concrete in proportion to their relative stiffness (area times modulus of elasticity). To satisfy minimum steel thickness requirements for the two face plates, paragraph 10.14.6.1 of the ACI 349 Code [30] is utilized. This paragraph applies to composite members with a concrete core encased by structural steel. The effective width of the steel plates is based on the postbuckling strength of the plate. The postbuckling strength of the plate is determined from a plate simply supported with an unbraced length equal to the span length between the embedded horizontal angles (Figures 3.18 and 3.19). The concrete is required to provide stability for the horizontal stiffeners.

This approach for the postbuckling strength of a plate assumes that the total load is carried by strips adjacent to the supported edges which are at a uniform stress equal to the maximum edge stress $f_{e}$ in Figure 3.19. These strips are indicated by dashed lines in Figure 3.19 (b) and by solid lines in Figure 3.19 (c). one concern that arises with this entire approach is that when the center strip of plate buckles, more of the load shifts to the concrete core rather than to the edges of the face plates. However, the design assumes that the compressive loads are distributed in proportion to the stiffness of the concrete and steel before buckling occurs. The transfer of loads from the buckled plates would result in higher compressive stresses in the concrete. How this may affect the concrete design needs to be evaluated. 
Another concern arises with the interaction effect of in-plane shear loads and compressive loads on the steel plates. All inplane shear loads are carried by the steel plates. The simultaneous application of shear loads with compressive loads will affect the postbuckling strength of the steel face plates. This may result in a narrower effective width $b_{e}$. Therefore, the interaction effect of shear and compression should be investigated further.

In utilizing the postbuckling strength of plates, another question arises in the selection of the $\mathrm{K}$ factor for determining the effective length of the steel plates between stiffeners. The design utilizes a value of 0.65 when the plate is continuous. This design value corresponds to a fixed-fixed end condition for a column. However, based on compressive tests on concrete filled steel bearing walls [20], the best agreement between calculated and test data was reached for an end condition of a fixed-pinned column. This end condition corresponds to a recommended $\mathrm{K}$ factor of 0.80 for design. Since the buckling load is proportional to $\mathrm{K}$ squared, this difference in $K$ becomes more significant. Thus, if the postbuckling strength of plates is utilized in the design of structural modules, the use of an appropriate $K$ factor needs to be reviewed in greater detail.

For the $I$ modules the issue of strength only applies to construction loads because these modules are used only as forms. once the concrete hardens, the strength of the steel forms is not required nor relied upon. The steel modules are designed for concrete pressure of 1,050 psf.

Composite floors consisting of steel beams or girders supporting reinforced concrete slabs have been used extensively in all types of commercial, industrial, and residential buildings with success. Provided the design follows existing design practices, the composite floor modules are expected to have sufficient strength and will perform their intended function. However, any deviations from currently accepted codes should be identified and reviewed in greater detail.

The analysis and design of the structural modules is performed in accordance with particular sections of the AISC N690 Specification [29], ACI 349 Code [30] and the ASCE Standard 4-86 [31]. In some instances interpretations and assumptions are made in applying the requirements contained in these documents. In the case of AISC N690, Section $Q 1.11$ does address composite construction. However, it only covers composite construction of steel beams or girders supporting a reinforced concrete slab. It does not address composite construction of bearing and shear wall structural elements. For critical locations in the face plate, Westinghouse performs an additional stress evaluation to combine normal and shear stresses. This evaluation is based on the maximum distortion energy theory. For design purposes, Westinghouse

$$
3-8
$$


developed a set of allowable stresses corresponding to three load combinations; normal, severe, and extreme/abnormal. Based on the above examples, it is evident that there is no single code or standard which provides all of the necessary requirements for the analysis and design of composite steel/concrete structural modules.

The development of a standard for structural modules would be very beneficial. While it need not duplicate the requirements, equations or specifications contained in other documents, it should provide guidance on various aspects that are unique to modular construction. Topics should include analysis, design, fabrication, erection, storage, handling, inspection, and QA/QC. Where existing information on these subjects are available in other documents and are applicable to structural modules, they could be referenced. Where interpretations or new criteria are needed, they should be specified in the new standard.

A related issue that still needs to be resolved is the reliance by Westinghouse on criteria documents that have not been approved as yet by the NRC. In particular, AISC N690 [29] has not been formally approved. In addition, the ASCE Standard 4-86 [31] has not been endorsed by the NRC staff. These criteria documents should be reviewed for acceptance in the analysis and design of advanced light water reactors.

\subsubsection{Ductility}

Ductility of concrete and steel in conventional design vary depending on the type of load and whether reinforcement is present in the concrete. Reinforced concrete and structural steel in flexure possess substantial ductility. In the case of the $M$ module, there is no steel reinforcement embedded in the concrete. This should not be a concern since the concrete is not relied upon to take flexural loads. The steel face plates are designed to resist all bending moments.

In compression, both reinforced concrete and structural steel typically exhibit very little ductility. The $M$ module relies on the concrete and steel to resist compressive loads. For the steel face plates, postbuckling strength is needed to resist the applied loads.

For shear loads carried by concrete alone, the ductility is also very low. A low value of ductility exists because when concrete fails in shear, it is quite brittle. When steel stirrups are present, the ductility ratio increases. The $M$ modules do not rely on the concrete to resist shear loads for design purposes. The steel face plates are designed to resist in-plane shear loads. However, as discussed in Section 3.3.3, the stiffness provided by concrete in shear is utilized in the seismic analysis. 
The determination of the actual ductility of structural modules which combine unreinforced concrete and steel plates, becomes very complex. Thus, the results of test data should be reviewed to determine the ductility present for the specific configurations.

Several tests have been performed in Japan on composite steel/concrete structures. These are described in section 2.3 of this report. One test [20] applied compression and shear loads to concrete filled steel bearing walls. The steel plates were attached to the concrete using stud bolts. While the loaddisplacement plots in the report demonstrate ductile behavior, an estimate of the ductility ratios are difficult to determine from the limited data contained in the report. In addition, the method of attachment of the steel plates using studs is different than the angle stiffeners used in the $M$ modules.

Another test [19] was performed in Japan on a 1/10th scale model of an inner concrete structure composed of concrete filled steel bearing walls. This test was performed on both a composite steel and concrete configuration and an equivalent reinforced concrete structure. Repetitive positive and negative loads were applied at the upper and lower slabs while the base was fixed. A review of the load deflection curve demonstrates that the composite. structure does have substantial ductility. A comparison of the curves for the composite structure with those of the reinforced concrete structure suggests that the composite structures is even more ductile than the reinforced concrete structure. However, it should be noted that the configuration of the composite structure. in this test is different than the $M$ modules. The test specimen utilizes studs to join the steel plates and concrete, and shear bars to connect both face plates. This is quite different from the $M$ module configuration.

To obtain a better estimate of the expected ductility of the structural modules, a further review of the existing information should be obtained from Japan to the extent possible, and/or a simple test program could be implemented. such a test program could develop appropriate ductility ratios for the specific configurations and could be used to address some of the other issues and parameters raised in this report.

\subsubsection{Stiffness and Stiffness Degradation}

The stiffness of the $M$ module is determined based on the contribution of stiffness from the gross area of concrete and steel. This stiffness is used in developing the finite element model shown in Figure 3.15. This model is used to perform a response spectrum analysis to obtain the in-plane SSE loads. other forces are obtained by performing manual calculations. 
Since the concrete is unreinforced, the method used to determine the contribution of stiffness from concrete needs to be examined further. In compression, for example, tests [19] indicate that the inittal actual stiffness is approximately $80 \%$ of the calculated stiffness. This implies that the compressive stiffness based on the gross area of concrete may overpredict the actual concrete stiffness.

In shear, since there is no reinforcement, the ability of concrete to resist shear depends on many factors. These include the load path, concrete quality, consolidation, development of cracks, degree of concrete shrinkage and confinement, effectiveness of the horizontal angle stiffeners, temperature, aging, etc. The load path is a concern because if the load transfer from the floors to the concrete wall is not uniformly transmitted, then the entire concrete cannot be considered effective in providing stiffness. In the case of the $M$ modules horizontal floor loads must be transmitted to the face plates, then to the angle stiffeners and diaphragm plates, and then to the concrete. For vertical loads this concern is more obvious because loads are transmitted only at discrete locations from the wall to the base mat.

Another question that arises is the effect of stiffness degradation. Based on tests [19], stiffness degradation does occur and is approximately equal to a $30 \%$ reduction of the stiffness at the elastic condition (at SSE load levels). While this reduction seems large, it is less of a reduction than for a reinforced concrete configuration. Once again, there are a number of differences in these test specimens compared to the M modules as noted earlier.

\subsubsection{Reliability of Joints and Connections}

Typically, in modular construction the connection between structural modules has always been a concern. In the presentation made by Westinghouse to the NRC on 2/10/93, Westinghouse stated that the structural modules would be joined using full butt welds. Therefore, the welded connections should be as strong as the steel face plates. If there are other connections which do not develop the full strength of the joined modules, then careful consideration should be given to the analysis of the structure and to design of these connections.

\subsubsection{Damping Values}

In the presentation made by westinghouse to the NRC on $2 / 10 / 93$, Westinghouse stated that a damping value of $7 \%$ was used in the seismic analysis of the structural modules. Current NRC requirements for damping are specified in the NRC Regulatory Guide 1.61, "Damping Values for Seismic Design of Nuclear Power Plants," October 1973. The specified damping values under the SSE loads are 
$4 \%$ for welded steel structures and $7 \%$ for reinforced concrete structures.

The structural modules are a hybrid of welded steel and unreinforced concrete. Thus, an appropriate damping value for design should be somewhere between 4 and 7 percent. Based on the 1/10th scale model test [19], a damping value of 5\% was determined for the stress levels being considered. Therefore, Westinghouse would need to justify their use of $7 \%$ damping or additional testing could be performed. Without further justification, a damping value higher than 4 or 5 percent should not be used.

3.3.6 QA/QC for Design, Construction, and Transportation

To obtain the full benefits of modular construction, quality assurance (QA) and Quality control (QC) must play an important role. $\mathrm{QA} / \mathrm{QC}$ in some respects is even more important in modular construction than in conventional site fabricated structures. To a large extent most of the engineering and design must be completed before construction at the site begins. Modules may be mass produced so any error or deficiency would be repeated for all modules. Changes to suit site as-built conditions are more difficult to make because the modules are already fabricated. In addition, closer tolerances are required in order to properly join and fit modules at the site.

In addition to the conventional $\mathrm{QA} / \mathrm{QC}$ requirements for nuclear power plants, additional concerns that are unique to modular construction need to be addressed. Some of the additional areas to be addressed include the constructability of the pre-engineered design, in-process inspection, tests, and hold points for inspection of the modules during the fabrication process; and the requirements related to the transportation, handling, storage, assembly, and erection of large modules. Information describing how these items will be addressed for modules in the AP600 plant was not provided. Guidance for these items could be given in a standard developed for structural modules as discussed in section 3.3 .1 .

\subsection{Overall Conclusions and Issues}

Based on the above evaluation of the Westinghouse AP600 approach to modular construction, it appears that the potential benefits can be achieved if the design is well planned and executed.

The general philosophy to primarily rely on the steel plates to carry most loads is a conservative approach. In many ways the use of composite steel and concrete appears to result in a better design as compared to conventional reinforced concrete structures. Tests suggest that the ductility and ultimate strength are higher for composite structural elements than for reinforced concrete

$$
3-12
$$


elements. In addition, stiffness degradation appears to be lower for composite structural elements than for reinforced concrete elements.

After reviewing the AP600 modularization concept, a number of issues were identified which should be addressed. Some of the issues could be resolved by further review, some by additional tests, and some may require justification or additional information from Westinghouse. These issues are described below:

1. The postbuckling strength of plates is relied upon in the design of the structural modules to determine the effective width of the steel plates. When the center strip of plate buckles, more of the load shifts to the concrete rather than to the edges of the face plates. However, the design may not include this additional compressive load since compressive loads were assumed to be distributed in proportion to the stiffness of the concrete and steel before buckling occurs.

2. The simultaneous application of shear loads with compressive loads will affect the postbuckling strength of the steel face plates. This interaction effect of shear and compression should be investigated further.

3. The appropriate $\mathrm{K}$ factor for determining the effective length of the steel plates between stiffeners when using the postbuckling approach needs to be reviewed in greater detail.

4. There is no single code or standard that provides all of the necessary requirements for the analysis and design of composite steel/concrete structural modules. The development of a standard for structural modules to provide guidance on various aspects that are unique to modular construction could assist in addressing this concern.

5. AISC N690 [29] and the ASCE Standard 4-86 [31], which are used for analysis and design of the structural modules, have not been approved by the NRC.

6. While tests were performed in Japan for somewhat different composite structural modules, more information and/or testing for the AP600 modules should be pursued in the area of ductility, ultimate capacity, stiffness and stiffness degradation and damping.

7. A damping of $7 \%$ is used for the seismic analysis of the structural modules. NRC Regulatory Guide 1.61 recommends a damping value of $4 \%$ for welded steel and $7 \%$ for reinforced concrete. One test performed in Japan 
suggests damping is approximately 5\%. . Thus, justification would need to be developed for the use of damping values higher than 4 or $5 \%$.

8. Information regarding $Q A / Q C$, fabrication, transportation, handling, storage, assembly, and erection of structural modules is lacking. Requirements and guidance for these items could be specified in the standard proposed above in issue number four. 


\section{Load Combination and Factors}

Combination No.

Load description

Dead

Liquid

Live

Earth pressure

Normal reaction

Normal thermal

Wind

SSE

Tomado

Accident pressure

Accident thermal

Accident thermal reactions

Accident pipe reactions

Jet impingement

Pipe impact

Stress Limit(1),(4)

Coefficient $\begin{array}{lllllllll}1 & 2 & 3 & 4 & 5 & 6 & 7 & 8 & 9\end{array}$

$\begin{array}{llllllllll}D & 1.0 & 1.0 & 1.0 & 1.0 & 1.0 & 1.0 & 1.0 & 1.0 & 1.0\end{array}$

$\begin{array}{llllllllll}\text { F } & 1.0 & 1.0 & 1.0 & 1.0 & 1.0 & 1.0 & 1.0 & 1.0 & 1.0\end{array}$

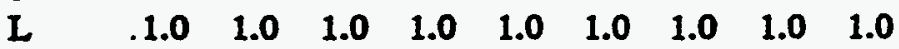

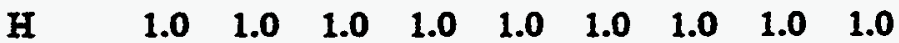

$\begin{array}{llllllll}R_{0} & 1.0 & 1.0 & 1.0 & 1.0 & & 1.0 & 1.0\end{array}$

$\begin{array}{lllll}T_{0} & 1.0 & 1.0 & 1.0 & 1.0\end{array}$

1.0

1.0

$1.0(3)$

1.0

$\begin{array}{lll}1.0 & 1.0 & 1.0\end{array}$

$1.0 \quad 1.0 \quad 1.0$

$\begin{array}{lll}1.0 & 1.0 & 1.0\end{array}$

1.01 .0

1.01 .0

1.01 .0

Notes:

1. Allowable stress limits coefficients are per AISC - N690.

2. Where any load reduces the effects of other loads, the coefficient for that load shall be taken as zero unless it can be demonstrated that the load is always present or occurs simultaneousily with the other loads.

3. Seismic loads will onily be combined with ruptures of pipes that are not seismically supported.

4. In no instance shall the allowable stress exceed $0.7 F_{u}$ in axial tension nor $0.7 F_{u}$ times the ratio of the plestic to elastic section modulus for tension plus bending. 


\section{Load Combination and Factors}

Combination No.

Land description

Dead

Iiquid

Live

Earth

Normal reaction

Normal thermal

Wind

SSE

Tornado

Aceident pressure

Accident thermal

Accident thermil reactions

Accident pipe renctions

Jet impingement

Pipe impact $\begin{array}{llll}1 & 2 & 3 & 4\end{array}$

1.4

1.4

1.4

$1.0 \quad 1.0$

$1.0 \quad 1.0$

1.7

1.4

1.01 .0

1.7

1.7

1.01 .0

1.7

$1.0 \quad 1.0$

$1.0 \quad 1.0$

1.7

1.0

1.0

$\begin{array}{lllll}1.0 & 1.0 & 1.0 & 1.05 & 1.05 \\ 1.0 & 1.0 & 1.0 & 1.05 & 1.05 \\ 1.0 & 1.0 & 1.0 & 1.3 & 1.3 \\ 1.0 & 1.0 & 1.0 & 1.3 & 1.3 \\ & & & 1.3 & 1.3 \\ & & & 1.3 & 1.3 \\ & & & & 1.3\end{array}$

1.0(3)

$\begin{array}{lll}1.5 & 1.25 & 1.0\end{array}$

$\begin{array}{lll}1.0 & 1.0 & 1.0\end{array}$

$1.0 \quad 1.0 \quad 1.0$

$1.0 \quad 1.0$

$1.0 \quad 1.0$

$1.0 \quad 1.0$

\section{Notes:}

1. Dexign is in scoordnnee with ACI-349 Strength Design Method for all load combinations.

2. Where any load-reduces the effeets of other loads, the corresponding coefficient for that load shall be triken as 0.9 if it can be demonstrated that the lond is always present or oceurs simultoneously with the other loads. Otherwise the coefficieat for the load shall be taken as zero.

3. Seismic loads will only be combined with ruptures of pipes that are not seismically supported. 


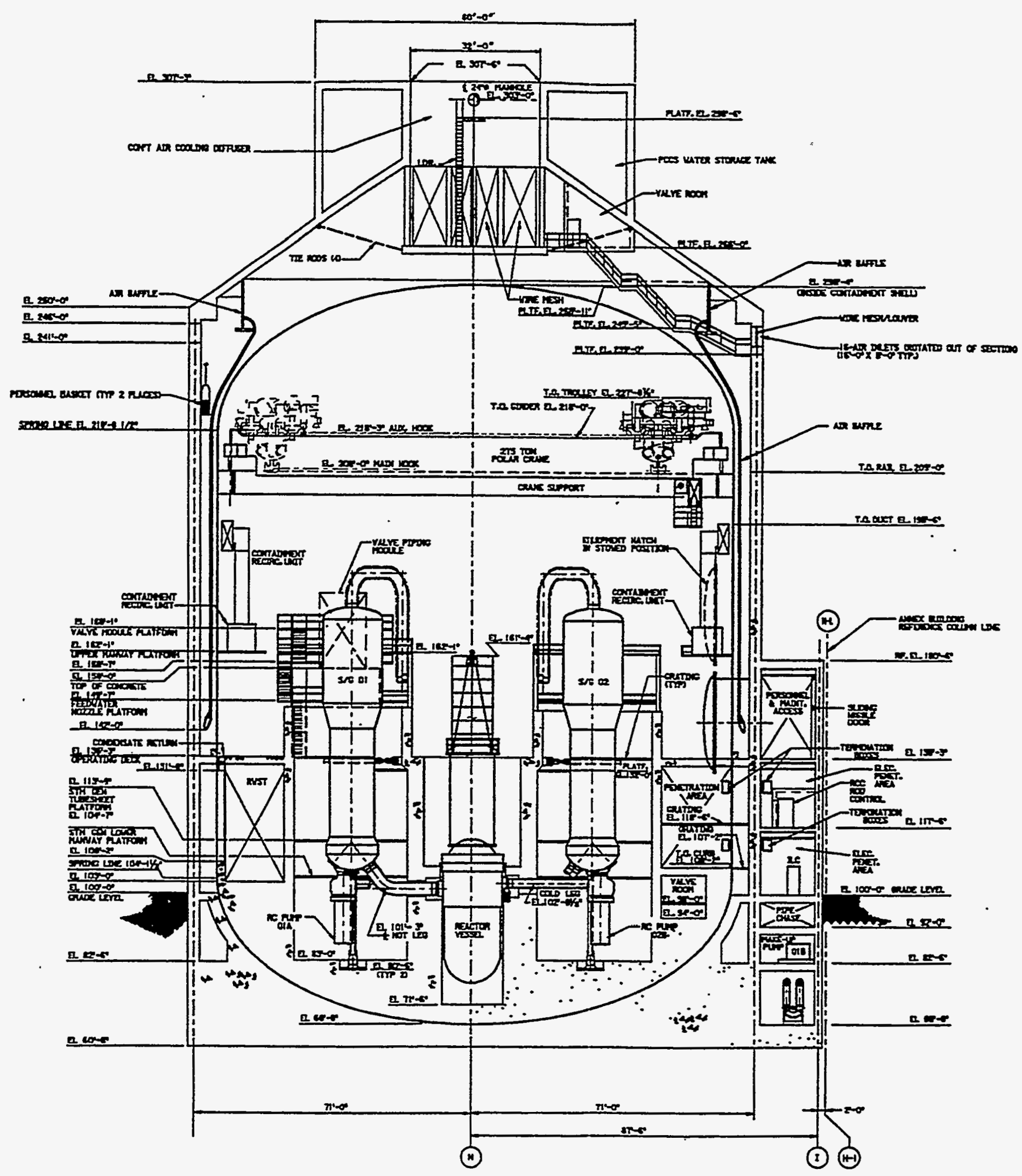

Figure 3.1 Elevation View of Containment [23] 


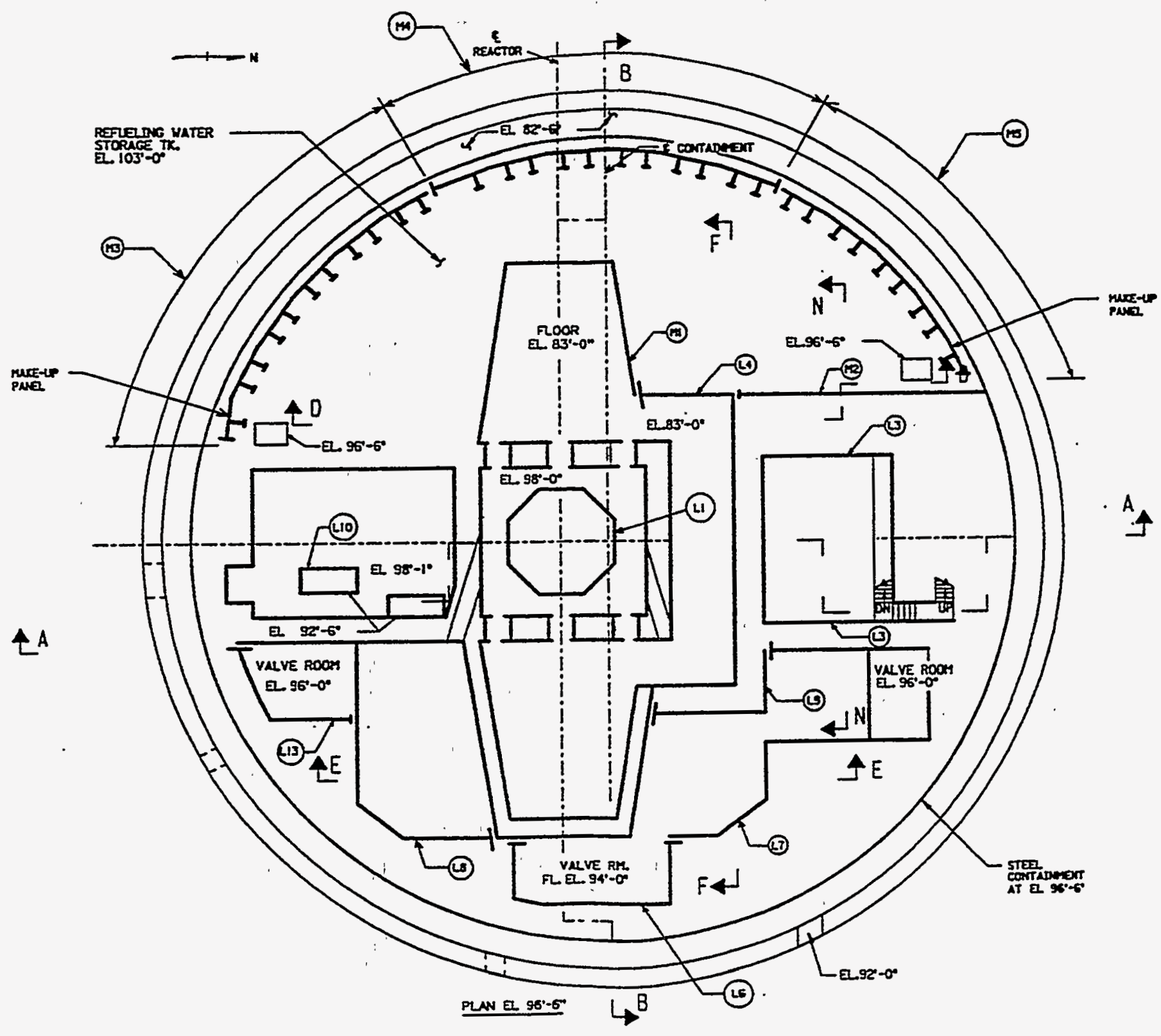

Figure 3.2 Structural Module Locations [23] 


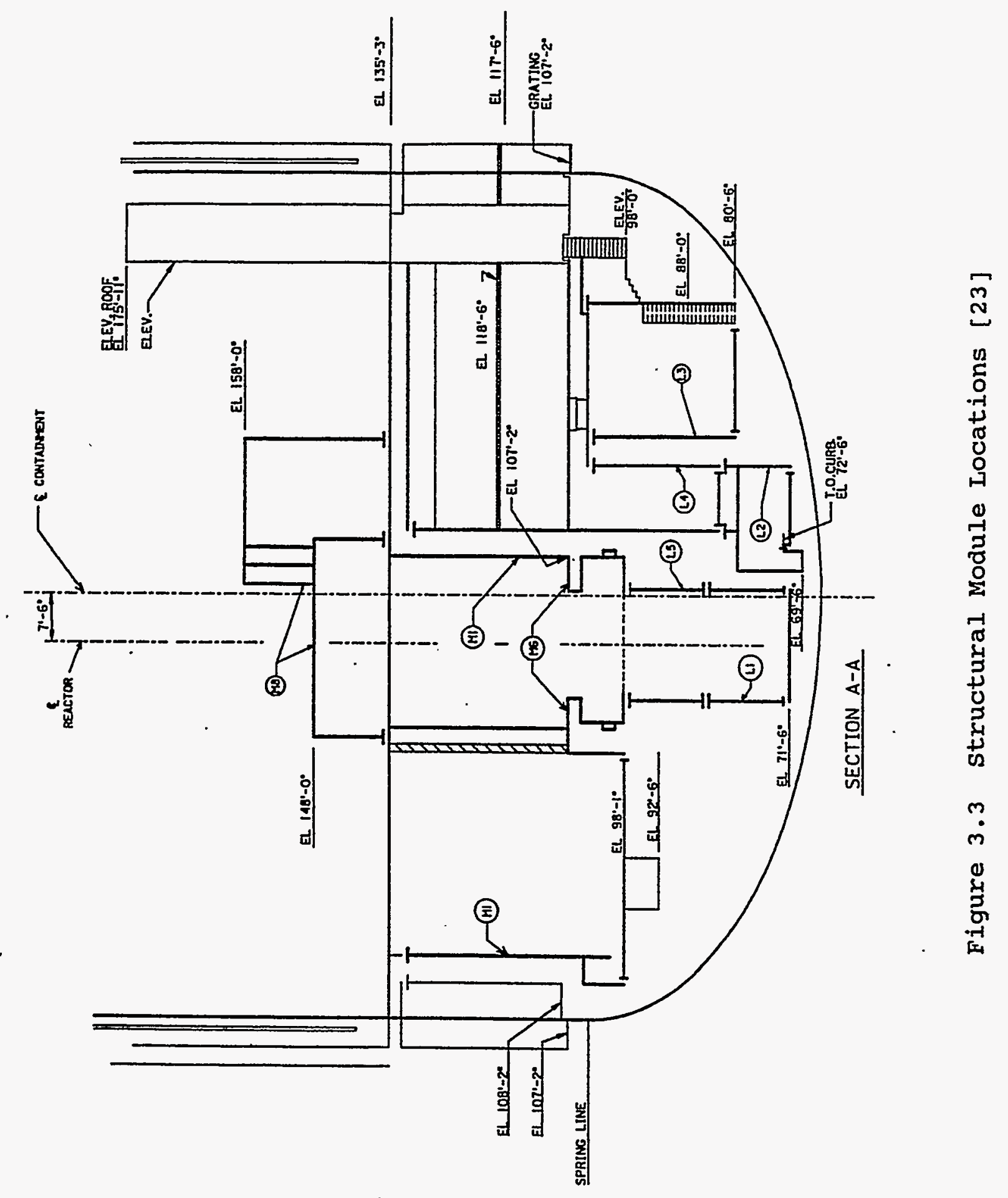




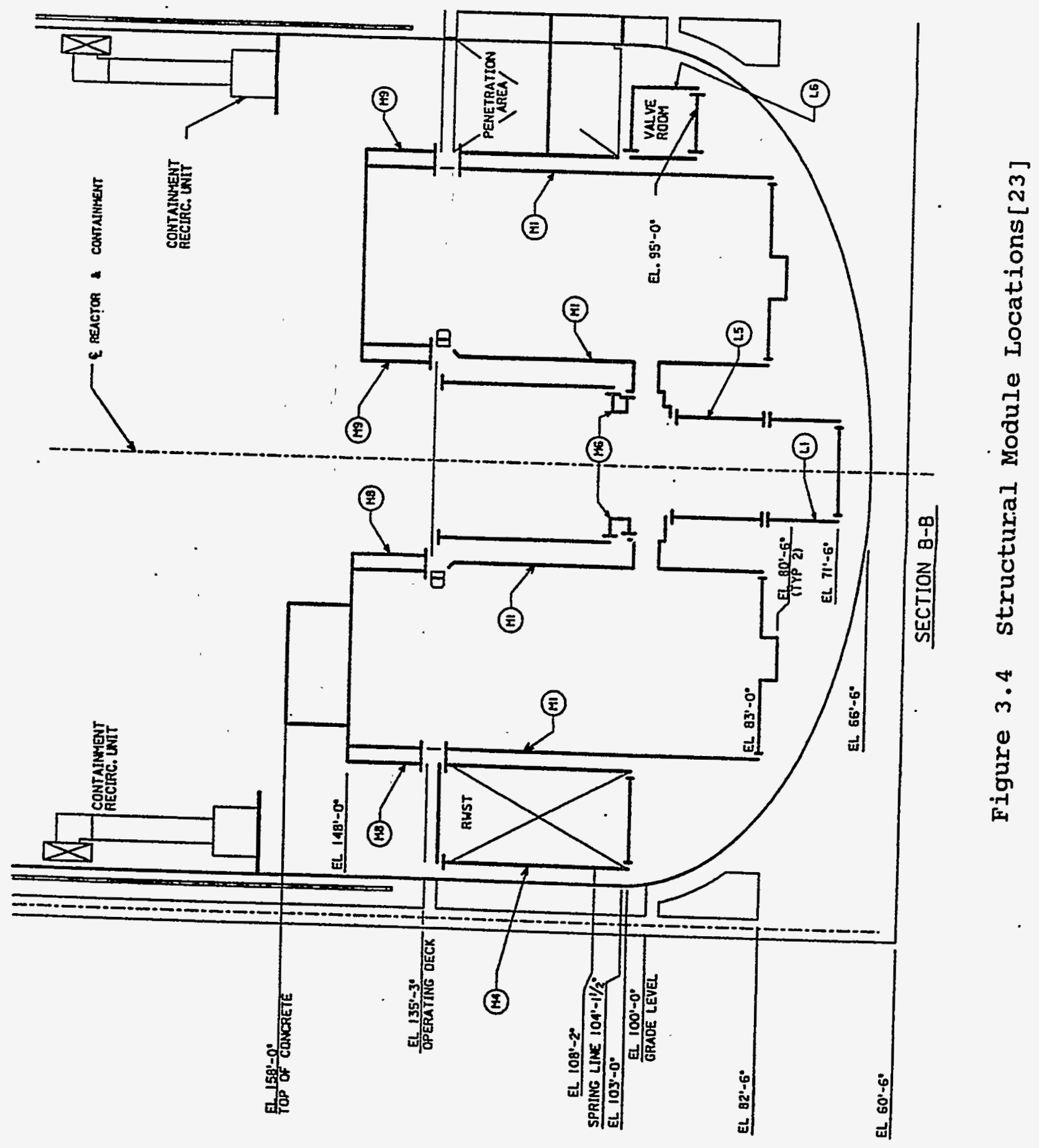




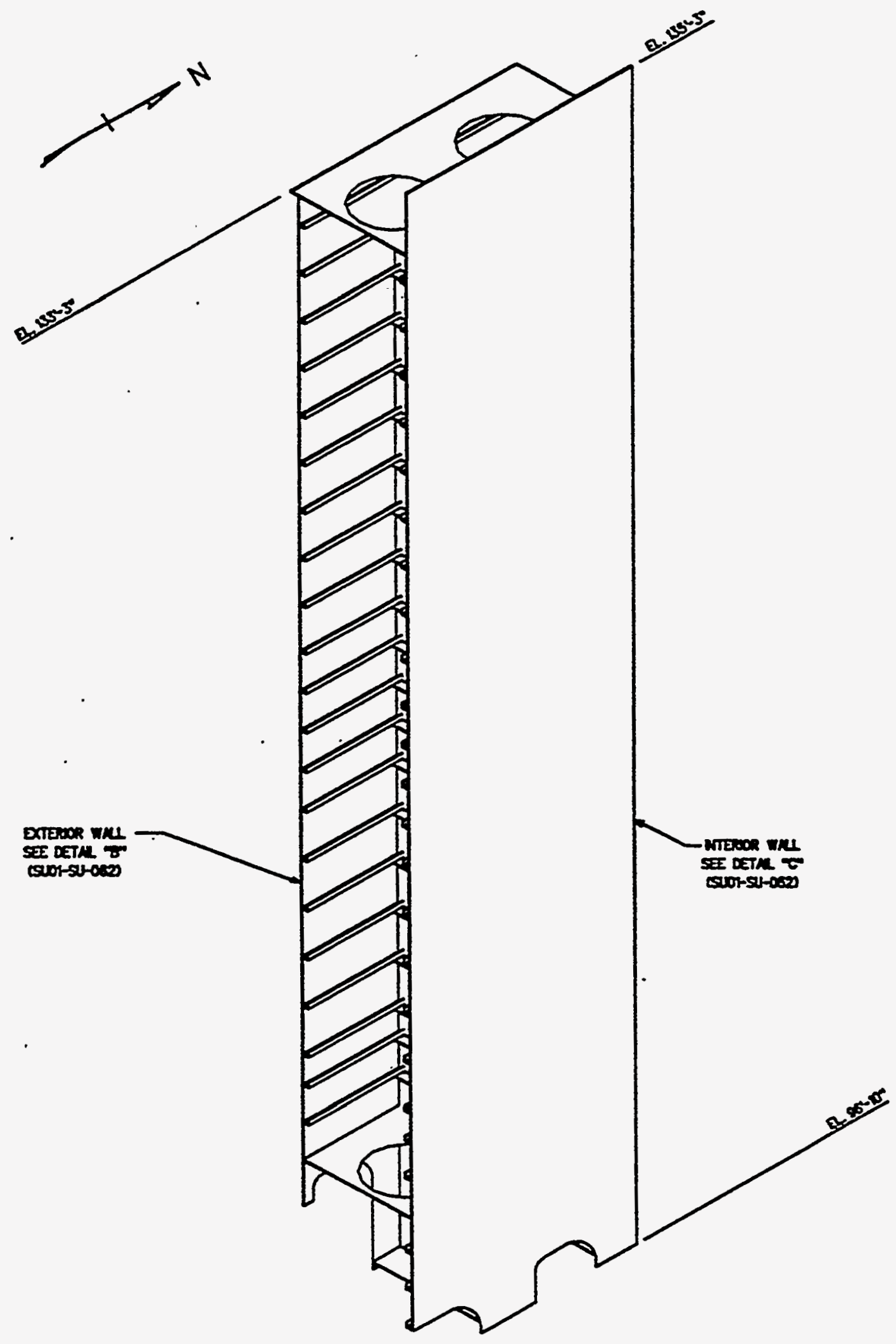

Figure 3.5 M-1 Typical Modular subunit [23] 

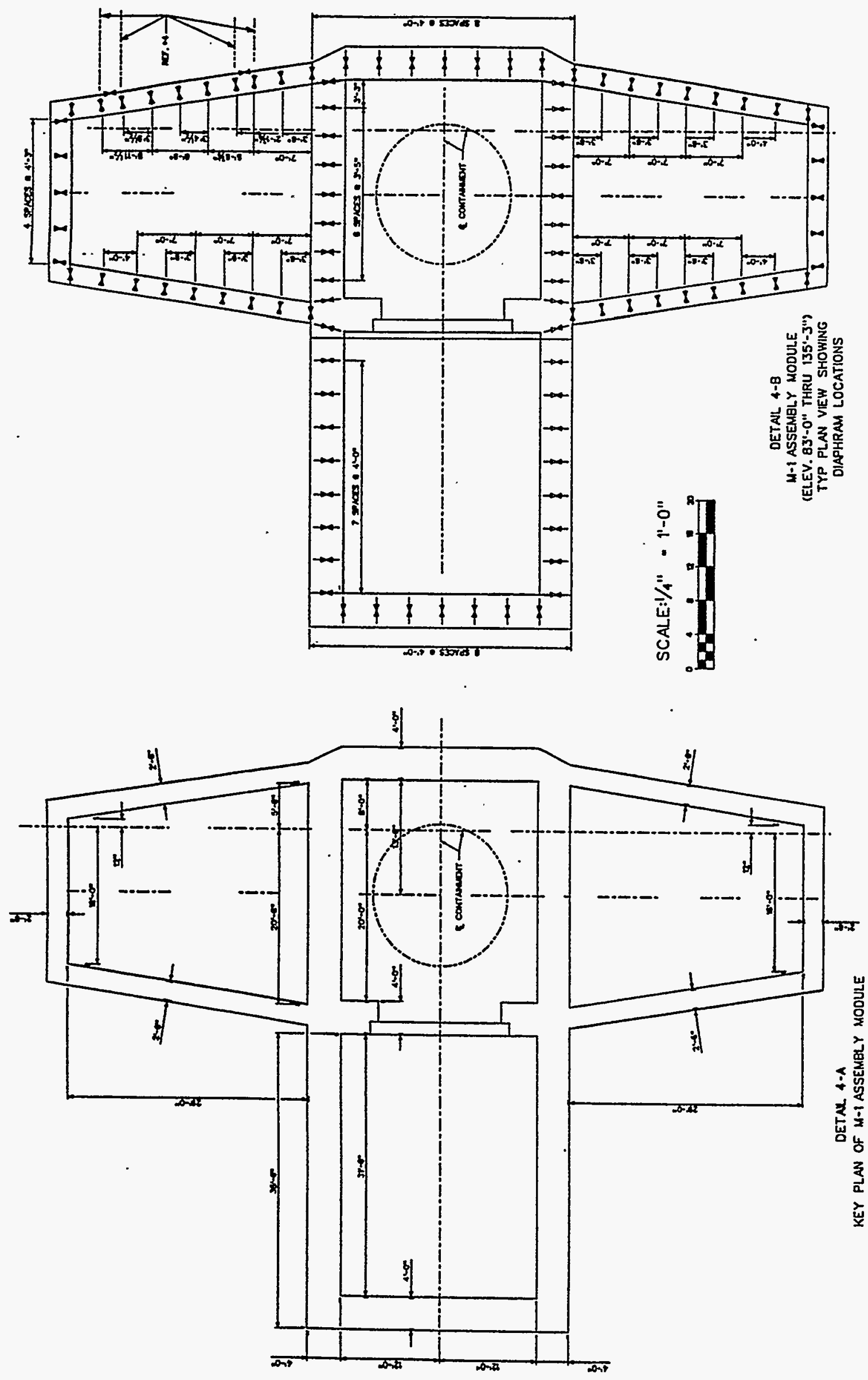

年 


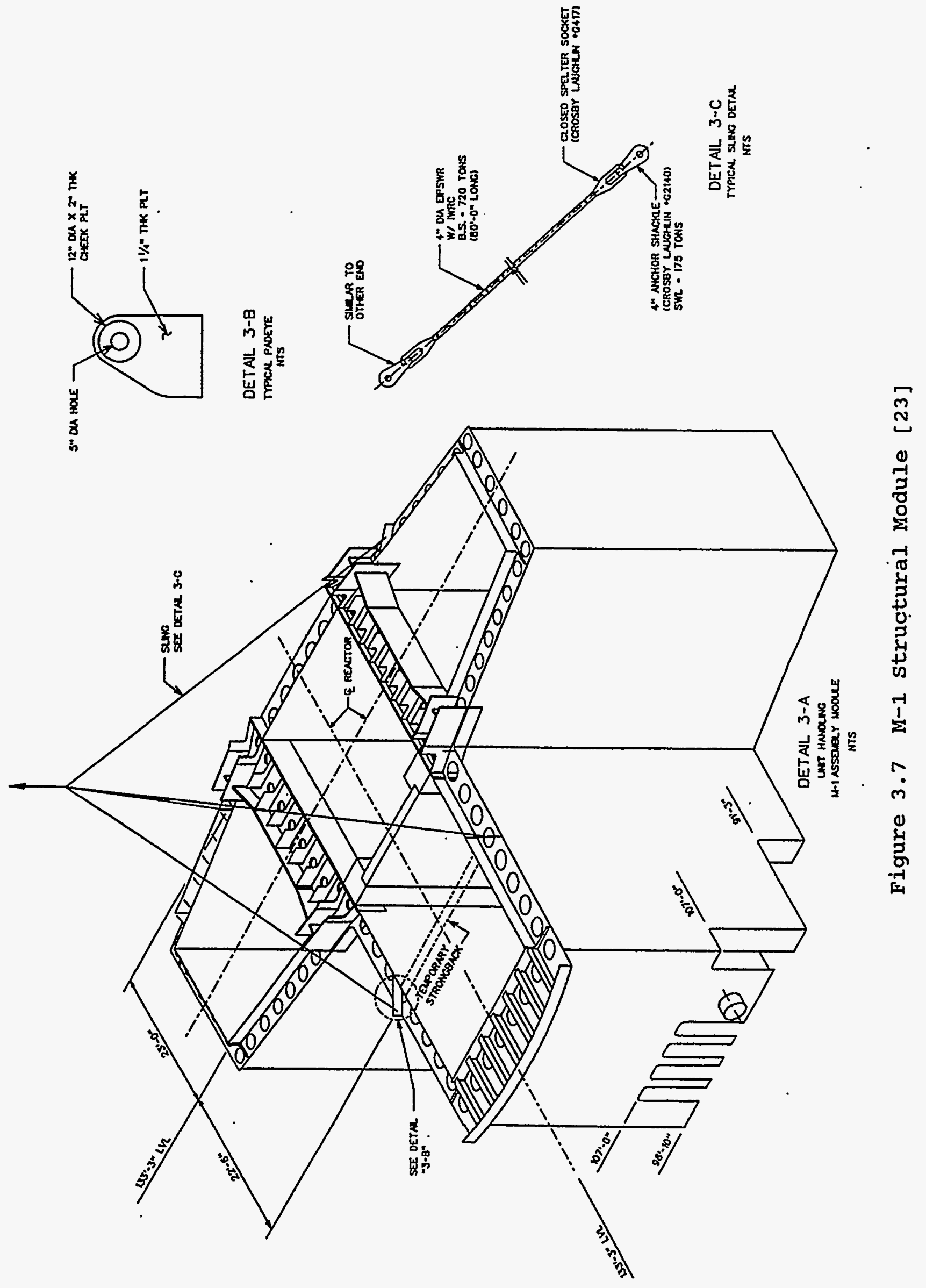




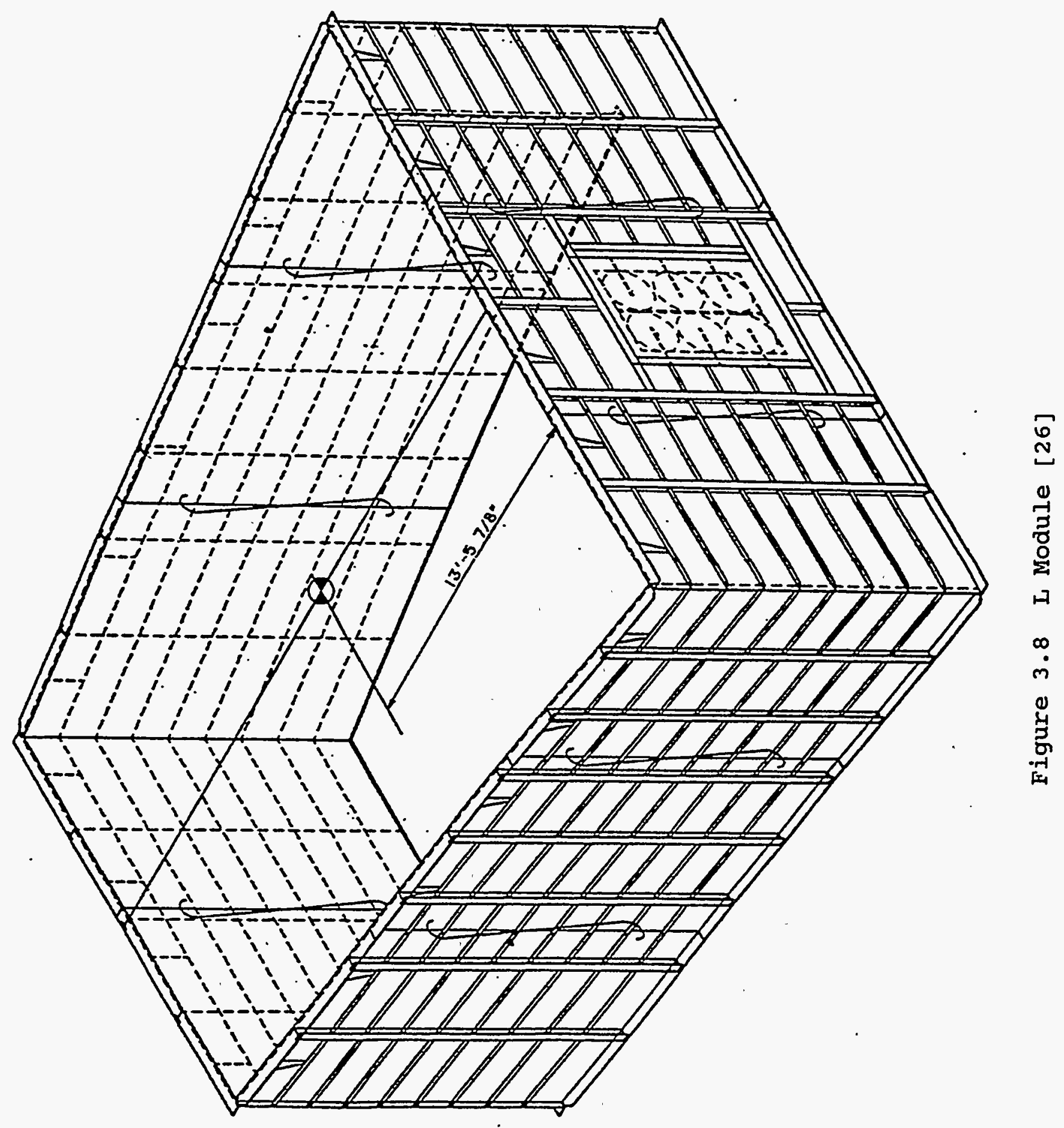




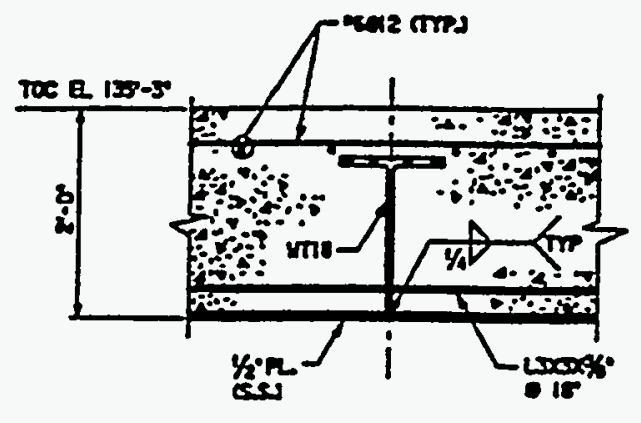

SECTION A

1150-ss-00
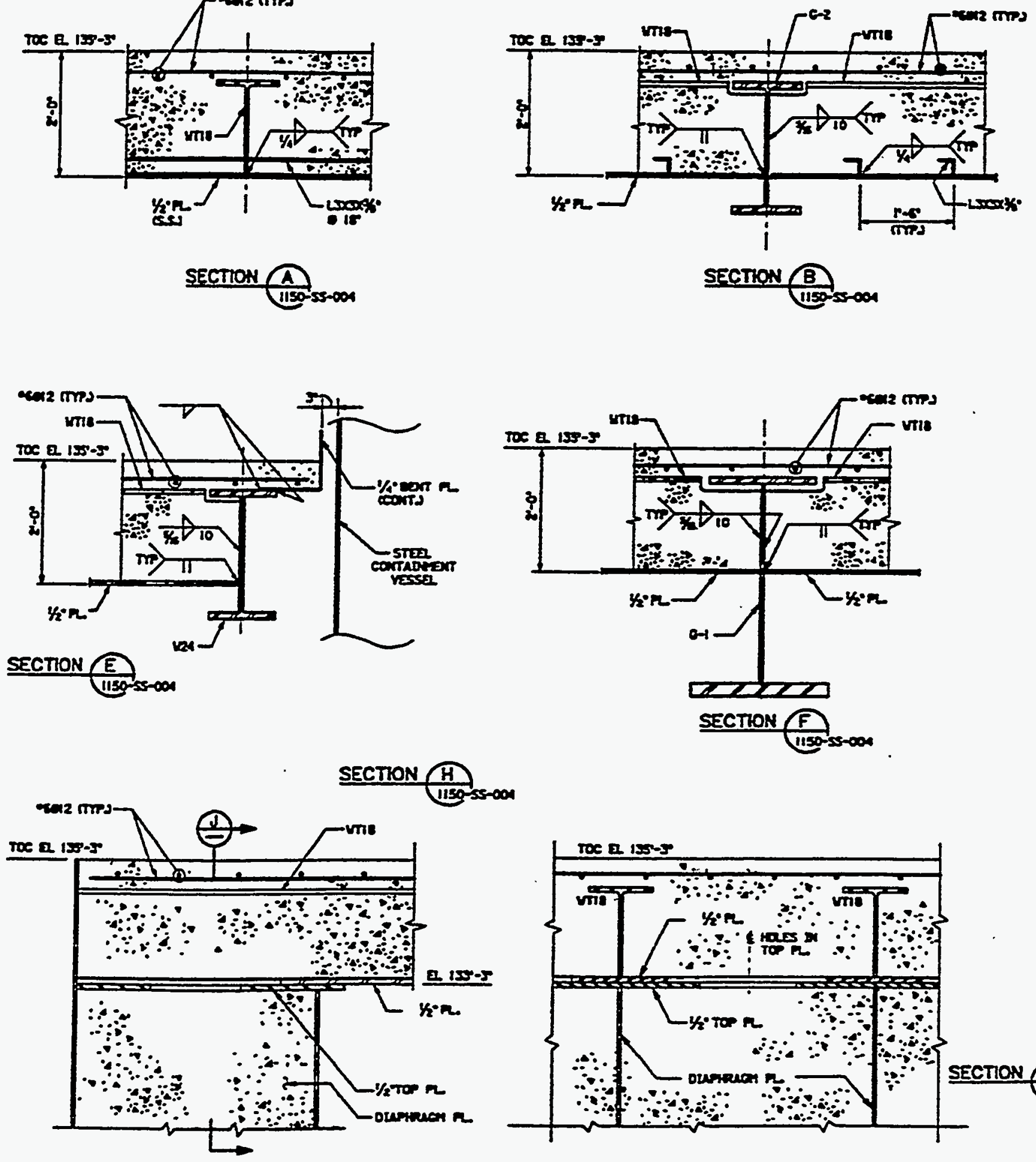

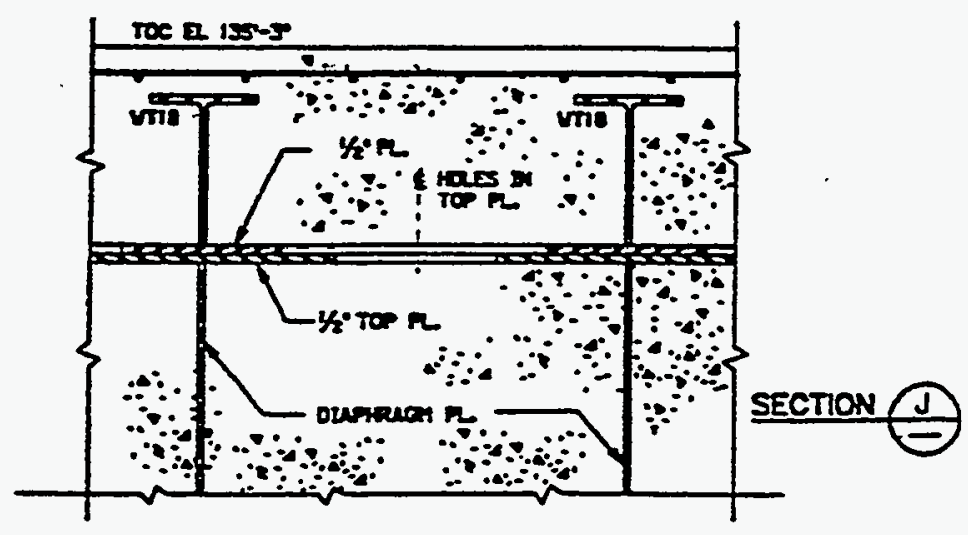

Figure 3.9 Floor Module Details [23] 

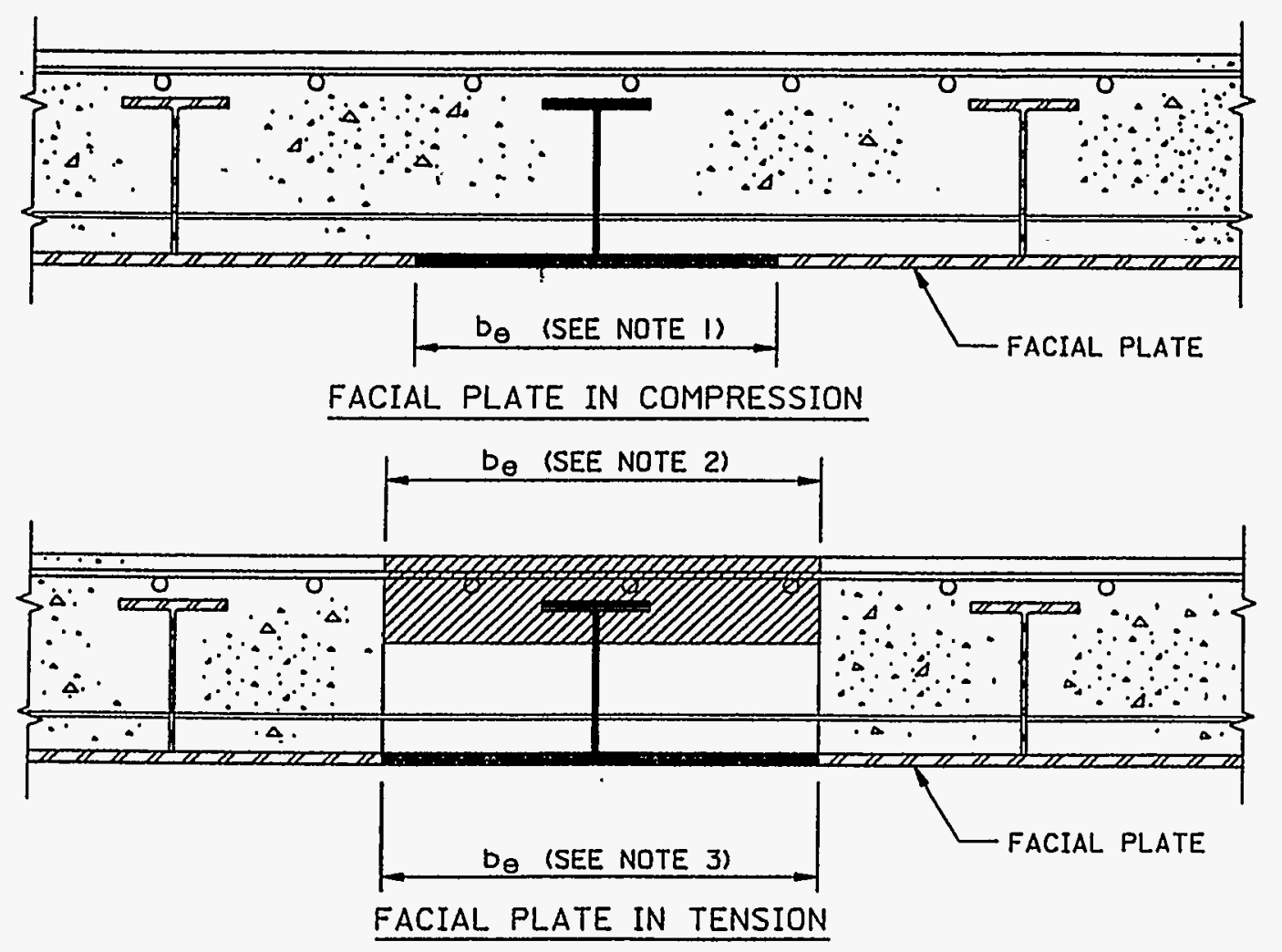

\section{NOTES:}

1. FOR FACIAL PLATE IN COMPRESSION, b $b_{\theta}$ IS DETERMINED PER SECTION 3A.5.

2. EFFECTIVE WIDTH OF CONCRETE, $b_{\ominus}$, IS DETERMINED PER SECTION Q 1.II.I OF AISC N69O.

3. FOR FACIAL PLATE IN TENSION, $b_{\theta}$, IS TAKEN TO BE ONE HALF OF THE DISTANCE TO THE ADJACENT BEAMS. 


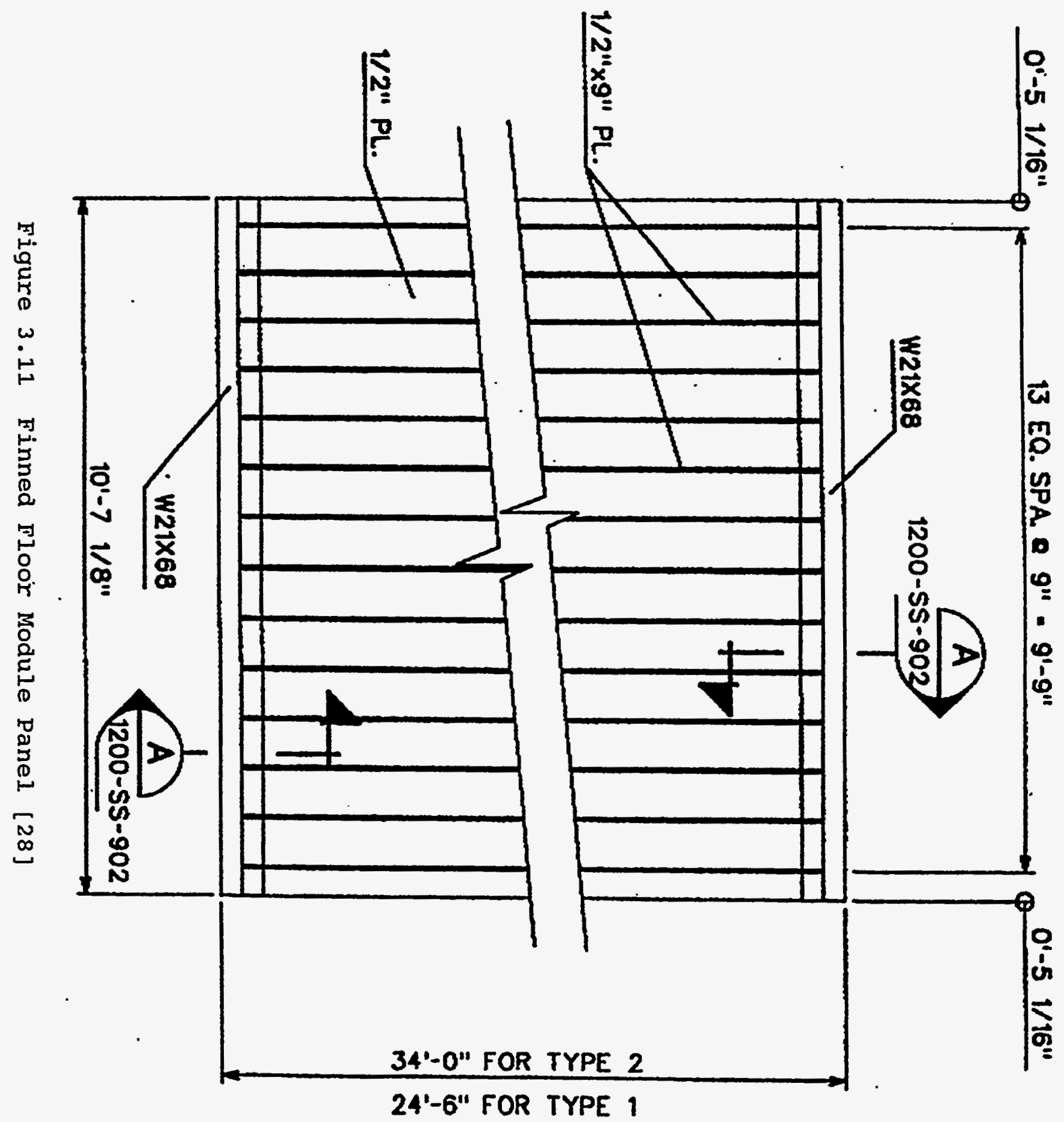




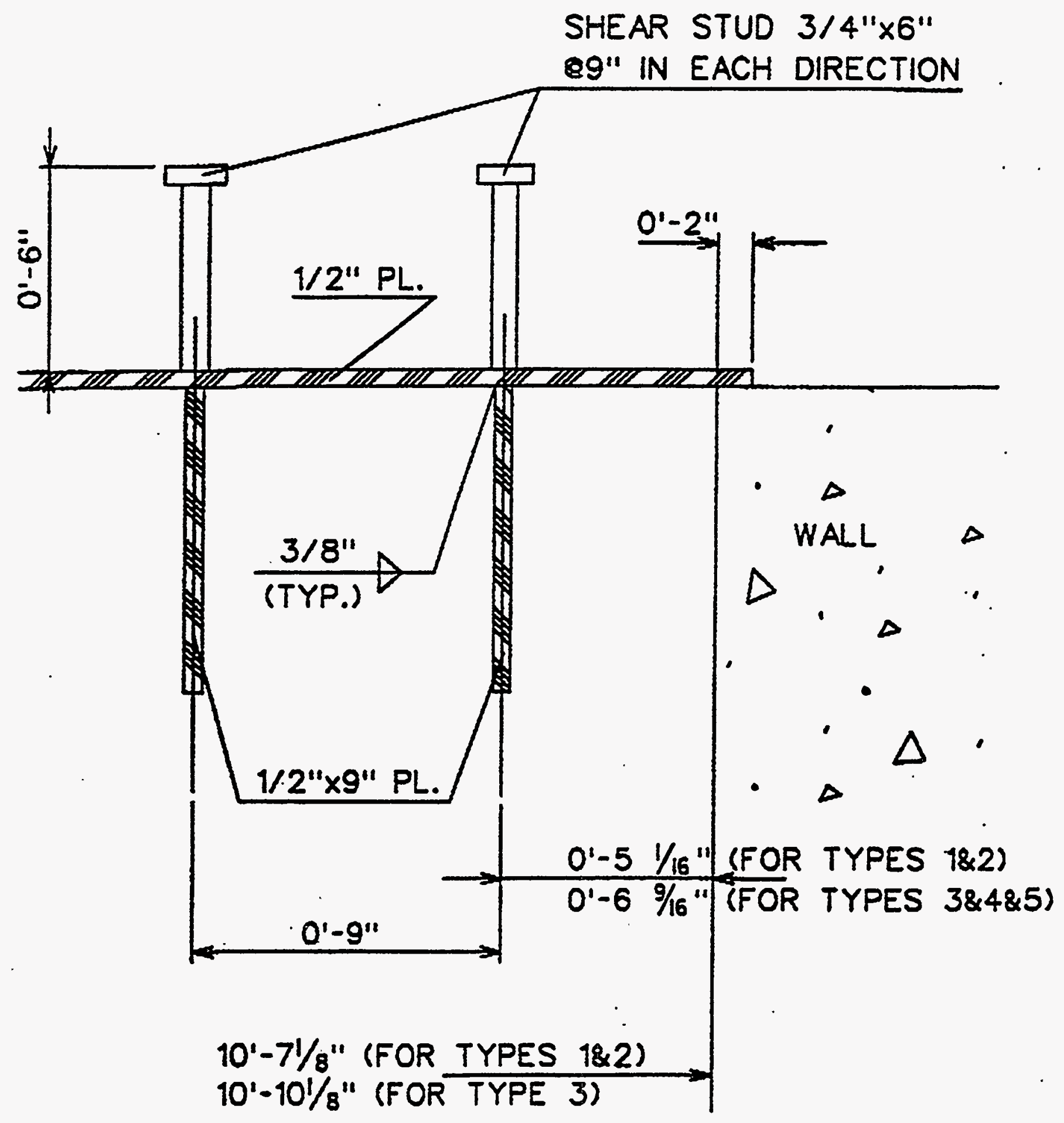

Figure 3.12 Finned Floor Module Detail [28]. 


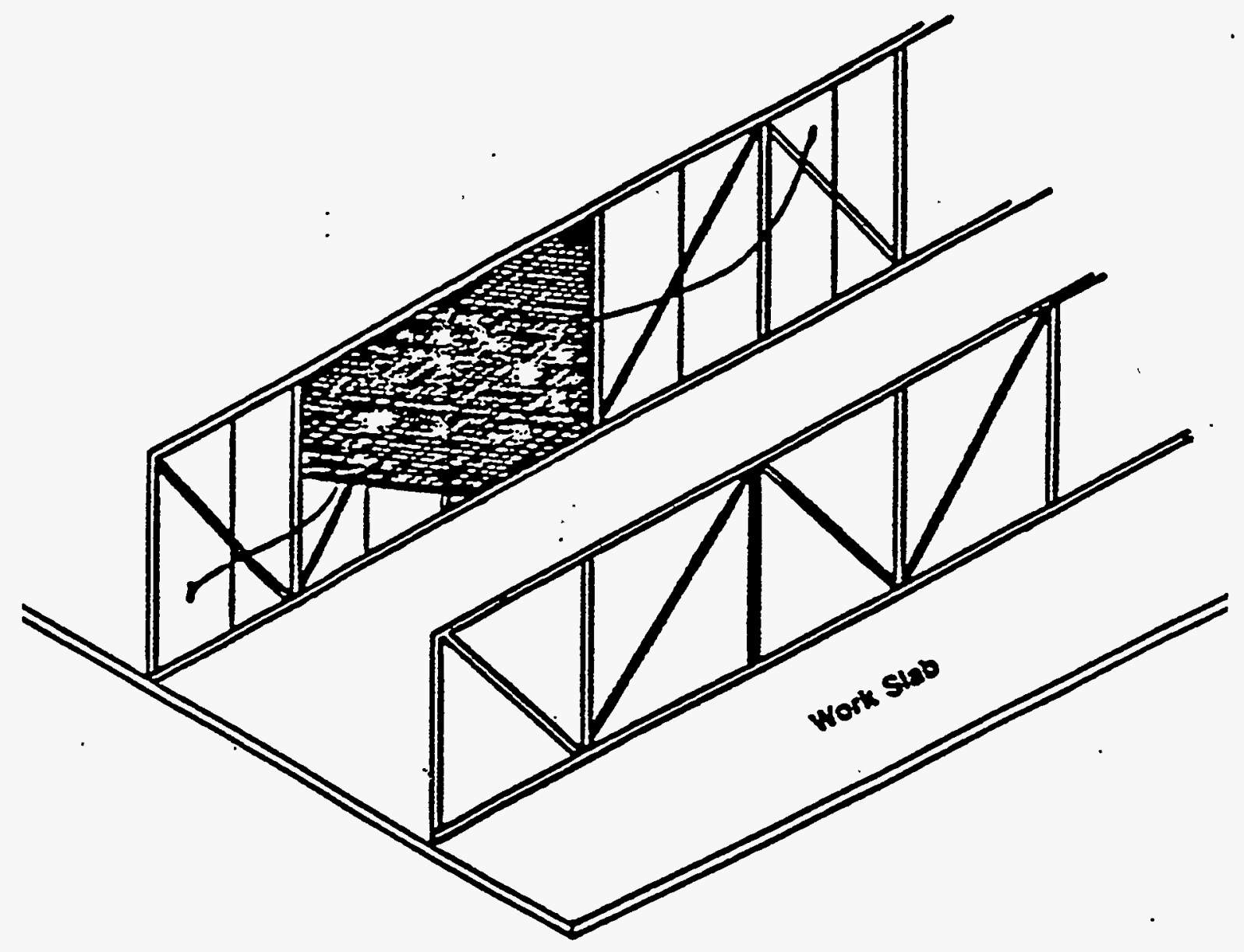

Figure 3.13 Typical Basemat Rebar Support Frame [24] 


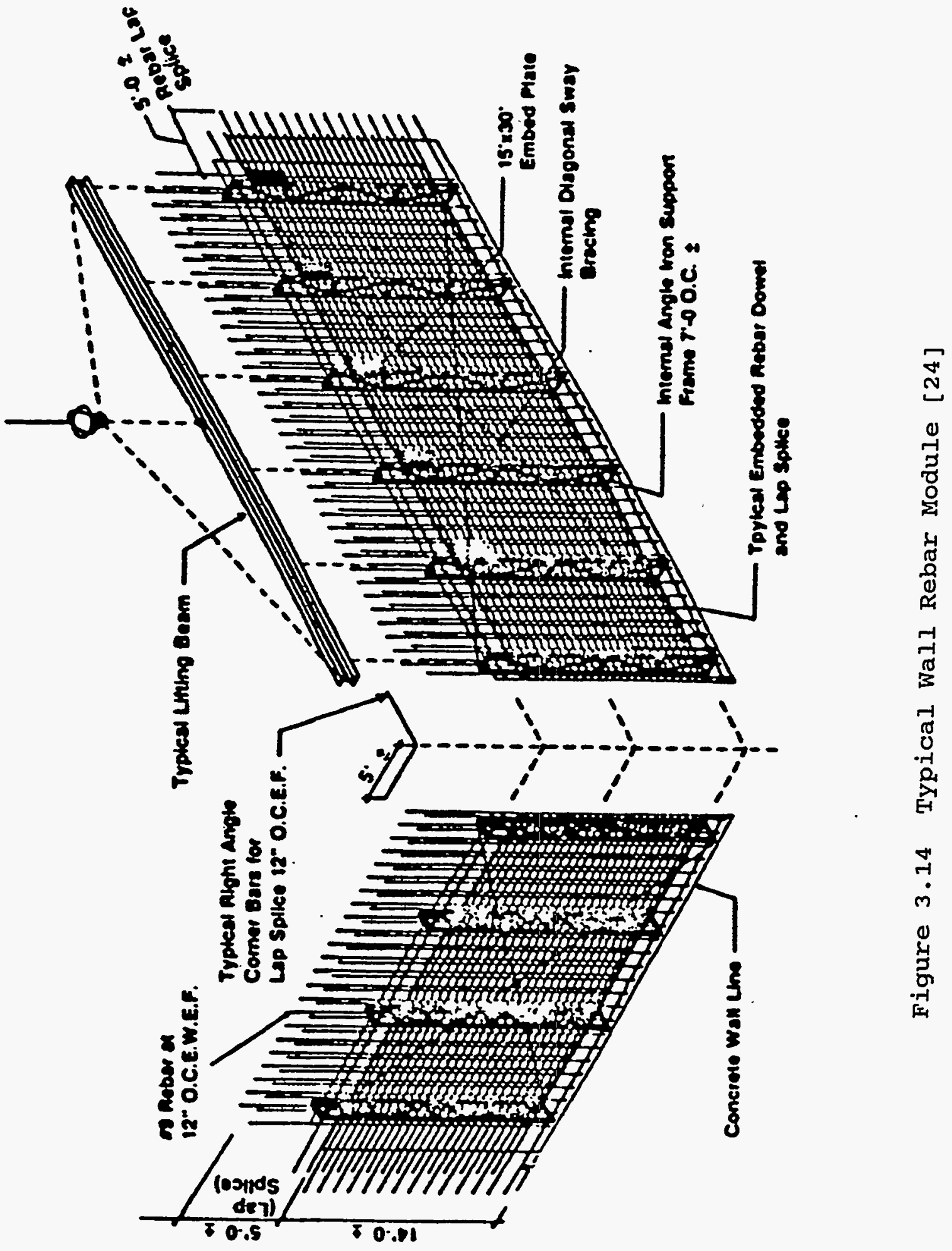




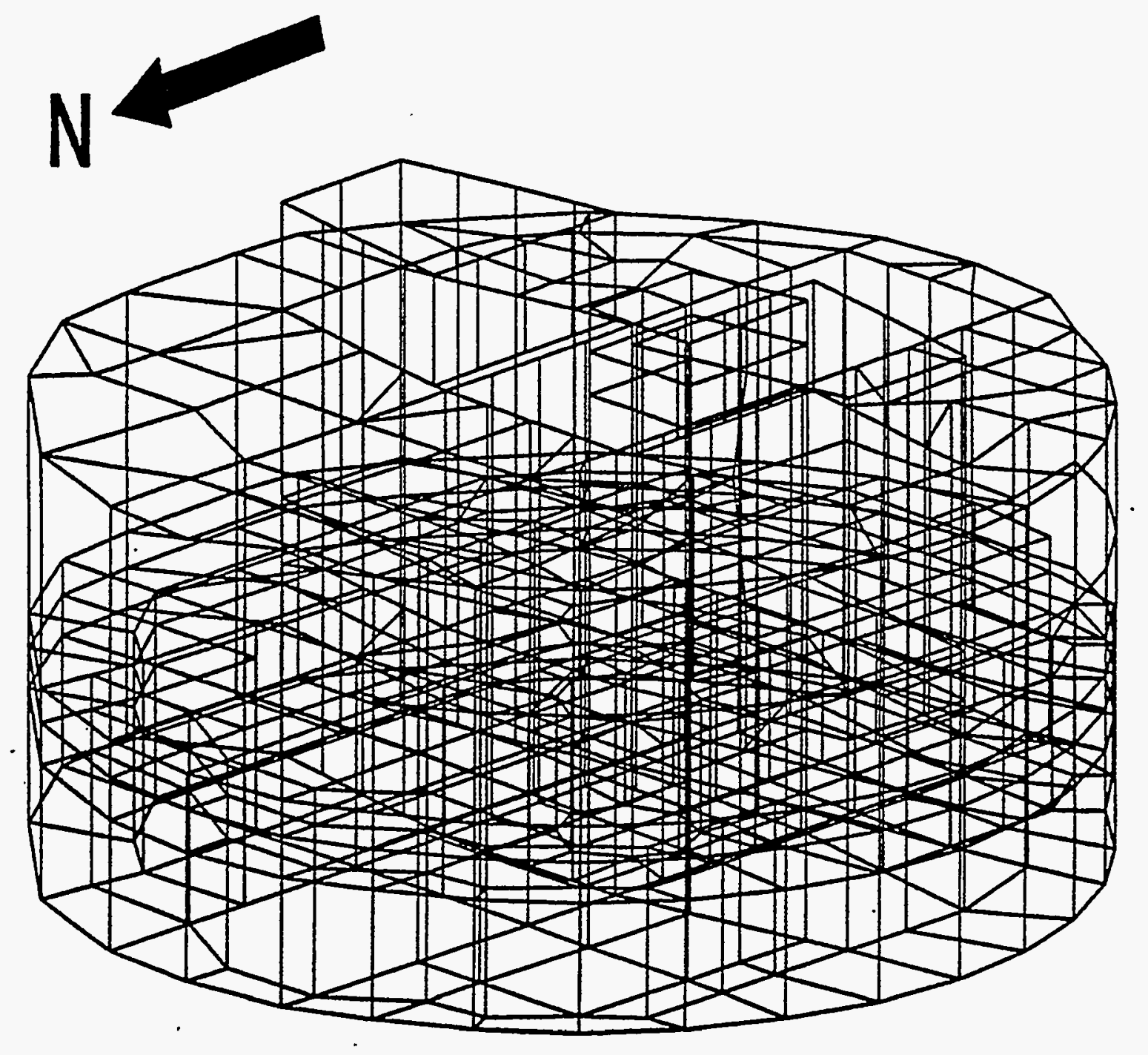

Figure 3.15 Containment Internal structures Finite Element Model [27] 


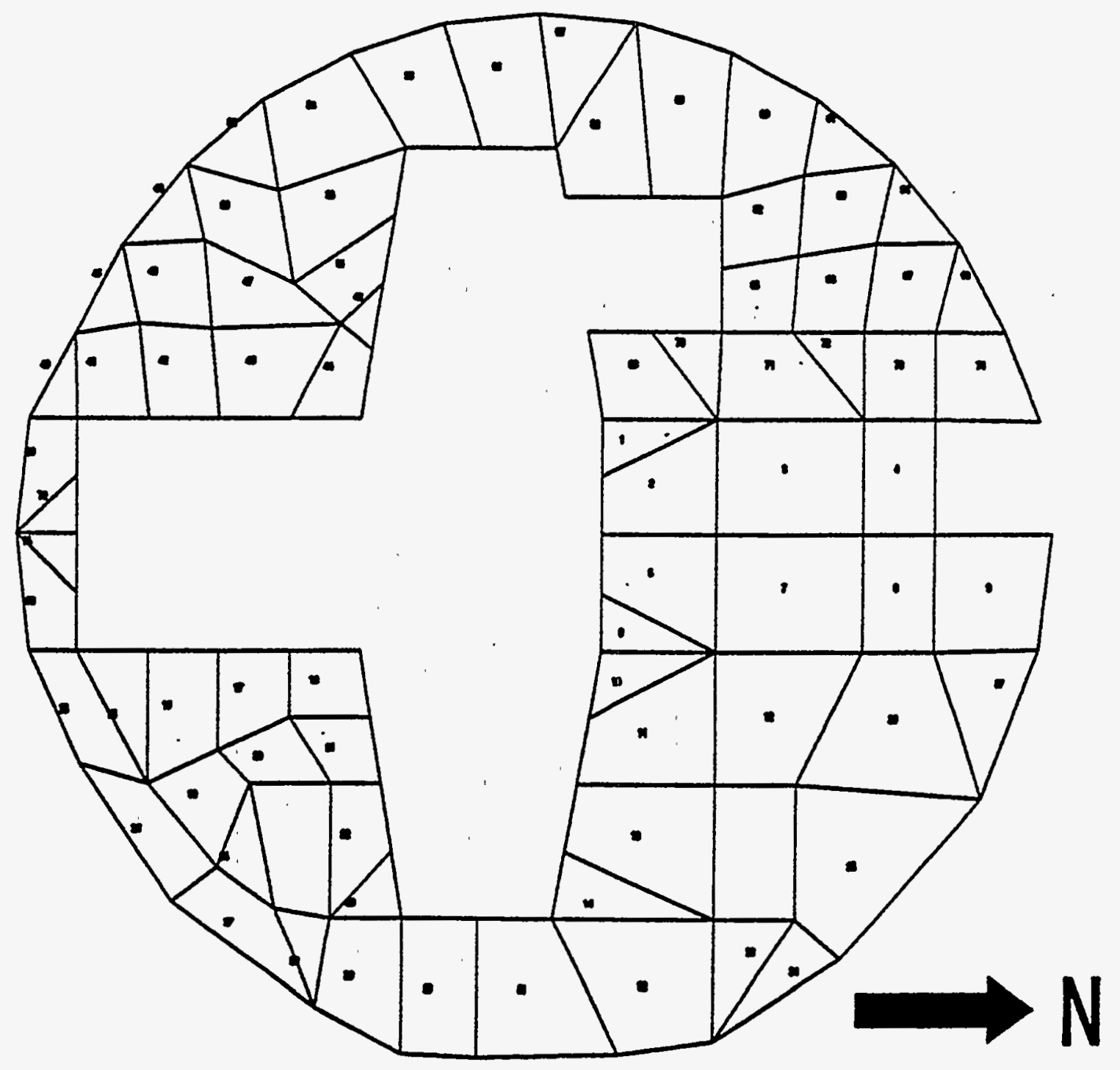

Figure 3.16 Containment Internal structures Finite Element Model - Plan Elev. 135'-3" [27] 


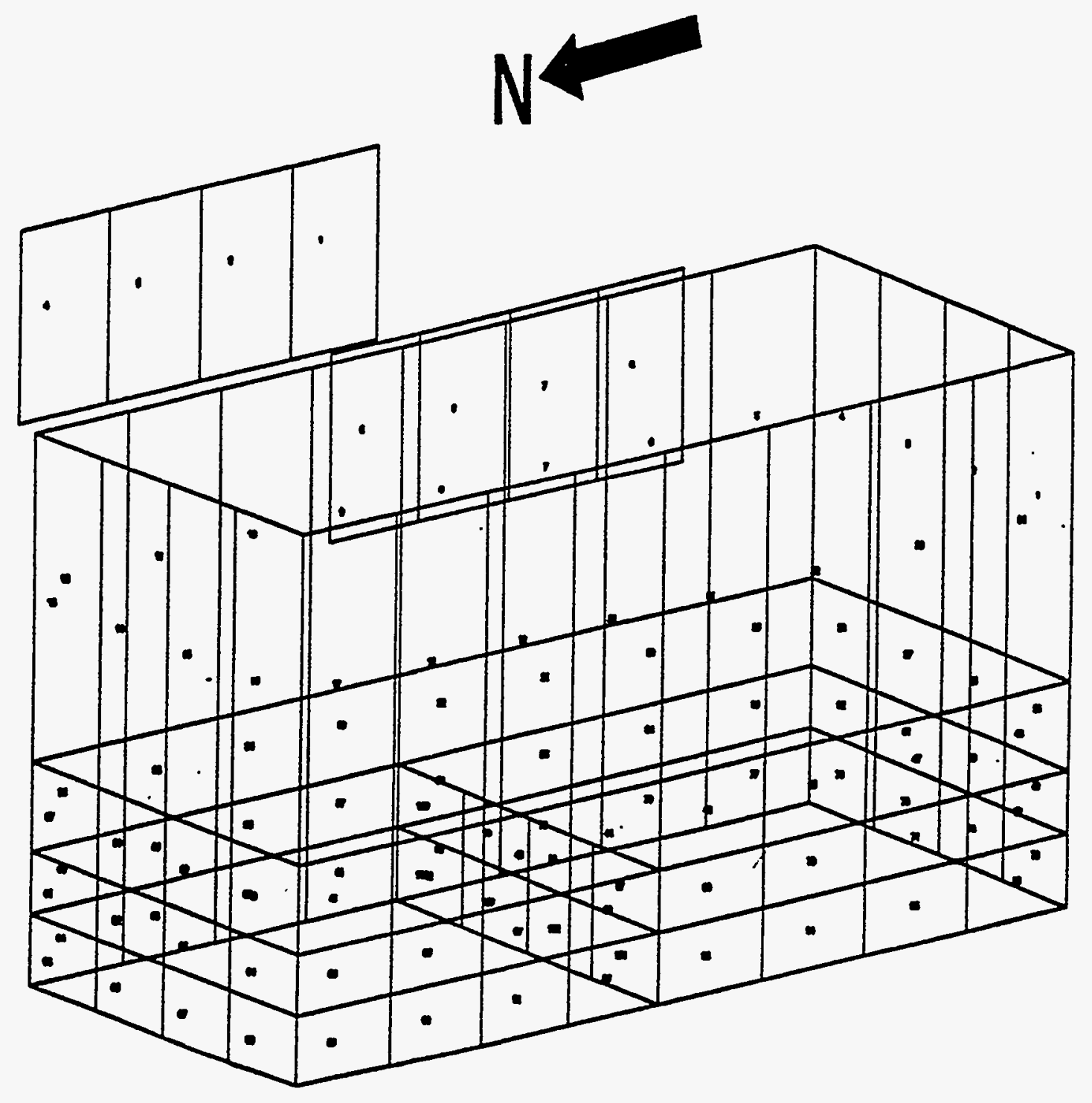

Figure 3.17 Containment Internal Structures - Finite Element Model Isometric View of Refueling Cavity Walls [27] 


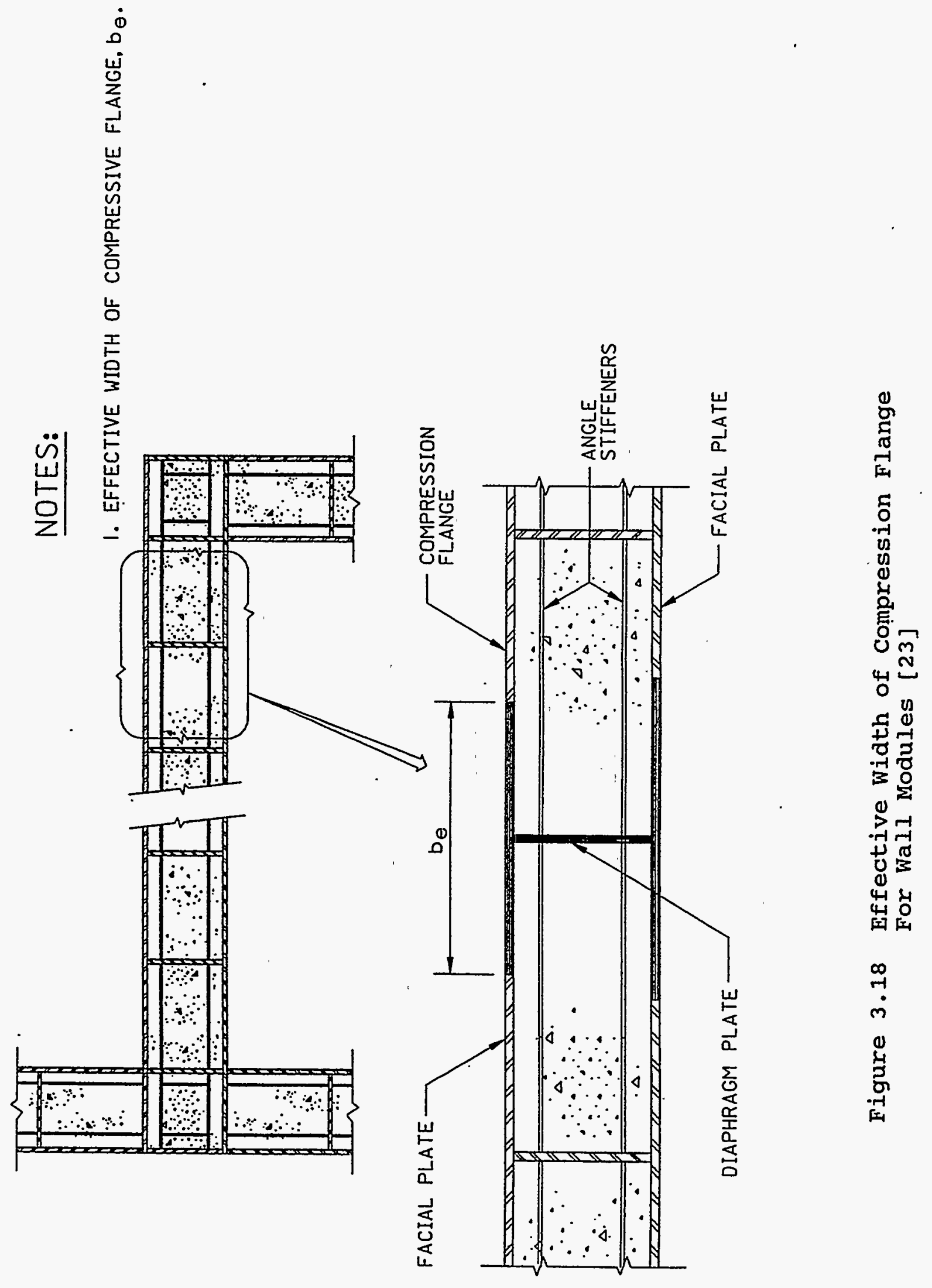


$\underset{\omega}{\stackrel{\omega}{\omega}}$

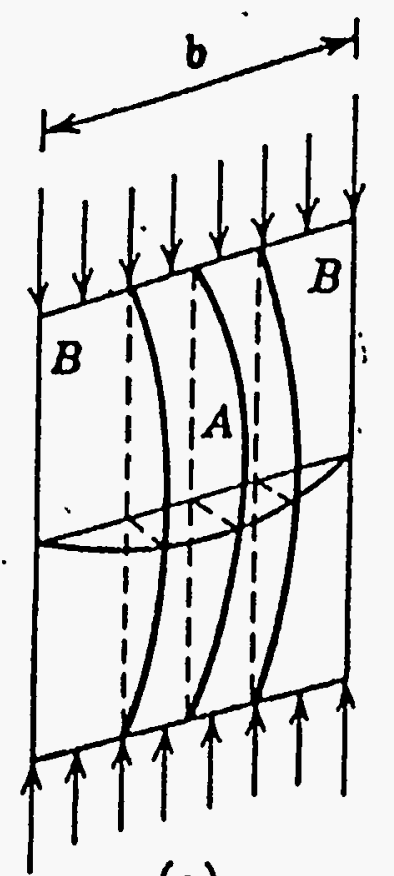

(a) (b)

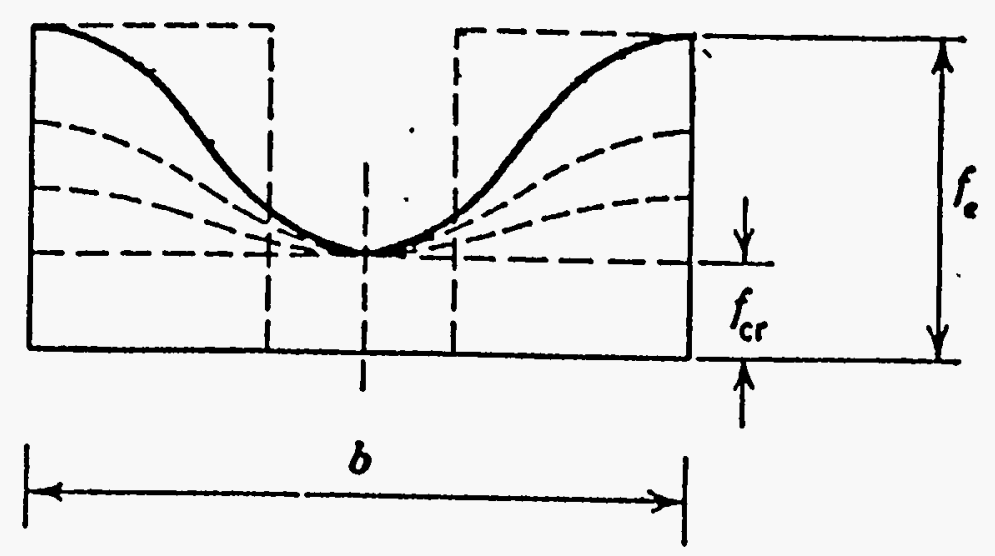

(c)

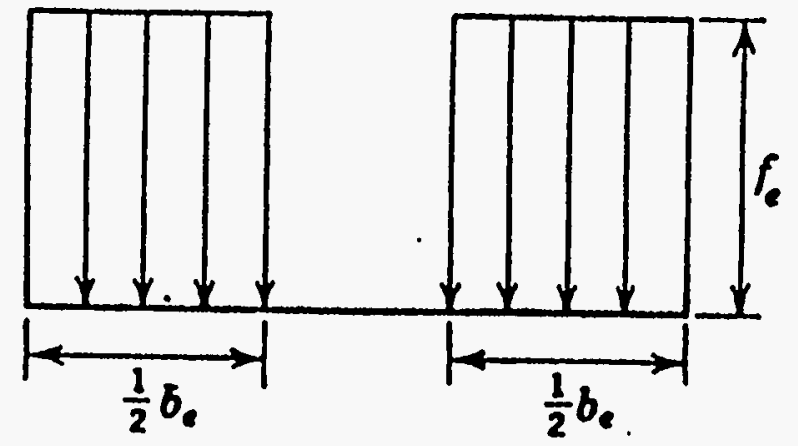

(a) plate simply supported on all sides

(b) actual stress distribution

$$
b_{e}=\sqrt{\frac{f_{c}}{f_{e}}} \times b
$$

(c) effective width 


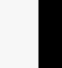




\subsection{EVALUATION OF GENERAL ELECTRIC APPLICATIONS}

\subsection{Description of Modular Systems}

The Simplified Boiling Water Reactor (SBWR) concept proposed by General Electric (GE) relies on building arrangements which optimize the layout of systems and personnel and equipment access for operation and maintenance. By reducing and simplifying the total quantity of systems and equipment, the total building envelope required to house safety systems was greatly reduced. These enhancements have resulted in the placement of all safety functions within the Reactor Building. Figure 4.1 shows the SBWR Reactor Building with the major components identified.

Another development in the SBWR design is to utilize modular construction techniques. The use of modules for concrete and steel components would shorten the construction schedule, improve the quality of fabrication, and reduce overall costs of construction.

Since the GE SBWR Standard Safety Analysis Report [32] does not describe the use of modular construction, this report relies upon information presented in the "SBWR Technical Description for NRC Staff" [33] and GE letter to the NRC [34]. The SBWR report presented to the NRC describes the various areas that modularization is being proposed. Specific structural components proposed for the SBWR design include:

1. Reinforcing bar assemblies for the basemat, building and containment walls, drywell and suppression chamber slabs, containment top slab, columns, floor slabs and beams.

2. Structural steel assemblies for the Reactor Building and Turbine Building superstructures. These modules will include roof trusses and siding.

3. Structural steel assemblies including stairs and platforms.

4. Steel liners for the containment, gravity-driven cooling system (GDCS) pool, isolation condenser (IC) pool, isolation condensor makeup pool, reactor well, steam separator storage pool, fuel transfer pools, spent fuel storage pools and spent fuel shipping cask loading pool.

5. Steel structures that will also serve as forms for the turbine pedestal, drywell vent wall and RPV vessel.

6. Equipment assemblies containing components such as piping, condensers, cranes, diesel generators, HVAC units and numerous other equipment. These modules are for the Reactor, Turbine and Radwaste Buildings. 
7. Precast walls in the Reactor, Turbine, and Radwaste Buildings.

Some of the major structural modules for the SBWR Reactor Building are shown in Figures 4.2 and 4.3. Some alternate modules for the Reactor Building are shown in Figure 4.4. Reinforcing bar modules for the basemat, columns, walls, and beams will be prefabricated and lifted into position with cranes. Structural steel modules will be lifted above the operating floor to construct the steel superstructure. The containment wall and pool liners will be prefabricated and installed as modules. Numerous steel structures inside containment will be placed into position and later filled with concrete. This type of modularization will be used for the reactor pedestal, diaphragm floor, wall between drywell and suppression chamber and the GDCS pool walls.

An open-top construction method will be employed for installation of the modules. A heavy lift crane will be used to place the prefabricated modules into the structure as soon as areas become accessible and before the overhead floor is constructed. This work would progress in parallel with civil construction activities on site. Figure 4.5 shows the placement of a vent wall module in the Reactor Building by a heavy-lift crane.

Large composite modules will be used for the superstructure in the region above the grade clean area of the Reactor Building which houses the electrical and HVAC rooms. The large composite modules will contain a structural steel frame, precast siding panels, equipment and connecting piping, ducts and cabling. These modules will be assembled in a site fabrication area from smaller modules and components fabricated locally. GE stated in Reference [33] that the use of these composite modules will require more investigation and evaluation in the next modularization review phase to confirm their applicability and economic benefit.

In a more recent correspondence between $G E$ and the NRC, some additional information was provided via a letter to the NRC [34]. This letter was written in response to questions/concerns outlined in an NRC fax to GE entitled, "Draft Topics of Interest Related to Modular Construction Techniques [35]."

The GE letter summarized the types of structural modules used. The types of modules described in this letter are:

1. Rebar cages with liner plates for containment and RPV pedestal walls.

2. Rebar cages with steel beam and metal deck for floor slabs.

3. Structural steel modules for vent wall structure and diaphragm floor slab.

$$
4-2
$$


4. Rebar cages for the isolation condensor pool girders and basemat.

GE stated that there will be no precast concrete modules for major structural elements. A summary of the modularization is shown in Figures 4.6 through 4.11 which were provided in the $G E$ letter. Explanations for each of the figures were not provided.

4.2 General Conclusions and Issues

The SBWR Technical Report [33] describes the extensive use of modularization for structural components. The report also describes the many benefits of modularization which include reducing the construction schedule to 30 months; moving work away from the congestion at the work site; expanding the work force to fabrication plants; and reducing onsite warehousing, labor, management, inspection, and testing. The shifting of work to build the modules at fabrication plants should improve the quality of construction, inspection, and testing. The lifting of modules into position using a crane from above, before ceiling slabs are poured, eliminates the more time consuming and difficult horizontal movement by rigging. The use of modules permits much of the work to be performed in parallel, thereby reducing the construction schedule. All of the improvements also lead to economic benefits. as a result of the shortened construction schedule, less interference among the different trades, better quality and less rework required.

Although the various applications of modular construction were described in the SBWR report [33], no information was given with respect to the design, inspection, testing, handling, storage and quality control/assurance of structural modules. In addition, the SBWR report was presented in December 1989 to the NRC. Many of the structural modules proposed were probably in the conceptual phase. since that time, some of the specific modularization concepts probably were modified, eliminated, or new modules developed.

Upon reviewing the SBWR Standard Safety Analysis Report [32], no description is provided regarding the use of modular construction. Section 3.8 of the SSAR describes the reinforced concrete containment, containment internal structures and other Seismic Category I structures. However, no description of the use of structural modules or analysis and design criteria is included in the SSAR.

Based on a recent GE letter [34] it appears that fewer types of modules are being considered while others have been modified. Further clarification and descriptions are needed to fully understand the configuration of the currently proposed modules. Unfortunately, the figures provided with the GE letter do not provide sufficient information. 
It also appears that the GE structural module design may not be that far along in the process based on the responses provided in their letter. For example, in response to a request for a description of the erection plans, GE wrote that "the erection plans have not been fully developed, but will be available for the appropriate phases of the construction program as needed." In response to a question on the $Q A / Q C$ program for on-site storage, GE wrote that "the details of the $Q A / Q C$ programs for on-site storage have not been developed, but will meet all applicable regulations and industry standards as appropriate."

In response to a question on the analysis and design criteria resulting from the use of modular construction, GE wrote that "there are no changes to the loading, loading combinations and structural acceptance criteria due to modularization. However, criteria for the structural design of modules will be developed as appropriate." With respect to codes, standards, tests and practices to be used to address various analysis and design parameters, very brief responses were provided in the GE letter. Some of their responses are as follows:

- Since no precast concrete modules are-anticipated to be used, degradation of ductility and stiffness due to modularized construction is not expected.

- The strength of the joints and the connections between the modules are the same as the monolithic construction. The actual design and construction of the joints between the structural steel and reinforced concrete members requires detailed design and evaluation. This will be performed as module design is developed, as applicable.

- The kind of structural modules anticipated to be used for SBWR, such as rebar and structural steel, are not functionaliy sensitive to the parameters such as damping, stiffness, and ductility.

- Structural ultimate capacity is not affected by the proposed modularized construction. Therefore, the margins are not affected due to utilization of modular construction techniques.

Based on these responses, there are a number of additional questions that arise. obviously, more detailed information is needed on the type of modules to be used, including engineering drawings and/or sketches showing more details of these modules. The responses given in the GE letter need to be expanded upon. The basis for some of their statements also need to be explored. For example, why is the structural ultimate capacity unaffected by the proposed modular construction?

$$
4-4
$$


Probably the best way to obtain the additional information and discuss the various areas of interest is to meet with the appropriate GE engineers and/or subcontractors. If they are far enough along in their modular construction concept and design, many of the above questions could be addressed. 


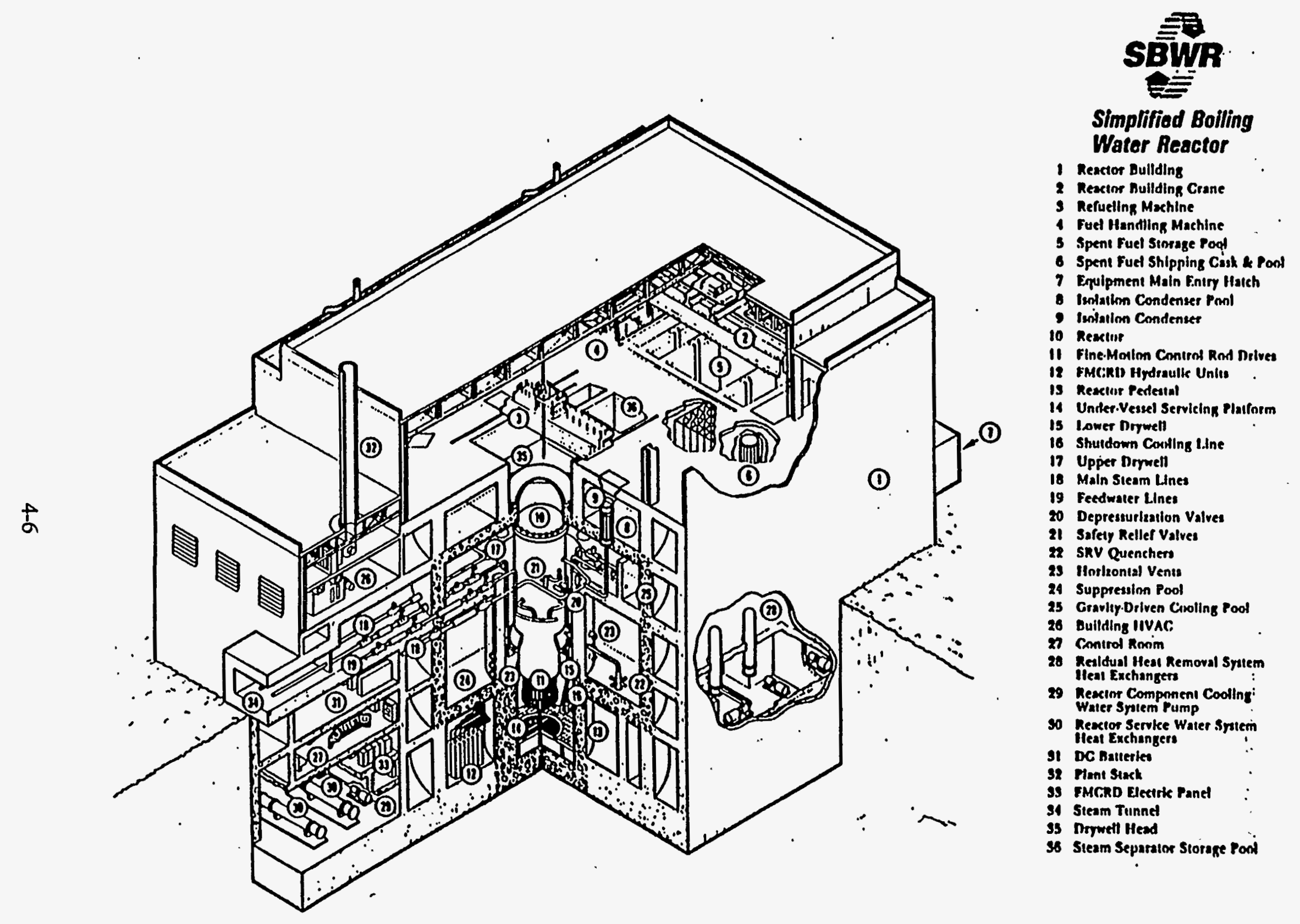

Figure 4.1 SBWR Reactor. Building [33] 


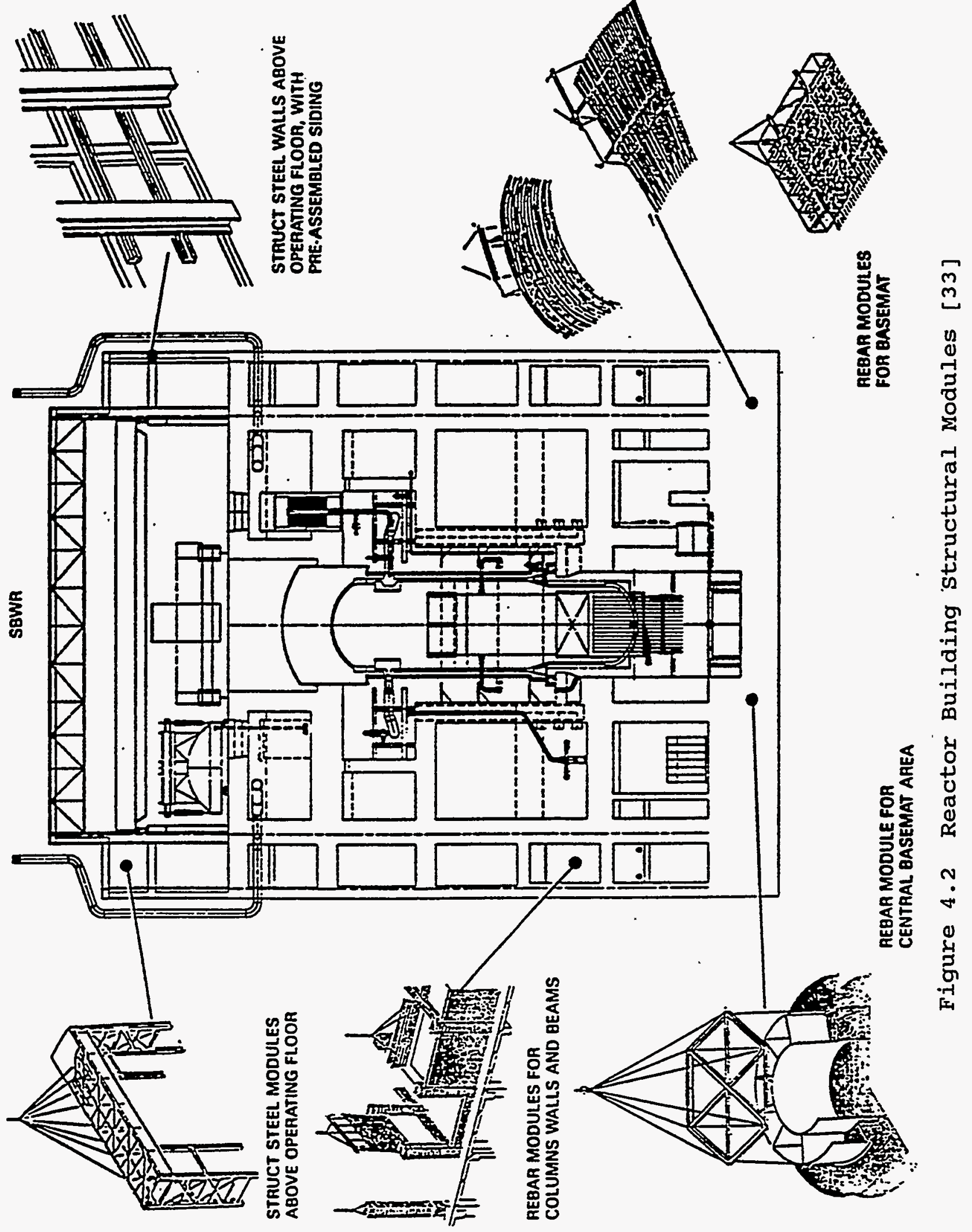




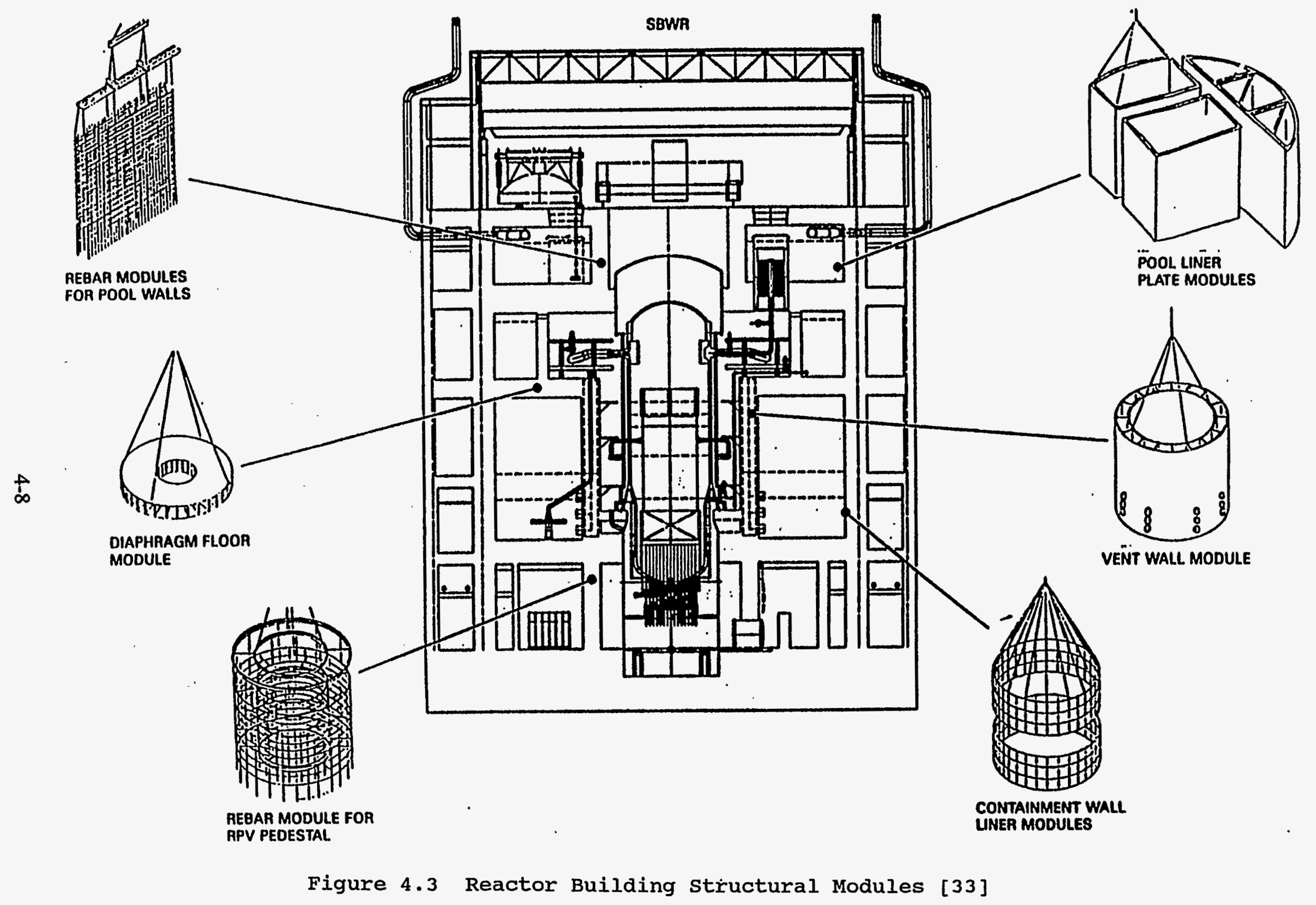




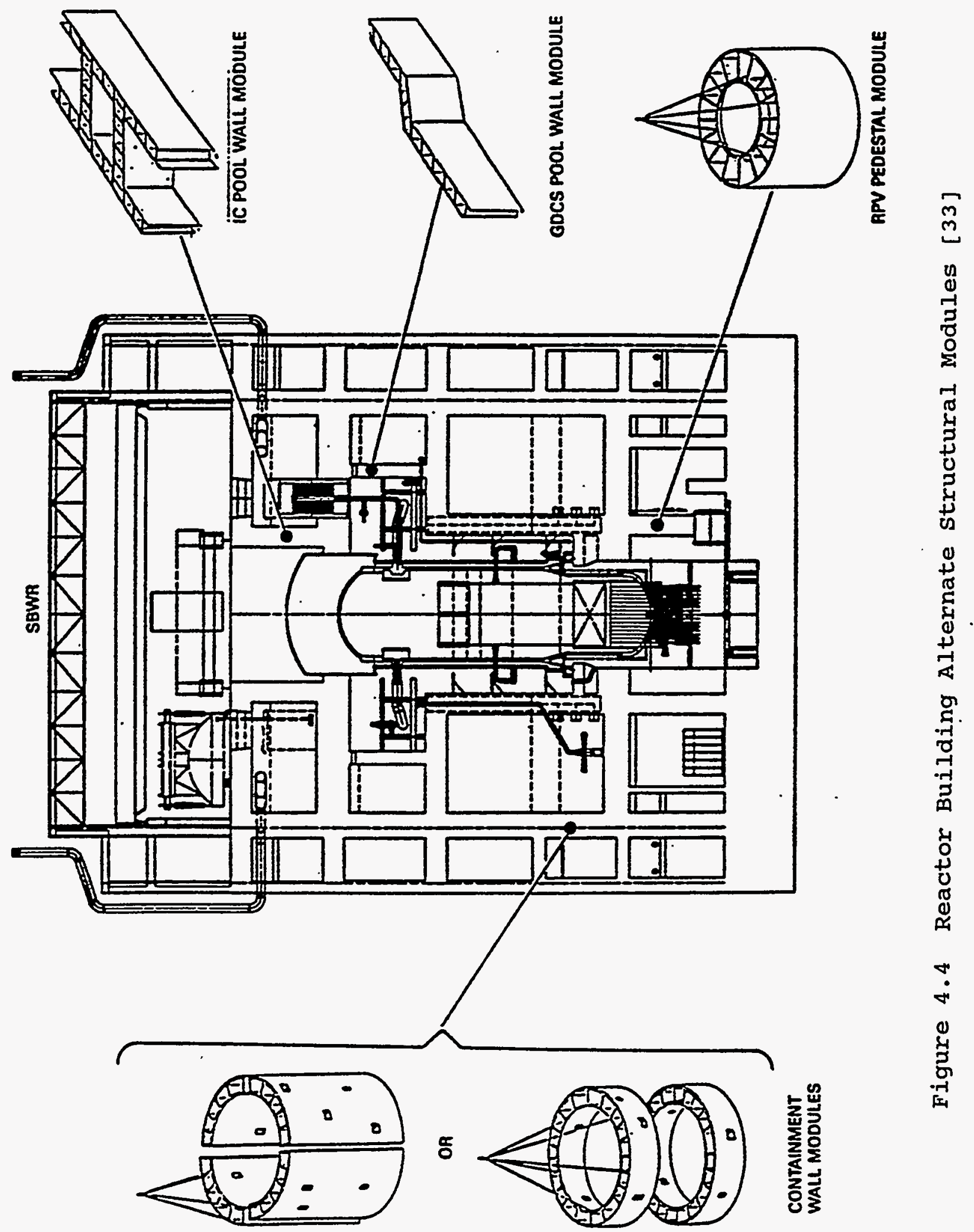




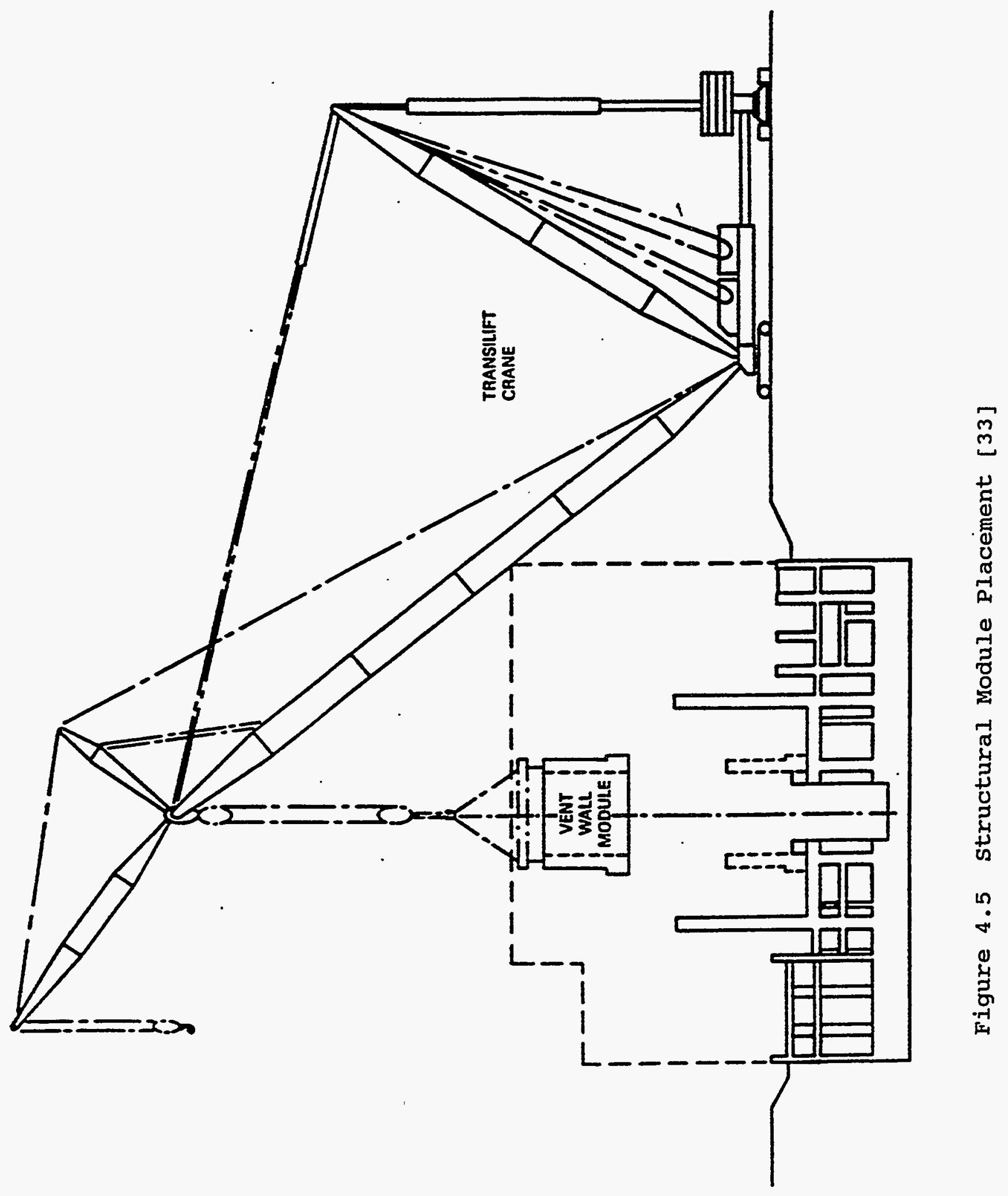




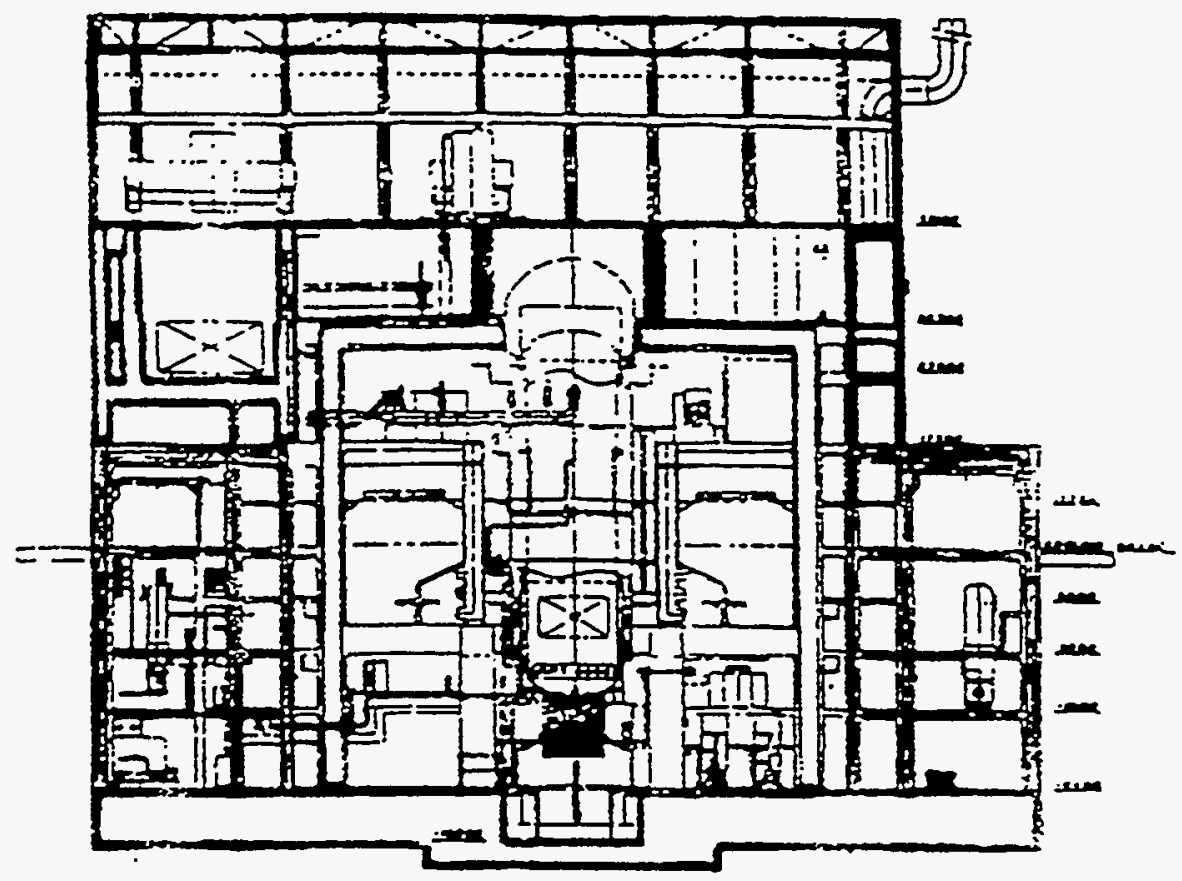

NIB - MODULARIZATION

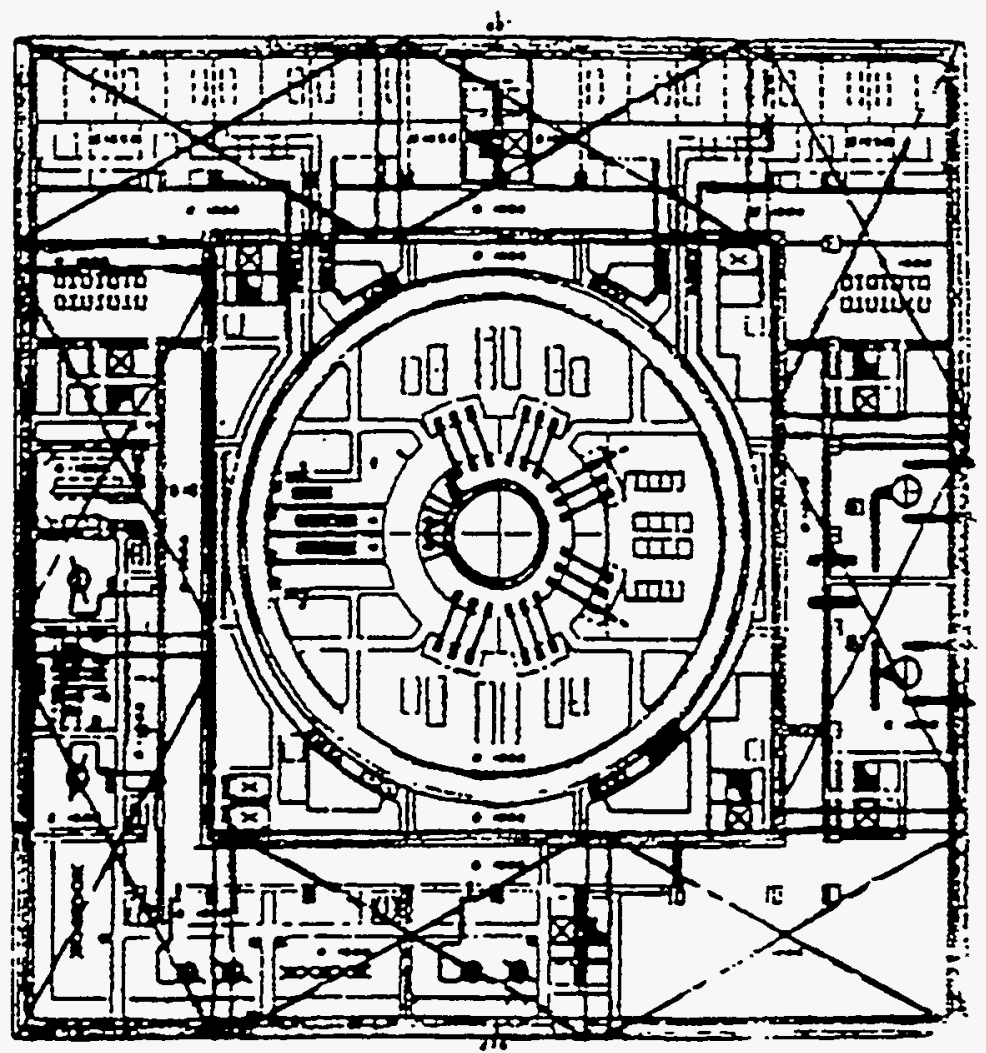

Figure 4.6 SBWR Structural Modules [34] 


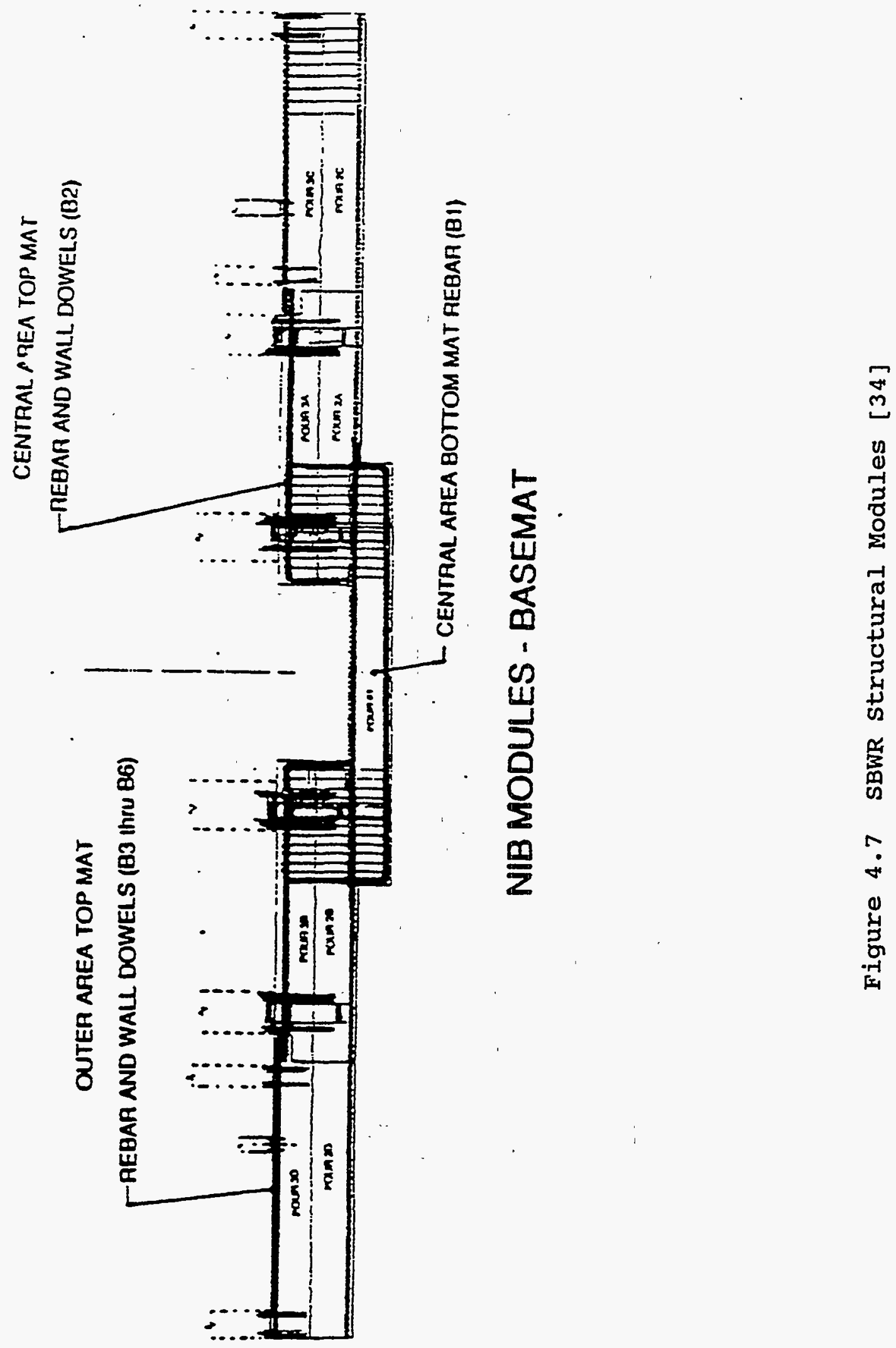




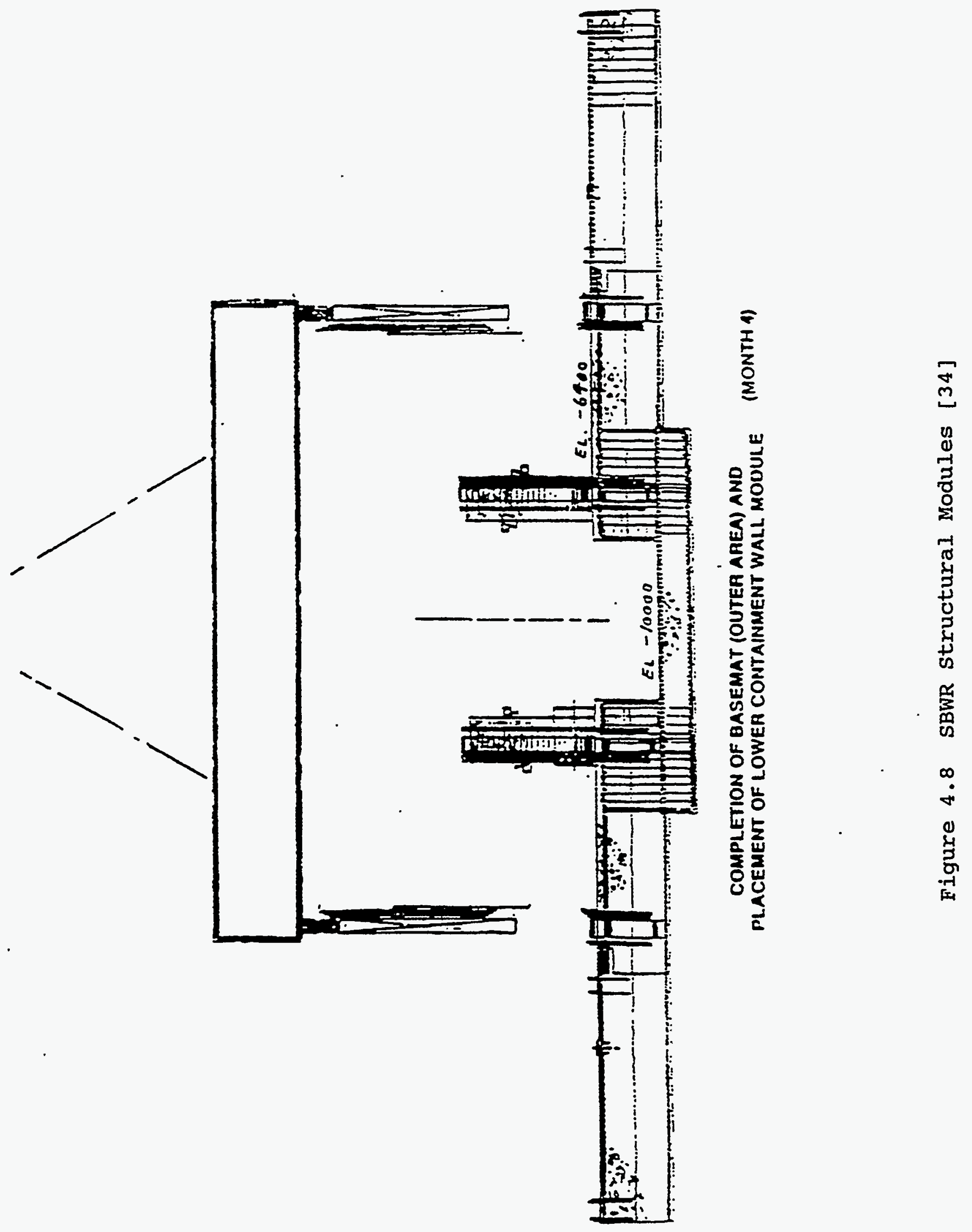




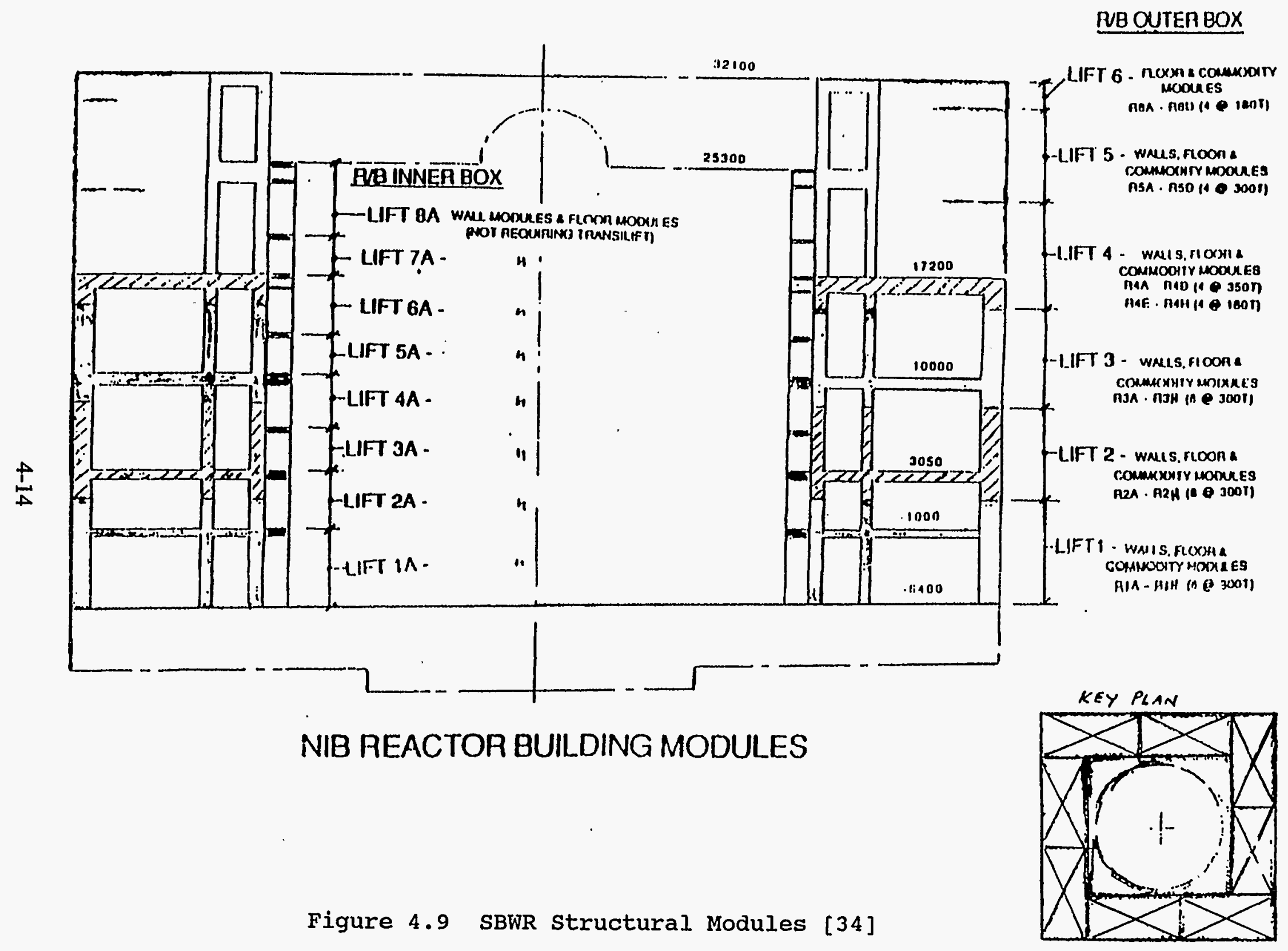



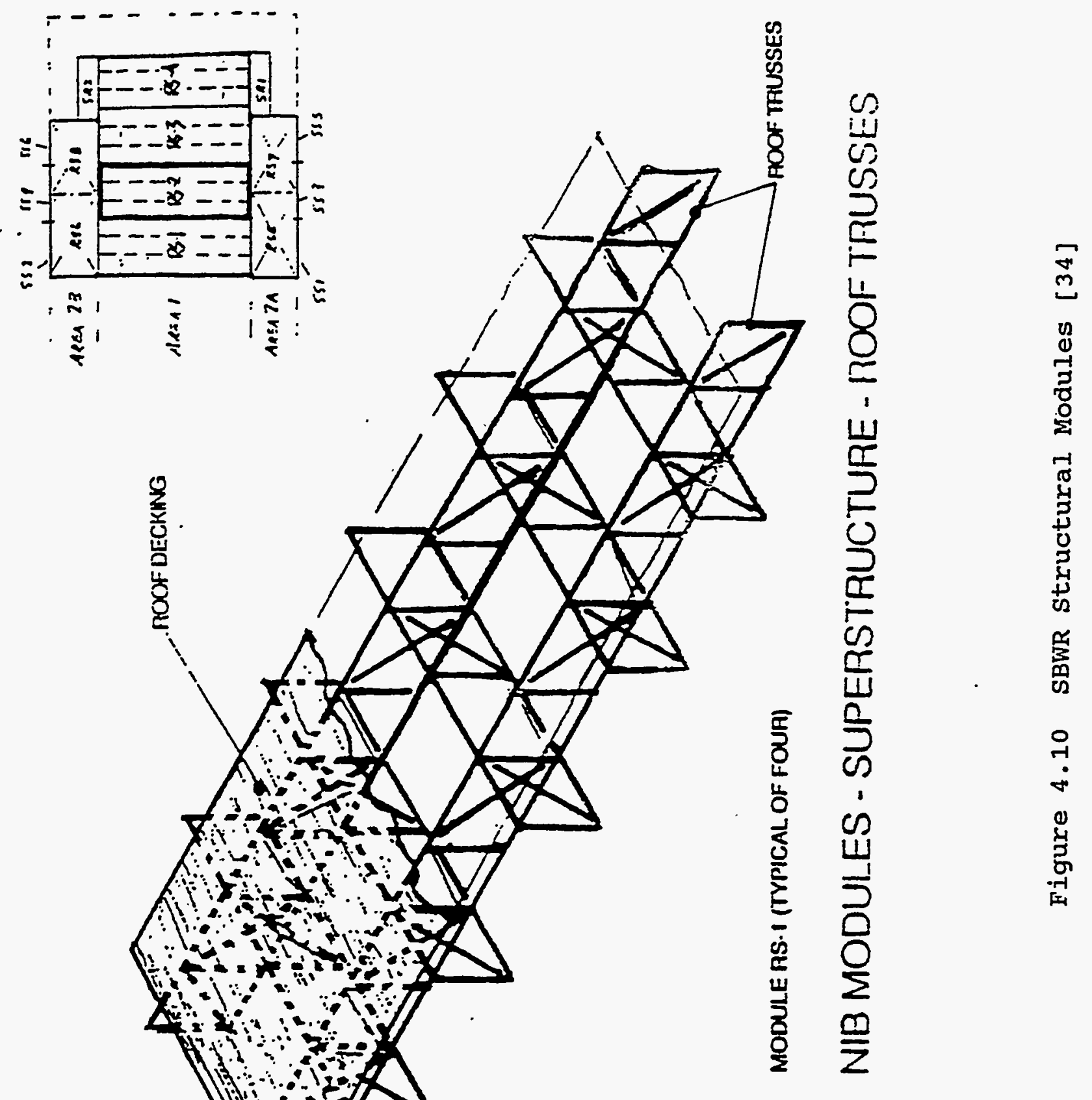

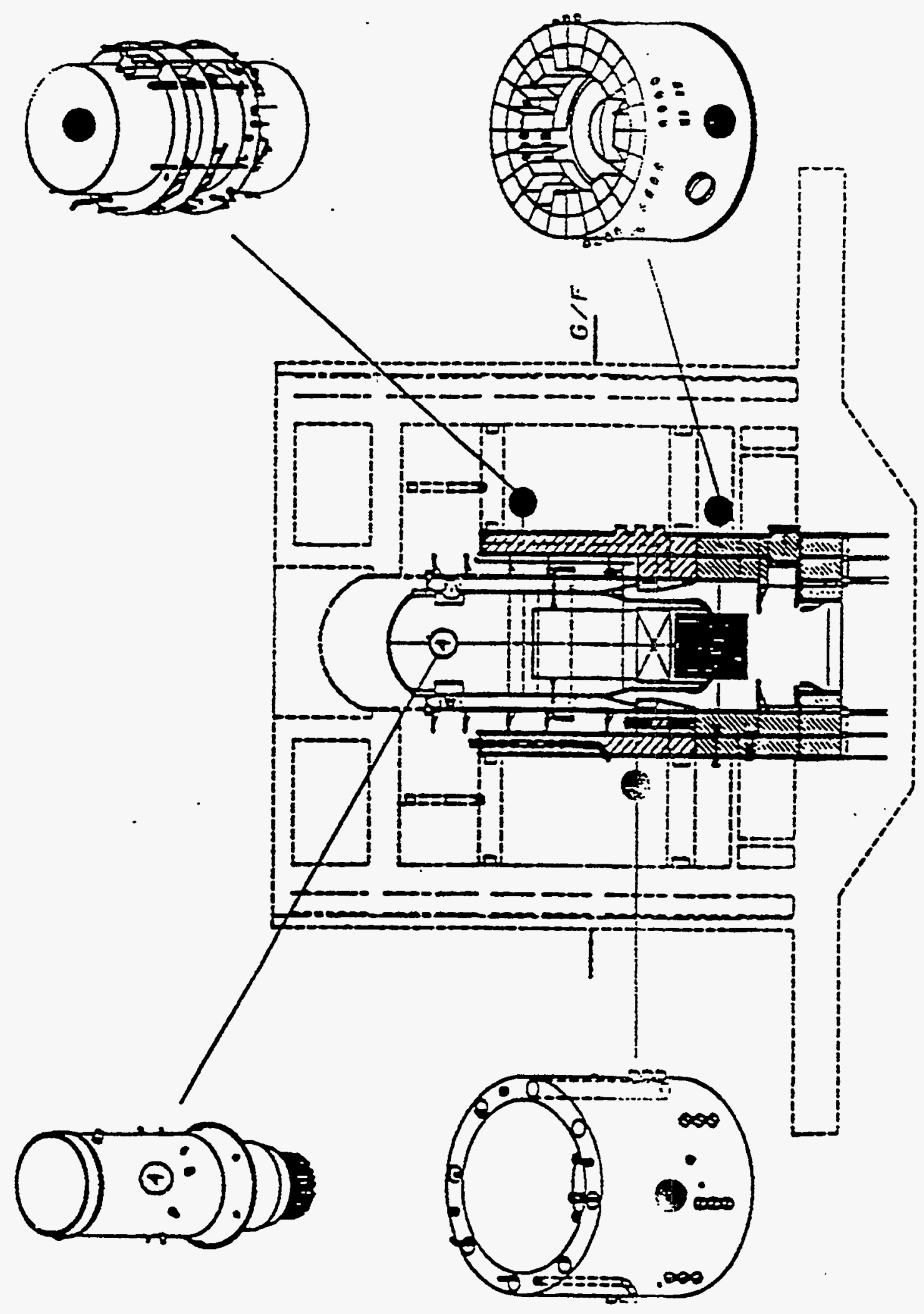

D 


\subsection{SUMMARY OF ISSUES AND RECOMMENDATIONS FOR FUTURE ACTIVITIES}

During Phase I of this program, existing standards, tests and practices used in modular construction have been reviewed. In addition, the application of modularization to the Westinghouse AP600 plant and General Electric SBWR plant have been evaluated. The goal of these reviews was to identify what issues or concerns exist and what more is required in order to support NRC licensing activities.

One issue identified during these reviews is that there is no single code or standard that provides all the necessary requirements or guidance for the analysis and design of composite steel/concrete structural modules. In the case of the AP600 plant, the design relies upon the AISC N690 Specification [29], ACI 349 code [30] and the ASCE standard 4-86 [31]. Various portions of AISC N690 and ACI 349 are used depending on the specific application. While AISC N690 does address composite construction, it only covers composite construction of steel beams or 'girders supporting a reinforced concrete slab. It does not address composite construction of bearing and shear wall composite members.

Another issue is the use of AISC N690 and ASCE Standard 4-86 for the analysis and design of structural modules. The ASCE. Standard is used in the seismic analysis of the safety-related structures. AISC $\mathrm{N} 690$ is utilized in the design of the safetyrelated steel structures. Both of these documents have not been endorsed by the NRC.

The appropriate damping value is another issue that needs to be resolved. The AP600 plant utilizes a $7 \%$ damping value for the seismic analysis of the structural modules. NRC Regulatory Guide 1.61 recommends a damping value of $4 \%$ for welded steel and $7 \%$ for reinforced concrete. Thus, an appropriate damping value for design should be somewhere between 4 and 7 percent. One test performed in Japan [19] suggests that damping is approximately 5\%. The construction details of the composite structural modules used in this test were somewhat different than the configuration proposed in the AP600 plant.

In reviewing the AP600 plant design approach for the composite structural "M" modules, a few concerns were identified with the use of the postbuckling strength of steel plates. The postbuckling strength of plates is relied upon in the design of the structural modules to determine the effective width of the steel plates. When the center strip of the face plate (between the diaphragm plates) buckles, some of the load shifts to the concrete rather than to the edges of the face plates. However, it is not evident whether the design included this additional compressive load since compressive loads were assumed to be distributed in proportion to the stiffness of the concrete and steel before buckling occurs. Another concern is how the simultaneous application of shear loads with compressive 
loads may affect the postbuckling strength of the steel face plates. Also, the appropriate $K$ factor for determining the effective length of the steel plates between the horizontal stiffeners needs to be reviewed in greater detail. Tests performed in Japan [20] suggest values different than those used in the AP600 design.

Tests performed in Japan seem to demonstrate that the use of composite steel and concrete modules result in a better design as compared to conventional reinforced concrete structures. Tests suggest that the ductility and ultimate strength are higher for composite structural elements than for reinforced concrete elements. In addition, stiffness degradation appears to be lower for composite structural elements than for reinforced concrete elements. However, the construction details of the walls tested were somewhat different than those for the AP600 modules. In addition, very limited information was included in the published papers for these tests to permit making generic conclusions.

Industry standards or guidance regarding $\mathrm{QA} / \mathrm{QC}$, fabrication, transportation, handling, storage, assembly, and erection of structural modules could not be identified. For the nuclear industry in particular, no information was submitted or developed as yet for the two advanced light water reactors reviewed in this. report. To address this issue and the applicability of existing codes and standards for analysis and design of modular construction, the development of a document to provide such guidance is recommended. This document or standard need not duplicate the requirements contained in other existing standards or codes but it should provide guidance on various aspects that are unique to modular construction. Topics that could be included are analysis, design, fabrication, transportation, assembly, erection, storage, handling, inspection, and QA/QC. Where existing information on these subjects are available in other documents and are applicable to structural modules, they could be referenced. Where interpretations or new criteria are needed, they should be specified in the new standard.

As described in Section 2.0 , a number of companies have been involved in studying the use of modular construction techniques in nuclear power plants. Companies such as Duke Power and stone \& Webster performed studies for the Department of Energy. Avondale Industries developed a comprehensive system of modular construction for use in their marine programs. They are now expanding their system for use in the industrial and utility markets. The shipbuilding and petrochemical industries have already used modular construction techniques. The fossil power industry has formed a working group to study power plant modularization. Thus, it is recommended that meetings with key individuals associated with Avondale Industries, AE/Construction companies such as Duke Power and Stone \& Webster, as well as other organizations be arranged to obtain additional information. In addition, meetings with 
Westinghouse and General Electric should be planned to address the questions and issues identified at this time.

Based on the various studies and tests performed in Japan on structural modules and composite structural elements, further efforts should also be made to obtain more information from the organizations performing work in this area. In this regard, an upcoming trip to Japan has been arranged for a BNL representative partly for this purpose. A meeting is planned with Professor $H$. Akiyama to discuss the development of design methods and testing of concrete filled steel structures. Professor Akiyama was involved in two of the test studies [19 and 20] referenced in this report. Visits are also planned with other researchers and a construction company to discuss shear wall testing and the application of the results to design procedures. Also to be discussed are modular construction techniques for new plant designs.

Another recommendation that should be considered is additional testing to address a number of the outstanding issues and parameters. No tests on composite shear wall designs of the type being proposed for the advanced light water reactors could be identified. Tests were performed on some composite shear walls in Japan. However, the configurations tested were somewhat different. One possibility is a cooperative effort with Japan to perform additional tests and/or exchange information on composite steel and concrete structural modules. Further testing could provide additional information on the stiffness, stiffness degradation, ductility, ultimate capacity, damping, cyclic load effects, and confirmation of analytic/design approaches for different steel/concrete wall configurations.

The use of modular construction has been proposed in advanced light water reactors to restore nuclear energy as an attractive option. Apparently, modular construction can reduce the costs and construction schedule thereby making nuclear power competitive with alternate sources of power. To achieve these benefits of modular construction while maintaining adequate safety and design margins, the recommendations described above should be implemented as part of this NRC research program. 


\section{-}


6.0 REFERENCES

1. DOE/NE-0067, "Modularization and Nuclear Power," Report by the Technology Transfer Modularization Task Team for U.S. Dept. of Energy, June 1985.

2. DOE/SF/16566-1, "Design for Constructability Program - Volume I: Executive Summary," Duke Power Company Report for USDOE Technology Programs in Support of Advanced Light Water Reactors, March 1990.

3. DOE/SF/16566-2, "Design for Constructability Program - Volume II: Program Description," Duke Power Company Report for USDOE Technology Programs in Support of Advanced Light water Reactors, March 1990.

4. DOE/SF/16566-3, "Design for Constructability Program - Volume III: Improving Construction Performance," Duke Power Company Report for USDOE Technology Programs in support of Advanced Light Water Reactors, March 19.90.

5. DOE/SF/16566-4, "Design for Constructability Program - Volume IV: Enhancing Constructability Through Design," Duke Power Company Report for USDOE Technology Programs in Support of. Advanced Iight Water Reactors, March 1990.

6. DOE/SF/16565-3, "Design Requirements/Guidelines to Facilitate Constructibility," Stone \& Webster Engineering Corporation Report for USDOE Technology Programs in Support of Advanced Iight Water Reactors: Construction, January 1989.

7. DOE/SF/16565-4, "Prefabrication and Modularization Approach and Implementation," Stone \& Webster Engineering Corporation Report for USDOE Technology Programs in Support of Advanced Light water Reactors: Construction, April 1989.

8. J. Grogan, R. Claussen and M. Williams, "Modular Construction of Fossil Power Plants - Report of Working Group Two: Issues and Action Items," Proceedings of 1989 Fossil Power Plant Construction Conference, Cincinnati, OH, Aug. 29-31, 1989, EPRI-GS-7255, JulY 1991.

9. J.H. Cottrell and C.P. Boudreaux, "Repowering and Phased Expansion with Modular Construction," Proceedings of second International Conference on Improved Coal-Fired Power Plants, Palo Alto, CA, Nov. 2-4, 1988, EPRI-GS-6422-Vol.1, 1989.

10. J.I. Ehasz and J.M. Brooks, "Modular Construction Brings Hydropower Up the Mississippi," Proceedings of 1989 Fossil Power Plant Construction Conference, Cincinnati, OH, Aug. 2931, 1989, EPRI-GS-7255, July 1991. 
11. EPRI, Advanced Light Water Reactor Utility Requirements Document, Volume III, ALWR Passive Plant, Chapter 1, Overall Requirements.

12. H.D. Farin and W.E. Cummins, "AP600 Layout Features to support 36 Month Construction Schedule," Proceedings of International Conference on Design and Safety of Advanced Nuclear Power Plants (ANP'92), Tokyo, Japan, Oct. 25-29, 1992.

13. F.T. Johnson, R.S. Orr and C.P. Boudreaux, "Modular Construction Approach for Advanced Nuclear Plants," Transactions of Joint Meeting of the European Nuclear Society and the American Nuclear Society, Washington, D.C., Oct. $30-$ Nov. 4, 1988 .

14. M.P. Iagache, "Constructibility Enhancements for Advanced BWRs," Proceedings of International Conference on Design and Safety of Advanced Nuclear Power Plants (ANP'92), Tokyo, Japan, Oct. 25-29, 1992.

15. D.A. Dilling, R.H. Hren and C.R. Snyder, "Modular Construction/Shop Fabrication in Advanced Reactor Designs;" Proceedings of the American Power Conference, Chicago, II, April 24-26, 1989.

16. G. Bagchi and C.P. Tan, "Modular construction from a Regulatory Perspective," Proceedings of the 2nd ASME/JSME International Conference on Nuclear Engineering, San Francisco, CA, March 21-24, 1993, Vol. 2, ASME 1993.

17. S. Suzuki, Y. Shimazaki, K. Sekiguchi and W. Kokubo, "Introduction of Large Block Prefabrication Method," Proceedings of International Conference on Design and Safety of Advanced Nuclear Power Plants (ANP'92), Tokyo, Japan, Oct. 25-29, 1992 .

18. A. Kaneuji, Y. Okuda, K. Hara and H. Masumoto, "Feasibility Study of Concrete Filled steel (SC) Structure for Reactor Building," Transactions of the 10th SMIRT, Vol. H, pp. 67-72, August 1989.

19. H. Akiyama, H. Sekimoto, M. Tanaka, K. Inoue; M. Fukihara and Y. Okuda, "1/10th Scale Model Test of Inner Concrete Structure Composed of Concrete Filled Steel Bearing Wall," Transactions of the 10th SMIRT, Vol. H, pp. 73-78, August 1989.

20. H. Akiyama, K. Sekimoto, M. Fukihara, K. Nakanishi and K. Hara, "A Compression and Shear Loading Test of Concrete Filled steel Bearing Wall," Transactions of the 11th SMIRT, Vol H, pp. 323-328, August 1991.

$$
6-2
$$


21. H. Suzuki and B. Kato, "Shear Strengths of Concrete-Filled Steel Box Elements," Composite and Mixed construction, Proceedings of the US/Japan Joint Seminar, Seattle, WA, July 18-20, 1984, pp. 254-266, ASCE, 1985.

22. H. Ge and T. Usami, "Strength of Concrete-Filled Thin-Walled Steel Box Columns: Experiment," ASCE, Journal of Structural Engineering, Vol. 118, No. 11, November 1992.

23. Westinghouse Electric Corporation, "Simplified Passive Advanced Light Water Reactor Program, AP600 standard Safety Analysis Report," prepared for U.S. Department of Energy, June 26, 1992 .

24. Westinghouse Electric Corporation, "AP600 Plant Description Document," WCAP-13202, January 1992.

25. NRC/Westinghouse Meeting, 2/10/93, "AP600 Structural Modules, Containment .Internal structures."

26. NRC/Westinghouse Meeting, 2/10/93, "Structural Modules Procedures for Design."

27. NRC/Westinghouse Meeting, 2/10/93, "Structural Modules, Design Example, Refueling Cavity - West Wall."

28. Westinghouse Electric corporation, Fax from R. orr to NRC, "Finned Floor Modules," February 16, 1993.

29. American Institute of steel construction (AISC), "Specification for the Design, Fabrication and Erection of steel Safety-Related structures for Nuclear Facilities," AISC N690-1984.

30. American Concrete Institute (ACI), "Code Requirements for Nuclear Safety Related structures," ACI 349-90.

31. American Society of Civil Engineers (ASCE), Standard 4-86, "Seismic Analysis of Safety-Related Nuclear structures and commentary," September 1986.

32. General Electric Company, "SBWR Standard Safety Analysis Report," 25A5113 Rev. A, August 1992.

33. General Electric Company, "Extract From SBWR Technical Description for NRC Staff," GE Nuclear Energy, December 1989.

34. General Electric Letter, P.W. Marriott to.NRC, "Use of Modular Construction in the SBWR," dated 1/18/93.

35. NRC Fax to J.C. Baechler of General Electric, "Draft Topics of Interest Related to Modular Construction Techniques," dated $12 / 15 / 92$. 


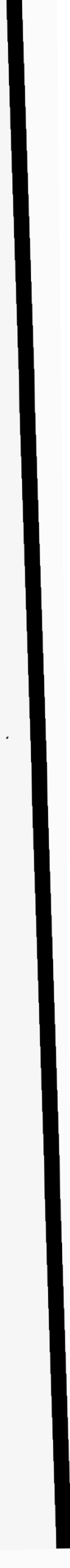




\section{APPENDIX B}

\section{MODULAR CONSTRUCTION REVIEW CRITERIA}

\section{BNL TECHNICAL REPORT NO. L-2261(5)/7-95}




\title{
MODULAR CONSTRUCTION REVIEW CRITERIA
}

\author{
J. Braverman \\ R. Morante \\ C. Hofmayer \\ Engineering Research and Applications Division \\ Department of Advanced Technology \\ Brookhaven National Laboratory \\ Upton, New York 11973
}

July 1995

Prepared for the U.S. Nuclear Regulatory Commission

Office of Nuclear Regulatory Research

Washington, D.C. 20555 


\section{TABLE OF CONTENTS}

1.0 INTRODUCTION $\ldots \ldots \ldots \ldots \ldots \ldots \ldots \ldots \ldots \ldots \ldots \ldots \ldots \ldots \ldots \ldots$

2.0 SCOPE/DEFINTIONS $\ldots \ldots \ldots \ldots \ldots \ldots \ldots \ldots \ldots \ldots \ldots \ldots \ldots \ldots \ldots \ldots$

3.0 DESCRIPTION OE STRUCTURES $\ldots \ldots \ldots \ldots \ldots \ldots \ldots \ldots \ldots \ldots \ldots \ldots \ldots$

4.0 APRLICABLE CODES, STANDARDS AND SPECIFICATIONS $\ldots \ldots \ldots \ldots \ldots \ldots$

4.1 Steel/Concrete Composite Floors, Beams and Columns . . . . . . . 11

4.2 Concrete-filled Steel Modules $\ldots \ldots \ldots \ldots \ldots \ldots \ldots \ldots \ldots \ldots$

4.3 Structural Steel Modules $\ldots \ldots \ldots \ldots \ldots \ldots \ldots \ldots \ldots \ldots$

4.4 Precast Concrete Modules $\ldots \ldots \ldots \ldots \ldots \ldots \ldots \ldots \ldots \ldots \ldots$

4.5 Prefabricated Rebar Mats, Cages and Subassemblies $\ldots \ldots \ldots \ldots \ldots 12$

5.0 LOADS AND LOAD COMBINATIONS $\ldots \ldots \ldots \ldots \ldots \ldots \ldots \ldots \ldots \ldots \ldots$

5.1 Steel/Concrete Composite Floors, Beams and Columns . . . . . . . 13

5.2 Concrete-filled Steel Modules $\ldots \ldots \ldots \ldots \ldots \ldots \ldots \ldots \ldots$

5.3 Structural Steel Modules $\ldots \ldots \ldots \ldots \ldots \ldots \ldots \ldots \ldots \ldots \ldots$

5.4 Precast Concrete Modules $\ldots \ldots \ldots \ldots \ldots \ldots \ldots \ldots \ldots$

5.5 Prefabricated Rebar Mats, Cages and Subassemblies $\ldots \ldots \ldots \ldots \ldots 14$

6.0 DESIGN AND ANALYSIS PROCEDURES $\ldots \ldots \ldots \ldots \ldots \ldots \ldots \ldots \ldots \ldots$

6.1 Steel/Concrete Composite Floors, Beams and Columns . . . . . . . 15

6.2 Concrete-filled Steel Modules . . . . . . . . . . . . . . 16

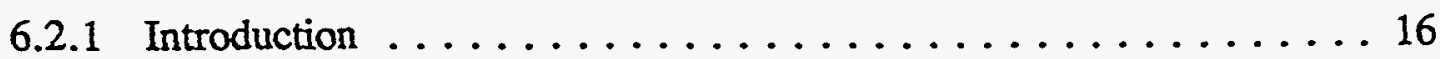

6.2 .2 Analysis/Design Considerations . . . . . . . . . . . 16

6.2.3 Generic Program for Structural Verification . . . . . . . . 17

6.2.3.1 Predictive Analyses . . . . . . . . . . . 18 
6.2.3.2 Comparison to Test Data . . . . . . . . . 20

6.2.3.3 Application of Analytical Methods to Final Design . . . . 24

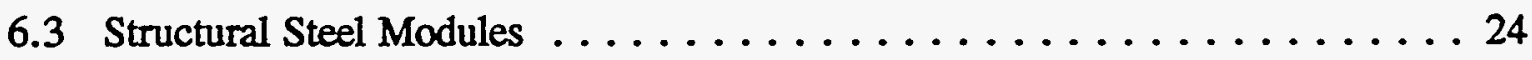

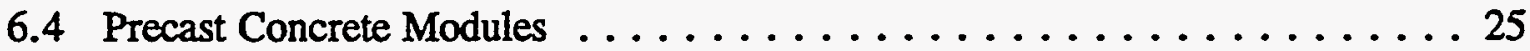

6.5 Prefabricated Rebar Mats, Cages and Subassemblies $\ldots \ldots \ldots 26$

7.0 Structural ACCEPTANCE CRITERIA $\ldots \ldots \ldots \ldots \ldots \ldots \ldots \ldots \ldots$

7.1 Steel/Concrete Composite Floors, Beams and Columns $\ldots \ldots \ldots \ldots$

7.2 Concrete-filled Steel Modules $\ldots \ldots \ldots \ldots \ldots \ldots \ldots \ldots \ldots$

7.3 Structural Steel Modules . . . . . . . . . . . . . . . . . . . . 29

7.4 Precast Concrete Modules . . . . . . . . . . . . . . . . . 29

7.5 Prefabricated Rebar Mats, Cages and Subassemblies . . . . . . . . 29

8.0 Materials, QualtTy Control and Special Construction Technoues . . . . 30

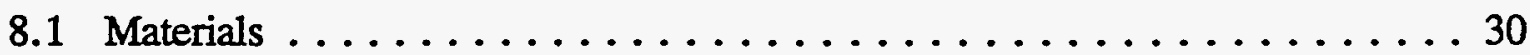

8.2 Quality Control ....................... 30

8.3 Special Construction Techniques $\ldots \ldots \ldots \ldots \ldots \ldots \ldots \ldots \ldots \ldots$

9.0 TESTING AND INSERVICE INSPECTION REOUTREMENTS $\ldots \ldots \ldots \ldots \ldots \ldots$

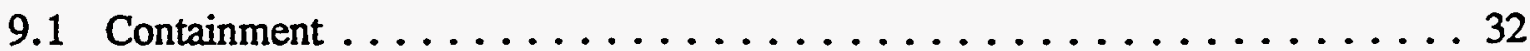

9.2 Structures Other Than Containment $\ldots \ldots \ldots \ldots \ldots \ldots \ldots \ldots \ldots \ldots$

10.0 Regerences $\ldots \ldots \ldots \ldots \ldots \ldots \ldots \ldots \ldots \ldots \ldots \ldots \ldots \ldots \ldots \ldots \ldots \ldots \ldots \ldots$

APPENDIXA - QUALTTY ASSURANCE $\ldots \ldots \ldots \ldots \ldots \ldots \ldots \ldots \ldots \ldots \ldots$ 
 


\section{MODULAR CONSTRUCTION REVIEW CRITERIA}

\section{$1.0 \quad$ INTRODUCTION}

The objective of the NRC Design Certification process is to evaluate and approve, from a safety perspective, a standard nuclear power plant design which can be constructed at most U.S. sites without a detailed, site-specific design/analysis effort. Once approved, economic benefits can be realized by utilizing the standard design at multiple sites. However, if a design inadequacy should be uncovered after design approval and subsequent construction of multiple identical plants, it could have a very serious impact on the nuclear power industry.

The proposed use of modular construction techniques for nuclear power plant structures is an integral element of cost and schedule control for advanced reactor standard designs. Its use should also provide improved control of construction quality and uniformity. Given its importance to overall plant safety, it is imperative that proposed utilization of modular construction be evaluated in depth, to ensure that structural performance and margins of safety are maintained at levels comparable to existing nuclear plant structures.

Currently, there are no specific licensing criteria that provide guidance for the use of structural modules in nuclear power plants. Consequently, the Modular Construction Review Criteria was prepared to provide guidance for use in licensing review activities. Its purpose is to supplement criteria already presented in the NRC Standard Review Plan (SRP)(Reference 10.1).

The scope of this review criteria is limited to structural modules. The type of modules include steel/concrete composite floors, beams, and columns; concrete-filled steel modules; structural steel modules; precast concrete modules; and prefabricated rebar mats, cages, and subassemblies. A more detailed description of these modules and their application to advanced reactors is provided in Section 3.0.

The modular construction review criteria have been developed following the same subsection headings presented in the SRP Section 3.8, Design of Category I Structures. This makes the review criteria more functional because it describes for each SRP subsection, criteria unique to modular construction. 


\subsection{SCOPE/DEEINITIONS}

The Modular Construction Review Criteria are intended to supplement the SRP (NUREG-0800) where additional guidance is needed to address unique structural design/analysis methodologies and/or construction techniques associated with the use of modular construction for advanced reactors. The scope is limited to Seismic Category I building structures covered by Sections 3.8.1 thru 3.8.5 of the SRP.

As used in this report, "Modular Construction" is defined as "any building structure or substructure which is fabricated at a remote site in transportable-sized modules, and then moved to the erection site for final assembly and placement". The "remote" site may be thousands of feet or thousands of miles from the erection site.

A number of specific types of structural modules have been identified for inclusion in the review criteria, based on preliminary submittals for design certification of advanced reactors. These are:

- Steel/Concrete Composite Floors, Beams, and Columns

- Concrete-Filled Steel Modules

- $\quad$ Structural Steel Modules

- Pre-cast Concrete Modules

- Prefabricated Rebar Mats, Cages, and Subassemblies

Appropriate review criteria for other types of structural modules can be readily deduced from the specific review criteria provided for the identified module types.

SRP Chapter 17 (Quality Assurance) has also been studied in detail, to assess whether supplemental review criteria are required for modular construction. The SRP covers all areas of quality assurance pertinent to modular construction, as well as traditional construction. However, the requirements are somewhat broad, raising the possibility that some important element for modular construction may be overlooked in the review. Therefore, additional guidance has been developed to ensure that important elements for modular construction are reviewed in sufficient detail. This information is provided in Appendix A. 


\subsection{DESCRIPTION OF STRUCTURES}

Modular construction techniques can be applied to many structures found in advanced reactor plants. The Electric Power Research Institute's (EPRI) program on Advanced Light Water Reactors (ALWRs) recognized this and the associated benefits of a reduced construction schedule and lower costs. Thus, through the Utility Requirements Document (Reference 10.2), EPRI has required that ALWR plants be designed to maximize the benefits of modular construction techniques.

The Utility Requirements Document lists examples of modules which have been previously developed and represent the minimum level of effort expected for ALWRs. These include:

- Basemat reinforcing steel assemblies

- Reactor vessel pedestal structural steel

- Reactor vessel nozzle support ring

- Containment vessel or liner plate

- Refueling pool and spent fuel pool liner plates

- Precast concrete walls, beams, slabs (where practical)

Examples of structural components which are candidates for reinforcing steel assemblies/modules in future ALWRs are numerous. They include: crane wall modules; basemat and foundations; building walls, floor slabs, columns, and beams; containment walls; containment hatch cages; tunnel cages; primary shield wall cages; and composite containment liner and reinforcing steel cages. Some of the reinforcing steel modules require special steel support structures such as upper rebar mat support frames. Large rebar modules also require structural support systems to maintain the rebar spacing, to stiffen the cages or modules, and for alignment to adjacent rebar modules. Examples of rebar modules for pool walls and Reactor Pressure Vessel (RPV) pedestal are shown in Figure 3-1 (from Reference 10.3).

In the past, a number of nuclear plants have modularized the containment wall and dome liner in sections. Wall liner modules were typically preassembled into multiple rings from individual 30 feet long by 10 feet high panels. These modules included penetrations, embedments, appurtenances, and temporary girders to resist wind loads. These girders are placed on the inside of each ring to maintain the circular shape of the liner. Containment dome liners have also been preassembled and lifted into place in one or two sections. 
The refueling pool, fuel transfer canal, and spent fuel pool are candidates for liner type modules. Liner panels, sized for shipping limits, can be preassembled in fabrication shops. On-site, the panels can be assembled into larger modules prior to erection. In previous nuclear plant construction, liner modules have been used inside containment (refueling pool and fuel transfer canal) and in the fuel storage building (fuel transfer canal and spent fuel pool). Examples of containment wall liner modules and pool liner modules are shown in Figure 3-1.

Structural steel preassemblies/modules have also been utilized to varying degrees in the past on nuclear power plants. Preassembly of structural floor steel framing, metal decking, and reinforcing steel has been used on some projects. Steel framing and metal decking are used to support concrete slabs. Composite construction of steel floors, beams, and columns could be modularized for use in advanced reactor plants. The steel modules would be prefabricated, assembled at the site, lifted into position, and then filled with concrete. Figure 3-2 (from Reference 10.4) shows a composite floor module consisting of a steel face plate, horizontal Tees and angle stiffeners, and rebars.

Another use for structural steel modules is for building superstructures. These modules could include roof trusses, siding, equipment, and connecting piping, ducts, and cabling. Stairs and steel platforms can also be modularized. Examples of structural steel modules for building superstructures are shown in Figure 3-2.

Structural steel modules may be used as steel forms for concrete structures such as the RPV pedestal, drywell vent wall, and containment internal base structures. These steel forms would typically consist of steel plates reinforced with stiffeners on the concrete side of the plate. These forms are permanent since they are left in place after the concrete cures. The steel form modules are used in lieu of removable forms. The advantage is that these wall modules, can be fabricated and preassembled offsite in parallel with other ongoing construction activities. This reduces construction efforts at the site which results in cost savings to the project. In addition, savings are achieved by reducing or eliminating the time spent waiting for sections of concrete to cure before other phases of construction can proceed. The need to strip forms, clean-up, and patch exposed concrete surfaces is also eliminated. Figure 3-3 (from Reference 10.5) shows a structural steel form type module which is left in place.

For walls where strength, stiffness, and radiation shielding are required, concrete-filled steel modules may be used. Such walls exist inside containment, auxiliary building, and other seismic Category I structures. These modules would typically be constructed from steel plates spaced apart and connected by web plates. The steel plates may be stiffened by structural angles connected to the plates or held in place by studs welded to the plates. The angles or studs then become embedded in concrete when it is poured. An example of a modular subunit for a concrete-filled steel wall module is shown in Figure 3-4 (from Reference 10.6). The steel modules can be prefabricated in offsite shops and transported to the site as subunits where they can be assembled into large modules. Then the modules can be lifted into position, anchored, and filled with concrete. Figure 3-5 (from Reference 10.6) shows an assembled concrete-filled steel wall module 
being lifted.

Steel wall modules without concrete fill can also be utilized where shielding from radiation is not required. Large water storage tanks are potential candidates for this type of module.

Precast concrete modules have been previously used in nuclear power plants. The applications include precast concrete panels for superstructure curtain walls, manholes for electrical and piping use, vaults for cables, trenches for cable and for pipe, electrical duct banks, catch basins, and precast architectural panels and walls. The use of precast concrete modules beyond these applications is expected to be limited. Difficulties arise in the transportation and handling of large and heavy precast concrete modules. In addition, the wall thicknesses of massive concrete sections with congested rebar make it extremely difficult to design and construct connections between modular interfaces. 


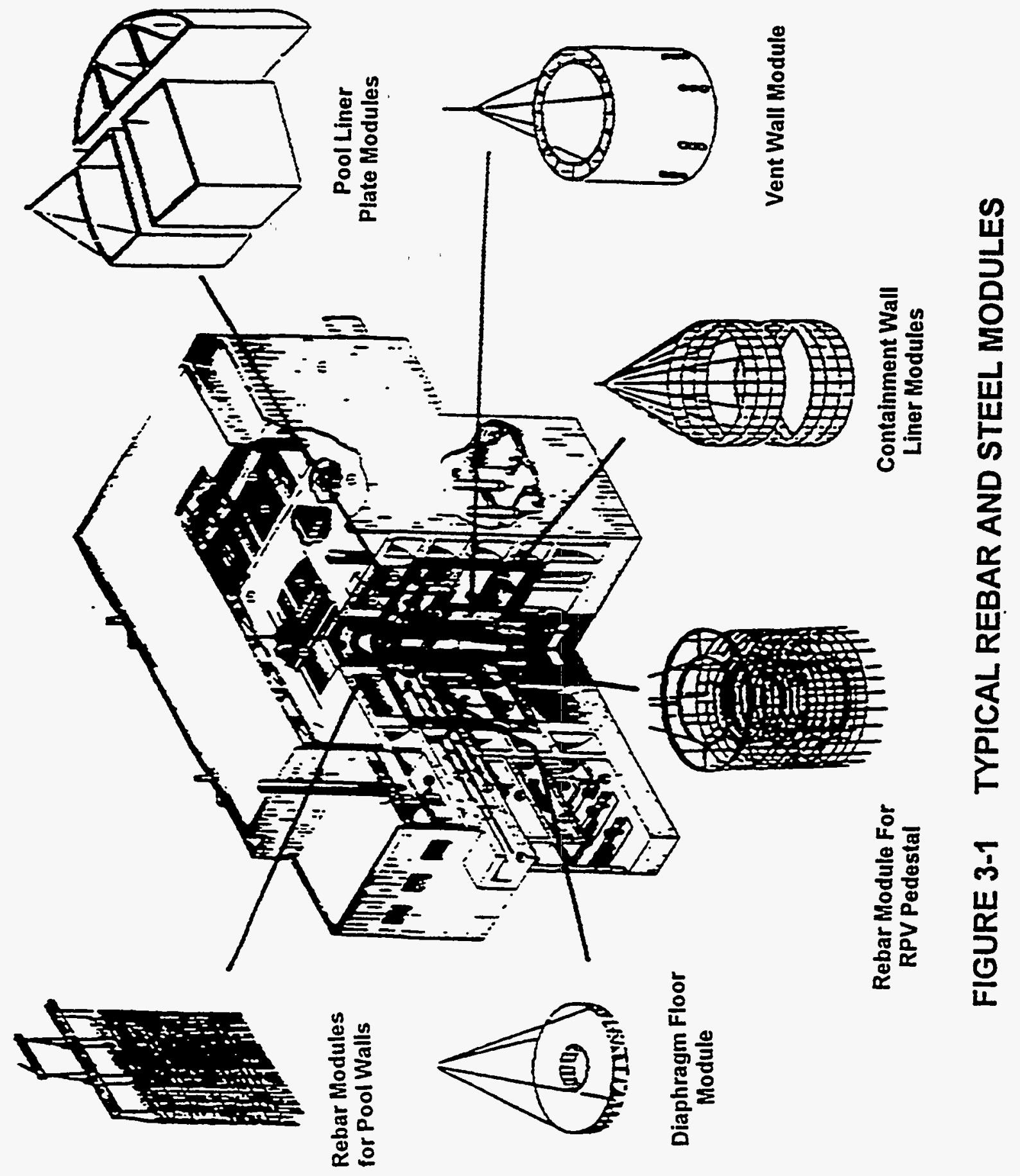




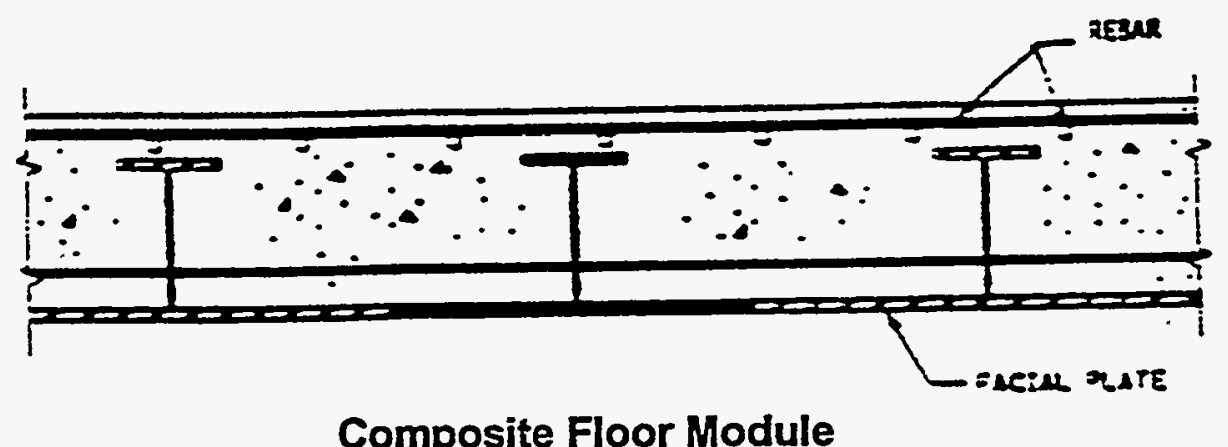

Composite Floor Module

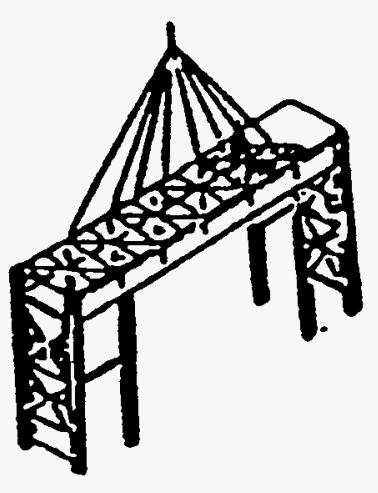

Struct. Steel Modules Above Operating Floor

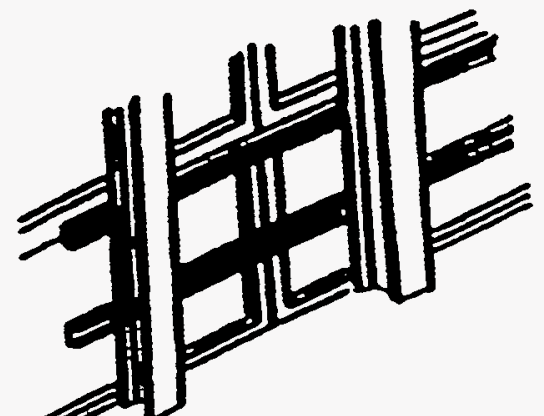

Struct. Steel Walls Above Operating Floor, with Pre-Assembled Siding

FIGURE 3-2 COMPOSITE FLOOR AND STRUCTURAL STEEL MODULES 


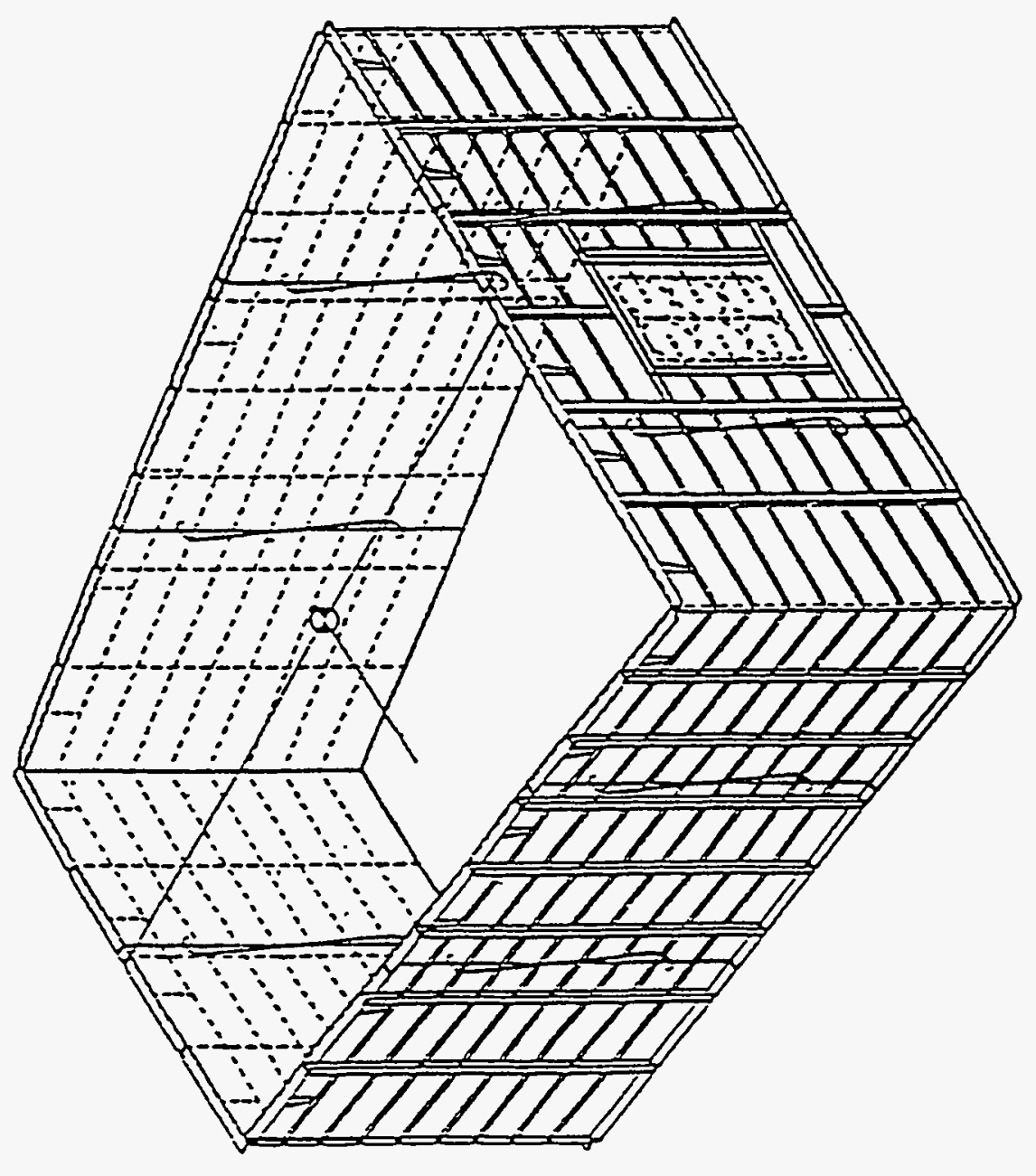

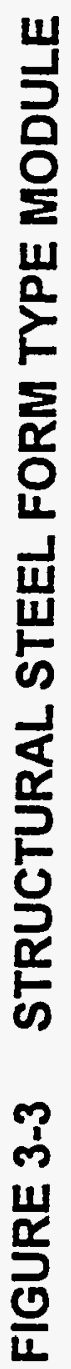




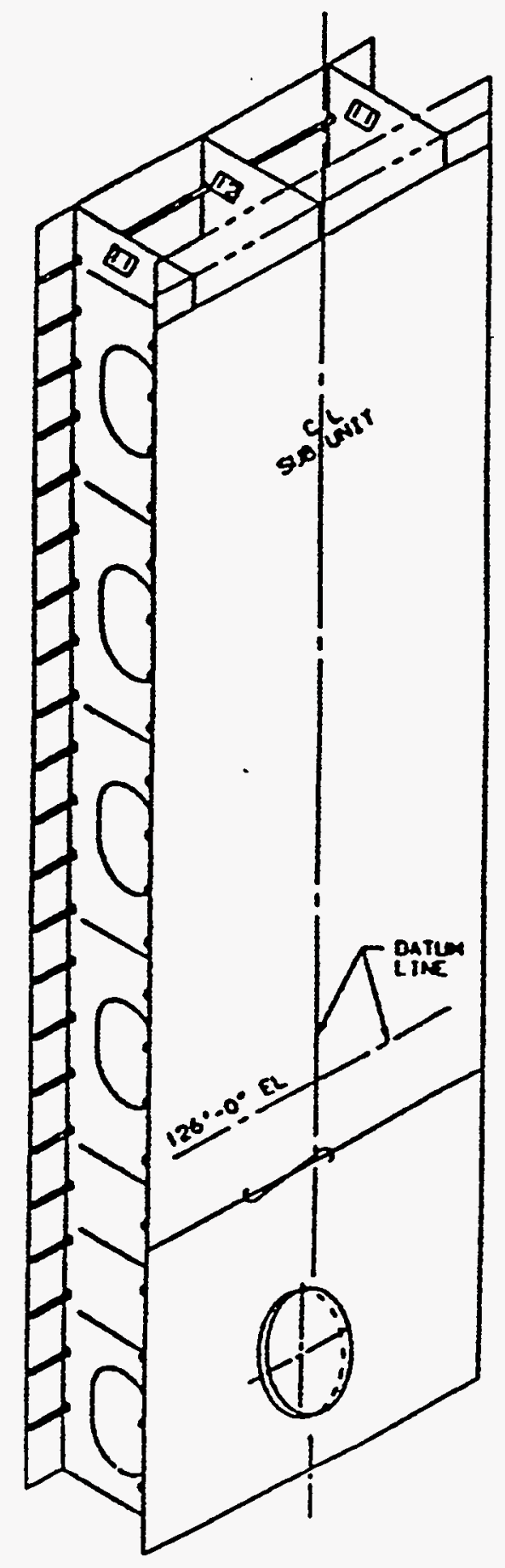

FIGURE 3-4 MODULAR SUBUNIT FOR CONCRETEFILLED STEEL WALL MODULE 


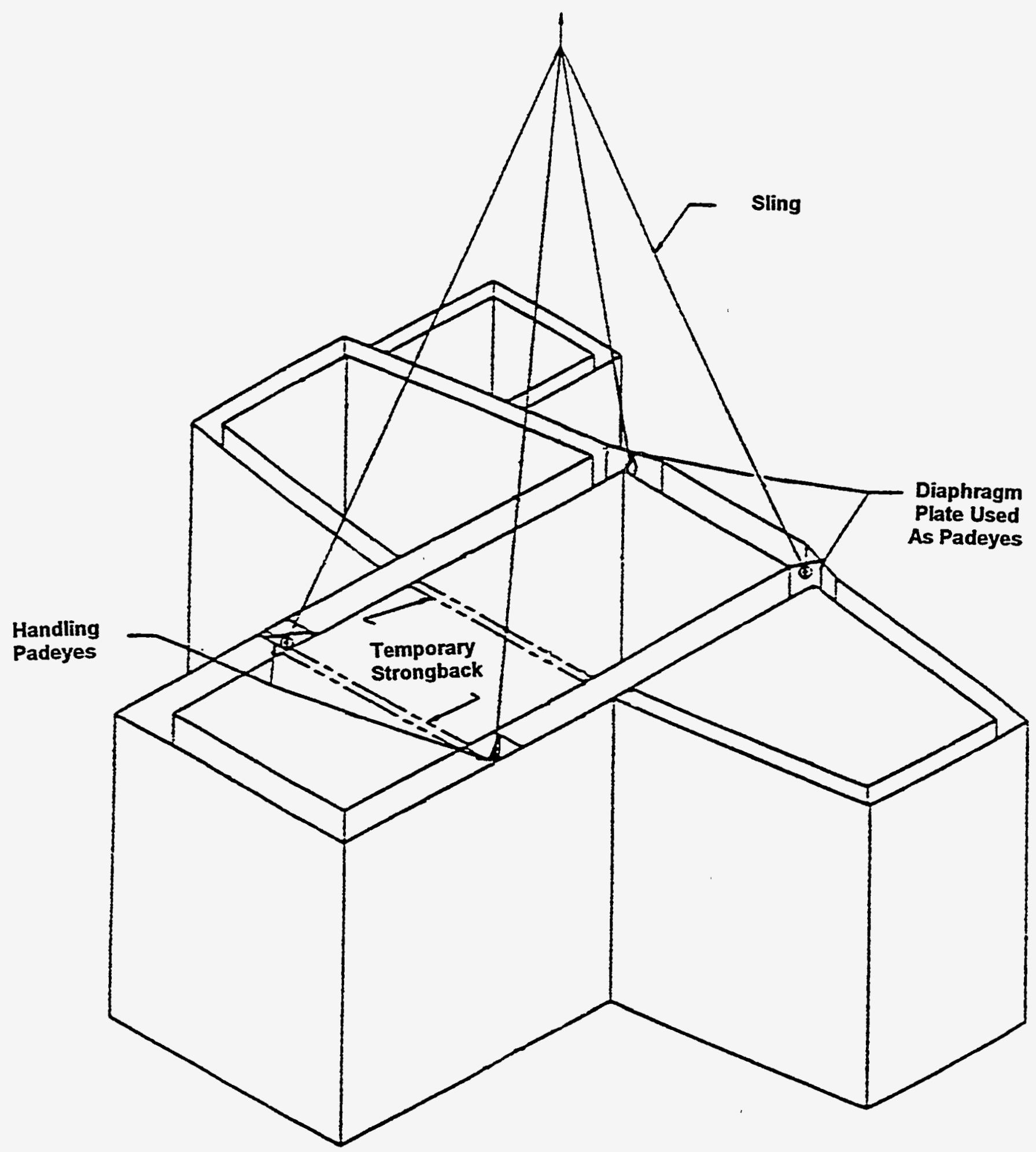

FIGURE 3-5 CONCRETE-FILLED STEEL WALL MODULE 


\subsection{APPLICABLE CODES, STANDARDS AND SPECIFICATTONS}

\subsection{SteEL/CONCRETE COMPOSTTE FLOORS, BEAMS AND COLUMNS}

These types of modular structures have been previously accepted for use in commercial nuclear power plants. The American Institute of Steel Construction (AISC) Specification * (Reference 10.7) and the American Concrete Institute (ACl) Code 349 (Reference 10.8) cover steel/concrete composite floors, beams, and columns. Therefore, they can be used, as applicable and as supplemented by current NRC technical positions and Regulatory Guides.

\subsection{CONCRETE-FIILED STEEL MODULES}

The lack of U.S. codes and standards covering this type of modular construction lends uncertainty to the design/analysis/construction basis. Reliance on a program of analysis and test, as described in Section 6.2, is the only alternative until applicable codes and standards (typically based on pioneering applications such as the ones proposed for advanced reactors) are developed and accepted by the NRC for use in safety related, nuclear power plant applications.

Guidance can be obtained from accepted codes standards and regulatory guides, to the extent of their applicability. It is reasonable to limit steel and concrete stresses and deformations to AISC and ACI design allowables as specified in SRP Section 3.8 provided the predicted stresses and deformations are obtained from verified analysis methods, benchmarked against test data. Both overall behavior and local interaction of the steel and concrete portions of the module need to be evaluated.

Additional load combinations, dimensional controls, and inspections should be specified, as needed to ensure structural integrity and proper fit-up of the complete modular assembly.

\subsection{STRUCTURALSTEEL MODULES}

The provisions of the AISC Specification (Reference 10.7) or American Society of Mechanical Engineers (ASME) Boiler and Pressure Vessel Code (Reference 10.9) as appropriate to the specific application, and as supplemented by current NRC technical positions and Regulatory Guides, can be used as the design/analysis/construction basis for a structure assembled from steel modules. The only difference from current practice is in the fabrication/erection process.

- When endorsed by the NRC, it is expected that ANSI/AISC N690 (Ref. 10.15) will replace the AISC Specification as the reference standard for steel structures in the SRP. 
Additional load combinations, dimensional controls, and inspections should be specified, as needed to ensure structural integrity and proper fit-up of the complete modular assembly.

\subsection{Precast Concrete Modules}

The use of precast concrete modules for safety-related structures or substructures is expected to be limited. The ACI Code 349 (Reference 10.8) can be used as the design/analysis/construction basis, provided the precast module meets the requirements which would apply to the corresponding poured-in-place concrete structure. Any applicable NRC technical positions and Regulatory Guides should also be satisfied. Special provisions to limit transportation loads, especially vibration and impact loads, are necessary to preclude damage during transit to the site. Special connection detailing is required to join pre-cast modular units into a final modular assembly. Inspection of precast modular units is necessary to ensure that the as-received condition and the in-place condition meet the applicable design requirements.

\subsection{Prefabricated Rebar Mats, Cages and Subassemblies}

These "structures" do not represent a complete structural unit. Either the ACI Code 349 (Reference 10.8) or the ASME Code (Reference 10.10) defines the steel reinforcing requirements, depending on the application. Adherence to these design requirements is necessary. The in-place placement, connectivity, and splicing of rebar must meet the appropriate code requirements, regardless of the sequence leading up to the concrete pour. Any applicable NRC technical positions and Regulatory Guides should also be satisfied.

The procedures to ensure that the in-place geometry of the reinforcing steel meets the design requirements should be specified. In addition, the procedure for joining of rebar subassemblies to create a complete rebar assembly should be specified, with emphasis on ensuring the continuity of load transfer. 
The SRP defines the loads and load combinations, expected during plant operation, to be used for structural design. These are directly applicable to design of structures erected utilizing modular construction techniques. For modular construction, however, the process of off-site fabrication, transportation, and site erection may impose significant additional loads which typically are not considered for in-place construction. While these additional loads are not likely to control the overall structural design, it is important that each modular unit has sufficient strength and stiffness to resist these loads without any degradation of operating load capacity and without unacceptable permanent deformation. To allow either condition could negate the initial design assumptions.

During off-site fabrication, the method of supporting the module during the various stages of fabrication and the method of lifting and moving the module from one work station to the next will control the induced stresses and deformations. The completed module must be hoisted onto the transportation vehicle, supported, and tied down. These operations will impose a second set of loads on the module. During transit, the module will likely be subjected to both vibration and impact. Upon arrival on-site, the module is hoisted off the vehicle and supported on the ground. Final site assembly will impose lifting and fit-up/joining loads on the module. All of these construction-related activities must be executed in a manner which limits stress, deformation, and fatigue usage to acceptable levels (i.e., maintain the initial design basis).

In general, the construction-related loads need not be combined with the operating loads defined by the SRP because they do not occur concurrently. The exception to this would be any residual effects resulting from construction-related loads. For example, in concrete-filled steel modules, some residual stress and deformation of the steel plates is possible as a result of the in-place concrete pour process.

\subsection{STEEL/CONCRETE COMPOSTTE FlOORS, BEAMS AND COLUMNS}

These types of construction have been previously accepted for use in commercial nuclear power plants by the NRC. Therefore, additional loads and load combinations are not considered necessary in this case. Procedures for minimizing shipping and handling loads should be specified, to ensure no loss in capacity to carry operating loads and load combinations.

\subsection{CONCRETE-FILLED STEEL MODULES}

The size of the steel modular units is typically constrained by maximum shipping dimensions/weight (e.g., see Reference 10.11 for Rail Transport) or by crane lifting capacity. Lifting loads need to be considered in the design of the steel module, to select the number, locations, and geometry of the lifting lugs. Fixtures for supporting the modules during transportation to the site should be designed to ensure that vibration-related cyclic stresses and impact-induced stresses do not exceed specified criteria. 
A loading unique to concrete-filled steel modules is the hydrostatic pressure against the steel walls, during the on-site concrete pour. The pour rate (height of each concrete lift) must be limited to ensure that the steel plate stresses do not exceed a specified allowable value or the steel plate thickness must be specified to ensure that a desired pour rate is achievable.

\subsection{StRUCTURAL STEEL MODULES}

The discussion in Section 5.2 applies here, except that concrete pour loads do not exist.

\subsection{BrECAST CONCRETE MODULES}

The discussion in Section 5.1 applies here.

\subsection{Prefabricated Rebar Mats, Cages and Subassemblies}

These structural elements are part of a poured-in-place reinforced concrete structure, which is subject to currently defined operating loads and load combinations. Placement procedures should be sufficiently detailed to preclude the development of excessive loads during the handling and placement of the rebar. 


\subsection{Design and ANalysis Procedures}

There are unique aspects of modular construction that need to be considered in design and analysis. This section of the report describes the additional guidelines and procedures that should be followed to demonstrate the structural adequacy of the design.

In view of the limited use of modular construction techniques for structures at nuclear power plants, the design and analysis procedures used for advanced reactors should be carefully reviewed. Three sources of information for accomplishing this are 1) the Safety Analysis Report (SAR), 2) the design reports, and 3) the structural audit. As indicated in Appendix C to SRP. Section 3.8.4, the design report provides the reviewer with design and construction information more specific than that contained in the SAR. The design report also assists the reviewer in planning and conducting a structural design audit.

A structural design audit is a necessary step in view of the unique modular construction techniques. In addition to the objectives currently described in Appendix B to SRP Section 3.8.4, the audit should ensure that the analysis and design addresses all processes related to modular construction, including fabrication, transportation, handling, storage, and erection.

\subsection{STEEL/CONCRETE COMPOSTTE FlOORS, BEAMS AND COLUMNS}

Composite steel/concrete floors have been previously utilized in the nuclear industry. The composite elements consist of steel beams or girders supporting a reinforced concrete slab whereby the two structural elements are interconnected so that they act together in resisting bending loads. Floor systems can also be constructed from steel beams supporting steel decking upon which concrete is poured. Composite compression members consist of concrete reinforced longitudinally with structural steel shapes, pipe, or tubing with or without longitudinal bars.

Current NRC requirements and industry codes and standards are sufficient to define acceptable design and analysis requirements for composite structures. The AISC Specification, supplemented by NRC technical positions, provide requirements for composite construction consisting of steel beams or girders supporting a reinforced concrete slab or steel deck in nuclear facilities. ACI 349 provides requirements for composite compression members for nuclear facilities. The ACI code covers two types of composite columns: a structural steel encased concrete core and reinforced concrete around a structural steel core.

While acceptable criteria exist, special consideration should be given to unique aspects pertaining to modularization of composite structures. The design of the modules must consider the loads generated as a result of the fabrication, handling, transportation, and erection of steel as well as the pouring of concrete. These are discussed in Section 5.0. These loads will often require supplementary steel to provide sufficient stiffness to maintain the module configuration from off-site fabrication to final placement. 


\subsection{CONCRETE-FILLED STEEL MODULES}

\subsubsection{INTRODUCTION}

The current state-of-the-art for structural analysis of nuclear power plant structures is sufficient to provide a solid basis for understanding and predicting the behavior of modular structures, provided the physical conditions of the fabricated module and the erected modular assembly are accurately known. However, the current lack of modular design and construction experience raises a number of issues that need to be addressed.

Limited experience is available from work conducted in Japan for concrete-filled steel modules similar to those proposed for advanced reactors in the U.S. While the reported test results provide a general sense of "robustness", the scope of the reported results is insufficient to support generalizations about proper design/analysis assumptions.

Consequently, the only currently viable approach to the design certification of concrete-filled steel modules appears to be the performance of a detailed analysis and comparison to supporting test data, to substantiate both the design approach and the resulting design.

\subsubsection{ANALYSTS/DESIGN CONSIDERATIONS}

The following points should be considered in the design and analysis of concretefilled steel modules:

- Structural behavior of modular units must be well understood. It is not sufficient to rely on perceived "conservative" assumptions of stiffness, load path, and structural strength criteria. In the design of modular units and the connection details, it is very likely that subtle situations exist, for which a simplifying assumption may not be readily classified as "conservative".

- The connections between modular units which make up a complete modular assembly are critical elements in the response of the assembly. The connection detail will determine the load transfer path between modular units and the joint "ductility". This must be well understood to accurately evaluate the local behavior of the modular unit and the overall behavior of the modular assembly.

- Given the current state of the art in computer-aided structural analysis, detailed modeling/analysis of the modular unit and modular assembly can be 
performed. This analysis coupled with confirmatory testing of the basic modular unit and connection details, should make it possible to accurately predict both local and overall structural behavior. The need for so-called "conservative" assumptions should be minimized, and where necessary, the sensitivity of the structural behavior of the modular unit to a parameter variation should be performed to verify the original perception of "conservatism".

- The complex interaction between steel and concrete cannot be adequately evaluated if the design methodology selectively relies on only one of the two structural elements to carry specific types of loading (i.e., bending, shear, and compression). A potentially serious pitfall of this approach is that the designer/analyst must work with several "different structures" to carry the applied loads. The probability of making an error is increased and the use of engineering judgement to qualitatively check numerical results becomes difficult. Most importantly, interactions which are ignored by the design methodology may precipitate a loading path and progressive failure which is the limiting condition of structural strength.

Advanced reactors have a design life of sixty $(60)$ years - $50 \%$ longer than current operating plants. Based on the recent NRC study (Reference 10.12) on aging degradation of civil/structural features at several older operating plants, it was concluded that with proper maintenance, in-service inspection, and occasional repair and correction of an unforeseen degradation condition, civil/structural features should not be a controlling factor in the life extension of existing plants to 60 years. Also, as part of this study, the conditions observed at operating plants were evaluated in the context of a 60 year design life for Advanced Reactors. The results of this study should be considered in the development of design, construction, inspection, and maintenance specifications.

\subsubsection{GeNeric Program For Structural Verification}

A structural verification program should be performed to substantiate the design/analysis methods for construction of safety-related concrete-filled steel modules. This program should also demonstrate that these methods maintain sufficient margins of safety when compared to design/analysis standards for other structural components such as reinforced concrete or structural steel. To achieve these objectives, the following elements should be included in the structural verification program:

- $\quad$ Predictive Analyses
- $\quad$ Comparison to Test Data 


\subsubsection{PrenICTUVE ANALYSES}

Some of the steel and concrete modules being proposed for advanced reactors are quite unique in their design and application. To understand the complex behavior of the concrete-filled steel module, analytical studies should be performed and verified by test data. These studies should first be performed on small subunits or panel sections to understand the local behavior, to identify important parameters, and to assess the sensitivity of the modules to these parameters. In addition to the subunits, analyses of connections also need to be performed since connections are generally known to be a concern with modular construction.

Using a general purpose structural analysis computer program, a finite element model of a single subunit or panel section should be developed. To understand the behavior, a simplified representation of the steel and concrete can be made initially with layered shell elements. Then, enhancements in the model can be introduced step-by-step to match the actual configuration and material behavior. In this manner the response due to each modeling refinement can be evaluated as it is introduced. Some of the envisioned modeling steps/evaluations are layered shell versus solid elements, vertical displacement compatibility at embedded stiffeners, concrete cracking in tension, face plate buckling, concrete shear slippage, and bond loss at steel/concrete interface.

Initially, static analyses should be performed to investigate the stiffness properties of the modules. It is desirable to determine the stiffness values for shear (in-plane and out-of-plane), bending (about both in plane axes) compression, tension, and interaction of two or more component loadings. These analyses should be performed for incrementally increasing loads since, at some point, the concrete would begin to crack and the stiffness value would decrease.

The results of the analytical studies should be compared to test data. The test data could be obtained from existing available tests or new tests performed specifically for the modular design concept being proposed. A description of acceptable test data and recommended test program, if required, is presented in Section 6.2.3.2.

The results of the stiffness analyses should be compared to the test data. Where test data indicate behavior different from the analytical models, then 
the causes of this deviation should be identified. If sufficient test data is available to explain these differences, then adjustments to the model can be made and additional analyses performed in an effort to match test results. If the test data are only available on reduced scale specimens, then the above analyses should also be performed on a reduced scale model.

Once the stiffness results match the test data, the sensitivity to selected parameters should be performed. These should be performed by varying parameters such as compressive strength of concrete, tensile strength of concrete, shear strength of concrete, degree of bond (concrete to steel), and others.

Stress analyses should also be performed to determine the stress distribution throughout the modules at different load levels. Loads consisting of shear, bending, compression, and interaction of two or more loads should be applied. The results should be compared to actual stresses obtained from test data. The effects of parameter variation should also be performed to determine the sensitivity of the stress distribution to variation in properties.

In addition to analyzing individual subunits, such as a panel section, any special configurations such as tee or angle connections (e.g., two shear walls intersecting at $90^{\circ}$ or some other angle) should also be evaluated using the procedures described above.

The above evaluations should also consider the effects of uniform temperature change and thru-wall temperature gradient arising from normal operating and accident conditions.

\section{DUCTILIT/SAEETYMARGIN}

To obtain an understanding of the level of ductility and the margin against ultimate capacity, test results should be obtained at progressively increasing loads beyond the elastic range of material properties. If acceptable test data is not available and new tests present limitations (e.g., size, weight, loading equipment, scaling questions, sufficient data), then additional analyses may be required. These analyses will need to consider nonlinear effects such as plastic deformation, buckling of the steel material, concrete cracking effects in tension and shear, and concrete crushing in compression. If required, geometric nonlinearity such as large deflection effects should also be considered. The results of these analyses should be compared to the corresponding tests where data is available to confirm modeling assumptions. Then the analyses can be expanded where additional information is needed. The effort should verify that the ductility and margins against ultimate 
capacity are comparable to other conventional structural components used in nuclear power plants.

\subsubsection{COMPARISON TO TEST DATA}

The technical basis for any design/analysis methodology is either (1) direct verification by full scale and/or reduced scale prototype testing or (2) consensus by industry experts (i.e., codes and standards). Codes and standards, being primarily experience-based, typically lag the initial applications of new structural design concepts. However, new structural design concepts are typically incremental, rather than radical, departures from accepted practice. Consequently, considerable guidance is available in existing codes and standards which is applicable to the new concept.

The extent of applicability of existing codes and standards to new design concepts can be subject to considerable disagreement. Given the NRC's responsibility to ensure with a high level of confidence that the public safety is maintained for all credible events, it is necessary to demonstrate that the application of existing codes and standards to new design concepts maintains safety margins which are at least equivalent to existing safety margins. Therefore, any structural design concept which falls outside the boundaries of currently accepted codes and standards should require verification of the design/analysis methodology by comparison to applicable test data.

If a sufficient body of applicable test data already exists in the open literature, then project-specific testing may not be required. However, it is the applicant's responsibility to submit a sufficiently detailed justification for the proposed design/analysis methodology, based on the existing test data.

In the absence of a sufficient body of existing test data, a project-specific test program will probably be required to address areas of uncertainty about the structural behavior. The scope of the test program will be defined by the degree of uncertainty.

\section{TEST PROGRAM OBJECTIVES}

The objectives of the testing program are twofold:

1) to establish that proposed design/analysis procedures produce a conservative design,

2) to assess the inherent "ductility" and excess load carrying capacity above design loads. 
These objectives can be addressed through the use of reduced-scale models. However, if it is feasible to build and test a full scale model of the basic modular unit, two additional benefits can be realized:

1) uncertainty about extrapolation of reduced-scale model test results to the actual structure is greatly minimized, and

2) proposed fabrication, erection, Quality Control (QC), Quality Assurance (QA), inspection and test specifications to be used during actual construction can be implemented for the test model. Supplementary nondestructive examination of the completed test model can be performed to verify the finished product quality, to define the initial conditions before loading, to identify any unacceptable conditions which may warrant revisions to the proposed specifications, and also to provide valuable input for proper analytical modeling of the structural modules.

\section{SELECTION OE TEST MODELS}

The predictive analyses discussed in 6.2.3.1 provide insight into the key structural parameters which affect the response of the modular unit. The test models must be designed to ensure that the results of the analyses can be verified and/or that the shortcomings of the analysis models can be identified. The suggested types of test models are as follows:

- One (1) typical, full scale modular unit fabricated in accordance with the shop production procedure and filled with concrete (if applicable) in accordance with the field production procedure. All applicable shop/field tests and inspections to be performed.

- A scale model of the full scale modular unit described above.

- A scale model of each significant variation in the modular unit geometry, materials, or fabrication procedures.

- A scale model of a typical in-line connection, a comer connection, and a connection between modular units. Connections to be in accordance with applicable production procedures and inspections. (Note: The connection detail may be tested at full scale, if feasible.)

\section{SCOPE OE TEST PROGRAM}

The specific program scope will depend on the degree of uncertainty about 
the significant structural responses of the modular unit and the connections. In some cases, only selective testing may be needed to fill the voids in an existing body of test data. In other cases, a comprehensive test program may be required to generate a sufficient body of test data for verification of the design/analysis methodology. It is the applicant's responsibility to identify the requirements for testing, develop an appropriate test program scope, conduct the test program, and verify the design/analysis methodology based on test data.

\section{Test Data Reourrements}

The types of test data required to verify the design/analysis methodology include the following:

- Load vs Deflection data for all significant load types (e.g., in-plane and out-of-plane shear, out-of-plane bending, compression, tension), in order to verify the analytically derived stiffnesses. The load-deflection behavior up to and somewhat above design allowable load levels should be determined. Loads should be applied incrementally, with decreasing increment size as the load increases. . The point of departure from linear load-deflection behavior is particularly significant, since this defines the limit of applicability for the initial stiffness. In general, it is desirable to limit design allowable loads to the initial linear stiffness range of response.

In the first series of tests, each different type of load should be applied individually and incrementally increased up to the point of departure from linear behavior. Following completion of these uniload tests, a test to specimen failure (if feasible) should be conducted using the anticipated worst-case loading combination. The set of forces (moments, shear, and compression or tension) should be applied simultaneously in proportion to the expected governing/critical case. Detailed load-deflection data should be collected for all responses previously measured in the uni-load tests, up to failure or the maximum loading capability of the test facility. The results of this test provide valuable information about the inherent "ductility" and reserve strength capacity above design allowable loads.

Stiffness degradation caused by simultaneous application of several loads can be estimated by comparing the measured response for multiple loading to the linear combination of measured uni-loading 
responses. If this effect is significant at design allowable load levels, then the initial stiffnesses used in design/analysis will have to reflect this.

An alternative to the simultaneous application of forces, described above, may be utilized. The series of uni-load tests can be performed at incrementally increasing loads up to failure. This approach, however, would require more specimens and the issue of the interaction effects of two or more forces would still have to be addressed.

Strain Measurements should be recorded at key locations, throughout the loading tests described above. The strain measurements, converted to stresses, can be compared to analytical predictions, to verify the analytical model.

Strain measurements should also be recorded at locations of structural discontinuity and locations of uncertainty about the actual load path. Local inelastic deformations may occur at load levels significantly below the "elastic" limit for module behavior; they are potentially significant when the individual modular units are assembled into larger structures.

Test models of connection details should have sufficient strain measurements recorded to ensure a comprehensive understanding of the connection behavior for the various types of loads transmitted through it.

Progression of Concrete Cracking (where applicable) should be monitored during the loading tests. It is important to track the deviation from linear behavior against physical, irreversible degradation of the structural system. The initiation and progression of concrete cracking may or may not correlate with measured stiffness degradation. Confinement of the concrete may significantly modify its behavior. Recording of this data will provide a basis for quantifying the effects of concrete cracking in the design/analysis methodology. Monitoring the progression of concrete cracking is not straightforward due to the steel face plates. Acoustic emission or other special nondestructive examination techniques will probably be required. 


\subsubsection{APPLICATUON OE ANALYTICAL METHODS TO FinaL DESTGN}

A complete analytical model of the assembled structure, which is constructed from individual module subunits, should be developed. The effects of important items such as openings, type of loads, load path, and boundary conditions can only be evaluated with the full model. The use of an accurate and complete model also eliminates the need to make simplifying and possibly unconservative assumptions.

Typically this model would be quite large; therefore, to develop an efficient mathematical model, it may be necessary to define an equivalent shell element stiffness. This may be done using layering, orthotopic properties, or other methods to simulate the extensional, shear, and bending stiffness properties derived from analysis and test data of the subunits, as discussed in the previous Sections.

The model should properly reflect the boundary conditions, mass distribution, openings', and dynamic effects of any water. The loadings applied to the model should include all applicable loads described in Section 5.0 of this document. The seismic analysis must comply with Sections 3.7.1 through 3.7.3 of the SRP.

For seismic analysis, damping should be consistent with Regulatory Guide 1.61 (Reference 10.13). Damping of 5\% for SSE load combinations is considered reasonable. Higher damping values could be used if supported by specific, applicable test results.

\subsection{STRUCTURALSTEEL MODURES}

Steel plate modules may include sections of free standing steel containments; containment liners for concrete containments; and liners for refueling pool, fuel transfer canal, and spent fuel pool. Some of these modules have been utilized in the past for the construction of nuclear power plants. Modularization of the containment dome liner was used for the construction of the Wolf Creek Generating Station and Hope Creek nuclear plant, among others. Plants which utilized fuel-related liner modules include Palo Verde, San Onofre, and Beaver Valley stations.

In view of the successful use of steel plate modules in the past, current NRC guidance and industry codes and standards are sufficient to define acceptable design and analysis requirements. However, special consideration needs to be given to several items that are unique to modular construction. The additional loads resulting from the construction/preassembly of larger modules need to be addressed. Currently, larger capacity lift cranes are available which may impose significant concentrated loads. These 
loads must be considered early on in the design stage of the modules. Also, when lifting these modules under windy conditions, the large cross sectional area of some modules may develop loads that will require specific consideration in their design and handling.

In addition, supplementary steel will need to be pre-engineered to provide sufficient stiffness to maintain the module configuration from preassembly through transporting, lifting into place, and placement of concrete. This additional steel would not be wasted in a good design if its load carrying capability is included in the analysis and design of the assembled structure.

Steel frame modules may be used for building steel framework such as building superstructures (roof trusses, siding, etc.), structural steel platforms, wall partitions, and floors (steel framing, metal decking, and reinforcing steel). Some of these modules have also been used in the past on nuclear power plants with success. As in the case of steel plate modules, current NRC requirements and industry codes and standards are adequate to define design and analysis requirements. The AISC Specification, supplemented by NRC technical positions, provide acceptable requirements for the design of steel frame modules in nuclear power plants. Additional considerations described for steel plate modules also apply to steel frame modules.

\subsection{Precast Concrete Modules}

Due to weight considerations during transportation and handling, and difficulty in designing connections of load carrying precast concrete elements, they have not been widely used for safety related structures at nuclear power plants. Precast concrete elements have been used in limited cases such as superstructure curtain walls, manholes, vaults, electrical duct banks and precast architectural panels and walls.

Current NRC requirements and industry codes and standards define acceptable design and analysis requirements which would apply to precast concrete elements. ACI 349 provides requirements for design of precast concrete members which it defines as concrete elements cast elsewhere than their final position in the structure. Provisions are presented in the Code to address special conditions important to the design of precast concrete members. These include consideration of all loading and restraint conditions from initial fabrication to completion of the structure, requirements for design of connections, detailing requirements, and provisions for precast wall panels. Additional requirements are also specified for identifying and marking the members and for transporting, storing, and erecting the precast members.

In view of the limited use of precast concrete modules for safety related structures at nuclear power plants, the analysis and design procedures should be carefully reviewed, particularly in the critical area of connections. The effects of all interconnecting details must be considered in the analysis and design to assure proper performance of the 
structural system. The connection details must be designed to provide for manufacturing and erection tolerances and temporary erection stresses.

\subsection{Prefabricated Rebar Mats, Cages ant Subassemblies}

These prefabricated rebar units or modules do not represent a final structural unit. Consequently, they are not subject to the loads associated with the design basis of the plant until after the pour and curing of the concrete. However, the prefabrication of many rebars into mats, cages, or subassemblies does introduce concerns dealing with the handling and placement of the rebar elements. Some of the rebar modules will require special steel support structures to hold them in place. The structural support system may also be required to maintain the rebar spacing, to stiffen the rebar modules to prevent "racking" during handling, and for alignment to adjacent rebar modules.

Special attention needs to be given to the splicing of adjoining rebar modules since staggering of the splices may be impractical. Special procedures will also be necessary to ensure that the final placement of the reinforcement matches, within acceptable tolerances, the design requirements.

Current NRC guidance and industry codes and standards define acceptable design and analysis requirements which would apply to steel reinforcement modules. The ACI code or the ASME code provides requirements for the design of steel reinforcements which could apply to modules constructed from prefabricated rebar. 
If the design of a specific type of modular unit is governed by recognized ASME, ACI, and AISC codes, as supplemented by the SRP and Regulatory Guides, then the only additional considerations for modular construction are those related to off-site fabrication, handling, shipping, storage and site erection. These were previously discussed in Section 5.0.

The design process assumes that the geometry of the as-built structure is the same as the nominal design geometry, to within the dimensional tolerances which are accounted for in the design analysis. For modular construction, there are three major operations which potentially contribute to deviations from the nominal design geometry: off-site fabrication, transfer to site, and final erection of the structure using modular units. The cumulative effects of all three operations must not exceed the allowable dimensional tolerances accounted for in the design analysis. Off-site fabrication in a controlled environment should permit adherence to fairly tight tolerances. Handling, shipping and storage operations should be controlled by procedures to ensure that no permanent distortion is introduced. The major source of dimensional deviation is expected to be fit-up of the individual modular units to form the completed structure.

Existing codes and standards typically specify the maximum allowable tolerance on key dimensions. However, to accommodate final on-site assembly of the modular units, more generous tolerances may be needed. Exceptions to code allowable tolerances should be carefully reviewed to ensure that the calculational methodology used is applicable to larger deviations from nominal geometry. The applicant should provide the necessary technical justification in sufficient detail to facilitate an independent review.

The structural materials used in modular construction must meet or exceed the minimum specified properties, per the applicable codes. It must be demonstrated that construction related activities (from off-site fabrication to final on-site erection) do not degrade the material structural properties below what was assumed in the design analysis.

For steel modules and steel components of composite modules, applied static loads due to lifting, handling, tie down and other operations should not cause material yielding, except at very localized stress concentrations. Vibration loads during transit or other operations should not induce alternating peak stress cycles which exceed the material endurance limit, per the applicable code. If an operation, such as shipping, subjects a modular unit to impact loads, every effort should be made to minimize them. The worst case combination of ambient temperature and impact loading should be evaluated, to preclude the possibility of brittle failure during any construction-related operation.

For precast concrete modules and composite steel/concrete modules fabricated off-site, concrete stresses should be maintained below applicable code design allowables for all construction-related operations. Possible vibration and impact loads should be minimized by procedural control. Cracking of concrete as a result of construction-related activities is not acceptable, unless such 
cracking has been adequately considered in the design analysis. All potential causes of concrete material deterioration must be eliminated.

For unique structural module designs, not presently governed by recognized codes and Regulatory Guides, a specific set of structural acceptance criteria must be defined. To the extent feasible, these should be drawn from applicable sections of currently recognized codes, as supplemented by Regulatory Guides. Any unique acceptance criteria should reflect the design philosophy embodied by the currently recognized codes. A detailed analysis program, verified by supporting test data, will be necessary to define the two key behavioral states of the module under load. The onset of nonlinear behavior establishes the limit of applicability for linear analysis methods, which are traditionally used for design calculations. The behavior of the structure beyond the limit of linear response must be investigated, to determine the ultimate load capacity and effective "ductility". Design margins against failure can then be defined in a manner consistent with those in currently recognized codes. The objective is to ensure that a comparable factor of safety is maintained. The applicant must submit the technical basis for the structural acceptance criteria for unique module designs. The information must be both comprehensive and concise, to accommodate an independent review.

\subsection{STEEL/CONCRETE COMPOSTIE FLOORS, BEAMS AND COLUMNS}

The structural acceptance criteria for design/operating loads should be in accordance with the applicable ACI and AISC requirements, as specified in SRP Section 3.8. The general discussions in Section 7.0 concerning tolerances, material, and acceptance criteria for construction-related loads are also applicable.

\subsection{CONCRETE-FILLED STEEL MODULES}

Currently, no code or standard provides specific acceptance criteria for concrete-filled steel modules. For this reason, a detailed analysis verified by test data is the preferred approach to demonstrate the adequacy of the analysis methods and the design.

If the predicted stresses and deformations from the analysis/design methods are verified by testing, then steel stresses and deformations can be limited to AISC allowables and concrete stresses and deformations limited to ACI allowables, as supplemented by NRC technical positions with regard to these codes.

In addition to meeting stress and deformation limits on individual components, it is necessary to demonstrate that the combined steel and concrete module provides a margin of safety and structural performance comparable to existing nuclear plant structures. This should include demonstrating that there is adequate ductility, acceptable stiffness degradation, and comparable margins of safety against failure. 
Acceptance criteria for loads related to fabrication, shipping, and construction/erection should be developed by the applicant and reviewed on a case by case basis. Vibration loads should be evaluated to ensure that they do not contribute to fatigue usage; otherwise, these additional cyclic loads need to be included in the design fatigue analysis. The general discussions in Section 7.0 concerning tolerances, material, acceptance criteria for construction-related loads, and unique module designs are also applicable.

\subsection{StRUCTURALSTEEL MODULES}

The structural acceptance criteria for design/operating loads should be in accordance with the applicable ASME or AISC requirements, as specified in SRP Section 3.8. The general discussions in Section 7.0 concerning tolerances, material, and acceptance criteria for construction-related loads are also applicable.

\subsection{Precast Concrete Modules}

The structural acceptance criteria for design/operating loads should be in accordance with the applicable ACI requirements for the equivalent poured-in-place concrete structure, as specified in SRP Section 3.8. The structural acceptance criteria for connections between precast concrete modules should ensure that the structural performance is equivalent to or better than poured-in-place construction. The general discussions in Section 7.0 concerning tolerances, material, and acceptance criteria for construction-related loads are also applicable.

\subsection{Prefabricated Rebar Mats, Cages and Subassemblies}

The structural acceptance criteria for design/operating loads should be in accordance with the applicable ASME or ACI requirements for rebar in reinforced concrete structures, as specified in SRP Section 3.8. The general discussions in Section 7.0 concerning tolerances, material, and acceptance criteria for construction-related loads are also applicable. 


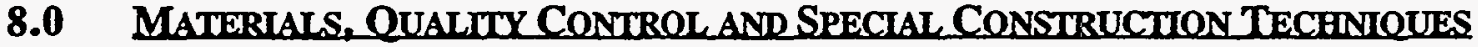

\subsection{Materials}

The current guidance presented in the SRP is directly applicable to modular construction. Concrete and steel materials should meet the applicable specifications of ACI, AISC, or ASME. Any material not covered by the appropriate code or not previously accepted for the proposed application must be reviewed on a case-by-case basis for acceptability. The applicant should provide sufficient test data and user experience documentation to establish acceptability for the proposed application. In the utilization of modular construction, a widely accepted material may be proposed for a unique application. It is important that the material/application combination be reviewed for acceptability.

Special consideration should be given to the potential for in-service material degradation. This is particularly important for a sixty-year operating life. Potential material degradation should be addressed in one of two ways: in-service inspection and remediation or initial design to preclude the degradation. Susceptible areas which will be inaccessible after completion of construction should be addressed as part of the design process; i.e., eliminate the potential for in-service degradation.

For susceptible areas which will be accessible for inspection after completion of construction, an appropriate allowance for degradation - based on in-service experience at currently operating plants and a defined schedule for periodic inspection - should be factored into the design calculations. A remediation criterion should also be defined.

One unique aspect of modular construction, from a materials perspective, is the potential effect of the construction process - from offsite fabrication to final site placement and joining - on the material properties. It is imperative that the nominal design values for important structural properties be maintained in the as-built condition. All potential causes for material degradation during the construction process must be appropriately addressed and dispositioned by the applicant in sufficient detail to facilitate an independent review.

\subsection{QUALTY CONTROL}

The SRP invokes the Quality Control requirements of ASME Section III for containments, ACI 349 for concrete structures and AISC Specification for steel structures. There is direct applicability of these requirements for all of the types of modular construction considered herein, except for concrete-filled steel modules. The applicant should specifically define the quality control measures to be implemented for any type of modular construction not directly covered by one of the aforementioned codes. As applicable, the quality control requirements of these codes should be incorporated. The goal is to ensure that a level of quality control comparable to that required by existing codes is implemented for any unique type of modular construction. 
For concrete-filled steel modules where composite behavior of the concrete and steel is assumed in the design/analysis, control of construction processes which affect the soundness of the interface between steel and concrete is essential to ensure achievement of design assumptions. The applicant should specifically address the measures to be taken and the proposed methods of verification.

For concrete-filled steel modules, the quality and strength of the in-situ concrete, compared to the results of the standard 28 day cylinder tests, should be addressed. Existing test data and/or proposed verification methods should be described.

For all types of modular construction, proper control of handling, shipping and storage operations is essential to meet overall quality requirements. For unique types of modular construction, the applicant should describe the measures to be taken to control these operations, citing prior applicable industry experience, existing test results, and/or proposed verification methods as the validation basis. For other types of modular construction, the applicant should commit to the implementation of measures which have previously been successful, by reference to an applicable code or procedure.

As previously discussed in Section 7.0, it is essential that final erection tolerances assumed in the design/analysis are not exceeded. Each step of the modular construction process must be sufficiently controlled to ensure that the cumulative effect of all operations satisfies the tolerance criteria. For unique types of modular construction, the applicant should describe the control measures to be implemented to meet the specified design tolerances.

\subsection{SPecial CONSTRUCtION TECHNTOUES}

Modular construction techniques which are new or unique should be fully described so that an evaluation can be made to assure that the structural integrity of the completed structure is maintained. The description of the modular construction techniques should cover the entire process from fabrication of the modules through transportation, storage, handling, inspection/testing, and erection. The information provided should demonstrate that the methods used do not degrade the structural quality of the modules in any manner that might affect the structural integrity of the structure.

For transportation by rail as an example, information should be provided regarding the maximum size and weight limit for the modules, how the modules will be packaged and secured to the rail cars and supported to minimize vibrations and impact loads, how they will be protected from the elements during transportation, and how the loading and unloading will be handled to avoid over-stressing the modules. Similar type of information should be provided for the other steps in the modular construction process. 


\subsection{TestING AND INSERVICE INSPECTIONREOUREMIENTS}

\subsection{Contanment}

Regulatory Guide 1.70 (Reference 10.14) and the SRP define specific testing and inservice inspection for concrete and steel containments, per the ASME Code Section III and applicable Regulatory Guides. For steel containments, Regulatory Guide 1.70 also specifies that "programs for inservice inspection in areas subject to corrosion should be provided." Also applicable to containments, Regulatory Guide 1.70 states: "If new or previously untried design approaches are used, the extent of additional testing and inservice inspection should be discussed." The SRP specifies that this be reviewed on a case-by-case basis.

The above is directly applicable to containments assembled by modular construction techniques. On a case-by-case basis, consideration should be given to the need for scale model and/or prototype testing prior to final approval of a new design. This will depend on the degree of uniqueness, the confidence level in the proposed design/analysis methodology, and the extent to which the structural acceptance criteria provide safety margins comparable to ASME Code Section III.

The utilization of modular construction techniques, especially in conjunction with a new or previously untried design, should be evaluated in depth for potential causes of inservice material degradation. This has been previously discussed in Section 8.1. As necessary, the applicant should describe its inservice inspection program to monitor potential degradation and also define the corresponding acceptance/remediation criteria.

\subsection{STRUCTURES OTHER THAN CONTAINMENT}

For structures other than containment, there is no specific testing and inservice inspection defined in Sections 3.8.3, 3.8.4 and 3.8.5 of Regulatory Guide 1.70 and the SRP. The extent of compliance with applicable codes (e.g., ACI, AISC, ASME) and Regulatory Guides should be indicated by the applicant. The need for and scope of testing and inservice inspection of these structures is initially determined by the applicant, subject to review and acceptance on a case-by-case basis.

One special case is addressed: a containment internal structure which is "related directly and critically to the function of the containment concept." 'A historical example is the drywell of a BWR Mark III containment. For this special case, the applicant should specify a testing and inservice inspection program consistent with the requirements for containments. This program is reviewed on a case-by-case basis.

The above is directly applicable to structures assembled by modular construction techniques. In addition, considerations for new designs and inservice material degradation, as discussed in Section 9.1 for containments, are also applicable. 


\subsection{Referkences}

10.1 NUREG-0800, "Standard Review Plan for the Review of Safety Analysis Reports for Nuclear Power Plants," U.S. Nuclear Regulatory Commission.

10.2 EPRI, "Advanced Light Water Reactor Utility Requirements Document," Volume III, ALWR Passive Plant, Chapter 1 Overall Requirements.

10.3 Lagache, M.P., "Constructibility Enhancements for Advanced BWRs, " Bechtel Power Corporation, presented at the International Conference on Design and Safety of Advanced Nuclear Power Plants, Tokyo, Japan, October 25-29, 1992 (ANP92).

10.4 Bagchi, G., Tan, C.P., "Modular Construction From a Regulatory Perspective," U.S. Nuclear Regulatory Commission, ASME/JSME Nuclear Engineering Conference - Volume 2, ASME 1993.

10.5 Farin, H.D., Cummins, W.E., "AP600 Layout Features to Support 36 Month Construction Schedule," Bechtel Power Corporation/Westinghouse Electric Corporation, presented at the International Conference on Design and Safety of Advanced Nuclear Power Plants, Tokyo, Japan, October 25-29, 1992 (ANP-92).

10.6 Johnson, F.T., Orr, R.S., Boudreaux, C.P., "Modular Construction Approach for Advanced Nuclear Plants," Westinghouse Electric Corporation/Avondale Industries, Inc., presented at the American Nuclear Society/European Nuclear Society International Conference, Washington, D.C., October 30 - November 4, 1988.

10.7 AISC, "Specification for Design, Fabrication and Erection of Structural Steel for Buildings," American Institute of Steel Construction.

10.8 ACI 349, "Code Requirements for Nuclear Safety Related Concrete Structures," American Concrete Institute.

10.9 ASME Boiler and Pressure Vessel Code, Section III, Division 1, Subsection NE, "Class MC Components," American Society of Mechnical Engineers.

10.10 ASME Boiler and Pressure Vessel Code, Section III, Division 2, "Code for Concrete Reactor Vessels and Containment," American Society of Mechanical Engineers.

10.11 Association of American Railroads, "General Rules Governing the Loading of Commodities on Open Top Cars (Section No. 1)." 
10.12 Braverman, J., Morante, R., Hofmayer, C., "Assessment of Aging Degradation of Civil/Structural Features at Selected Operating Nuclear Power Plants," Brookhaven National Laboratory Technical Report L-1521(6)/5-93, prepared for USNRC Office of Nuclear Reactor Regulation, May 1993.

10.13 Regulatory Guide 1.61, "Damping Values for Seismic Design of Nuclear Power Plants," U.S. Nuclear Regulatory Commission.

10.14 Regulatory Guide 1.70, "Standard Format and Content of Safety Analysis Reports for Nuclear Power Plants," U.S. Nuclear Regulatory Commission.

10.15 ANSI/AISC N690, American National Standard: "Specification for the Design, Fabrication and Erection of Steel Safety-Related Structures for Nuclear Facilities," American Institute of Steel Construction. 


\section{Appendix A}

\section{QUALTILASSURANCE}

This appendix was written in a format that matches Chapter 17.1 of the "Standard Format and Content of SARs for Nuclear Power Plants", Regulatory Guide 1.70 Rev. 3. The applicable paragraph number from the Regulatory Guide is shown in parenthesis next to each heading.

\section{QuALITY ASSURANCE DURING DESTGN AND CONSTRUCTION (17.1)}

\section{ORganization (17.1.1)}

Modular Construction makes it possible to simultaneously utilize many contractors/sub-contractors/suppliers for off-site fabrication of modules. Potentially, off-site fabrication may be conducted on a world-wide scale, to meet a compressed construction schedule. Control of intensive off-site construction activity is critical to achieve overall quality assurance objectives. The applicant's QA organization should be described in detail, with particular emphasis on tracking, coordinating, and ensuring uniform adherence to the QA program requirements.

The site organization charged with receipt inspection has a more critical and more demanding role on a modular construction project. This site organization should also be described in detail.

The delegation of QA responsibilities by the applicant to lower tier contractors/subcontractors/and suppliers should be defined in detail, along with the applicant's management system to ensure uniform and consistent understanding of, commitment to, and implementation of the delegated QA responsibilities.

\section{QUALITY ASSURANCE ProgRAM (17.1.2)}

For modular construction, coordinated and consistent adherence to a unified QA program is critical to meeting the overall quality objectives. The applicant should describe in detail the structure of a unified QA program, which delineates both the general requirements applicable to all levels of project participation and the more specific requirements applicable to each level of project participants (e.g., level 1 main contractors hired directly by applicant; level 2 - subcontractors to main contractors; level 3 - suppliers to subcontractors).

\section{DESTGN CONTROL (17.1.3)}

Modular construction can simplify design control, if the detailed design, design verification, and constructability review are completed before fabrication, assembly and placement of the modules. Lack of design control can be disastrous for modular 
construction, since success lies in minimizing the on-site construction effort by essentially eliminating the need for field changes. Adequate provision for field fit-up tolerances between sub-modules and between modules and other structures is necessary to preclude field changes to the design.

Coordination of the design process and design interfaces is absolutely essential for modular construction. A single data base for design data should be created, for use by all participating design organizations. Responsibility for and control of the database should be clearly defined.

\section{PROCUREMENT DOCUMENT CONTROL (17.1.4)}

Utilization of modular construction has been promoted for advanced reactors in order to shorten the construction schedule. Off-site fabrication of the different modules can proceed simultaneously with site preparation work. Compared to previous construction practices, it is likely that there will be more contractors, sub-contractors and suppliers working simultaneously to fabricate modules. It is also likely that some project participants will be foreign companies.

Given this likely scenario, the critical importance of procurement document control should be evident. Such issues as uniformity of quality standards, use of internationally recognized specifications (if applicable), consistent interpretation of requirements, inspection and audit, and non-conformance reporting/disposition should be addressed. A comprehensive plan of action and the implementing organization should be clearly delineated.

\section{INSTRUCTIONS, PROCEDURES, AND DRAWINGS (17.1.5)}

This information should be contained in a data base for use by all affected organizations. Responsibility for and control of the data base should be clearly defined.

\section{DOCUMENT CONTROY (17.1.8}

The establishment of a document control system is mandatory. A computer based network is the only realistic approach to ensure that all affected organizations have timely access to the current revisions of controlled documents. The system should be set up to identify document "need dates" to support the design/fabrication/construction/test/start-up schedule. 


\section{CONTROL OF PURCHASED MATERIAL, EOUIPMENT, AND SERVICES 17.1 .77}

The simultaneous off-site fabrication of modules, to meet a compressed construction schedule, may require the qualification and use of suppliers who have little or no previous experience with commercial nuclear power quality assurance requirements. Frequent surveillance of such suppliers should be conducted early in the project, to prevent any problems from developing later.

The planned use of inexperienced suppliers, especially foreign suppliers, makes it imperative that the supplier evaluation and surveillance process be formally documented and that organizational authority and responsibility be clearly defined.

\section{IDENTIETCATION AND CONTROL OF MATERIALS, PARTS, AND COMPONENTS (17.1.8)}

The applicant should develop a unified identification system for modules, which module fabricators would be required to use. A data base containing completion status, physical location, and other pertinent information for each module should be developed and maintained on-line.

\section{CONTROL OE SPECIAL PROCESSES (17.1.9)}

For the case of concrete-filled steel modules, the procedure for the in-place concrete pour should be identified as a special process and addressed in accordance with the SRP Chapter 17 acceptance criteria.

Fit-up and joining procedures for on-site assembly of modular units should be classified as special processes.

It may also be appropriate to include unique or innovative methods used in off-site fabrication of modules as special processes. All affected sub-contractors must adhere to the same procedures and requirements.

\section{INSPECTION (17.1.10)}

Comprehensive process monitoring and inspection of modules must be performed at the off-site fabrication facilities. The applicable procedures and requirements must be the same for all affected sub-contractors. No module should leave the fabricator's facility without documented evidence that it has been manufactured and inspected in accordance with the governing requirements. Modules should be inspected upon receipt at the construction site, to verify fitness for use and/or to identify any deficiencies in advance of scheduled need. On-site correction and re-inspection of any deficiencies should be accomplished before placement of the module in the final assembled structure. 
Fabrication of a full scale mockup of a typical module should be considered in developing the detailed process monitoring and inspection requirements. Also, the initial results of process monitoring and inspection should be evaluated to identify any recurring deficiencies in the fabrication process. Early correction of any deficiencies is important in order to meet both the quality and schedule objectives.

\section{TEST CONTROL (17.1.11)}

Modules of unconventional design may require structural testing to establish stiffness and strength characteristics (e.g., concrete-filled steel modules). The minimum quality assurance requirements for an acceptable test program should be in accordance with Regulatory Guide 1.70 and the Acceptance Criteria of the SRP.

\section{Control of Measuring and Test EOUIPMEnT (17.1.12)}

To the extent practical, all module fabricators and their suppliers should use the same procedures and calibration standards to ensure the accuracy of their measuring and test equipment.

\section{HANDLING, STORAGE, AND SHIPPING (17.1.13)}

Regulatory Guide 1.70 and associated SRP acceptance criteria are oriented toward non-structural systems, components and equipment. Off-site fabrication of large structural modules is not specifically addressed. However, the intent of the criteria is applicable to modular construction.

The fundamental objective for structural modules is to ensure that the structural design basis is maintained throughout all handling, storage, and shipping operations, including final on-site placement of the module. The specific control measures will vary with the type of module, but should include provisions to preclude the following:

- material yielding and dimensional distortion during handling operations

- excessive vibration and impact loads during shipping

- material degradation due to environmental conditions during fabrication, shipping, and storage (both off-site and on-site)

- exposure to reactive agents which may attack the structural materials 
INSPECTION, TEST, AND OPERATING STATUS (17.1.14)

All off-site fabricators should use the same status tracking system. This system should also be implemented on-site, to ensure continuity and consistency throughout the construction process.

\section{NONCONFORMING MATERIALS, PARTS, OR COMPONENTS (17.1.15)}

Modular construction techniques should minimize the number of nonconforming conditions which arise on-site. Modules fabricated off-site, in a more controlled environment, should satisfy all applicable specifications before shipment.

The applicant is ultimately responsible for the disposition of nonconformances. However, delegation of significant decision making to the module fabricators is probably necessary to avoid delays in the construction schedule. Uniform procedural guidelines and disposition criteria should be used by all affected organizations, to ensure consistency in the disposition of nonconformances. A single data base should be established for documenting, tracking, and resolving nonconformances. Monitoring is necessary to ensure adherence to the established system.

\section{CORRECTIVE ACTION (17.1.10)}

A unified corrective action: program should be implemented by all project participants who are subject to nuclear quality assurance requirements. Each affected contractor, sub-contractor and supplier should use this unified program to resolve conditions adverse to quality which are identified within their operation. Consistency and coordination are essential.

\section{QUALTTY ASSURANCE RECORDS 017.1 .17}

A master QA Records Management System should be developed, to include all required QA records generated off-site and on-site. The physical location of each QA record should be tracked during the design and construction phases. After plant startup, all QA records should be consolidated at a single location (e.g., the plant site) for long term retention and efficient retrievability through the records management system. Duplicate sets of QA records, on electronic media, is recommended both on-site and off-site in properly protected environments.

\section{Aupris (17.1.18)}

A comprehensive audit plan, tied to design/construction milestones, should be developed for the entire project. The responsibility for audits at each level of the 
design/construction hierarchy should be clearly identified. To the extent practical, a uniform set of procedures and criteria should be used for all audits.

Early verification of adherence to quality assurance requirements is absolutely essential for the successful application of modular construction. 


\section{TITLE AND SUBTITLE}

(Soo instructions on the reverse)

NUREG/CR-6486

BNL-NUREG-52520

Assessment of Modular Construction for Safety-Related Structures at Advanced Nuclear Power Plants

5. AUTHOR(S)

J. Braverman, R. Morante, C. Hofmayer
3. DATE REPORT PUBLISHED

\begin{tabular}{l|l} 
MONTH & YEAR
\end{tabular}

March 1997

4. FIN OR GRANT NUMBER

L2261
6. TYPE OF REPORT

\section{Technical}

7. PERIOD COVERED (inclusivo Datos)

8. PERFORMING ORGANIZATION - NANE AND ADDRESS (FNRC, provide Division, Office or Rogion, U.S. Nuctoer Regulatory Commission, and meiling eddross; if contrector, provibe neme end miling eddross.)

Brookhaven National Laboratory

Upton, NY 11973-5000

9. SPONSORING ORGANIZATION - NANE AND ADDRESS (f NRC, type "Same as above"; if confractor, provide NRC Division, Ofico or Region, U.S. Nucloer Regulabory Commission, and mailing addross.)

Division of Engineering Technology

Office of Nuclear Regulatory Research

U.S. Nuclear Regulatory Research

Washington, DC 20555-0001

10. SUPPLEMENTARY NOTES

H. Graves, NRC Project Manager

11. ABSTRACT (200 words or lows)

Modular construction techniques have been successfully used in a number of industries, both domestically and internationally. Recently, the use of structural modules has been proposed for advanced nuclear power plants. The objective in utilizing modular construction is to reduce the construction schedule, reduce construction costs, and improve the quality of construction. This report documents the results of a program which evaluated the proposed use of modular construction for safety-related structures in advanced nuclear power plant designs. The program included review of current modular construction technology, development of licensing review criteria for modular construction, and initial validation of currently available analytical techniques applied to concrete-filled steel structural modules. The program was conducted in three phases. The objective of the first phase was to identify the technical issues and the need for further study in order to support NRC licensing review activities. The two key findings were the need for supplementary review criteria to augment the Standard Review Plan and the need for verified design/analysis methodology for unique types of modules, such as the concrete-filled steel module. In the second phase of this program, Modular Construction Review Criteria were developed to provide guidance for licensing reviews. In the third phase, an analysis effort was conducted to determine if currently available finite element analysis techniques can be used to predict the response of concrete-filled steel modules.

Modular Structures-Construction, Nuclear Power Plants-Modular Structures, PWR Type Reactors-Design, Analytical Solution, Concrete Evaluation, Finite Element Method, Fabrication, Licensing, Steels, Validation

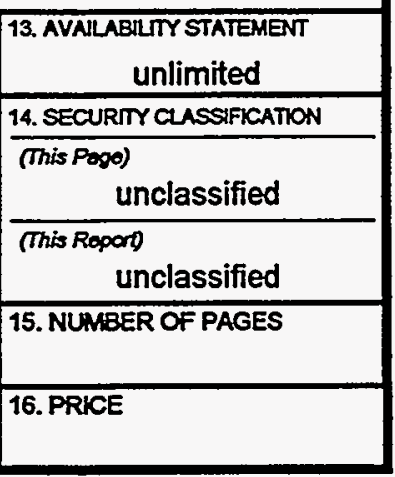

